Citizenship, Othering and Learning:

A Comparative Study with Groups of Young People from

Pembrokeshire and Cardiff

By

John Lucan Heffernan

Submitted for the degree of Doctor of Philosophy in Human Geography

Wednesday $23^{\text {rd }}$ September 2020
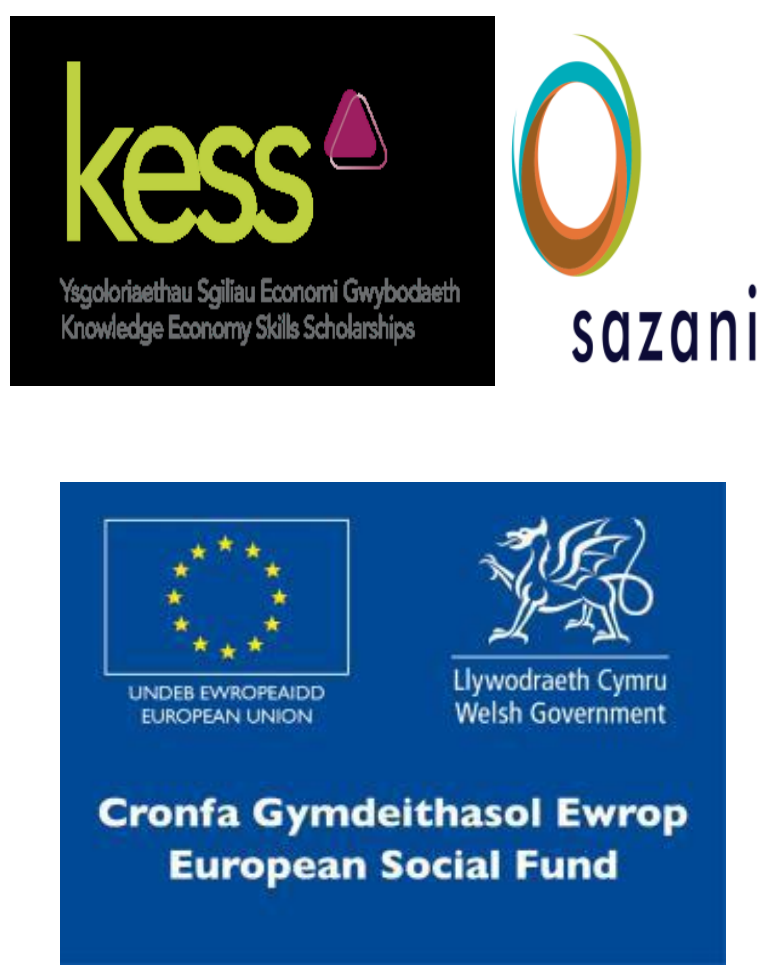


\section{Declaration/Statements page}

\section{DECLARATION}

This work has not previously been accepted in substance for any degree and is not being concurrently submitted in candidature for any degree.

Signed: John Lucan Heffernan (candidate)

Date: Wednesday $23^{\text {rd }}$ September 2020

\section{STATEMENT 1}

This thesis is the result of my own investigations, except where otherwise stated. Where correction services have been used, the extent and nature of the correction is clearly marked in a footnote(s).

Other sources are acknowledged by footnotes giving explicit references. A bibliography is appended.

Signed: John Lucan Heffernan (candidate)

Date: Wednesday $23^{\text {rd }}$ September 2020

\section{STATEMENT 2}

I hereby give consent for my thesis, if accepted, to be available for photocopying and for inter-library loan, and for the title and summary to be made available to outside organisations.

Signed: John Lucan Heffernan (candidate)

Date: Wednesday $23^{\text {rd }}$ September 2020

NB: Candidates on whose behalf a bar on access has been approved by the University (see Note 7), should use the following version of Statement 2:

I hereby give consent for my thesis, if accepted, to be available for photocopying and for inter-library loans after expiry of a bar on access approved by the Swansea University.

Signed: John Lucan Heffernan (candidate)

Date: Wednesday $23^{\text {rd }}$ September 2020 


\section{THESIS SUMMARY}

Candidate's full name: John Lucan Heffernan

Candidate for the Degree of: PhD Human Geography

Full title of thesis: Citizenship, Othering and Learning: A Comparative Study with Groups of Young People from Pembrokeshire and Cardiff.

\section{Summary:}

What is the state of citizenship and citizenship education among the young people of Wales?

Furthermore what are the understandings, thoughts, views and opinions of young people towards citizenship in a time of neo liberalism and neo communitarianism? A time when othering is found in countries policies, politics and media landscape that represents and powerfully defines immigration as a cause for fear and matter of security.

This thesis uses academic research and theory in combination with youth work experience and the industrial expertise of Sazani Associates to develop and evaluate curriculum materials to engage young people in questions of citizenship and othering through the promotion of critical thinking and empathy. This begins with a thorough examination of literatures exploring citizenship, othering and empathy's histories, developments and new and emerging categories and definitions. Analyses of key literatures include the works of Bauman, Isin, Painter and Jeffrey, Gregory, Katz and Rankine. These combine with practitioner skills to inform a participatory action research based approach including elements of play, imaginative reconstruction and board games. The result is a collection of materials which cover a range of citizenship and othering topics including how citizenship is gained, kept and lost and asking participants to explore their own experiences of micro and macro aggressions and othering.

This thesis finds that the participants, who were all from a minority ethnic background enjoyed the opportunity to have fun, express themselves and participate in a mutually respectful learning partnership. The thesis argues that this kind of approach could have beneficial results on the development of young people but found initial opinions embedded in neo liberal attitudes leading to a neurotic form of citizenship. The conclusion argues that these can be positively challenged but a major obstacle to this comes in the form an educational system seen as the default provider and based upon valuation and producing essential citizens ready for work.

Key words: citizenship, othering, securitisation, Bystander, education, empathy 


\section{Contents page}

$\begin{array}{lc}\text { Acknowledgements } & 8\end{array}$

$\begin{array}{ll}\text { Dedication } & 9\end{array}$

$\begin{array}{ll}\text { List of diagrams, graphs, images and tables } & 10\end{array}$

$\begin{array}{ll}\text { Chapter One: Introduction } & 13\end{array}$

- Early events, influences and experiences. 14

- Introduction to my research. 18

- Themes aims and questions 19

- Chapter contents 24

Chapter Two: Literature Review. $\quad 30$

- Citizenship and Britishness. 31

- Citizenship and the state. 34

- Citizenship beyond the state. 37

- Citizenship, security and the imaginative geographies of us and them. 40

- Citizenship and the Prevent programme. 44

- Citizenship, education and young people. 48

- Young people and empathy.

- The Bystander Approach. 55

Chapter Three: Designing and planning the research process:

$\begin{array}{lr}\text { methods, ethics and pilot project. } & 58\end{array}$

- What is Participatory Action Research (PAR)? 59

- Why PAR? 61

- Potential issues and their solutions within PAR? 61

- Putting PAR into practice. 64

- Ethics. 66

- Gaining ethical consent. 68

- Pilot Project. $\quad 71$

- Changes made following pilot project. $\quad 72$

- Research project one: Butetown Youth Pavilion. 73

- Research project two: Grangetown Youth Pavilion. 75 
- Research project three: Monkton Priory project. 75

$\begin{array}{ll}\text { Chapter Four } & 79\end{array}$

$\begin{array}{ll}\text { Part One: Zombie Apocalypse. } & \mathbf{8 0}\end{array}$

- Introduction. $\quad 80$

- Planning and Preparation. 80

- Delivery and engagement. 83

- Discussion and reflection. 87

$\begin{array}{ll}\text { Part Two: Brave New World. } & 97\end{array}$

$\begin{array}{lr}\text { - Introduction. } & 97\end{array}$

- Planning and Preparation. $\quad 97$

- Delivery and engagement. 99

- Discussion and reflection 108

$\begin{array}{ll}\text { Chapter Five } & 114\end{array}$

$\begin{array}{ll}\text { Part One: Citizenship Snakes and Ladders. } & 115\end{array}$

- Introduction. 115

- Planning and Preparation. 116

- Delivery and engagement. 119

- Discussion and reflection. 121

$\begin{array}{ll}\text { Part Two: Political Approval Board game. } & 127\end{array}$

$\begin{array}{lr}\text { - Introduction. } & 127\end{array}$

- Planning and Preparation. 129

- Delivery and engagement. 131

- Discussion and reflection. 140

$\begin{array}{ll}\text { Chapter Six: } & 149\end{array}$

$\begin{array}{ll}\text { Part One: Should they stay, or should they go? } & 150\end{array}$

- Introduction. 150 
- Planning and Preparation.

- Delivery and engagement.

- Discussion and reflection.

Part Two: Liberty versus security.

- Introduction.

- Planning and Preparation.

- Delivery and engagement.

- Discussion and reflection.

- Introduction.

- Planning and Preparation.

- Delivery and engagement. 196

- Discussion and reflection.

- Planning and Preparation.

- Discussion and reflection.

- Overview 231

- Research questions two and three 233

- Research question one 236

- Research question four 241

$\begin{array}{lr}\text { References } & 249\end{array}$

$\begin{array}{lr}\text { Appendixes } & 269\end{array}$ 


\section{Acknowledgements}

Like most things in life this would not have been possible without the help and support of a lot of different people. First I must mention Mark Proctor, Director of Sazani and my good friend. Sometimes you require other people to be the heroes of your own life and without a doubt Mark saved mine by creating this opportunity for me, or, delayed my death, depending on your life choices and perspectives. I would like to thank Adam Cumine and all the staff at Green Links for helping me heal and Tobi Evans for supporting me to finish as well as the employees of Sazani Associates for their assistance through out. Financially I would not have been able to do this without the KESS II structural funds.

I owe a huge debt of thanks to my lead supervisor, Dr. Angharad Closs - Stephens, not just for her tireless professionalism, understanding and guidance but also for taking a last minute chance on a slightly manic practitioner and his rather rushed application back in the early summer of 2016. My second supervisor, Dr lan Clegg, was also instrumental, providing reassurance and making me understand that I was actually progressing in both my thinking and my writing. I also must thank the accommodation of the four youth projects that I worked with through out this project.

Finally none of this is possible without all my friends and family. To the boys of Seawolf who reminded me right from the start that I was not always a youth project manager. To the Fat Dads Sports and Social Club for making the same jokes about eating pot noodles, watching homes under the hammer and listening to the Levellers throughout the whole 4 years. To my mother and father who told me they would always have my back and which the writing up of this allowed me to spend some truly special time with. To my sister for proof reading and holding back on the criticism and the rest of my family; Jason, Phil, Dee, Pat, George, Jack and Henry for playing my games and humouring my trials of critical thinking. Finally to my close friends and their families for their love and support: Dave, Deonne, Osian, Will, Henry, Ben, Audrey, Leo, Gabi, Sandro, Ethan, Brittany, Mark, Cuthbertson, Suzie, The members of Tuesday Night Music Club, Amy, Fuzz, Ruby, Tom and Chippie. I am glad that there are not too many people to mention. 


\section{Dedication}

In 2013 I took a group of young people to London. Included in our trip was a visit to the youth theatre Zoo Nations 'Groove on down the road', a street dance adaption of the Wizard of $\mathrm{Oz}$ by young people, for young people. In the programme there was a modified version of the W.B. Yeats poem 'The Cloths of Heaven' by the Company's founder.

Had I the heaven's embroidered cloths,

Enwrought with golden and silver light,

The blue and the dim and the dark cloths

Of night and light and the half-light;

I would spread the cloths under your feet:

But I, being young, have only my dreams;

I have spread my dreams under your feet;

Tread softly teacher, because you tread on my dreams.

I have tried and always will try to tread softly.

This work is dedicated with lasting love and affection to all the young people I have worked with over the last twenty years. 


\section{List of diagrams, tables, graphs and images}

3.1 - Diagram of ethical, practitioner and PAR equilateral triangle. 69

4.1.1 - Table of items for Zombie Apocalypse tribes. 81

4.1.2 - Table of Others with twists.

4.1.3 - BYP table of rules and punishments 84

4.1.4 - Table of BYP voting record on admittance of others 84

4.1.5 - Table of GYP rules and punishments 85

4.1.6 - Table of GYP voting records on admittance of others 86

4.1.7 - Table of Prior rules and punishments 86

4.1.8 - Table of Priory voting record on admittance of others 87

4.1.9 - Table of first round comparative and overall voting records 89

4.1.10 - Table of second round comparative and overall voting records 91

4.2.1 - Table of combined resource selection - BYP 99

4.2.2 - Table of participant J resource selection with reasons - BYP 100

4.2.3 - Table of participant K resource selection with reasons - BYP 101

4.2.4 - Table of combined resource selection - GYP. 103

4.2.5 - Table of combined resource selection - Priory. 105

4.2.6 - Table of Prior's rights and responsibilities. 106

4.2.7 - Combined selection of resources across the three projects. 108

5.1.1 - Table of Snakes (negative) and ladders (positive). 118

5.2.1 - Graph showing BYP team A budget allocation. 
5.2.5 - Graph showing Priory team A budget allocation.

5.2.6 - Graph showing Priory team B budget allocation.

5.2.7 - Graph showing BYP comparative spending.

5.2.8 - Graph showing GYP comparative spending.

5.2.9 - Graph showing Priory comparative spending.

6.1.3 - Table of Priory group one decisions and discussions.

6.1.4 - Table of Priory group two decisions and discussions.

7.1.1 - Map of most violent and peaceful places.

7.1.2 - Map of risk of natural disasters.

7.1.3 - Map of wealthiest and poorest countries in the world

7.1.8 - Image of newspaper headline attacking migrants.

7.1.9 - Image of Katie Hopkins opinion piece. 
Atticus Finch and Tom Robinson.

7.2.3 - Image of Women's Tennis Association (WTA) celebrating its fortieth birthday.

7.2.4 - A Sharp White Background.

7.2.5 - Still from the 2017 film Wonder. Auggie. 
Chapter one: Introduction 


\section{Early events, influences and experiences.}

On Tuesday $15^{\text {th }}$ April 1986 the United States carried out air strikes against Libya and its leader Colonel Gaddafi in retaliation to a nightclub bombing in West Berlin ten days earlier. The planes which carried out this mission launched from US air bases located in the United Kingdom. I had just turned nine years old and the following day it was the talk of the playground. Some of the debate was about whether planes had launched from the US air force base located at RAF Daws Hill less than a mile from our school. We mostly discussed whether this would trigger all out nuclear war. As a middle school pupil I was aware of the dangers of nuclear war, especially as my home town of High Wycombe would be one of the first places to be obliterated due to the presence of a US Airforce base and RAF Strike Command. I understood the conflict had two sides, the USSR and the USA and that the UK was on the USA side. This understanding came from education, the media and James Bond films. This playground discussion of politics was nothing new as the 1980 s were eventful times. We had witnessed the Falklands war and Miners' strike, would later see the Lockerbie bombing in 1988, Tiananmen Square and the fall of the Berlin Wall in 1989 as well as the ever-present troubles in Northern Ireland and a sustained IRA bombing campaign in mainland Britain. This, combined with growing up in a family that was vociferous in their views, led to an early interest in politics. As a Catholic I was taught peace and love and, confused by the lack of these attributes in several of my teachers, began questioning religion, thinking critically including cross referencing teachings with behaviours and learning that the world was often a complex place. Growing up with the threat of Armageddon my friends and I spent a great deal of time discussing what we would do in the event of the three minute warning and whether it would be better to know or not know that we had 180 seconds to live. Having read Raymond Briggs' When the Wind Blows ${ }^{1}, \mathrm{I}$ thought seeking shelter futile. What I realise in retrospect is that at that tender age the three minute warning would have been the only way I would have plucked up the nerve to tell a girl I liked them, but to do that would require being in school where we would almost certainly have been made to spend our last moments praying.

\footnotetext{
${ }^{1}$ This was a cartoon book by Raymond Briggs and is the story of an elderly couple trying to survive after a nuclear attack by following government guidelines. They both die of radiation poisoning. I read it because I'd liked the author's other works including 'The Snowman' and 'Father Christmas goes on Holiday' and had quite a surprise in this change of direction.
} 
Then came the 1990 s and international conflicts which seemed destined to bring destruction appeared to come to an end. The first Gulf War in 1991 did not escalate into a global conflict and there was a decade of symbolic events such as Mandela's walk to freedom in 1990, Boris Yeltsin on a tank in 1991 and the Good Friday Agreement in 1998. As a teenager and young man in this period it seemed I was living in a world of peace and tolerance unimaginable ten years earlier. We had a pot smoking saxophone player in the White House and Cool Britannia in 10 Downing Street and "things could only get better". As the twenty first century progresses, I have realised that those heady days in the 1990s actually planted the seeds of many of the problems that we face now. The first Gulf War marked the start of Osama bin Laden's vendetta against the USA. The EU expanded and led by globalist Tony Blair, so did the UK's involvement in it, from which nationalism and Brexit have grown, aided by British newspaper propaganda. The collapse of the Soviet Union opened up a brand new market for neo-liberal economics, which in its infancy seemed the key to prosperity but has led to a world where everything has a price. There was little done about the environment, deregulation of the financial sectot and the decade saw the birth of companies like EasyJet offering cheap air fares. Immigration, the international terrorist threat, neo-liberal economics, the banking crisis, nationalism and globalisation are all part of current citizenship debates. Whilst the Cold War carried the very real likelihood of mutually assured destruction, a glance at a map would give a person a basic grasp of the situation. As international terrorism and global capitalism has become more detached from the control of the nation state there are no obvious sides because there is no obvious conflict, meaning the world is still complex, but in a different way from my youth.

An understanding of complexity or at least the existence of it was reinforced by my further and higher education studies where I studied law and criminology. One of the things I took away from these is that the UK is idiosyncratically complex. We have no constitution that can be held, no liberty bell which can be rung and no oath of allegiance. We are a nation state made up of four countries that have a complicated relationship with themselves and each other. Since the Norman Conquest we have had nearly a thousand years of an evolving

\footnotetext{
${ }^{2}$ This refers to the D:Ream song of the same title used first as a theme song and then a celebrative anthem by the Labour Party in the 1997 General Election.
} 
society and laws and much of it is confusing. The leader of a political party has to get permission from the monarch to form a government, but the monarch cannot say no even though they can. We vote for Members of Parliament and not our Prime Minister, our judges wear wigs, litigators wear gowns and parliament's official opening is marked by slamming the door in a person's face. We are unable to find consensus on whether to use the imperial or metric scales and in sports we developed offside and the leg before wicket rule. Common law relies on precedent and ambiguous, subjective defences such as reasonable force. I have a solid understanding of these matters and the philosophy behind them but that is because of specifically studying it. In Philip Pullman's latest book 'The Secret Commonwealth' the Gyptian boatman Giorgio Brabandt describes how to look at the secret commonwealth to Lyra Belacqua:

"You got to look at it sideways. Out of the corner of your eye. So you gotta think about it out the corner of your mind. It's there and it en't, both at the same time." Pullman, (2019:312)

I believe this can be equally applied to the unwritten constitution of the UK, it is there and it is not, you cannot hold it and you cannot touch it, and imagination and education are important in seeing it. This causes uncertainty in definitions and questions of citizenship and otherness.

My studies led me to pursue a career working with young people in schools and youth projects. I aspired to educate and be a role model who could help young people make sense of their world. I had a colourful and challenging career regularly encountering tragedy and farce and everything in between. This thesis was inspired by young people that I have worked with over this time and was also achieved in partnership with young people. There are two standout examples highlighting the identification of need and the inspiration, both of which occurred when I was a project manager of a local, independent youth project. The first example describes a young person's behaviour and views and the second is the response of young people to an international terrorist attack.

In 2010 a young Polish girl, recently moved to Wales, began attending the youth drop-in. A boy who was a member of the project subjected her to a torrent of racist abuse. On hearing 
this I escorted the boy out of the youth project, as I was doing so he called her a ' $\mathrm{P} * \mathrm{i}^{\mathrm{i}}$ ' and told me he was sick of 'them coming over here and taking our jobs'. I told him that she was Polish, to which he shrugged and said that they were all the same. I could not get out of mind his sweeping statement which homogenised non-UK people as all the same. I was troubled by how his lack of knowledge of history, geography and politics led him to this uninformed opinion. I was also a little concerned that my focus was on him not being able to distinguish between someone from Poland and Pakistan. I remember not knowing how to deal with the perpetrator, unsure what response should be given to the factual inaccuracies as much as the racism and xenophobia. I started thinking that if a person was going to be a bigot, they should at least be an informed bigot.

The second example from practice took place on Tuesday $17^{\text {th }}$ November 2015 as it followed the Paris terrorist attacks four days earlier. When the youth drop-in opened a group of young people entered, marched up to me and asked me; "John, are we all going to die?" I remember this exactly as I was tempted to shrug and say "Yes, it's called the circle of life". Looking at them I knew they were in no mood for humour. What followed was ninety minutes of conversation where young people asked questions which I tried to answer. I tried to put things in perspective and assure them that it was unlikely they were going to be blown up in the immediate future. This group made many casual remarks, including racist remarks. Yet I could see that they were trying to understand what was going on in the world. A colleague of mine remarked afterwards that they would not have had the patience to respond so fully to some of what was said. When I reflected on that later I realised that they had done me an honour in saving their questions for me. I asked them - "why me?" The answer was because I gave them time, listened to them and did not just tell them. This reminded me of the responsibility I had as a trusted adult and that in my role within a youth drop-in, I had the time to listen, whereas other professionals may not.

These two moments both have strong connections to the research that I have pursued. The first story explains a desire to educate and inform young people in order that they can better understand the world and consequently make more informed and hopefully less concretely racist decisions. The second story does the same but also demonstrates how sometimes people need a trusted, non-judgemental space, an individual to ask questions of 
and the opportunity to admit to a lack of knowledge. It also demonstrates that a practitioner dealing with these scenarios must not just have knowledge of the topics but also the patience, concern and empathy to allow questions to be asked.

\section{Introduction to my research.}

This research has been funded by the European Union Social Fund, as part of the Knowledge Economy Skills Scholarships (KESS II) programme. KESS II supports Doctoral and Research Master awards in all Welsh Universities, jointly sponsored by industrial partners based in the Convergence Area of Wales. One of the identifying factors of convergence areas is that they are areas of deprivation and living in one of these areas was a key criteria for acceptance. The programme's aims include the promotion of high-level skills and development and supporting innovation in the workplace through focusing on research areas related to business and practice. My industrial partners are Sazani Associates. Sazani Associates are a West Wales based Non-Governmental Organisation who work in Africa and across Europe. The majority of their work focuses on sustainable development and global education through an integrated approach to working with people or groups: assets based rather than needs or wants. This means listening to people and encouraging them to look at what they have and how these assets can be best utilized. It is a deliberate rejection of the shopping list approach often used with communities where members talk about what they do not have which can create negativity and unrealistic expectations. It is working with people and avoiding the pitfalls of assuming that experience and education makes someone an expert in other people's realities.

I had worked in partnership with Sazani Associates during my time as a project manager. In 2010 I successfully applied for a grant through the Community Cohesion Fund. The project was titled C.U.R.E - the Cultural, Urban and Rural Exchange project. The aim was to tackle the type of attitudes of young people described in the first story through practice and issues such as stereotypes, racism, global citizenship and uninformed pre-conceptions. Sazani provided training for both the staff of my youth project and another youth organisation based in Cardiff who worked in Grangetown and Butetown. We ran exchange projects where Muslim young people from Cardiff and Swansea came to our project in Pembrokeshire and 
vice versa. Generally a successful project, it challenged the young people from Pembrokeshire's pre-conceptions and stereotypes of Muslims. Realizing that many Muslim young people liked the same clothes, music and sports, had Welsh accents and were equally interested and hopeless at flirting broke many prejudices. We repeated this project in 2012, 2013 and 2014 until we were cut off from accessing the funding scheme. I also worked with Sazani on a resilience project in Bulgaria which I discuss in more detail in the introduction to my first research chapter.

In 2016 Sazani offered me the chance to carry out a Masters in Research through the KESS II programme and this was extended to a Ph.D. half way through the academic year. I began this thesis as a 39 year old man who had spent the previous 17 years working with children and young people in youth and education services. I therefore returned to education with a wealth of practitioner experience, knowledge and opinions. This combination made for an interesting re-integration to the academic world. Next to my new colleagues, my language was comparatively crude and coarse and I would often speak from experience when participating in tutorials and discussions. In one ethics lecture, there was a long discussion about teenage pregnancy. Afterwards the discussion continued over coffee and I shared some of my practitioner experiences with my new colleagues. It occurred to me later that I now had the time to think about these issues because I did not have to immediately act on them. There would be no distressed girls or young women, overwhelmed boys or young men, or angry fathers who had just discovered they were becoming grandfathers threatening me or some terrified teenage boy I had hiding in my office. I understood that this Ph.D. was an opportunity to learn and reflect on my experiences and combine it with new knowledge and attempt to create a meaningful bridge between academia and practice.

\section{Themes, aims and questions.}

This project is about many of the themes identified in this introduction up to this point. In the next part of this chapter I will focus on the research aims, questions and what will be found in the subsequent chapters. 
The aims of the research are to explore and compare the thoughts, views and opinions of young people towards citizenship and othering in Cardiff and Pembrokeshire. To research, test and develop curriculum materials to use with young people to engage them in questions of citizenship and othering which can then be used for ongoing work with the same or different groups of young people. I will look at what the young people got out of engaging from these resources and contribute to debates in Children's Geography, empathy and citizenship.

The questions that will be addressed by this thesis are:

1. What are the thoughts, views and opinions of young people in Cardiff and Pembrokeshire towards citizenship and othering and how do they compare?

2. How can curriculum materials and games be used to engage young people in questions of citizenship and othering?

3. How effective and valuable are those curriculum materials and games when used with young people in Cardiff and in Pembrokeshire, including any potential future application?

4. How do these materials and the findings contribute to and advance existing debates in Children's Geography, empathy and citizenship?

The objective of this thesis is to engage with young people and support them to participate in a series of activities that will allow them to share experiences and their views on citizenship and Othering. They will be invited to discuss issues, ask questions and share knowledge. They will also have the opportunity to fill in gaps in their knowledge through the use of empathy and information that challenges myths and misinformation. I have aimed to do this in a non-judgmental manner and with understanding and respect for the participants. Through my own reflections and the feedback of the participants I will review the activities to see how they worked and what could be improved. The young people's engagement and participation will give me interesting feedback on the strengths of the activity. I will also look at what impact, if any, delivering in formal and non-formal environments has on the work and alongside that, in a similar vein, how relationships 
between myself, the young people and the hosting organisations might impact my research and potential future work.

The outcomes and findings of this research will be the thoughts, views and opinions of the young people involved in the activities. It is possible that due to the nature of the venues and young people it will not be a set group of participants who attend like clockwork. With regard to the findings, as well as being unethical to attempt to predict what these outcomes might be it would also be futile as young people are reliably unpredictable. At the conclusion of this Ph.D. I would like to be in possession of resources that could potentially form a mini curriculum with a relevant application in citizenship education. The proof of their relevance should be the evidence from the research that the activities work in engaging young people on the subjects and themes of citizenship and othering along with some indication that they have encouraged critical thinking. This should see this work benefit organisations including my industrial partner and contribute to a pro-social public good.

This work is important for several reasons. Whilst there have been studies such as Thomas and Sanderson (2011) with Muslim young people around identity and citizenship, in this research Muslim community are only one participant group. There is a great deal of work with young people that focuses on young people's perceptions and experiences of citizenship. Some of these such as Hart (2009) and Geboers (2014) look at the engagement of young people as citizens and their role and development as citizens. Other studies investigate the effect of citizenship programmes such as the National Citizenship Service in England upon young people (Murphy, 2017) and the Welsh Baccalaureate in Wales (Hayden \& Thompson, 2007). What these studies concentrate on is young people's roles or reactions to an adult's pre-determined set of parameters of what citizenship is.

The early research activities that I will carry out in particular allow young people to express their views on the meanings and construction of citizenship. This differs slightly from other studies that often explore young people's thoughts and views on the existing or pre-defined meanings of citizenship. This research will work with groups of young people of whom the vast majority are from a black or minority ethnic background. Thomas and Sanderson's (2011) study is a good example of how some research is done with members of these 
communities based on them being a minority. My research will be more focused on stimulating discussion and cognitive empathy and understanding, regardless of background, identity and ethnicity. This is influenced, like this whole study, by practical experience of working with young people over a 17 year period. In this time I have learnt that young people are very often fully functional social agents who ignore, humour or make a mockery of attempted impositions on their behaviour by adults. As a practioner returning to academia I believe that my perspective is different to that of most researchers. This is one reason for my choice of Participatory Action Research as a method, because it includes the possibility of reflexivity.

In regard to the design of activities this research builds on similar approaches by Vladimirou (2015) and particularly Jennings (2010). Vladimirou (2015) researched the relationship between civic emotions and 'other' orientated civic virtues through participatory drama with young people. Whilst I will not be using drama, I will be creating fictional scenarios to explore real world issues and like Vladimirou, when analysing results I will be looking at what encourages expression and what inhibits it. Jennings (2010) carried out a year long study that focused on tolerance and intolerance by focusing on the Nazi Holocaust. Jennings stressed that the time frame and use of existing, experienced staff was important to the success of the study, which was to build empathy. In analysing the delivery I will also examine the impact of existing relationships in exploring issues including developing empathy. Jennings used a historical event as a way of empowering young people to promote social justice in their own communities. This approach is one that I will be building on, including some of the same data recording techniques such as Venn diagrams, field diaries and media recording techniques.

Currently, there is a drive in Wales for the promotion and teaching of citizenship. In 2015 Professor Graham Donaldson published a Welsh Government commissioned report and review titled "Successful Futures: Independent Review of Curriculum and Assessment Arrangements in Wales". Donaldson (2015) put forward his view on the areas that schools should be concentrating on in order to prepare children and young people for adult life. He proposed four areas, all of which were adopted by the Welsh government and became the basis of a new curriculum. The four key areas are that children and young people become: 
- Ambitious, capable leaners who are ready to learn throughout their lives;

- Enterprising, creative contributors who are ready to play a full part in life and work;

- Ethical and informed citizens who are ready to be citizens of Wales and the world;

- Healthy, confident individuals who are ready to lead fulfilling lives as valued members of society.

The curriculum will contain six areas of learning and experience rather than the more traditional subject based approach. These six areas are: humanities, expressive arts, health and well-being, languages, literacy and communication, maths and numeracy and science and technology. Each of these six areas of learning and experience will contain the three cross curricular themes of literacy, numeracy and digital competence. The final part of this jigsaw are the four key skills that will be embedded across all learning. These are:

- Critical thinking and problem solving;

- Planning and organisation;

- Creativity and innovation;

- Personal effectiveness.

All areas of this curriculum will contain an international and a Welsh dimension particularly citizenship where the Welsh Government (2015) listed the following criteria for the establishment of ethical and informed citizens:

- Find, evaluate and use evidence in forming views;

- Engage with contemporary issues based upon their knowledge and values;

- Understand and exercise their human and democratic responsibilities and rights;

- Understand and consider the impact of their actions when making choices and acting;

- Are knowledgeable about their culture, community, society and the world, now and in the past;

- Respect the needs and rights of others, as a member of a diverse society; 
- Show their commitment to the sustainability of the planet and are ready to be citizens of Wales and the world.

This work did not come about because of the new curriculum, which was very much in its consultation stage when this project began. Indeed the new curriculum is not due to come into effect until September 2021. However there are several similarities between my work and the ambition of the new curriculum, meaning that this research could have extra relevance and very real application as part of this very new, bold and ambitious educational reform. This curriculum development allows this work to make a contribution to citizenship debates, Children's Geographies and contemporary education in Wales.

\section{Chapter content.}

The next chapter is the Literature Review and a lot of the works covered were read in my Masters year when I was familiarising myself with many new subjects. This process consisted of starting with a subject and then following a thread of the areas which I found interesting or relevant. Within the literature review it should be possible to detect the influence of my practice experience, highlighted by my two earlier anecdotes, and how it influenced the literature that I was drawn to and enthralled by. From the literature review came the identification of the areas of citizenship and othering which I wanted to make the focus of my research and the use of different forms of empathy as a way of delivering the subjects to young people. It was through reading the literature that I moved away from the original area of extremism and radicalisation as they seemed to be the effects of citizenship and othering. It became obvious that these were symptoms of larger, historical problems. As I knew that I would be working with young Muslims I decided early on that I should familiarise myself with certain literatures including the Prevent Programme. This led to speaking to the Prevent workers in Dyfed Powys Police, Pembrokeshire Youth Offending service and the South Wales Police. The conclusion of this was that researching these themes initially identified would almost certainly not be allowed as the work around it was tightly controlled by the Home Office through statutory bodies, which again can be seen in the literature. This led to the shift in focus to citizenship and othering that seemed far more in keeping with the aim of developing a series of activities or a mini curriculum. 
The literature review begins by looking at the history of citizenship in the UK and the components and structures of UK citizenship including understanding the terms used in referring to these elements. In this section I share the work of Painter and Jeffrey (2009) which was very significant in helping me to understand the debates around citizenship. In the second section I look at the relationships between the components and how their combinations and interplay has seen different types of citizen and citizenship emerge and evolve over time. Isin's (2004) the Neurotic citizen, one of the key texts in this thesis, is first displayed in this part of review. The third part of the review introduces othering, Orientalism and imaginative geographies for the first time in the chapter, these are used to examine and explain citizenship and othering in the Post 9/11 world. This leads into discussing the Prevent programme and the closely associated securitisation. The chapter also focuses on children's geographies, looking at research on citizenship and citizenship education with children and young people. This opens up the review to looking at how human geography engages with children and young people and what it engages them about. The penultimate section explores different types of empathies and the Bystander technique and how this influenced my decision to use the term othering in my work. The review concludes with briefly looking at neo-liberalism and how citizenship education has been affected by an economic approach to areas of public service that were traditionally thought to be immune to it.

Chapter three is the methods chapter. I thought my research would take a traditional form such as the use of questionnaires or focus group because that had been my experience of academic research as an undergraduate. However my tutor encouraged me to be creative and explore other methods which might allow for creativity and practice based activities to be adapted or used. One advantage in this method is the contribution it makes to developing curriculum materials. The start of this chapter follows on from some debates in the literature review by examining the opportunities and problems attached with researching in Children's Geographies. I wanted to combine practice into my field work and I explain how I came across Participatory Action Research (PAR) methods and why PAR became the influential model and foundation of my mixed methods approach. The next part of this chapter explains the origins and meaning of PAR and explores some of the issues 
connected with PAR and how they might be overcome. I also write about what I found appealing about PAR in my work, including discussing reflexivity.

Reflexivity within PAR is important and it is an early example of how academic theory can have a positive impact on practice as it was successfully used to counter-balance possible over-confidence in my engagement skills. One short coming I found in my readings about PAR was that while it drives home the importance of working with, not on, people and building positive relationships, it is not forthcoming about strategies for doing this. Using reflexivity I drew upon experiences of good practice of how this can be done with young people. The final part of my methods chapter examines the subject of ethics, firstly through exploring ethics in PAR and debates around University Ethics boards attitudes towards PAR. I then consider ethical issues in social research including looking at Economic and Social Research Council guidelines. Next, I explain the process of gaining ethical consent from the University Ethics Board. An area I focused on was who could participate in terms of age and how that linked to the ability to give informed consent. Another consent issue was who could give consent; the young person, their parent or carer or both? I finish by describing the pilot project and the resulting changes to both the activities and delivery for the research itself. Finally I introduce the venues and organisations where I carried out my research and briefly explain how I secured access and gained consent.

The heart and core of this thesis are chapters four through seven of this dissertation. Each chapter features two research sessions. The write up of each research session is structured in the same way:

- Introduction;

- Planning and preparation;

- Delivery and engagement;

- Discussion and reflections.

The introduction explains the background to the session and which themes and aims are to be covered by the activities delivered in the sessions. Planning and preparation 
demonstrates how the activities were designed and the sessions constructed. This may include reference to the pilot project and occasions when I drew on practitioner experience. Delivery and engagement explains how the young people participated and the results that came from the sessions. Finally, I discuss the views of the participants and compare them with other groups and make reference back to arguments and points from the academic literature. I also include my own reflections on the session and the activities, including ways they could be improved, changed and expanded.

The first research findings chapter features two sessions titled 'Zombie Apocalypse' and 'Brave New World'. With the threat of obliteration by nuclear war now diminished, what people would do to survive in a post disaster world has replaced the question of what a person would do if the nuclear warning sirens went off. 'Zombie Apocalypse' asks a young person a more modern version of what they would do in an end of the world scenario. This session explores citizenship creation and how othering is included in this process. 'Brave New World' is the sequel to 'Zombie Apocalypse' and follows the participants as they rebuild following the end of the apocalypse. This explores the social contract between the governed and governors and the rights and responsibilities people would have in the new world. In this session I gradually transition from an imaginary world to our real one and the discussion moves to real world issues.

Chapter five covers the research sessions 'Citizenship Snakes and Ladders' and the 'Political Approval Game'. As the titles suggest, these are both games where the activity focuses on two board games that I adapted and designed myself. 'Snakes and Ladders' uses the British citizenship test as a way of exploring history and allows the participants to consider the conditions and expectations of citizenship for a person who does not gain it naturally and whether this creates an imbalance from those who have it from birth. In 'Political Approval' the participants choose the allocation of budgets to different areas of public spending, which explores their priorities. Then they compete in teams to win a general election by gaining approval points based on their spending decisions and choices when presented with events and situations that mirror real life events that governments face. 
The first four sessions cover important subjects and themes through games and imaginary scenarios whereas the last four sessions become more formal in delivery. In chapter six the two research sessions are both rooted in real life scenarios. The first is called 'Should they stay or should they go?'. This examines the allocation and retention of citizenship through real life examples of people who have faced being stripped of their citizenship. As with previous sessions, it gives young people the opportunity to explore complex issues, ask questions and express their opinions. This continues in the second session of the chapter: 'Liberty versus Security', which explores the relationship between these two ideals. Again, using real-life occasions these concepts are discussed. These sessions stimulate controversy as a method of exploring issues but ensuring that the debate is set up in a way in which the participants feel safe and protected.

Throughout all the sessions, discussions of what lives count and how we decide whose life matters is a re-occurring theme which comes to the fore in the final two activities. These look at othering in a micro and macro way. The first is called 'The Warmth of Other Suns' after the poem by Richard Wright and the book by Isabel Wilkerson of the same name. The poem and book relate to migration and the responses it provokes and fittingly so does this session. It invites the participants to look at their own views on the subject of immigration and challenge them through information and cognitive empathy. The final session is called 'Against a Sharp White Background' and invites young people to share personal stories of when they have witnessed othering; including times they may have been victims and perpetrators of it. One of the aims of this is to explore their views towards othering.

The final chapter is the conclusion and offers an overview of the project and how it met the aims and objectives of the research outlined in this chapter and the abstract. I explore how successful the work has been, particularly in encouraging the participants to engage and express their views and whether the activities could be used as a mini curriculum and in future work on a similar subject. This includes briefly looking at how it has already been used in different but related work and how it could be used in other similar work. This features a short discussion on the new Welsh curriculum and whether there is room within its delivery for work such as mine. This includes exploring the skills and experience required to carry out a research project or deliver this style of activity with young people, especially 
when using a PAR influenced approach. I discuss how much my practitioner experience may have helped and also ways that it might have unduly influenced. This conversation about an academic researcher in children's geographies culminates in the discussion of an academic practitioner and how there potentially exists the space for a new hybrid kind of worker within human and Children's Geographies. This thesis was finished in the Covid - 19 lockdown period of 2020 and one concept emerged from this time and that was the idea of the essential citizen. The finale of my conclusion chapter and this thesis then is my contribution to a style and type of citizen to be considered alongside existing examples such as the cosmopolitan, national or neurotic citizen.

This thesis has represented a time in my life of considerable stability and calm. The three years of funding represents the longest period in my life of guaranteed income. I have been able to calm my mind and process the experiences of practice and learn from them, instead of being consumed by them. I have relished the opportunity to learn again in my middle age. It is a different experience to my undergraduate university experience as it is a different time of my life. What I am conscious of is making sure that this time is worthwhile. I would like this work to be a stepping stone to other opportunities rather than a sabbatical from previous times. Most of all I would like to retain some semblance of the enthusiasm, time and thirst for knowledge that completing this Ph.D. has given me. If I left this work behind I would miss the intellectual company that I have kept. 
Chapter two:

Literature review. 
In this chapter I will build on the questions outlined in the introduction by turning to the relevant literature to explore these questions and issues further. The chapter is divided into eight sections. First, I look at citizenship and Britishness, including a brief history of UK citizenship, focusing on post world war II society. Second, I look at the relationship between the citizen and the state before exploring relatively new concepts of citizenship beyond the state. Continuing the theme of beyond the state, in the fourth section I regard citizenship in terms of security and the imaginative geographies of othering or us and them. This leads to the fifth part which discusses citizenship and the Prevent programme, an example of citizenship framed in securitisation and particularly relevant to people from a Muslim background or community. Prevent focused on young males and in the sixth section I examine citizenship education and children's geographies during recent times in the UK. In sections seven and eight of this chapter I look at empathy and the Bystander approach that was key in inspiring me to find an approach of inclusive neutrality.

\section{Citizenship and Britishness}

As explained by Bhambra (2016) citizenship in the United Kingdom is a relatively new concept and that it came into existence with the passing of the British Nationality Act (BNA) 1948. Bhambra (2016) tells that prior to 1948 it was subjecthood and within the framework of British colonialism there was no formal or official definition or assignment of British citizenship. If you lived in a country subject to British rule you were considered to be a British subject, regardless if you were from Kingston upon Thames or Kingston Jamaica. Bhambra (2016) says that this changed after the end of world war two with the dismantling of the British Empire, a country in need of rebuilding and a Labour government tasked with implementing their post war dream of a welfare state. The BNA 1948, almost overnight, gave British citizenship to people living in the UK, its colonies, its former colonies and its dominion territories.

The creation of the welfare state was closely linked to a new form of citizenship. Marshall (1950) wrote at great length about what he saw as social citizenship that featured progressive taxation on labour and capital. Combined with an investment by the state in its citizens through increasing access to educational opportunities he believed it would create 
greater equality between the different social classes. A significant component of Marshall's (1950) social citizenship was the social contract that guaranteed citizens a civilised life in return for obedience to the law and contributing to society through work and raising families. Marshall (1950) saw the foundation of citizenship rights to be rooted in an historical British identity based on the protection of the individual from tyranny and these three concepts:

1. Common law

2. Habeas corpus (protection from wrongful arrest)

3. The jury system

All of these are indicative of the belief that a person is believed innocent until proven guilty. Turner and Isin (2008) discuss in more depth the historical politics behind this notion of protection from tyranny. They say the Civil War disposed of the divine rights of monarchs and removed the notion of absolute power. Combined with the three pillars of common law as put forward by Marshall (1950) it results in a form of citizenship where rights are protected rather than promoted. Turner and Isin (2008) contrast this to the citizenships of France where following the revolution their citizenship was defined through liberty, equality and fraternity, an example of the promotion of rights. Another example of how citizenship rights can differ is evident in the American Revolution, which was built on the concepts of participation in civic society and small government. Turner and Isin (2008) discuss Marshall's work and how he saw citizenship as an institution that guaranteed its members a: "civilised life, protecting them from the unpredictable vagaries of accident, sickness and unemployment" (Turner \& Isin, 2008:7). They took a historical and modern view of citizenship whereas the social contract required citizens to work, nurture family, contribute to cultural and civil society and pay taxes. They raise the question whether this form of citizenship still makes sense in an age of globalisation.

Painter and Jeffrey (2009) have made an extensive contribution to the citizenship literature including the following three rights, which have similarity with the work of Marshall:

1. Civil rights: liberty is not restricted and this is protected.

2. Political rights: to participate in governance and government.

3. Social rights: a certain standard of economic and social well-being. 
They believed that these rights were interchangeable and one could be used to achieve another. An example is how institutions of citizenship such as parliaments act under the banner of political rights to uphold civil rights and push for improved social rights. They explain that this flexibility is paradoxical as one of these three can be used directly or indirectly to restrict the other. An example being the restriction of civil rights for the purpose of security identified by Norcup (2010) in Labour's attempts to introduce identity cards in 2006 as a security measure in response to the July 2005 London terrorist attacks. Her rebuttal of this argument is twofold: first they would not have stopped the attacks and second it would be an internal passport that could be used to restrict the movement and therefore the rights of citizens to move freely.

Painter and Jeffrey (2009) discuss the different components of citizenship and how important these may be in how a citizen accesses their rights. This leads Painter and Jeffrey (2009) to distinguish between two types of citizens:

1. Citizens in law or De jure.

2. Citizens in practice or De facto.

A simple example of this is the migrant worker who is a de facto citizen through contributing to the economy through spending and taxation but is not a de jure citizen as they have no political right to participate in the democratic processes. This is a formal limit to citizenship. Jackson (2010) also breaks citizenship down into two similar components which build on the notions of de jure and de facto.

1. Political citizenship. This adheres to traditions of the original social contract through looking at the rights and responsibilities of the citizen and the state. It expands it however to include the geographical limit of the state's territory and boundaries.

2. Cultural citizenship. As with de facto citizenship, this focuses on the application of citizenship duties but extends it to include identity and belonging.

Jackson (2010) states that cultural citizenship can be fluid and often international, meaning it can extend beyond the national borders established through political citizenship. 
Karanti and Gill (2002) suggest another organisation of the components of citizenship:

1. Nominal citizenship is the formal membership of a political unit.

2. Substantive citizenship relates to the rights given and the obligations of a citizen and the acting out of these in everyday life.

3. Functional citizenship relates to identity and creating a shared sense of identity.

A topical example of this is an EU citizen living in the UK. Their political membership is with the EU, they practice citizenship rights and obligations in the UK and may identify from their country of origin. All three of Painter and Jeffrey (2008), Jackson (2010) and Karanti and Gill (2002) offer a citizenship framework composed of legal and practical elements. What should be emphasised is that they are just frameworks and what is hung on them can always change and how this is done can partially or completely include or exclude people from citizenship. Through their definitions all three component models hint strongly towards a social contract without stating specific duties. Turner and Isin's (2008) explanation of the USA basis of citizenship allows for a different social contract, one where the government promises not to interfere on the understanding the citizens take an active role in civic and social life. This alternative contract needs to be remembered in the next part of this chapter where I will explore new, different and emerging types of citizenship.

\section{Citizenship and the state}

Balibar (2015) explores the relationship between the state and its people as key to citizenship. This can be seen in the previous mentioned works around the social contract, whatever shape it may take. As Balibar says "no regime can completely eliminate the risk posed by the necessity of gaining acceptance from its people, who can decide to obey - or not" (Balibar, 2015:8). He continues by explaining that democracy is the tool which is most used to change a regime. This means that democracy, the state and citizenship are inextricably linked, but the relationship is rarely stable or equal. One example of this relationship is the democratic deficit which Painter and Jeffrey (2009) see as a modern example of how faith in democracy has been eroded. Norris (2011) sees the democratic 
deficit as the disparity between perceived democratic performance and the public aspiration of what these should be. If the state is deemed to be failing to meet the public's expectations then they may vote in different ways or express discontent with the process. This negative view may be encouraged by the media promoting a certain narrative. Failure may also be due to evolving self-expression of citizens. Negri (1999) provides a breakdown of the balance and distribution of power between the state and its citizens. The state has control over the instruments and institutions of power whereas citizens are part of a collective whole and have the power to appoint people or political parties to the position of control of these institutions. Citizens have constituent power and the state has constituted power. Supporting Balibar (2015) view of a shifting nature to the relationship between state and citizens Painter and Jeffrey (2009) say that this relationship often focuses on who is and is not a citizen and therefore entitled to the rights. This can be played out within political discourse, where the state or those seeking constituted powers will "seek to define discursively who is and who is not a citizen" (Painter and Jeffrey, 2009:80) This can mean that the constituted powers will listen to the voice of the constituents or alternatively that the powers will try to convince the citizens that views held by the constituted powers are the most credible.

King (2007) discusses that this discourse will often focus on rights and asks the question of whether citizens are given or earn their rights. The traditional British stance would be that citizens are given theirs, as this ties in with both a historical perspective and Marshalls social citizen. However there exists literature which suggests that this is no longer the case in regard to UK citizenship. In 2004 Engin Isin published 'The Neurotic Citizen'. It provides the bridge which explains the transformation of the social citizen to the neurotic citizen via an intermediate position as a bionic citizen. The bionic citizen is a self-governing citizen who is expected or empowered to make their own choices, rather than have them made for them. This could include decisions on education, health or employment and the bionic citizen depends on themselves and not the state for a civilised standard of living and believes everyone else should do likewise. Isin (2004) then introduces the politics of fear where politicians and the media in particular promote risk without any reassurance. This may involve the promotion of manufactured uncertainties which highlight the risk surrounding issues such as the economy, the environment and security. These risks, be they real or 
exaggerated are made believable by ignoring knowledge and evidence in favour of fear. The bionic citizen being self-reliant sees all these dangers as the fault of other people. They may blame immigrants for taking jobs, or the unemployed for claiming welfare and this makes them angry and gestates a highly sensitised sense of entitlement to their rights. This might mean not having to pay taxation to see it being sent overseas. Thus emerges the neurotic citizen, concerned with their rights to have rights and willing to ignore the evidence of their realities. The bionic part of the neurotic citizen means that they will never look inward and instead blame things beyond themselves and treat others with resentment and hostility. I believe that Isin chose the term neurotic carefully as it is not a stable state of mind or one that responds to rational debate or evidence. Instead it responds to media or opinions that reflect this neuroticism.

The bionic citizen is in keeping with a USA style civic citizen which in a UK context has led to discussion over the role of the state and the civic actions of citizens. Barber (2009) explains that a move towards a civic form of citizenship places an expectation upon citizens to carry out acts that may have previously been regarded as the responsibility of the state such the increased role of charities. Murphy (2017) and Sinclair et al (2010) refer to this a neocommunitarian form of citizenship that quantifies and measures citizenship. Sinclair et al (2010) talks about how these tools of measurement can include hard outcomes such as gaining paid employment but also about individual responsibility and self-responsibility. What neo-communitarian citizenship does is present issues around expression or participation of political views and could be seen as undermining political and legal rights (Banaji, 2008). Younis et al (2002) and Hart (2009) believe that modern citizenship should encapsulate both civic and political engagement and volunteering and voting can both be seen as social acts. This type of argument is more in favour of what Staeheli (2013) calls liberal citizenship. At the heart of Staeheli's (2013) writings is the relationship between obligations and responsibilities within citizenship. Obligation is compulsory and one example could be military service conscription. Responsibility remains a citizen's choice, such as joining the army. Liberal citizenship is mandated by liberal democracy and assumes that "citizens consent to be governed and, in consenting, voluntarily agree to their responsibilities" (Staeheli, 2013:523). The act of voting is one way in which any obligation is removed by citizens giving voluntary consent. Staeheli (2013) warns us that this consent can 
also be used to reduce rights in two ways. The first is that so many rights and responsibilities have an inevitable normality about them that very little attention is paid to them. This could include ignoring privatisation of many parts of public service. The second is coercing a neoliberal citizenship behaviour that involves the individual looking out for themselves. This then transfers the burden of ensuring that citizens meet their responsibilities from the state to the constituent. This is encouraged by both the bionic and the neurotic citizen and the neo-communitarian citizen is a natural descendent of them due to their constant need to prove through hard outcomes that it is fulfilling its responsibilities.

In accepting Isin's version of a neurotic citizen and seeing this concept as one that threatens or overtakes the social citizen there has to be recognition of the role of the media. Gillespie and O'Loughlin (2009) look at this relationship between audience, news media and citizenship. They state that "to be a citizen today almost inevitably entails engagement with news media" (Gillespie and O'Loughlin, 2009:95). It can have particular influence on our social and cultural practices or the substantive or cultural acts of citizenship. For existing citizens or those looking to integrate the media can provide vital resources to understand expected citizenship behaviour. It may seem that this only applies to constituents but the state will also engage with the media in order to communicate with its citizens. In whatever shape it takes "citizenship is profoundly entwined with media engagement" (Gillespie \& O'Loughlin, 2009:95). This has particular significance for the section in this chapter that reviews Othering and how it affects definitions of citizenship especially with regard to the identity.

\section{Citizenship beyond the state}

So far I have introduced the idea of the social citizen, the bionic citizen, the neurotic citizen, the liberal citizen and the neo-communitarian citizen. To finish off this section I will briefly look at other forms of new and emerging citizenship and how these have enabled the comeback of another more traditional type of citizenship. Painter and Jeffrey (2008) identify insurgent citizenship and cosmopolitan citizenship. Insurgent citizenship looks to challenge lawful authority and the operation of the state through civic action including strikes, marches and riots in order to claim or reclaim civil, social and even political rights. 
Cosmopolitan citizenship sees a social and cultural movement of socialisation beyond the nation state, as also alluded to by Jackson (2010) in his views on cultural citizenship. Archibugi (2003) believes that if a political element is added to cosmopolitan citizenship then it could create the opportunity for cosmopolitan democracy, when democracy and voting "asserts itself beyond national borders" (Archibugi, 2003:10). The EU could be seen as a working example of how shared socialisation can lead to the formation of a democratic body such as the European Parliament. Karanti \& Gill (2002) would term this as a composite citizenship. This is when political units such as states voluntarily come together to form a composite state. The defining feature of a composite state is that each country still holds the right to be recognised separately. Therefore all political or legal citizenship still stems from membership of a nation state. However as Karanti \& Gill (2002) warn, or prophesied, the next step is a federation which Brexit demonstrates is not always welcome. Opposing the idea of citizenship concepts or components that transcend the nation state are views of citizenship that are rooted in the idea of the one nation state, where the nation you are a citizen of, especially a political citizen, takes more prominence and importance than another (Nussbaum, 2012). Starkey (2017) believes that this nationalistic standpoint sees a rejection of the idea of global or cosmopolitan citizenships and especially cosmopolitan democracies and puts country or nation states first.

Next, I explore Othering and how it is linked to identity within citizenship and looking at issues such as securitisation and immigration. Doty (2014) explains how citizenship can be granted and is "linked to social and political phenomena that involve power and struggles over meaning and identity." (Doty, 2014:202). Doty (2014) gives the example of the use of the terms legal and illegal, the latter is a clear identification that a person is not a fully fledged citizen or considered part of a collective identity. This is what I have come to term as Othering. This also marks the crossroad between theory and practice discussed in my introduction and referenced in how my research design came about in my methods chapter. Michael Foucault is widely recognised as one of the key thinkers on space and place and one of the key theories covered by Philo (2010) was Foucault's theory of 'Otherness'. He explains that a society through discourse and construction will classify individuals and behaviour as the Same and as the Other. The Same is seen as normal and the other as not normal and therefore something that requires action such as policing. Another leading 
thinker on the subject was Georg Simmel and his work on the stranger. Rogers (1950) describes how Simmel saw the stranger as "the wanderer who comes today and stays tomorrow" (Rogers: 1950:402). The stranger will be seen to intrude into positions in a society, especially economic positions that are occupied. Berger and Calabrese (1975) explain that a stranger can be viewed with suspicion and xenophobia because of the uncertainty and unpredictable nature of their behaviour. Parks (1928), who was a member of the Chicago School of sociology, discusses how individuals may sense a lack of intimacy with others who differ in variables such as ethnicity, race and religion. This social distance may apply to people who are fellow citizens through political membership. This supports Rogers (1950) explanation of Simmel that the stranger can be seen as a member of a system but one seen as not being strongly attached to the system. The Other and the Stranger are similar because they are identified as a potential problem or threat because they are perceived not to share a common identity. Pykett (2010) explains how this can impact on the design of citizenship as national identity can define how we represent ourselves and is also defined by who it includes and excludes. This provides further explanation to the notion of functional citizenship (Karanti \& Gill, 2002) and that citizenship or national identity is subjective, unlike political citizenship which will involve documentation and cultural citizenship which is seen in simple every day acts. A person can have political and cultural citizenship but still be considered Other. The works of Foucault, Simmel and Parks give credence to Hughes (2009) proposition that problems around the other, immigrant or stranger are far from new.

Pykett (2010) says that an important geographical dimension that contributes to identity is post-colonial identities. The recent history of British citizenship has a strong focus on relationships with ex colonies and territories. Karatani \& Gill (2002) explain that following the BNA 1948 many immigrants arrived from Commonwealth countries, not through invitation or necessity but motivated by economic factors such as a better standard of living. They were still called British citizens and the descendants of British subjects dating back several generations. In response to a public outcry the Conservatives passed the immigration Act (1971) which meant that subjects of former British colonies or territories were now treated the same as non-British citizens. Under Margaret Thatcher the Conservatives replaced the BNA 1948 with the British National Act 1981. This came on the 
back of Thatcher using immigration as a significant part of her 1979 general election campaign. The BNA 1981 cut ties between people from the UK's former colonies. It also changed the rule that being born in the UK would be a precursor to automatic citizenship. Instead a person would have to have at least one parent who was either a British citizen or settled in the UK with no restrictions on the time they were allowed to stay. Painter and Jeffrey (2009) view is that migrants are often subject to the limitations and exclusions of citizenship and that while the given reasons are often economic ones in the interest of the state "exclusions are more crucially connected to defending the mythical homogeneity of a given state" (Painter \& Jeffrey, 2009:84).

\section{Citizenship, security and the imaginative geographies of us and them}

This led me to look at imaginative geographies surrounding the nation state, how this can relate with identity, post colonialism and our perceptions of others, especially since the 9/11 terrorist attacks. Bauman (2004) spoke of how there are often statements such as a country is full and argues that this is "a statement in sociology and political science. It refers not to the state of the earth, but to the ways and means of its inhabitants" (Bauman, 2004:7). Everything has been claimed and globalisation has penetrated every corner of the world. Bauman (2004) also discusses what he terms the 'human waste' of wars which can lead to people pursuing a better life elsewhere. The lack of political space means there is nowhere for this human waste to go without permission. These redundant people are often judged through financial terms and whether it is beneficial to the owners of political space to accept them. Building on this I read Edward Said and began to understand the concept of imaginative geographies. Said's book Orientalism (1978) saw imaginative geographies as how power, description, imagination and perception can manifest themselves through opinion and attitudes. These opinions and attitudes can have particular regard to ethnicity, culture and behaviour. Through critiquing Western countries' colonisation and post-colonial Said (1978) says that the west takes a self-constructed view as morally and intellectually superior. This perception of how a country sees itself can give imaginations substance in behaviour and performance. Said (1978) talks of colonialism and Orientalism in which he diagnosed countries such as the UK's attitude towards the perceived undeveloped world. Through our own self-aggrandizement and a narrow range of sources we view massive 
continents, consisting of hundreds of languages and cultures as one place, which we named the Orient. Morrin (2011) says of imaginative geographies and Said's work that it allows for the invention and construction of "boundaries around our very consciousness and attitudes, often by inattention or the obscuring of local realities" (Morrin, 2011:339). I would summarise that it is how we build walls in our heads before we build them on land.

Gregory (2006) recognises the existence of Orientalism and suggests that over time and saturation Western populations build up a memory bank of this imaginative geography which paints the east in a negative light. Gregory (2006) explores how this residual memory was given fresh impetus in the immediate aftermath of 9/11. He looks at the language of the US President George. W. Bush and how he was quick to use emotive terms such as good and evil and moral absolutes. Bush saw the USA embarking on a "war to save civilisation...either you are with us or you are with the terrorists" (Gregory, 2006;47). Gregory (2006) also explains how this description of the enemy was tapping into our residual memories. Bush referring to a poster saying dead or alive induces memories of John Wayne and Gary Cooper bringing bandits to account in old western movies. Bush described Afghanistan "in an unmistakeable echo of Presidents Reagan's characterisation of the USSR as an 'evil empire'"' (Gregory, 2006:48). He also described Iran, Iraq and North Korea as an "axis of evil" (Gregory:2006:48), which duplicates the description of Germany, Italy and Japan in World War II. Gregory (2006) gives us an example of Morrin's view that imaginative geographies can ignore realities. The identified 9/11 terrorists were all from the middle east and the leader of Al Qaeda, Osama Bin Laden, had been introduced to the Mujaheddin ${ }^{3}$ at the insistence of American intelligence agencies to aid their war against the USSR. As Gregory says, 'Imaginative geographies of 'friend' and 'enemy' spin like the tumblers on a slot machine" (Gregory, 2006:75).

Unlike the cold war and the Second World War this war on terror was not against other countries but against a global terrorist threat firmly and inextricably linked to the religion of Islam. Fisher (2015) offers historical context behind international terrorism, its construct

\footnotetext{
${ }^{3}$ These were Afghan resistance fighters against the USSR in the 1980 's. They were heavily funded by the USA and interestingly were heroic freedom fighters who helped James Bind in the 1987 film The Living Daylights.
} 
and how post $9 / 11$ rhetoric magnified this. She begins by distinguishing between the I.R.A. ${ }^{4}$ and international terrorism as the I.R.A. had a singular enemy and purpose. Fisher (2015) says that international terrorism first emerged in the 1980's and focused on people from Said's orient. This correlates with events such as the revolution in Iran, terrorist acts such as the Lockerbie bombing and individuals like Colonel Gaddafi. Fisher (2015) discusses how spatial places of belonging are key to the east versus west international terrorist construct. This means that a person living in the west can still be from the east and therefore potentially involved in international terrorism. Sasikumar (2009), using the example of Canada post 9/11 tightening its immigration controls, discusses how the 'us or them' attitude of the USA saw other countries pressured to be in the 'us' category. This involved re-examining and even redefining their national identity in regard to how they treated their own citizens and immigration in order "to persuade the USA that it (they) is not a safe haven for terrorists" (Sasikumar, 2009:138). Hughes (2009) looks at how this global terrorist threat has added additional mistrust of the other. Previously the dangerous other was a threat to a nation's resources or would be accused of refusing to integrate and this is now compounded by a potential terrorist threat. The result of this is that immigration has become "defined and represented ever more powerfully as a matter of security" (Hughes, 2009:19).

This post 9/11 war on international terrorism and the threat it presents at home has seen the rise in the UK of securitisation. Prior to the construct and identification of the Islamic international terrorist threat Buzan et al (1998) defined securitisation as "the process by which issues are identified, labelled and reified as threats to the community" (Buzan et al, 1998:21). Gillespie (2006) sees it as a process through which habits, individuals and cultural practices become a matter of security, Gillespie and O'Loughlin (2009) say that post 9/11 "multicultural British citizens are increasingly challenged about their loyalties to Britain...treated as a potential enemy within, they are not unnaturally anxious about the precariousness of their citizenship status" (Gillespie \& O'Loughlin, 2009:90). Noxolo and Huysmans (2009) discuss how securitisation moves issues of security away from objective threats and to more subjective and unfixed definitions and that there are two types of securitisation prevalent in the UK. The first is the securitisation of migrants and refugees

\footnotetext{
${ }^{4}$ Irish Republican Army fought against the British Army for a United Ireland.
} 
and the second the securitisation through successive counter terrorist programmes of people living in the UK. Both could be seen to build on the pre-existing framework that connects Muslims as an international terrorist threat.

Securitisation of refugees and immigrants is also linked to the securitisation and othering of Islamic communities. Pugh (2004) sees acts such as refusal to accept refugees as an example of an act of dehumanisation which often uses natural disaster metaphors to describe migrants and refugees. This language combined with the dual threats of terror and stealing of resources allows for the definition of refugees and immigrants to be manipulated. Mountz (2015) calls this the politics of fear in which a security process is given priority over human suffering. The suffering and identity of the individual becomes invisible and all migrants are again othered through the characterisation of Orientalism and the terrorist threat to the West. This invisiblisation is marked by "active obscuring of identities, histories, and causes of displacement" (Mountz, 2015:5). In contrast the action and sights of security can be hypervisible such as armed Police and act as permanent reminder of the existence of a threat and the risk it poses (Mountz, 2015). Butler (2009) asks questions around what counts as human and what is defined as a valuable life. If a life is not recognised as valuable or liveable then it has no value. The consequence of a life with no value is it does not matter. This can be used as a definition of dehumanisation in that it promotes the worth of one life over another. This in turn resonates with Isin's (2004) neurotic citizen. It could be argued that prioritising a nation's rights over those of other nations due to security and fear sees the emergence of a neurotic nation.

A rich seam of sociological and political geographies literatures focuses on multiculturalism, racial equality and secularism in Britain. For example, Fortier (2008) explores the journey of multiculturalism in Britain from the time of New Labour in 2000. This political road map included policy guidelines for intercultural mixing to prevent racial violence. However the framework of this debate changed over the following years. Discussions on whether the hijab should be allowed to be worn in schools and former foreign secretary Jack Straw's remarks about his unease over the niqab raised questions about racial equality and secularism. Later the London Terror attacks on 7/7/2005 "brought multiculturalism and integration to the forefront of passionate public and political debate" (Fortier, 2008:3). 
One example of this is explained by Thomas and Sanderson (2011) in the Labour government's interaction with the Muslim Council of Britain. They explain that Prime Minister Blair wished to make the council the official voice of Britain's Muslim. Until, that was, the council expressed views on the governments foreign policy in the Middle East and Iraq when this support and the accompanying funding dried up. This provided a pivotal moment when narratives about legitimate and illegitimate British citizens intensified. As Fortier (2008) explains, the London bombers were all British citizens, but were portrayed as foreigners to the nation. Sara Ahmed's work further describes how racist atmospheres contributed to particular bodies being rendered out of place. As Ahmed (2014) states, representations of British Muslims are significantly influenced by emotion - as she puts it, the right wing press frequently portray Britain as a soft touch for 'illegal immigrants' and that "to 'take in' is to be 'taken in'" (Ahmed, 2014:30). This sort of thinking can be seen in actions surrounding making Britain a 'hostile environment', designed to make immigrants feel unwelcome. This is an example of the model of neoliberal, neurotic style citizenship availing itself in the UK.

Berry et al (2006) found that the experiences of Muslim communities during this time of government supported multiculturalism, led to low levels of self esteem among ethnic minorities due to experiences of discrimination. In the next part of this review, I explore the relationship between citizenship and the Prevent Programme, which I focus on because the targeted group was often young Muslim men and some of the communities I would be directly working with in my research.

\section{Citizenship and the Prevent programme}

This neurotic outlook and reversal of risk, where we look at what the other may do to 'us' rather than what is happening to 'them' can be seen in UK counter terrorism since 2002. Heath Kelly (2013) explains the UK's counter terrorist approach is named the CONTEST strategy. It has four key areas:

1. Pursue: detection, investigation and prosecution.

2. Protect: the country's infrastructure, crowded places and transport

3. Prepare: response of emergency services 
4. Prevent: stop involvement or support of terrorism

The Prevent programme is often the one most associated with children and young people. Stanley and Guru (2015) explain that it was designed to steer young people away from terrorism by focusing on at risk communities and looking for extremist or radicalised behaviour, which are defined in the strategy as:

- Radicalisation: How a person comes to support terrorism and extremism that leads to terrorism.

- Extremism: Opposing British values including democracy, rule of law, liberty, freedom of speech and tolerance of other faiths etc.

Stanley and Guru (2015) also tell us that it was very much focused on Muslim communities who were seen as more at risk of radicalisation and extremism. Heath - Kelly (2013) sees this as constructing a perception of risk as stemming from Muslim communities by giving this risk terms such as radicalisation it provides a transition that can both explain and prevent extreme views and actions. She argues that it allows ourselves to make sense of "the production of terrorism" (Heath-Kelly: 2013:396). She also suggests that risk is a technique used to enable governments to implement security policies. She sees this actioned in the Prevent programme by young Muslim men often being defined as at risk of radicalisation simultaneously meaning they may carry out risky behaviour and the risk has been transferred to everyone else. This means that young Islamic men are both victims and the criminals. Their communities in turn are expected to combat extremist views to reduce the chance of radicalisation but are suspected of promoting or hosting those views. This leads to what Fisher (2015) regards as "a forever unfinished practice of othering" (Fisher, 2015:57). This means those perceived as a threat will have differences highlighted to make them other. The counter terrorist action becomes aimed at these others including the prevention of future acts. This leads to a "mutually reinforcing feedback loop" (Fisher, 2015:60) where it becomes embedded that all members of the other group are potentially dangerous.

The impact of Prevent has been seen as causing more of a problem than what it is trying to solve. Thomas (2012) sees it as a hardening of defensive attitudes within Muslim 
communities. Fisher (2015) believes that it has taken away Britishness from those who may be seen as potential terrorists, allowing them to become other and be actionable against. Hopkins \& Dunn (2016) explore the experiences of the everyday Muslim in the West. They say that they are associated with explosive actions and figures which results in a stereotype and public ill will towards Muslims that manifests itself in Islamophobic behaviour. This stereotype is enforced by government strategy and also by a media that "pursues business models that benefit from the scandalising of public interest" (Dunn and Hopkins, 2016:255). Dunn et al (2015) state that there exists a high state of Islamophobia but this does not lead to acts of terror as if it did there would be a genuine security issue. When looking at the securitisation approach of Prevent it is key to remember the historical context of British citizenship. Many immigrants and Muslims who live in the UK are often one or both of British citizens or descendants of British subjects. This removal and/or redefining of their status is nothing new.

As well as the securitisation aspect of the strategy Prevent has also been criticised for the mechanics of how it was implemented. Thomas (2012) reports that Prevents attempts to inform and educate young people was largely unsuccessful due to the practitioners involved. Many practitioners did not feel confident, informed or resourced enough to deliver. Another issue was that the Police were one of the lead agencies in delivery and this was a problem as they were seen as the agents of securitisation and treated with suspicion, especially by Islamic communities. Lamb (2012) suggests that the Police took such a prominent role as other organisations were seen to not have the necessary capabilities or capacities. This can be evidenced by Stanley and Guru (2015) who argued that social work was in danger of becoming the default agency in the identification and reaction to radicalisation with little or no guidance into what constituted either risk or risky behaviour. Thomas (2012) discusses how Prevent work was part of community cohesion strategies. Kelly (2013) is dismissive of attempted cohesive social activities such as cricket and football matches. Her dismissal is quite casual and demonstrates to me that while she is an expert in many elements of this subject she may lack an understanding of practice.

Thomas and Sanderson (2011) demonstrate a greater understanding of the importance of practitioners through soliciting the support of youth workers to carry out a study on Muslim 
young people and national identity. They wanted to explore the discourse alluded to in Prevent that Muslim communities did not want to be part of Britain or identify as being British and that religion played a more significant role in their identities. Cantle (2005) says that there exists a "clear association created by Prevent between 'Muslim Identity' and the 'terrorist threat'" (Cantle, 2005:45). Thomas (2009) saw Prevent as a tool that saw engagement with Muslim young people as "Muslims only rather than through other forms of identity and experience that many share with non-Muslim countries" (Thomas, 2009:285). Thomas and Sanderson (2011) carried out their work in areas of Rochdale and Oldham which are very diverse cities, and also have histories of racial tension. The research design used "the existing relationships between youth workers and young people to maximise opportunities for open and honest responses" (Thomas and Sanderson, 2011:1031). They carried out interviews with 75 young males from Muslim communities. The majority of them identified positively with Britain as the country they were citizens of. They distinguished themselves from an English identity which they saw as predominantly white and negative. They questioned the culture of this English white majority in terms of substance misuse, promiscuity, violence, a lack of family values and consumerism. They did believe that British foreign policy targeted Muslims and that some elements of politics and the media have shown clear prejudice against Muslims in Britain. Despite this the majority identified themselves as either British Asian or British Muslim. This demonstrates a plurality to their identity, one which they suggest that white English people in their communities would struggle with and yet one which "appears relatively unproblematic for most young Muslims" (Thomas and Sanderson, 2011:1034). It contradicts views that a dominant religious identity is the cause of the home grown terror threat. Most of the study focused on the young people's identity and it can safely be said that their political citizenship was mostly British. Their religion however meant that they had an extra element to their substantive citizenship where they saw themselves as members of a practicing international community. Thomas and Sanderson (2011) found that this was partly in response to UK domestic and foreign policy and not an indication of somehow feeling less British. In fact this study may highlight a difference between British citizens who are descendants from colonisation and those that are not. Perhaps for people with mixed heritage there exists an inherited sense of being part of a global world which makes cosmopolitan citizenship a natural state of mind. The strong conclusion of Thomas and Sanderson's (2011) 
study is that "moral panics around the national loyalty of young British Muslims are misplaced, with a significant majority proud to be British" (1041). However this also comes with the warning that a nation state believes that its citizen's loyalty should first and foremost be to the host state.

\section{Citizenship, Education and Young People}

This notion of one nation citizenship can be seen in recent incarnations of citizenship education in the UK. Murphy (2017) reviewed the Conservatives government's flagship National Citizenship Service (NCS). He found that it was a programme which concentrated on citizenship acts rather than exploring what young people thought it meant to be citizens. It encouraged citizens to become active and develop certain life skills based around volunteering and duty to others. This is very much an execution of the de facto or substantive citizenship. Murphy (2017) found the NCS to be a neo-communitarian approach, which focused on the civic and ignored political and legal rights; "it fosters compliance with a form of practice which offers little scope for critical thinking and enquiry about existing power relations and structural inequalities" (Murphy, 2017:89). The main practice is that of gaining employment or participating in activities that would help gain employment i.e. volunteering. Bagnall (2010) confirms that the NCS made volunteering a major part of active citizenship. Murphy (2017) found that many young people participated in the NCS as it improved their life chances through enhanced CV's and improved university applications. Hayden \& Thompson (2007) found similar views regarding participant's motivations when conducting a review of the Welsh Baccalaureate. They also found that the experience of the programme varied in different parts of Wales. There are views such as Westheimer and Kahne (2004) who suggest that active citizenship should consist of both social and legal behaviour. Younis et al (2002) and Hart (2009) believe that true citizenship should include a broad range of both political and civic acts. This makes the absence of the practice, execution or determination of legal and political rights in citizenship education a very worrying trend. This could be seen as further deepening the obsession of the already neurotic citizen regarding their rights to have rights. It implies that only through personal responsibility should a person have rights and therefore anyone who does not do this 
therefore should not have rights. Barber (2009) also questions what choices are given by a semi imposed neo-communitarian approach. Afterall the reality is that the NCS would enhance CVs and improve university applications. Does this mean the work is truly voluntary and do all young people have an equal offer and access to opportunities?

Another debate that programmes such as the NCS and Welsh Baccalaureate provoke is one that is at the heart of Children Geographies. This revolves around the treatment of children and young people, how the work of human geography engages with them and what it engages with them about. Aitkin (2007) discusses whether children and young people should be seen as pre adults, less important than adults due to their lack of autonomy, or should they be treated as fully fledged social agents. This lack of autonomy can be seen in five areas highlighted by Vanderbeck (2007) in which children's geographies are very silent upon:

1. Voting ages

2. Drinking ages

3. Sexual consent

4. Media access

5. Compulsory education

Whilst there is now some discussion upon voting ages, sex and alcohol remain controversial topics. In terms of research or studies in these areas it could involve acknowledging that young people are breaking the law or putting themselves at risk which raises ethical issues. There are also contradictions in practice versus law such as the application of Frasier guidelines in regard to dealing with sexual behaviour and its consequences. What is important to realise is that young people may not be involved in the legal decisions of when they do things, but are often in charge of deciding to do things. Gordon and Taft (2011) use the term adultism to describe the imposition of adult rules and narratives on young people and within this young people are powerless as they are not treated as fully competent social actors in their own lives.

Kraftl (2013) studies children geographies and argues, "children are far more capable and independent than adults usually admit" (Kraftl, 2013:5). However, he goes on to say that it 
is not wrong to question if they are too young for certain subjects, where they may not be able to engage with the bigger picture of adult discourses. Kraftl (2013) encourages adults reflect on their own positions and ensure that a child or young person's voice can be heard within adult discourses.

This does not mean that the ability to research with young people in their own, non quantifiable space has been pushed from the field of children geographies. Horton and Kraftl (2017) carried out research with children and young people on the use of playgrounds in outdoor play, which focused on the children's thoughts and feelings and not the adult's view of what a playground should be. This study looks at play, in both terms of space and behaviour, which connects with Ludic geographies.

Woodyer, Martin and Carter (2015) refer to Ludic geographies as a range of fun activities and how they might be utilised in human and children's geography in both research and debate. Woodyer, Martin and Carter (2015) explain that nowadays "play is viewed through an instrumental lens, seen as a learning process preparing children for adult life" (Woodyer, Martin and Carter, 2015:44). It is probably important to distinguish between the social learning children experience through play e.g. how to share, and the deliberate use of it in treating children and young people as pre-adults in training. Ludic geographies encourages ambiguity in play that does not have to be part of a prescribed agenda motivated by a certain political philosophy. A recent example of how politics attempts to use play comes from Carter, Kirby and Woodyer (2015). They looked at how a toy range of serving British soldiers fighting in Afghanistan and Iraq were put on the market in 2009 "as an attempt to tap into a particular national mood of re-enchantment with the Armed Forces." (Carter, Kirby and Woodyer, 2015:1051). These toys were marketed as exciting for children to learn about military manoeuvres and for parents on account of the positive role models the toys would promote. Accordingly, Carter, Kirby and Woodyer (2015) argue that the relationship and representation of geopolitics and domestic politics is not only done through text, objects, bodies and projects but also play. Play is a way in which issues may be presented but also a method for how practices of play can influence views and behaviours.

If the consensus of citizenship is that the performance and compliance of working and selfsufficiency is of utmost importance then the fact that young people are not contributing to 
this can also reinforce that they are not full citizens and therefore require training in how to be one, e.g. volunteering. This can mean a reduction in public funded recreational settings. Mason (2015) talks about how there has been a great reduction in the number of openaccess youth provisions. Open access youth provisions are ones where the young people can within reason do what they choose under no obligation to engage with structured activity. Mason (2015) explains that this is because open access youth work does not produce quantitative results which can be exchanged for funding, which places emphasis on a prescripted curriculum that blocks innovation and progressive working methods and makes securing funding for open access spaces difficult. Open access can mean doing nothing and this is not allowed as children should be contributing by enhancing their future contributions by volunteering or gaining accreditation.

There are areas in which children and young people do have the opportunity to explore, learn and influence political and legal aspects of citizenship. Horschelmann \& Van Blerk (2012) discuss how the establishment of bodies such as youth councils have been used to involve children more in decision making where the young people contribute as capable, choice making citizens and not citizens in training. The decisions of young people in these councils can be seen as citizenship training through choice making. Tyrrell (2012) looks at how Children's Geographies can explore the marginal conceptual spaces at the edge of an adult centred world. The reality of these spaces is that within them young people do not have the same ability to influence their lives as adults do. This is down to a combination of developmental issues, institutions and legislation. Tyrell (2012) is of the view that Children's Geographies should look to empower and that this can be achieved through "researching with of for, rather than about children" (Tyrell, 2012:124). This compliments the view of Van Blerk and Kesby (2012) who believe that children's geographers should use innovative methods such as participatory action research (PAR) as a way of empowering young people. While government programmes such as the NCS may promote a neurotic-neo communitarian citizenship model that concentrates on individual responsibility and selfresponsibility (Sinclair et al 2010), Children's Geographies can give the opportunity for young people to focus on their own perspectives of rights and identity. 


\section{Young people and empathy}

If children and young people are to be empowered to consider meanings of citizenship Pedwell (2012) and Nussbaum (1999) believe using empathy is one way to cultivate their views on the meanings and construction of citizenship. Pedwell (2012) believes in a striving for the ideal of a pro-social sympathetic citizen through "perspective taking" (Pedwell 2012: 283). She believes that the use of affective empathy will utilise emotions such as sympathy and compassion to promote concern and care for others. Pedwell (2012) explains that the definition of affective empathy is allowing for "the ability to put oneself in the other's shoes empathy...the affective attribute is that we want to define our society and which we hope will characterise our interactions with those living outside our border" (Pedwell, 2012:280). In earlier work Pedwell (2010) discusses how affective empathy and perspective taking often occurs by the privileged about the less privileged. Pedwell (2010) describes this as the marginal subject. The use of the term marginal could put Pedwell's work in line with Tyrell (2012). While Tryell (2012) suggests the work is carried out in the marginal areas, Pedwell (2010) tells us it is carried out on marginal people. This immediately implies that there is an imbalance of status that casts a shadow of power over those in the margins. For young people they are in the shadow of adults as they are not fully fledged social agents, lacking political rights such as voting. A migrant or refugee may also have no legal or political rights in spaces dominated by those citizens who do. Then there are minorities, who due to race, religion, ethnicity, sexuality or circumstance are similarly in the shadow of majorities.

Chabot \& Davis (2004) and LaCapra (2001) discuss how perspective taking requires the empathiser to recognise their own direct or indirect complicitness in the circumstances of those who they are to have the empathy for. Pedwell (2012) herself talks about how affective empathy for others, motivated by social justice issues, is only one form of motivation. Another motivation that Pedwell (2012) suggests is that of self-empathy, where a person is motivated by what is best for them. Yeomans (2016) also discusses self-empathy and how it focuses on self rather than other and talks of business people motivated by financial and market goals. Yeomans (2016) believes that true empathy is having it for others and letting it influence social behaviour and that it is "perhaps the mark of emotionally intelligent behaviour in contemporary social life" (Yeomans, 2016:72). Coplan 
(2011) is scathing of self-empathy calling is a pseudo empathy which requires little or no imagination or perspective taking. These conflicting motivations in empathy can also be seen in citizenship between the social citizen and the neurotic citizen. Why should someone feel sympathy for another when no-one is feeling sympathy or appreciative of them? This does not necessarily detract from the importance of empathy but it could mean that an affective empathetic approach is not guaranteed to be well received in citizenship education.

Clark (1997) lists three different types of empathy;

1. Cognitive empathy: Thinking or recognising that another person faces difficulties and understanding the cause of these difficulties.

2. Physical empathy: Physical mirroring behaviour to another person's difficulties. This might be laughing when someone else is laughing, crying when someone cries and so on. It can also be known as contagious empathy.

3. Emotional empathy: Understanding another's difficulties through having an emotional reaction e.g. anger, sadness, fear.

These three categories have overlapping elements, such as emotional empathy may be a reaction to cognitive empathy and physical empathy could reflect the emotional empathy. Clark's (1997) three categories of empathy interested me as a potential alternative to affective empathy, with the idea of cognitive empathy. This offers the opportunity to present a situation and its causes without implying to a person that they are a) complicit and b) should feel sympathy. DeWeid, Mass, Van Goozen et al (2007) also discuss cognitive empathy. Their definition focuses more on understanding another person's feelings and not the difficulties that they face. This opens up cognitive empathy as a way of exploring events and feelings in a non-judgemental way. DeWeid, Mass, Van Goozen et al (2007) suggest that this can be done through perspective taking processes, the same approach promoted in Pedwell's model of affective empathy. Pedwell (2012) discusses the use of imaginative reconstruction as a way of promoting perspective taking, which encourages identification with people in different situations. This could open the door for the innovative and new methodologies that Tyrell (2012) tells us can be used in children's geography as a way of 
exploring the different ways in which children and young people explore and view the world.

The use of imaginative reconstruction and perspective taking are useful tools and could be seen as the building blocks of empathy for others. However if they are used to promote a pure affective empathy model then it could be seen as adultism and another example of adults training pre-citizens. Through introducing an element of critical thinking it may be possible to maintain a more cognitive approach where the decision around emotions and sympathy are made by the individual. Browne and Freeman (2000) define critical thinking as an intellectual skill or competence that promotes "curiosity, openness to new ideas and a willingness to listen to others views" (Browne and Freeman, 2000: 302). Critical thinking therefore has a relationship to perspective taking, but it is one to encourage understanding and not an emotional reaction. This does not mean that emotions should be avoided, shelved or ignored in these debates. Afterall, these are emotional subjects that generate strong beliefs and opinions. However, beliefs and opinions can result in monological thinking and for this reason they are not always constructive in debates and discussions, which require more complex and dialogical thinking. A simple distinction between these two approaches can be demonstrated by the use of exclamation marks in monological emotional reactions and the question marks implied in a dialogical emotional reaction.

Ameida, Pedrosa de Jesus \& Watts (2011) highlight the importance of questioning in critical thinking as a way of encouraging understanding and perspective taking. Browne and Freeman (2000) go further on the subject of questioning and believe that this is best done through the stimulation of controversy to provoke debate and that this should be provided by the teacher. Whether Browne and Freeman (2000) mean practitioner or an actual teacher is not clear, experience would make me believe the latter. This can be related to criticisms of the Prevent programme surrounding who delivered the work and the dangers of resorting to a default setting of social workers. Yu-Chu Yeh (2011) believes that critical thinking and questioning requires the teacher to have mindfulness of their own knowledge, practice and opinions and not imposing or promoting them to students but instead allowing room for the students to express their views. Horvath \& Forte (2011) believe that 
participatory activities are effective in encouraging critical thinking and that there should be a partnership between teachers and students. This again has similarities with recommended approaches in children's geographies of working with young people and not on young people.

\section{The bystander approach}

An interesting use of empathy and critical thinking is the work of Katz, Heisterkamp \& Fleming (2011) and their Bystander programme. This challenges the complicitness of men through their silence and silent witnessing of violence towards women. It marked a shift from a view that men were all potential perpetrators of sexual or violent crime towards women. Katz, Heisterkamp \& Fleming (2011) believed that this created disconnect with men who did not associate themselves with this view. They decided to rebrand the term bystander by creating an association between violence and people they know who could one day be the victims of it - this could include sisters, friends, daughters, wife or colleagues. The bystander becomes involved rather than the traditional view of a bystander who is thought to be a witness to problem behaviour which they do nothing and are expected to do nothing about (Berkowitz, 2009). The Katz, Heisterkamp \& Fleming (2011) bystander is empowered as opposed to passive and the approach is "a pedagogical model that would provide critical information and refute common myths, but do so in a way that would invite, not indict, and engage them in critical dialogue" (Katz, Heisterkamp \& Fleming, 2011:686). The bystander approach features carefully chosen language designed not to provoke negative reactions through the use of neutral terms such as "power based violence" as opposed to "male violence", which is designed to suggest that anyone can be a perpetrator, victim or bystander. I believe that this neutrality of language could be achieved in conversations in citizenship and particularly exclusion by the term othering, because it avoids trigger words such as racism, extremism and radicalisation as othering can happen to anyone over anything. This neutrality of language can promote a pluralistic approach to challenge the dangers of singular messages promoted by the media and certain politicians. This may lead to compromise, understanding and people learning off each other through 
listening to and accepting different perspectives, no matter how at odds they are with your own.

The bystander approach, critical thinking and cognitive empathy are potentially at odds with neo communitarian approaches such as NCS and the closure of spaces for young people. In her book Undoing the Demos: Neoliberalism's Stealth Revolution, Brown (2015) discusses how economic imagining through valuation has inserted itself into all areas of the private, business or public domain. In regard to public education this was formerly considered noneconomic yet now costs are measured about outcomes resulting in an economic approach to education that looks to "the production of subjects, a code of conduct and a scheme of valuation" (Brown, 2015:48). Brown (2015) takes issue with this, saying that it ignores other forms of thinking including human conditions and experiences, creativity, traditions and aspiration. The obsession with valuation complements Isin's (2004) argument about the "neurotic citizen", facilitating the dismissal of humanitarian appeals by judging them on economic and not human costs. This raises the question of whether practitioners have the mindset, willingness or latitude to be innovative in delivering children's geographies. Davies (2018) takes the notion of valuation further and discusses the idea of the quantified self, and that now there are wearables such as smart watches and fitbits which allow a person to measure numerous aspects of their lifestyle, such as heart rate, blood pressure and calories. There are measurable targets for food consumption and exercise. These may magnify the thoughts of the neurotic citizen, who can prove their bionicness and challenge others to prove theirs. If someone meets all their health requirements why should they pay for the care of someone who does not?

All this reading has been applied in the invention of my research activities including the use of play and games. These activities and the methods behind them are explained in the next chapter and then put into action in Chapters four to seven. The challenge to me at this point was to take the critiques developed in this chapter and develop materials that could engage young people and explore the conflicts and tensions that these literatures raised. I wished to take contemporary real world issues around citizenship which have links and explanations based in the academic literature. Painter and Jeffrey's (2009) work around the components of citizenship and the interplay between them clearly impacts on othering behaviours in the 
UK and how we treat refugees and immigrants. Isin's (2004) bionic and neurotic citizen appears to manifest itself in neoliberal behaviour and attitudes to citizenship education which focuses on working and individualism and how that impacts views of a country's resources and services. The post colonial focused work of Gregory (2006) including Said's orientalism can be seen in political issues such as Brexit, the hostile environment and the treatment of the Windrush generation. The next chapters will demonstrate how I have taken these academic literatures and linked them through an innovative use of mixed methods to the real world of the research participants and practitioner development and experience.

This literature review has discussed a range of relevant books and articles, beginning with citizenship history, development, components and types and then looking at citizenship in relation to young people and education. In the next chapter I will build upon the latter aspects of this chapter by explaining how these themes influenced my choice of research methods and approach. I will also discuss ethical and engagement issues, which looks at the sometimes symbiotic relationship between theory and practice. In the second part of this chapter I will continue to look at the practical aspect of research and discuss the findings of a pilot project and introducing the host organisation where the research was carried out. 
Chapter three:

Designing and planning the research process: methods, ethics and pilot project. 
In the literature review, I discussed some of the opportunities and problems attached to research in Children's Geographies. The problems include areas of silence, adultism and the pursuit of quantitative outcomes. The opportunities centre on how they can empower and give young people the opportunity to explore political and legal aspects of citizenship. Tyrell (2012) believes that empowerment can be achieved by "researching with or for, rather than about children" (Tyrell, 2012:124). This approach appealed to me as it reflects my own beliefs in working with young people. Whilst studying a research methods module I came across participatory action research (PAR). PAR became the dominant approach in the design of my research sessions and activities because its approach is compatible with approaches inherent in Children Geographies. For example, its defining feature is working with participants rather than on them (Kemmis and McTaggart, 2005). In my research I built around a PAR approach to use methods including simulation, imaginative recreation and board games. These additional methods will be discussed in conjunction with the sessions they were used in during the research findings chapters. The first section of this chapter discusses what is meant by PAR, why I choose it, the potential issues with using it, how these may be solved and putting PAR into practice. The middle section of this chapter looks at the ethical issues and applications and the conclusion explores the pilot project and introduces the venues for the research itself.

\section{What is PAR?}

PAR refers to a range of participatory approaches that focus on action that "involves researchers and participants working together to examine a situation and change it for the better" (Hay, 2016:450). Kemmis and McTaggart (2005) list three attributes that make PAR different from other, conventional qualitative research methods:

- Shared ownership and collaboration of the research project;

- Community based analysis of social problems;

- Orientation towards community action.

Pedler (2008) sees the strength of PAR as delivering benefit to the research participants and that the views and advice of experts is not more important than those who are facing the problems being focused on. 
Kemmis and MacTaggart (2005) state PAR may involve a high degree of social or political issues and an important element of PAR is that an outside influence does not identify these issues. Caretta \& Riano (2016) believe that too often research on these subjects is top down, meaning that the people affected by them are ignored or not given a chance to voice frustrations and issues. Pickerill (2009) explains how issues can be based on groups or individuals' experiences of place and events and different people can experience these differently. PAR is about mutual inquiry and exploring problems from different perspectives and points of view, it is not looking for definitive answers and actions. The bottom up approach offered by PAR allows for equal relationships between all parties so that they can go about "engaging in processes of knowledge co-production between researchers and research participants" (Carretta \& Riano, 2016:259).

PAR allows the use of different techniques to engage with participants and to observe and record the action. Prokopy (2009) working in rural India found that a lack of literacy meant that participants could not contribute through traditional tools such as questionnaires and focus groups. Pyles (2015) when working in hurricane hit Tahiti did think traditional tools could be used but should be adapted to the participants and not be the sole method. Wang and Redwood Jones (2001) promote a use of different technologies and used a technique called photovoice where participants in rural China were given cameras and asked to take pictures of the things related to the topic that they viewed as significant. In conclusion, effective PAR requires understanding of the people, social contexts and cultural activities (Pyles, 2015). The researcher should embrace the fact that PAR involves uncertainty and an element of the unknown and remember these simple words "You can think. You can believe. But you can't, you mustn't, know" (Garner 2012:81).

Due to its powerful ability to work with groups of people towards achieving change PAR is often used in feminist approaches. My own approach was did not draw on these literatures, but feminist debates have an important place and history in investigations and explorations of citizenship and othering, and may be drawn on in future research with these groups of young people 


\section{Why PAR?}

Bizzel (2005) singles out Brazilian Paulo Freire because he promoted a working with rather than on style of education and learning. Bizzel (2005) describes how Freire believed that all humans were "active beings, capable of reflection on themselves and on the activity in which they are engaged" (Bizzel, 2005:134). This view led him to believe that students should be collaborators rather than participants in their education and that many educational systems believed in a banking form of education "in which knowledge has been deposited by authorities in their (students) passive minds" (Bizzel, 2005:133). There are also examples in the UK of when young people have made contributions to education design through being treated with increased parity. Horschelmann and Van Blark (2012) explain that the establishment of bodies such as school youth councils and youth parliaments treat young people as capable and choice-making citizens. In 2018 the Welsh Government reestablished the Welsh Youth parliament in an attempt to incorporate young people's views into policy issues and affairs.

Van Blerk and Kesby (2012) believe that PAR allows flexibility for practitioners to be innovative and gives young people the opportunity to concentrate on their own perspectives. Van Blerk and Kesby (2008) discuss how young people have different perspectives on the world to adults. Part of this relates to how they engage with the world which can be linked to Valentine's (2004) contention that public space is dominated by adults, even public spaces designed for use by young people. PAR treats young people as fully functional social agents and not citizens in training. This view is not shared by everyone. Gordon and Taft (2011) believe that young people are not fully competent social actors in their own lives. Whilst this contains some truth, it is not an obstacle to PAR. As Horschelmann and Van Blerk (2012) say, even within adult controlled or designed environments young people can still contribute equally and effectively.

\section{Potential issues and their solutions within PAR}

A criticism of PAR put forward by Mason and Urquhart (2001) is that there is always going to be a natural power imbalance between adults and young people which makes the existence of true partnership working or parity impossible. This could support Gordon and Tafts (2011) theory of adultism where young people cannot be fully competent social actors and 
are often powerless in the face of adults and their imposition of rules. This power imbalance is not restricted to Children's Geographies. Spivak (1988) describes how many post-colonial PAR projects were criticised because Western researchers assumed they knew more about the problems and solutions faced by people in the developing world than those who lived there, which could be seen as another manifestation of Orientalism. I believe that in carrying out PAR with young people the researcher faces the problem of combatting a combination of the first world intellect and adultism, which I term the Adultist Intellect trap. This means that a researcher could find themselves in a position of power and having to resist the temptation to impose or be driven by their own preconceptions. As suggested by Ruddick (2004) these preconceptions can be brought about by activism, where a well motivated researcher may have their opinions on what the views and outcomes of the research should be. Ruddick (2004) believes that this may conflict with the views and morals of a participant group and can be problematic for the researcher. A common cause of different perspectives is that the researcher will often come from a more privileged educational background to that of their research participants.

PAR proposes an equal relationship between theory and practice. Stringer (2007) discusses how PAR can require a certain skill set to engage with participants and the work can often be unpredictable in nature and to be successful, a researcher has to be able to establish trust and equality with participants in order to build the positive relationships that ensure good levels of participation. Smith (2001) supports this view, explaining that building trust can be challenging, especially if the research is not seen as having any real benefit to the collaborators. A PAR project may also encounter criticism when seeking ethical consent and presenting findings. Morgan, Cuskelly \& Moni (2014) explain that in a study of drug use the subject is illegal and participants may disclose other illegal activity in the course of the project. This is just one example of how a PAR may "encounter a range of ethical issues which may be unique to their project and for which there is no easy solution" (Morgan, Cuskelly and Moni, 2014:316). Burgess (2006) writes about how ethics boards may want to see the establishment of processes and identification of potential issues that may occur during the research. Burgess (2006) explains that this may create problems when presenting results as processes could be seen to pre-empt findings and undermine the idea of PAR partnership. Issues around presentation in PAR findings can be seen by the experiences of 
Hoggart (2017) whose results were questioned on the basis of personal bias on the subject of contraception in a London community of young women. This suggested bias led to the criticism that her findings had "privileged the perspectives of key informants and had not considered alternative understandings" (Hoggart, 2017:103).

The main problems with PAR are the adultist intellect trap and the nature of engagement. Adult intellectualism can create issues with personal bias, assumption and power imbalances. Engagement with the participants can be both challenging and unpredictable. PAR must incorporate reflexivity to resolve these problems. Kemmis and McTaggart (2005) see reflexivity as a technique that sees the researcher reflect on issues, actions, observations and consequences and to adapt research based upon these reflections. Pain (2004) explains that reflexivity should be present at all stages of the research process. Hay (2016) talks about how good reflexivity will combine self critical introspection and self conscious scrutiny meaning a researcher has to be honest with themselves, especially at the conceptual stage of a project when a researcher has to ask themselves if they have the necessary skills to carry out PAR with the partner group. This is where the relationship between theory and practice becomes apparent. Practice experience can make identification of potential issues, their impacts and how to respond easier. Practical experience should also aid with engaging the participant group. However a practitioner has to recognise that their role is that of an academic researcher and this represents a different position within the participant group.

The relationship between theory and practice is a balancing act that can be kept level through good reflexive practice including addressing issues connected to adult intellectualism. England (1994) believes that reflexivity allows the researcher to constantly analyse the power balance between themselves and participating collaborative partners. This is a complex relationship and reflexive practice should accept the views of Ozanne \& Saalcioglu (2008) who believe that partnerships within PAR can never be completely neutral, echoing Masons and Urquhart's (2001) view on a natural power imbalance between adults and young people. Kemmis and McTaggart (2005) explain that PAR will often be about a subject that the researcher has an interest in and passion for and this is important to the success of the work. PAR encourages the researcher to shed any pre-conceived ideas and views but not at the expense of ignoring relevant social positions, commitments and most of 
all experiences (Gillespie and Sinclair, 2000). Morgan, Cuskelly and Moni (2014) advise best on how to stop the power balance toppling to the side of the researcher. The researcher will have valuable expertise but should never occupy "the dominant role and be seen as the expert leader, decision maker and protector of the participants" (Morgan, Cuskelly and Moni, 2014:1306).

Regarding engagement with participants, Kemmis and McTaggart (2005) place importance on creating the spaces and circumstances where positive relationships and trust can be built, the timeframe for which should be included within the planning phase. Hoggart (2017) and Morgan, Cuskelly and Moni (2014) did PAR in the participants territory making them guests and having to respect that role. This is where PAR and practice have a shared value of voluntary engagement. If participants can walk away from a project then that can provide equilibrium to the power dynamic. With regard to the problem that a project might be jeopardised, if participants withdraw their participation or consent if they do not see value in it Kemmis (1998) advises a PAR practitioner to minimalise this risk by treating participant's views in the following way:

- Views are comprehensible to them;

- View is relevant and true to them;

- Views are genuine;

- Views are appropriate to the situation.

Using reflexivity, a researcher should critically evaluate their ability to create or adapt to an environment that allows this. Then they have to maintain this shared balance of power and allow all partners to "search together collaboratively for more comprehensible, true, authentic and morally right and appropriate way of understanding" (Kemmis and McTaggart, 2005:578).

\section{Putting PAR into practice}

As stated by Kemmis and McTaggart (2005) it is normal for PAR to be instigated or identified by the participants. The young people involved in this project did not instigate this research, however young people did. In my introduction I give examples of work with young people to illustrate how this project began. This is not saying all young people are homogenous, but it 
could be argued the education they receive at school is. What the young people demonstrated over my career as a practitioner was a desire to discuss and explore issues of citizenship and othering, although they would not have used these headings.

In the consideration of the unpredictable vagaries that are attached to PAR I was initially unfazed about my ability to deal with the unexpected whilst planning my research. As a front line practitioner I had dealt with a range of situations. However, when I applied reflexivity, I realised that confidence could easily cross over into arrogance. The reality was my previous job gave me an enormous autonomy and I had a positive reputation for doing good work. I would not have this in my research project and would be starting again. This is where PAR's equal treatment of theory and practice came to the fore. My practical experience meant that I was confident in dealing with the unpredictable and in the ethics application and project timeframe I gave myself an open window to complete my research. The advice given in the theory of PAR on how to engage made me spend time reflecting on what approaches and techniques I had previously used to build positive relationships with young people. I developed the following principles for my research practice, based upon academic and practitioner knowledge:

- Do not rely on reputation;

- Whilst experience is valuable do not rely on it;

- Be open and honest about my intentions and timeframes;

- Always arrive in the venue before the young people. Walking into a youth project full of young people can be intimidating; it is also more difficult to engage them as they will already be doing something else;

- Respect that you are a guest in their space and speak to them with respect and courtesy;

- Try and learn names and do not be afraid to re-ask. Greet people individually and by name;

- Explain safeguarding responsibilities at the earliest opportunity. 


\section{Ethics}

In this area the dual components of theory and practice in PAR can become contentious. Klocker (2012) explains that because of the potential uncertain ethical dilemmas that PAR may encounter there is a perception that Universities' ethics boards may be reluctant to grant approval. Klocker (2012) believes that this is overstated and what an ethics board will look for is that uncertainty is accounted for in the application and that a board will not hold it against the researcher if they did not instigate the research, as non academics do not spend their time thinking about research and forming groups to carry it out. As such it is "perfectly acceptable for academic researchers to initiate participatory endeavours" (Klocker, 2012:157).

One of the texts that "Offers ethical guidelines while attempting to avoid moralistic commandments" (Kiste, 1980:141) is Diener and Crandall's (1978) 'Ethics in Social and Behavioural Research'. They write about four key considerations in the social research process which are:

- Ethical treatment of participants;

- Ethics related to selected non-laboratory approaches;

- Professional issues;

- Science and society.

The three main elements in relation to the treatment of participants and non-laboratory approaches are informed consent, do no harm and deception. These three reflect the Nuremberg Code and biomedical ethics. Doing no harm is one of the most important ethical considerations for a social researcher and while there may be a risk it should be minimal, understood by participants and reasonable (Diener and Crandall 1978, Bulmer 1982, Economic and Social Research Council (ESRC) (2005, 2015). Homan, (1991), states that protection from harm can be given in two ways. Firstly providing protection through anonymity and secondly allowing the right to refuse participation, or to withdraw consent at any time in the study. Caulfield and Hill (2014) offer advice on minimising harm including paying attention to safeguarding, ensuring participants can withdraw without needing a good reason, support is available for sensitive issues and consideration that findings may be 
abused. One consideration is that it is not easy to predict harm, especially if it is unforeseen or unconnected to the subject of the work. Diener and Crandall (1978) say that informed consent is free from coercion or deception. The $\operatorname{ESRC}(2005,2015)$ and Caulfield and Hill (2014) recommend that the following information is given to participants to ensure that they can give informed consent:

- Title of study;

- Names and contact details of researchers;

- Description of research and purpose of research;

- Potential benefits;

- The right to withdraw at anytime;

- Storage of data;

- Confidentiality statement signed by researchers. This would have to include examples of when confidentiality may be broken.

Diener and Crandall's (1978) third and fourth ethical recommendations were professional issues and science and society. The first of these discusses how social researchers should be honest and accurate in their recordings and reporting and not plagiarize, lie or distort their research and avoid bias. Aldred (2008) suggests this may occur to not upset other agencies, individuals or funders that can result in conflicting aims including a researchers' desires to secure employment or a funders desire to see a certain result.

Robin (2001) believes there is a drive in social research for it to become "a value free intellectual enterprise associated with experimental quantitative, objective enquiry" (Robin, 2001:213). This is highlighted by Diener and Crandall's (1978) final ethical advice of Science and Society. They defined value free science as one not influenced by personal opinion or society and its purpose to ensure that science remains independent of the interference of people in authority. They say that this is idealistic and not completely practical. Social researcher will often choose a topic of interest and may be motivated to bring about changes in society, policy or practices. This is when bias becomes an issue, especially if their findings do not back up their ideas. Social researchers also have a duty to themselves and their societies. Poor ethical research can negatively influence the standing and reputation of 
professions and researchers, for example after the Tuskegee study many Black Americans have maintained a distrust of medical services (Bryant, 2012). Diener and Crandall (1978) discuss how social research causes erosion of freedom and autonomy as governments become more aware of behavioral issues in society and how to control them. It is hard to know what social researchers can do about this. Funders may be deceptive or selective in how they use research. The only realistic solutions appear for social researchers to apply the ethics of informed consent to themselves in choosing who they would accept funding from. Yet this could impact careers, aspirations and livelihoods.

\section{Gaining ethical consent}

A practitioner, particularly one who works with young people, may find themselves engaged in roles defined by the self-interests of the organisation they work for. My academic funding does not have an expectation beyond meeting the criteria of a Ph.D. My industrial partners are experienced enough to understand that good, ethical research is a strong source to develop future projects from. I felt my position in academia provided an opportunity for neutrality as I was no longer judged by a quantitative and valuation based systems. This was a form of liberation for me as I would not be defending and furthering an organisation, its members and the staff's job security. This meant that I had few concerns over personal bias and no requirement for fabrication, distortion or deception. A PAR approach also allows for this freedom as the participants are partners and reflexivity makes the researcher accountable to themselves. I also realised that there was a three way relationship between several elements of PAR, ethics and practice. 


\section{Diagram 3.1: Ethics, practice and PAR equilateral triangle}

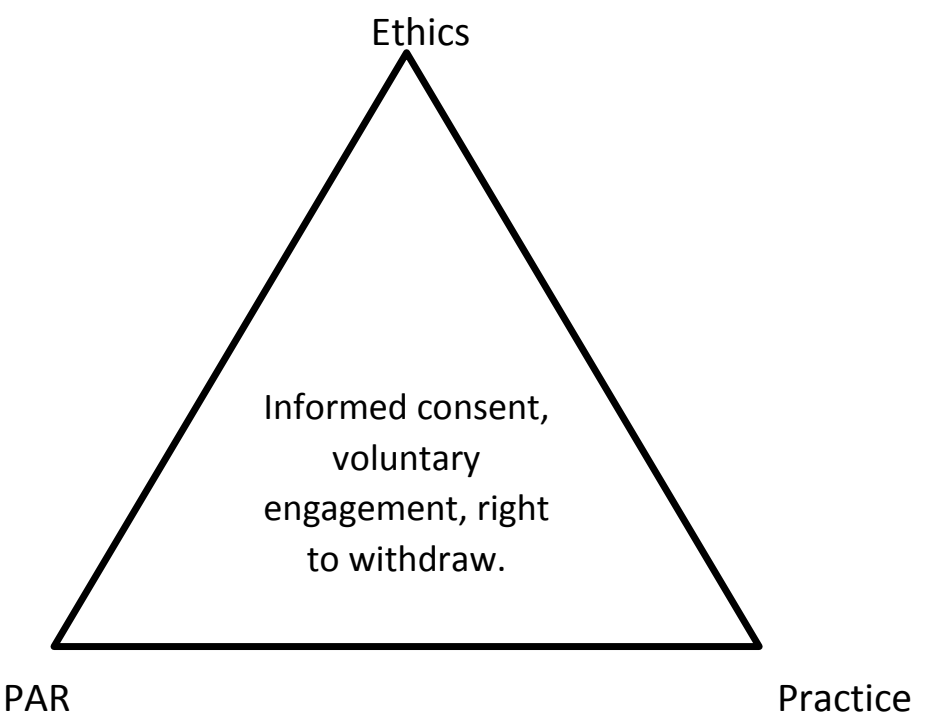

Ethics demands informed consent from participants, also expected in establishing a partnership relationship within a PAR framework. My practice has always been based on voluntary engagement, done through informed consent. The temptation of deception exists when seeking voluntary engagement as participants may require motivation. This leads to a blurred of line of incentive versus bribery. It is a form of adultism to think that all teenagers will volunteer without an incentive when the same is rarely expected of adults. Voluntary engagement allows for immediate withdrawal from the project and this can be avoided by honesty in gaining informed consent. I went about this in two ways, firstly by having a preliminary engagement visit where I would verbally explain what I was doing and give them consent forms and secondly by anonymising all the information at source by not using names in recording or reporting of the research findings.

My application was initially rejected, not for what was included but for what was not. The ethics board wanted to see evidence that I had considered academic guidelines such as those by the ESRC. This included the issue of who could give consent. I proposed that consent would be given by the young people and the managers of the hosting projects, respecting their role as gate keeper. I applied Gillick competencies and Fraser Guidelines to define the participation age of young people in the school year 9 or above, so the minimum age would have been thirteen or fourteen. Gillick and Fraser define young people as being able to make informed decisions about sexual health and pregnancy. A 14 year old deemed 
Gillick competent does not need parental consent to have an abortion. I am trained and experienced in making this judgement about a young person. My explanation to the ethics board was that if a young person can decide to have a baby, they were able to decide whether to participate in citizenship workshops. I planned to rely on my own judgement, those of the project staff and the choice of young people to determine participation. The ethics committee decided that I should also gain parental consent, which did aggravate me as I thought they were undermining my practitioner experience or ability. On reflection this was not the case as the topics covered in the research have the potential to be controversial; indeed, some of the work is designed to be. This could mean harm to any of the people connected with the research. In discussion with my supervisors I suggested a compromise where I would gain informed parental consent for young people to make their own decision. This way it would be the choice of young people to engage but their parents would give them permission to make this choice. I kept the age to the school year as I once ran a fourteen plus night at a youth project and remember young people who thought it ridiculous that their friend was admitted because their birthday fell earlier in the school year.

A more practical reason for seeking young people's consent was that getting letters back from home can be problematic. It turned out not to be and this also led to the ethics board wishing to see more thought to the storage of information. I created passwords for my computer and kept no personal information of any of the participants except their names and dates of birth. This was also kept securely in a locked drawer and I guaranteed they would not be showed to anyone. All evidence of research was labelled by activity, location and date and nothing more. No young person is recognisable in the research, except to me and the participants. In terms of withdrawing consent anonymising at source removed the danger that individual young people may change their mind about the use of their views. These changes, additions and compromises were accepted the second time around by the ethics board.

Gatekeepers are important and have to be treated with respect and full disclosure. Schmidt (2004) identifies that consultation with other professionals including those who work with the research group is vital. This informs the researcher and allows planning for unlikely but not unrealistic scenarios and the appropriate actions to be taken. The gatekeepers will be 
discussed in more detail in the descriptions of the individual projects. Finally, I am confident in saying that my work was influenced by benevolence and non-maleficence. I benefit more than the participants as I will use their views to write a Ph.D. and perhaps gain future employment but hopefully by the end we will all have learned something and perhaps see and understand the world a little differently.

\section{$\underline{\text { Pilot Project }}$}

When I transitioned from studying for a Masters to a Ph.D., I had a mini viva to secure my application. In this examination I enquired about running a pilot project and was informed that this would be a good idea. In the right setting a pilot project would allow me to trial my session activities, make mistakes and gain constructive feedback from participants. Pedwell (2012) discusses important elements that can lead to safe learning and trust building. These include the learners being able to admit to a lack or limit to their knowledge and feeling safe to learn and unlearn.

As the learner in the pilot project these points informed my search for the setting to run my pilot project. It had to be a place where I could feel safe to make mistakes and admit limitations or problems with my approach and activities. I wished to be somewhere where I could look foolish but keep going with my work without losing credibility. This would mean the backing of the organisations' management and staff and through them the patience of the young people.

The setting of a youth project appealed and led me to approach an independent youth project in Haverfordwest called the Garth Youth and Community Centre (GYCC) run by a former contemporary of mine. We had always had a positive relationship and I had never previously worked with young people in her youth provision. The manager agreed to host me and I ran a four month pilot project from the beginning of October 2017 to the end of January 2018, working with young people in year nine and above in the senior youth drop in. I explained from the outset that participant feedback on my delivery was as crucial as their thoughts on the activities and built time into each session for evaluation as well as a session for interviews and feedback. The Pilot was successful, and the main criticism was about the delivery rather than content. The participants thought all the areas covered were 
interesting and important but found some of the session too long and not interactive enough. In other words, they got bored, at one point to such an extent that many of them contemplated withdrawing from the project.

\section{Changes made following the Pilot Project:}

During the pilot project the sessions were delivered in the following order:

1. Zombie Apocalypse

2. Brave New World

3. Citizenship snakes and ladders

4. A Sharp White Background

5. The Warmth of Other Suns

6. Political approval game

7. Should they stay or should they go

8. The laws of God and Men

They really enjoyed sessions one, three, four and six, particularly playing the snakes and ladders board game and discussing othering in the fourth session. They found the remaining sessions interesting in content but my delivery lacking in interactive opportunities and too similar to a lecture. After one session the participants told me that they were getting bored and wanted to play a game. I realised that participation levels could be damaged and it also threatened the partnership relationship in the PAR approach. Genat (2009) explains how important this partnership is:

"The way the researcher negotiates, engages and facilitates research with the participant group is key to the research outcome" (Genat, 2009: 103)

Had their participation ceased then so to would the research. To prevent their disengagement, I could have relied on coercive techniques and incentives but this would have gone against the principles of voluntary engagement. There was also the ethical consideration that young people may avoid their youth centre in order to avoid participating in my research. Due to all of these factors I promised the young people that the following week would be a game. 
This shows the importance of respecting young people's leisure time, not adopting an adult intellectual approach of assuming I knew best and listening to their view. Whilst these views contained criticism of me it was constructive and not personal. That was the reason I was there so I was grateful for their honesty. On reflection I queried why an experienced practitioner had failed to be interactive and realised that it was in fact because most of my practitioner habits for the previous five years had focused on formal education or interventions. It had been a while since I had fun when working with young people and I really enjoyed it. They liked that I allowed them to express themselves and be partners in the control of the conversation, I just had to ensure the activities were more engaging.

Through out the research chapters I explain how some activities were changed to be more interactive and delivered in a different order. The new order for the research proper was:

1. Zombie Apocalypse

2. Brave New World

3. Citizenship Snakes and Ladders

4. Political Approval Game

5. Should they stay or should they go

6. Security versus freedom

7. The Warmth of Other Suns

8. Against a Sharp White Background

I decided to top load the order of the sessions with the game based activities in order to capture the interest of the participants. Using games, I could sustain their interest and build up to the activities looking at more serious, real world issues. I also sought to finish with the crescendo of empathy and critical thinking which I hoped the Warmth of Other Suns and Against a Sharp White Background would represent. Overall I was satisfied with the pilot project's success and felt confident and ready to embark on the research proper.

\section{Research project one: Butetown Youth Pavilion}

This is a modern building that hosts many educational projects during the day and is open four nights a week for youth club. My Sazani Associate contact, Ali Abdi, was the gatekeeper to accessing this project. Adil took me to the centre one evening when he was running a 
workshop. This gave me a chance to meet the manager and get a feel for the young people and their community. I arranged a time to come in and speak to the manager to discuss my research more. It is worth mentioning at this point that I was driving from Tenby to Cardiff many times a month/week in preparation for the research. I had planned for this in terms of time and money so that neither of these became a barrier to my research. In fact I used the two hour journey to reflect on the evenings sessions.

When I arrived to meet with the project manager I was not given the warmest welcome. The following is an entry from my research journal:

When I arrived I had to wait and took a seat outside the office and heard the manager go in and say to her colleague, with equal amounts of resentment and resignation "And now I've got to interview this Ph.D student". I knew how she felt. I've been in her position. That day you've dealt with everything from writing fund raising bids, supporting young people, cleaning the toilets and trying to remember if its the week that the bins go out. You've been in work all day and you still have the evening shift ahead of you. Then there is you, some PhD student who wants to find out how young people think. Great, hello you.

I had come prepared with all my paperwork including research outline, consent forms, DBS checks and references, both academic and professional. I imagined she was concerned with being lumbered with some academic with no youth work experience who would need supervision and support. This highlights a concern in PAR that the partners in the research can be skeptical or critical of the researchers' abilities. I came across as a competent and experienced professional who was carrying out practical research on an important subject. I recognised that she might have reservations, but by explaining my background and experience, providing details about the sessions and showing her my paperwork we established a rapport. I know how hard it is to manage a youth project and that a good manager wants the best for the young people they work with. I am fortunate to have the experience I claimed and this is important as if I had not, the research would expose this and I would have encountered many additional barriers.

I knew from Ali that very few females came to the youth drop ins and I wished to have amixture of male and female participants across the whole research and not just in the 
traveller project. This led to agreeing that I could attend the centre on a Wednesday when the girls project was on. The vast majority of the female members were from Islamic families and often only attended the centre on a Wednesday. This was for a combination of reasons including culture, family choice and personal choice. This meant that the three hours of girls night was precious social time, as for many of them it was the only time they socialised outside of school or family. I suggested running the sessions before the girls' night started, beginning my sessions at 4.30pm and overlapping into the evening session, which began at 5pm. I did this to respect young peoples' leisure time and to remove a potential barrier to participation. I arranged to visit two days later and attend the girls night to introduce myself and attempt to recruit some particiapnts for the following week. This worked, in no small part because of the managers support in breaking the ice with young people. In discussion with the manager I was able to ascertain what subjects or areas of conversation should be avoided. She told me that it would be best to stay clear of anything relationship, sexual or procreation related as many of the young people came from households where there was no open discussion of such issues.

\section{$\underline{\text { Research project } 2}$}

\section{Grangetown Youth Pavilion}

This was very much Ali's domain.

This is an old building that used to be a Crown Green bowling club house. The community, with Adil very much in the forefront, is fundraising to transform the building. A National Lottery grant had them well on the way to meet their goal of over a million pounds. Opposite the centre was a brand new $3 G$ astro turf pitch paid for by the legacy fund from the UEFA Champions League final played in the Principality Stadium in Cardiff. All of this was contained in Grangetown park, a well used community resource by people of all ages.

Ali opened the building most evenings for young peoples' drop-in sessions. Other rooms in the building were used by other organisations and community groups including a homework club. We agreed that I would attempt to do the sessions on a Wednesday so I would only have to drive up to Cardiff once a week. This did not work out due to a variety of reasons, but again, it is important to note that I anticipated this in terms of giving myself plenty of 
time and budgeting accordingly. Having a positive pre-existing relationship with Ali meant I felt comfortable in this setting, whilst remaining respectful. What remained the same is that I would be engaging primarily with young people. Building or reaffirming positive relationships with gatekeepers was therefore only a part of the process. The real work would begin the following week when I started my sessions.

Both these locations are in the area of Cardiff that was once known as Tiger Bay. Many of them are descendents from Somaliland merchant sailors who have had a presence in this community for over a century. Ali walked me around the community on a previous visit and showed me the wall that seperated the old Tiger Bay from the new Cardiff Bay. We walked through the underpass and I understood why his community felt marginalised as the difference in investment was very apparent. This was an important point of view to understand as I might be seen as associated with the new Cardiff Bay, being white and middle class. I explained to Ali the content of my sessions and asked him if there were any subjects that I might avoid. He told me that with the young people I was working with no subjects were off out of bounds but they would probably be uncomfortable discussing women's issues or issues connected with child birth.

\section{Research group three}

\section{Monkton Priory Project}

Monkton priory Project is a school within a school. The parent school is Monkton Priory Community School, which works with childen and young people from nursery age to year six. It is in the community ward of Monkton in Pembroke, West Wales. Monkton is ranked in the bottom $10 \%$ of deprived areas in Wales. The Priory Project is a school for gyspy traveller young people, mainly from school years $7-11$. It was set up over twenty years ago to provide education for the children of travellers. This was for two reasons, firstly there was conflict between the gyspy community and the government around school attendance. Many gyspy families expected the children to work and contribute to the household once they reached secondary school age. Many parents also did not want their children attending the local comprehensive school in case they got involved in inappropriate behaviours. When the project was initially set up there were also many families who would come to the area for seasonal work, for example, in December to pluck Turkeys. The Priory Project was set up 
to ensure those young people who were forbidden from attending mainstream school received an education and those children visiting could keep up with their schooling.

The gyspy travellers have been part of the community for generations and are very much integrated and accepted yet at the same time retain a fierce and independent sense of identity. I have worked with young people from the Monkton traveller community since 2006 in my numerous roles in Pembroke's youth project. I have worked in the Priory project as a tutor for 5 hours a week since I commenced my Ph.D in October 2016. Initially the project was going to be with the groups in Cardiff however I made the decision to expand it to include the Prioryfor the following reasons:

1- I wanted to explore how these activities went when delivered in a formal education environment as well as leisure time based settings.

2- I wanted to see if a pre-existing relationship with the participants and the organisation impacted on how well the activities went.

3- Gypsy traveller young people are a white minority ethnic group who have experience of discrimination and stereotypes.

Hart (1992) suggests that PAR projects should ideally be instigated by members of the marginalised group itself. It was experiences with young people from this area that partly instigated and inspired this research and so having some members of this community particpate seemed fitting. I know from previous experience that discussion around anything relating to sex, including relationships, gender and periods was off limits.

Gaining consent was a subject I discussed with each of the lead professionals in the hosting venue. In both BYP and GYP I took plenty of consent forms when I went for my pre-research visit. Whilst being introduced and speaking to the young people, I discussed the importance of young people giving their consent to take part and that I could not do this without them. I believe that this helped established an interest due to the power resting with the young people. I used this as a spring-board to telling them that their consent would require in turn consent from their parents or carers. Consent forms are standard and common place in youth and educational places, often used for internal and external activities and trips. I handed many forms out and left others in the centres and to my surprise and delight I had 
many consent forms returned. Over the course of the project the young people began self policing the forms by ensuring that new participants had completed them before they attended. In the Priory gaining consent was done by sending letters home to the parents who responded promptly.

These communities have very strong or strict family values particularly linked to gender roles which they self police. None of the activities looked at sex, gender or relationships but I realised I would have to be cautious of the direction in which the discussions around subjects might lead. This would avoid the 'wrong' kind of controversy which might have repercussions for myself, participants and hosting organisations. I also know is that all three projects are very popular with outside agencies. The funding environment is such that working with marginalised groups tends to be attractive to funders and as a consequence multiple agencies look to work with these groups. This would mean that my sessions could be cancelled in favour of other organisations. This was also accomodated for in the time I set aside for my research. 
Chapter 4:

Part one: Zombie Apocalypse.

Part two: Brave New World. 


\section{Chapter Four, part one: Zombie Apocalypse}

\section{Introduction}

I wanted the opening activity to be fun, engaging and stimulate debate, controversy and critical and empathetic thinking. In essence I wanted to show participants what they could expect over the forthcoming sessions, start building trust and positive relationships and was keen to introduce citizenship and othering at the beginning of my work. With encouragement from supervisors I took an activity from practice and developed it for use in my research. I have been using the Zombie Apocalypse (ZA) activity in my work since 2010. It was stimulated by discussions in my personal and professional life about how people would behave in a Zombie Apocalypse both specifically and as an example of a collapse of civilisation. I developed a game to engage young people in an alternative curriculum provision I ran designed to promote communication and teamwork through fun and discussion. In 2014 I worked with Sazani Associates on a resilience project in Sofia, Bulgaria. I was asked to develop training tools on how to prepare young people to respond positively in the event of a disaster. I adapted and refined ZA to link it to discussing how young people might and could behave in such a situation. I then took this into schools for a short series of sessions on building resilience among young people in West Wales as part of the Local Authority's Community Cohesion Strategy. The game asks young people to examine rights and responsibility in citizenship through interactions and reactions with and towards others, both real and imaginary. It allows them to explore what they believe is valuable and why. As an activity that has worked well previously in a variety of settings I felt confident taking it into a new environment.

\section{Planning and preparation}

ZA is serious play as it contains and encourages creative thinking and involves elements of make believe (Blanchard 1995). Playing ZA includes the three game playing levels of Spolin (1986) in that the participation is fun, it is creative as it requires the use of problem solving skills and there is catalytic action in their expression of thoughts which leads to learning. Game playing has been used in researching young people's views previously. Rieber, Smith and Noah (1998) describe lessons run by a USA High School teacher using the SimCity computer simulation which was able to teach about citizenship roles and responsibilities as 
well as economics 'within a structure that is consistent with curriculum objectives" (Rieber, Smith \& Noah 1998;33). Schrage (2000) points out adults are not always comfortable with the idea of playing, potentially seeing it as childish. I would suggest that teenagers can also be reluctant, especially if they desire to be treated as adults.

The activity uses imaginative reconstruction to establish the imaginary scenario, which in this case was that a global pandemic had erupted and turned most of the world's population into Zombies. I also explained to the participants that as the facilitator I set the scenarios parameters and had the final say on the rules. Next, I divided the group into teams to begin the activity. The first task concerns 'scavenging' and 'trading'. Each team is given an envelope containing a list of equipment they have 'scavenged' in the apocalypse complete with laminated pictures.

Table 4.1.1 - Items for tribes

\begin{tabular}{|l|l|l|}
\hline Tribe 1 & Tribe 2 & Tribe 3 \\
\hline First Aid Kit & Tobacco & Bullets \\
\hline Television & Water tank, & Matches \\
\hline Hammer & fresh food & 2 mobile phones \\
\hline Crossbow & Baseball bat & Castle \\
\hline Tinned food & f1000 cash & Bottled water \\
\hline Hotel & Mountain bike & Antibiotics \\
\hline Landrover & Forest camp & Samurai sword \\
\hline Electricity generator & Cave & Sports car \\
\hline Playstation & 100 litres of petrol & 10 litres of petrol \\
\hline Dirt bike & Machine gun & \\
\hline
\end{tabular}

The resources are a mixture of weaponry, supplies, shelters, machinery with a few red herrings thrown in. Examples of these are the money and the PlayStation which would be of 
little use in an apocalypse. The distribution is designed to encourage trading, which is the next activity. For example, tribe two has a machine gun and tribe three has the bullets. It is hoped that the tribes will agree to making some trades and through mutual consent arrive at the conclusion that they should join forces to create one tribe. If they do not I would ask them to explain why they did not want a merger, ensure they know I respect their decision but explain that for the purpose of the game I was exercising my right as the facilitator uniting them. Next, they would discuss their tribal rules and punishments amongst themselves and attempt to agree on them. The final part of this activity would be to discuss the admittance of others to their tribe. In my continued role as facilitator I would explain that their success made their tribe an attractive proposition for other, lone survivors. This would be done in two parts. The participants are given a sealed envelope, written on the outside is the profession of the applicant and inside is a piece of paper with a twist. Inviting participants to read out the first piece of information, I draw on Wilkerson's (2010) argument that people wish to join their tribe because it is better than where they are. They vote based upon this information and then open the envelope to reveal the twist and vote again. I was interested in seeing how their views on resources and security would influence their decisions. The twists would challenge initial judgements and I wanted to see if they would change their minds and why. The eight others and their twist were as follows:

Table 4.1.2 List of others with twists

\begin{tabular}{|l|l|}
\hline Person & Twist \\
\hline Medical Doctor, 45 & Convicted sex offender \\
\hline Soldier, 30 & Suffers from Post-Traumatic Stress Disorder \\
\hline 16 year old boy & Boy genius \\
\hline Religious Minister, 40 & Qualified counsellor \\
\hline Musician, 40 & Qualified electrician \\
\hline Farmer, 55 & Diabetic \\
\hline Builder, 25 & Racist \\
\hline
\end{tabular}


I used neutral terms such as minister, rather than priest or imam in line with the Bystander approach of not alienating participants from the discussion (Katz, 2013). I evenly split the usefulness in both the primary professions and the twists. The professions feature four which may be deemed useful: doctor, soldier, builder, farmer. The twists reveal that the four people often deemed un-useful could be: counsellor, electrician, genius, Territorial Army. This is deliberately done to demonstrate that people are complex and decisions made about them are often not.

During the pilot ZA worked well in engaging the young people as a first activity. There were two main changes made as a result of participant feedback. The first was to ensure all the others had a twist as the participants enjoyed the drama and theatre of the reveal and originally only four of the others had twists. I also changed the twists to a mixture of positive and negative narrative, rather than solely negative so that the participants would rethink and question previous judgements. The other substantial change was to divide the equipment into three lists rather than random selection to ensure that each tribe would have something to trade with. From the pilot I found the best way to record the information was to record discussions on a dictaphone and use flip chart paper for writing down the rules and punishments and the voting records for the others.

\section{Delivery and engagement}

\section{Butetown Youth Pavilion}

The participants at BYP consisted of five young people who split into three tribes: two friends both 14, two friends both 16 and one solo 17 year old. The three older participants welcomed me with scepticism, concerned that my game would be childish. As young adults this links to Schurage's (2000) observations that adults may often see games as beneath them and question their validity in a work/professional environment. To my surprise the participants were not familiar with each other. Previous experience has taught me that through project membership people are at the very least aware of each other. 
The tribes that featured the older participants quietly examined the items they had, whilst regarding the exuberant delight the youngest tribe showed at having a machine gun with mild disdain. During the trading their cold hauteur began to thaw and they relished pointing out to the youngest tribe that they had no bullets for their machine gun. This led to a reasonable conversational exchange and when no-one would trade with another tribe they decided amongst themselves to unite. The older participants then began engaging with moderate enthusiasm, grudgingly accepting that the game was not entirely childish. The new tribe set about establishing their rules and punishments, please note that the punishments are not set out against the crimes they punish.

Table 4.1.3 BYP rules and punishments

\begin{tabular}{|l|l|}
\hline Rules & Punishments \\
\hline Be equal & 3 crimes and out \\
\hline Share equally & Punishment through starvation, but not to death \\
\hline Rota for duties & No-one thrown to the Zombies \\
\hline Do not murder & Kicked out for a day so they realise how good they have it. \\
\hline Do not steal & \multicolumn{1}{|l}{} \\
\cline { 1 - 2 }
\end{tabular}

After we completed this section I informed them that Others wished to join their tribe and handed out the envelopes to participants. Like the pilot project they also enjoyed the suspense part of this activity.

Table 4.1.4 BYP voting record on admittance of others

\begin{tabular}{|l|l|l|l|l|}
\hline Applicant Description & First Vote & Twist Revealed & Second Vote & Change \\
\hline Doctor & $5 \mathrm{Y}$ & Sexual offender & $2 \mathrm{Y} 3 \mathrm{~N}$ & $3 \mathrm{TON}$ \\
\hline Farmer & $2 \mathrm{Y} 3 \mathrm{~N}$ & Diabetic & $5 \mathrm{~N}$ & $2 \mathrm{TON}$ \\
\hline Boy & $1 \mathrm{Y} 4 \mathrm{~N}$ & Genius & $2 \mathrm{Y} 3 \mathrm{~N}$ & $1 \mathrm{TOY}$ \\
\hline
\end{tabular}




\begin{tabular}{|l|l|l|l|l|}
\hline Soldier & $5 \mathrm{Y}$ & PTSD & $3 \mathrm{Y} 2 \mathrm{~N}$ & 2 TO N \\
\hline Musician & $5 \mathrm{~N}$ & Electrician & $2 \mathrm{Y} 3 \mathrm{~N}$ & 2 TO Y \\
\hline Builder & $5 \mathrm{Y}$ & Racist & $3 \mathrm{Y} 2 \mathrm{~N}$ & 2 TO N \\
\hline Minister & $5 \mathrm{~N}$ & Counsellor & $3 \mathrm{Y} 2 \mathrm{~N}$ & 3 TO Y \\
\hline Mother and daughter & $1 \mathrm{Y} 5 \mathrm{~N}$ & Member of territorial army & $4 \mathrm{Y} 1 \mathrm{~N}$ & 3 TO Y \\
\hline
\end{tabular}

\section{Grangetown Youth Pavilion}

In this session there were four participants all seventeen year old men and all friends who divided themselves into two equal teams and I laid the pictures from the third list face down and allowed them to randomly select items from it. The Grangetown tribes refused to trade with each other and they were adamant about staying in their hotel and castle respectively. Both tribes agreed that in a Zombie Apocalypse it was every man for himself. The participants viewed this stage of the activity as competition and their friendship displayed a jovial adversarial nature. I used my position as the facilitator to persuade them that they were together for the next stage of the activity.

\section{Table 4.1.5 GYP list of rules and punishments}

\begin{tabular}{|l|l|}
\hline Rules & Punishments \\
\hline Have each others backs & Given more duties \\
\hline Work as a team and be as one & One to one chat \\
\hline Share weapons resources and duties & \\
\cline { 1 - 1 } Respect for each other & \\
\hline Help one another & \\
\cline { 1 - 1 } Each person has a responsibility & \\
\hline One rule each & \\
\cline { 1 - 1 } &
\end{tabular}


Next we looked at what they would do when others wished to join their tribe.

Table 4.1.6 GYP voting record on admittance of others.

\begin{tabular}{|l|l|l|l|l|}
\hline Applicant Description & First Vote & Twist Revealed & Second Vote & Change \\
\hline Doctor & $4 \mathrm{Y}$ & Sexual offender & $4 \mathrm{Y}$ & ND \\
\hline Farmer & $4 \mathrm{Y}$ & Diabetic & $3 \mathrm{Y} 1 \mathrm{~N}$ & 1 TO N \\
\hline Boy & $4 \mathrm{~N}$ & Genius & $4 \mathrm{Y}$ & 4 TO \\
\hline Soldier & $4 \mathrm{Y}$ & PTSD & $4 \mathrm{~N}$ & 4 TO N \\
\hline Musician & $4 \mathrm{~N}$ & Electrician & $4 \mathrm{Y}$ & 4 TO $\mathrm{Y}$ \\
\hline Builder & $4 \mathrm{Y}$ & Racist & $4 \mathrm{~N}$ & 4 TO N \\
\hline Minister & $4 \mathrm{~N}$ & Counsellor & $4 \mathrm{~N}$ & ND \\
\hline Mother and daughter & $1 \mathrm{Y} 3 \mathrm{~N}$ & Member of territorial army & $4 \mathrm{Y}$ & 3 TO Y \\
\hline
\end{tabular}

\section{Priory Project}

The participants from the Priory project were all 15, three boys and one woman, and had been classmates for several years. The participants enjoyed the bartering: their approach was to attempt to con the other tribe into giving up something valuable e.g. medicine for something worthless, such as money. They did not actually make any exchanges but did agree that they would be better off working together.

\section{Table 4.1.7 Priory list of rules and punishments}

\begin{tabular}{|l|l|}
\hline Rules & Punishments \\
\hline $\begin{array}{l}\text { Don't backstab each other (metaphorically or literally), } \\
\text { listen to each others ideas. }\end{array}$ & $\begin{array}{l}\text { No physical punishment as it } \\
\text { drains resources }\end{array}$ \\
\hline No betrayal & Extra duties \\
\hline
\end{tabular}




\begin{tabular}{|l|l|}
\hline Share everything, no greed & $\begin{array}{l}\text { Cut rations until they understand } \\
\text { seriousness }\end{array}$ \\
\hline Say what you mean & Lose status \\
\hline No arguing & Execute \\
\hline Take turns on lookout & Hang them by their feet \\
\hline No waste & Replace what is taken \\
\hline
\end{tabular}

After this we explored the issues surrounding the admittance of others to their tribe.

Table 4.1.8 Priory voting record on admittance of others.

\begin{tabular}{|l|l|l|l|l|}
\hline Applicant Description & First Vote & Twist Revealed & Second Vote & Change \\
\hline Doctor & $4 \mathrm{Y}$ & Sexual offender & $1 \mathrm{Y} 3 \mathrm{~N}$ & 3 TO N \\
\hline Farmer & $4 \mathrm{Y}$ & Diabetic & $4 \mathrm{~N}$ & 4 TO N \\
\hline Boy & $3 \mathrm{Y} 1 \mathrm{~N}$ & Genius & $4 \mathrm{Y}$ & 1 TO \\
\hline Soldier & $4 \mathrm{Y}$ & PTSD & $4 \mathrm{~N}$ & 4 TO N \\
\hline Musician & $4 \mathrm{~N}$ & Electrician & $4 \mathrm{~N}$ & ND \\
\hline Builder & $2 \mathrm{Y} 2 \mathrm{~N}$ & Racist & $4 \mathrm{~N}$ & 2 TO N \\
\hline Minister & $4 \mathrm{~N}$ & Counsellor & $4 \mathrm{~N}$ & ND \\
\hline Mother and daughter & $1 \mathrm{Y} 3 \mathrm{~N}$ & Member of territorial army & $4 \mathrm{Y}$ & \\
\hline
\end{tabular}

\section{Discussion and reflection}

What was significant about this activity was that in all three projects the sovereignty of the tribe was undisputed, it demands your loyalty, your work and probably your sacrifice in a way that suggests subjecthood more than citizenship, despite there being no obvious monarch or equivalent. Yet across all the tribes there was emphasis on showing respect, sharing resources and equality and this indicates both rights and responsibilities were given 
equal consideration. The only group that would take tribal citizenship away would have been BYP, although they were conflicted on this, first ruling it out, then advocating a day's banishment followed by a three strikes and you are out rule. Grangetown and the Priory did not mention it but they did suggest loss of status within the tribe instead. Chabot Davis (2004) discusses how affective empathy can be created if a person recognises their complicity in another's fate. If the tribe were to throw someone to the Zombies it would be hard to ignore their role in the person's death. Instead the Priory and GYP tribes suggest punishment which would in some way differentiate citizens. They both advocated giving offenders additional duties, stripping them of responsibility and through that rights and status. There is no civilised standard of living, no social safety net and the use of capital and corporal punishments shows that laws are brutally enforced. This reflects the recognition across all tribes that survival is the key objective. This indicates a cultural identity based upon "a recognition of some common origin or shared characteristics with another person" (Hall, 1996: 2). The origin is the apocalypse and the shared characteristic is survival, to which the tribe is all important. The rules impose a high level of individual and self-responsibility that Sinclair et al (2010) would say is prominent in a civic model of citizenship. Barber (2009) suggests that in civic citizenship there is a reduction of choice as societal pressure forces you to conform. In the tribes, the brutalities of the punishments were designed to induce compliance. Painter and Jeffrey (2009) talk of protections to liberty as a key right of citizenship, yet what liberty exists in a crisis especially if liberty is seen to include the right to individual ownership? The game enabled us to ask questions such as does survival trump liberty to which the answer appears to be an overwhelming 'yes'. In a ZA, rationing, sequestration of property and conscription are harsh examples of how the risk of a collective threat imposes on liberty. Building on the social contract of citizenship as advanced by Marshall (1950) and defined by the likes of Turner and Isin (2008), the tribes behaviour in this game suggested that the priorities were working together, sharing and showing respect to stay alive. The general feeling was that if a person did not like this social contract then they were free to leave, so whereas expulsion did not heavily feature the concept of self exclusion did. This freedom to leave and probably die is a brutal form of liberty in these tribal communities. 
The stark rules combined with harsh punishments of the ZA tribes responded to my first research question in the participants putting the emphasis on the individual. This is in line with Josephs (2013) who suggest that in the neo-liberal world the responsibility of survival belongs to the individual. However this responsibility is displayed and acted out in their contribution to the collective survival. In a neo-liberal world the most important part of citizenship is what Karanti and Gill (2002) called the substantive or active element of citizenship. Identity and membership in these tribes seems to be mostly defined through an individual's work contributions and their behaviour. The attitudes of the participants towards the Others in the final part of the activity further explores this notion of tribal citizenship being contingent on work and behaviour.

Table 4.1.9 Comparative and overall results of first round of voting on admittance of others.

\begin{tabular}{|c|c|c|c|c|c|c|c|c|}
\hline \multirow{2}{*}{$\begin{array}{l}\mathbf{1}^{\text {st }} \text { vote } \\
\text { The Other }\end{array}$} & \multicolumn{2}{|c|}{ BYP } & \multicolumn{3}{|c|}{ GYP } & Priory & \multicolumn{2}{|c|}{ Overall } \\
\hline & Yes & No & Yes & No & Yes & No & Yes & No \\
\hline Doctor & 5 & 0 & 4 & 0 & 4 & 0 & 13 & 0 \\
\hline Farmer & 2 & 3 & 4 & 0 & 4 & 0 & 10 & 3 \\
\hline Boy & 1 & 4 & 0 & 4 & 3 & 1 & 4 & 9 \\
\hline Soldier & 5 & 0 & 4 & 0 & 4 & 0 & 13 & 0 \\
\hline Musician & 0 & 5 & 0 & 4 & 0 & 4 & 0 & 13 \\
\hline Builder & 5 & 0 & 4 & 0 & 2 & 2 & 11 & 2 \\
\hline Minister & 0 & 5 & 0 & 4 & 0 & 4 & 0 & 13 \\
\hline Mother \& daughter & 1 & 4 & 1 & 3 & 1 & 3 & 3 & 10 \\
\hline
\end{tabular}

With the exception of the farmer in BYP and the builder in the Priory most of the results were resoundingly for or against admittance. The three tribes all voted largely in the same way, the soldier and the Doctor were unanimously accepted in all three as their skills and experiences were highly valued. This may suggest a similarity of views around othering. A 
notable difference was the Priory accepting the boy. One participant though he should be refused as he had no skills and would drain valuable resources like food. The other participants identified that he was useful because he was young, fit and healthy. Unknowingly these teenagers identified their own usefulness in a crisis. They also felt guilt about letting him die, but this did not extend to the mother and child who they left to the Zombies. They were of a mind that in a ZA you had to be selfish and that the only important thing was helping the tribe survive.

One thing that stands out is that not everyone is allowed in, which means they are potential Zombie fodder. This very much highlights Butler's (2008) questions about who counts as human and what counts a being a life? It seems here that the right to life comes from a person's value to a society. In this case people with skills which could help survival were welcome and more often than not those without useful skills were not. There was little consensus on all skills, with debate over whether the farmers skills were useful or not: is there time to grow food in a ZA?

The vote for the mother and child in Grangetown was based on the argument 'imagine it was your sister'. This was interesting in that the attempt to establish empathy was through suggesting a personal connection. This was the bystander approach (Katz, Heisterkamp \& Fleming, 2011) and following it the other three members found it very hard to refuse the mother and child. A critique of this could be that it is an empathy that sees women and children as subordinate and therefore in need of pity. Yet none of the groups agreed with this 'women and children first' thinking as the mother and child were refused membership in all the tribes, which may represent a meritocratic equality of a sort.

Others with no skills were not welcome and the overriding condition for tribal citizenship became contributing to survival in a time of fear and uncertainty. Noxolo and Huysman (2009) ask whether "pre-empting danger is becoming a major category for organising social and political life?" (pp7). In this imaginary scenario fear of an external threat, in this case zombies and protection of resources became very powerful social organisers. Usefulness was the negotiating tool of defining tribal membership and the twists asked young people to explore the relationship between usefulness and risk. 
Table 4.1.10 Comparative, overall and swing of second round of voting on the admittance of others.

\begin{tabular}{|c|c|c|c|c|c|c|c|c|c|c|c|c|}
\hline & \multicolumn{3}{|c|}{ BYP } & \multicolumn{3}{|c|}{ GYP } & \multicolumn{3}{|c|}{ Priory } & \multicolumn{3}{|c|}{ Overall } \\
\hline The Other & $\mathrm{Y}$ & $\mathrm{N}$ & Swing & $\mathrm{Y}$ & $N$ & Swing & $\mathrm{Y}$ & $\mathrm{N}$ & Swing & Y & $\mathrm{N}$ & Swing \\
\hline Doctor & 2 & 3 & 3 to $\mathrm{N}$ & 4 & 0 & $N / D$ & 1 & 3 & 3 to $\mathrm{N}$ & 7 & 6 & 6 to $\mathrm{N}$ \\
\hline Farmer & 0 & 5 & $N / D$ & 3 & 1 & 1 to $\mathrm{N}$ & 0 & 4 & 4 to $\mathrm{N}$ & 3 & 10 & 5 to $\mathrm{N}$ \\
\hline Boy & 2 & 3 & 1 to $Y$ & 4 & 0 & 4 to $Y$ & 4 & 0 & 4 to $Y$ & 10 & 3 & 10 to $Y$ \\
\hline Soldier & 3 & 2 & 2 to $\mathrm{N}$ & 0 & 4 & 4 to $\mathrm{N}$ & 0 & 4 & 4 to $\mathrm{N}$ & 3 & 10 & 10 to $\mathrm{N}$ \\
\hline Musician & 2 & 3 & 2 to $Y$ & 4 & 0 & 4 to $Y$ & 0 & 4 & $N / D$ & 6 & 7 & 6 to $Y$ \\
\hline Builder & 3 & 2 & 2 to $\mathrm{N}$ & 0 & 4 & 4 to $N$ & 0 & 4 & 2 to $\mathrm{N}$ & 3 & 10 & 8 to $\mathrm{N}$ \\
\hline Minister & 3 & 2 & 3 to $Y$ & 0 & 4 & $N / D$ & 0 & 4 & $N / D$ & 2 & 11 & 2 to $Y$ \\
\hline Mother \& daughter & 4 & 1 & 3 to $Y$ & 4 & 0 & 4 to $Y$ & 4 & 0 & 3 to $y$ & 12 & 1 & 9 to $Y$ \\
\hline
\end{tabular}

In BYP the twists made all voting a lot closer than before. In both Grangetown and the Priory the voting remained decisive in nearly all situations but on five occasions in each venue there were big swings. The discussion matured from concentrating solely on usefulness to now include morality, threats to people as well as threats to resources. The tribes also began to introduce a skills deficit. For example, the Priory was going to stay with the soldier until they discovered that the mother had a similar background, at which point the soldier was jettisoned. The skill, not the person, was important. There were also strategies for inclusion. In BYP the soldier was highly valued and they did not want to lose them, so they accepted the minister to counsel him.

In all these imaginary scenarios the musician and especially the minister were given short shrift. The latter was only accepted by the Butetown tribe. The electrical twist in the musician's portfolio gained him entry to two of the three tribes. I was curious about their views on culture. Edsel and Witter (2010) describe how important art and music and the conservation of it was to the occupied countries and their liberators in WWII. Yet all the 
tribes saw music as frivolous and there was no place for singing or praying in a ZA. Throughout the research project, the Grangetown participants spoke often about their religious beliefs. I put it to them that the minister was one of their own, but they remained firm, stating that only God can judge them. This was said several times during the research, a combination of religious belief and Tupac appreciation.

Clarke and Doel (2011: 49) suggest that “...the post-modern world is as inhospitable to morality as the modern", a statement which can be explored through attitudes towards the Doctor and the builder. The Doctor's twist created a great deal of controversy and in BYP they referenced an ongoing EastEnders storyline involving sexual offenders and thought that the expertise did not make up for the crime. One of them was also concerned of potential retribution against the Doctor by other tribe members who could break the laws and that this would cause no end of problems. The calculation of the Doctor's skill versus the crime was shared by the Priory tribe but not by Grangetown who felt a Doctor was essential and could always be locked in a room. In this case the skill and, by extension, the contribution to survival the Doctor brought trumped their moral standpoint. This is a good example of how a person's practical value was the deciding factor in the decision of accepting others often at the expense of personal morality. The builder remained in BYP by the slimmest margin and the participants made it clear they did not like racists. The rejection of the builder in both Grangetown and the Priory saw moral viewpoints given more weight than usefulness. This imaginary world produced a conflicting and indifferent morality in people, which could be linked back to concepts such as the banality of evil (Bauman \& Tester, 2001). Seen through a very hard lens the participants decision making process towards the others is very much a rationalisation of evil. Whether a person is denied tribal membership through lack of usefulness or morality they would face an almost inevitable fate of death by Zombie. There are absolute decisions such as the builder whose racism almost instantly marks them out as a bad person. Yet in a small group, facing an external threat, racism is not necessarily a threat. The Doctor was judged more in an utilitarian fashion where their skills almost excused their crime. The first part of the Clark and Doel (2011) quote is as follows: "What matters to us is us, not them..." (Clarke and Doel, 2011:49). This would fit into Isin's (2004) theory of the neurotic citizen, who is only concerned about themselves and their rights and how others may impact this. The attitude 
toward the Doctor could reflect that and it would be interesting to see if they did not have secure accommodation (e.g. castle) would racism become less of an issue towards a person who could provide shelter.

This prioritising of the individual rights, both in the sense of the tribe and its members puts me in mind of Mountz's(2015) view of the inversion of risk. In this people perceive the world from a standpoint which revolves around decision making focused around the risk to themselves rather than the risk faced by others. It is not just potential behaviour, but also issues and views that are seen as the matter of security and in the eyes of people such as Buzan et al,(1998) \& Pugh, (2009) this has led to securitisation of the Muslim community in the UK. The tribes are safely ensconced with the safety of a castle, with food, weapons, water and medicine. Opposed to this, the eight others are facing the real risk of Zombies, yet the tribe judges them through their own position in the world. This reflects the perception of the refugees as a threat to our privilege, yet these same refugees may risk their lives daily. This can be seen in how all three tribes now accept the mother and child now that she has a use. The treatment of the mother and child also demonstrates two of Clark's (1997) three forms of empathy. They had a cognitive empathy where they recognised the difficulties all the others faced and the cause of these difficulties. They also all had an emotional empathy towards the young child as none of them were happy to initially leave her out. Yet it took the mother being useful for the child to be saved.

What I learned from this session is that the varied enthusiasm called for a delicate approach such as in BYP where I respected the enthusiasm of the younger girls and the reluctance of the older girls. The Priory and Grangetown participants showed none of the reservations of the BYP girls but the behaviour of the Grangetown males was problematic at times. It immediately tested the dynamic between practitioner and researcher. I did not feel that it was my place to challenge the content of the behaviour, only control it. Had this been a project where I had 'standing' or authority I might have done. However I was conscious of being a first time guest and so concentrated on bringing them back to task. Fortunately, none of their behaviour was worse than silly and revealed changes that could be made in the future. In Grangetown one group became fixated on playing Call of Duty for zombie killing practice. They had acquired petrol to fuel the generator when choosing from the final list. This illustrates the importance of having a contingency of pre-splitting the third list for 
when there are only two teams. Grangetown was an exhausting session which upon immediate reflection I thought unsuccessful. When I examined the results I realised that they had made excellent contributions. It is possible that my positionality as a visiting white man, and not from their community, may have had an effect on their engagement. I think it might have been harder if I had not been vouched for by one of their community leaders as not once were they disrespectful towards me. This demonstrates the importance of gatekeepers to working with some groups of young people to build trust and reassurance. The Priory students engaged with an enthusiasm that I have often seen in students who realise that it is not a formal lesson involving academic work and writing. It was also easier in the sense that I had an already existing positive relationship with the project and participants.

This activity showed that imaginary reconstruction worked well and ZA was effective as a curriculum material to engage young people in conversations around citizenship and othering and through that gaining their views and opinions. The activity worked as it was designed, namely as an imaginary scenario with rules. At points, particularly the discussion around others all three groups were in what Ciskszentmihalyi (1979) would term in the flow of the activity. This means they were fully engaged and temporarily forgetting any misgivings they may have had at the beginning of the activity. The use of the twist in the others exercise introduced complexity into what were initially, straightforward decisions. Whilst not strictly speaking critical thinking, it was dialogical thinking. This lays some groundwork for future work where the link between real life issues and the imaginary scenario will be more prevalent and obvious. The participants also engaged reasonably well and the session began to do what Edmonstone (2016) describes as developing trust between participants and practitioners. In BYP and Grangetown it was establishing a foundation of a relationship and in the Priory it morphed the existing relationship to include alternative education.

During the writing, editing and corrections of this manuscript a question was raised around the use of the word 'tribe' in this activity due to its potentially problematic colonial connotations. The recognition and acceptance of this demonstrates how my own thinking has become more informed, complex and dialogical in the production of this thesis. The initial use of the word was based upon creating a temporary and instant imaginative 
geography and shared identity among the participants, which I saw as vital. This is why I avoided the use of 'groups', which I thought too neutral. I also considered 'teams' but thought that is more commonly associated with games or sports. In any future use of this game, I would seek a more appropriate, sensitive term for participants.

This activity has shown in practice and in research that it is adaptable and could be developed and adapted to explore these other, related issues.

- Criminal justice systems, leading on from rules and punishments;

- Focus on resilience by using it as a pathway to discussing potential real life scenarios and their actions within them.

- To explore their views on morality through their decision making process in the Other section of the game. In this case it would have been interesting to find out more on their perception of use, e.g. does it only apply in a crisis;

- Following from the participant in the pilot I do believe that this could also be turned into a residential practical exercise, which would be very exciting to plan and deliver;

- In future sessions it would be interesting to explore the inversion of risk and challenge participants on how quickly their reasoning concentrated on their own survival;

- In the future it might be interesting to explore the mother and child as separate others to see if they would be more inclined to help a lone child;

- To give some of the group an other identity and get them to argue for admission, perhaps bringing in more elements of personality than usefulness in the process.

The activity could be bespokely adapted to focus on one or more of these issues or through extending the length of delivery to include them. This would be in keeping with the fluidity of how a practical activity to promote team building came to explore issues connected with citizenship and othering.

The acceptance of others through the framework of usefulness was largely their idea and demonstrated the neo-communitarian and valuation based concepts of citizenship in ongoing citizenship debates. It would be fair however to ask whether I set them on this road by listing people's skills and/or professions. It may have been less leading to begin the 
othering section by asking them how they would feel about other people joining their tribe. Across the three projects, participants were instantly pragmatic from the very beginning of the activity. I believe that this may partly have been due to the scenario being a familiar one thanks to films and televisions. The recognition of this familiarity is of course one of the reasons the activity came about. This supposition was validated by the participants referencing Zombie film canon such as World War Z and Zombieland. What I find curious about these two films is that they sanitise a ZA. In World War Z the apocalypse was averted and in Zombieland the apocalypse was quite fun. Yet, the activity was about citizenship and so the lightness of the activity probably allowed the questions of citizenship and othering to remain the focus rather than survival. I took away from this game some interesting findings and had established a good base on which to build on in future activities, beginning with Brave New World. 


\section{Chapter 4, part two: Brave New World}

\section{Introduction}

After Zombie Apocalypse I wanted to give participants the opportunity to become the architects of their own worlds. Matthews and Limb (1999) and Tyrrell (2012) discuss how young people have different ways of knowing, experiences and perspectives to adults which should be valued. I agree with this view and wanted an activity which could explore the views and opinions of the kind of society and social contract young people would like to see. In my literature review I give a brief history of British citizenship and through this activity I wanted to explore Marshall's (1950) citizenship and his concept of a social contract that guarantees citizens a civilised life. One of the areas of Marshall's (1950) work I wished to explore was the social contract and views upon a civilised standard of living and a welfare state.

Brave New World, like ZA, is influenced by an activity that I ran as a practitioner in which participants designed a town they would want to live in. The aim of this was to make them think about their own communities and their behaviour within it. This took place in what Vanderbeck (2007) would describe as an adultist approach, where the debate over public space and public services was dominated by an adult narrative. Yarwood \& Gardner (2000) give an example of this by suggesting that young people are often seen as a law and order risk in discussions on public space. Vanderbeck (2007) discusses how this adultist view can infiltrate views upon children's geographies and can potentially devalue or undermine the seriousness with which Children's Geographies are treated. One of my main intentions was to treat young people as full social agents throughout this research.

\section{Planning and preparation}

The activity Brave New World (BNW) follows on from Zombie Apocalypse (ZA). The activity looks to build on ZA in themes, participant discussions and engagement. The ZA activity and the first part of BNW are phase one of Lakin \& Mahoney's (2006) model of carrying out empowering PAR with young people to create trust between the research practitioner and the participants. This activity starts in the same imaginary world of ZA. As the activity moves along it gradually departs this fictional world and the participants begin explicitly exploring 
real world issues. This bridge between the imaginary and real should make the participants feel safe to admit to a lack and/or to a limit in their knowledge as well as acting a gateway to the future sessions.

To recreate similarities of post-World War II and hence allow space for the post war dream, the activity begins with the participants being informed that the apocalypse is over and they have survived. Their job now is to build a Brave New World of their own design. The post ZA world has similarities with the end of WWII: mass casualties, damage and the need for rebuilding. The first activity saw the participants working by themselves to design their ideal BNW. In the pilot the participants required a lot of prompting and so in the research I provided the participants with a blank canvass and a services sheet. The blank canvas was a blown up backdrop of a green and pleasant land from a stop frame animation set. The services sheet was inspired by a mapping technique tool used by my industrial partners Sazani Associates. I created a sheet with symbols, the majority of which represented some form of traditional services associated with Painter \& Jeffrey's (2010) social rights of citizenship and their concept of high politics, dealing with state security and low politics, which are required for everyday life. The sheet was made up of the following services:

High politics: Law and order, CCTV, armed forces, borders and passport control.

Low Politics: power stations, eco power, schools, universities, hospitals and health services, dentists, fire brigade, social care and welfare, public housing, libraries, community and leisure centres.

Many of these are current publicly funded services and I wanted to find out if participants would choose them and explore how the participants thought they should be financed and run. This would give an indication of the models of citizenship they would like to see. These resources are suggestions and not an exhaustive list. The participants would be encouraged to think of their own. Using pencils, scissors and glue the participants would stick, write and draw the services they wanted on the canvas of the BNW. After they had completed this task the participants would be invited to feed back to myself and the group of what they had chosen and why. 
The next activity was to have a discussion on what rights and responsibilities citizens would have in the BNW. The final activity in this session would focus on immigrants and refugees. In regard to immigration the questions I was keen to put to young peoples were:

1. Why might their BNW need immigrants?

2. What are your rules on immigrants?

3. How should they be treated once they have arrived and should they have the same rights as natural citizens?

Using my position as facilitator I would give the participants one last development in the imaginary world. Through explaining that the citizens of the country the zombie virus originated in are fleeing persecution and seeking sanctuary in the BNW and what would the participants do about this? It was my belief that in the discussions around rights, responsibilities, immigrants and refugees we would leave the fictional world behind and begin discussing real world issues. These discussions would be recorded and if practical recorded on flipchart paper.

\section{Delivery and engagement}

\section{Butetown Youth Project}

The participants who engaged in BNW were the eldest woman and two younger girls from the previous week. They all engaged well but at different levels and in different ways.

Table 4.2.1 BYP overall selection totals

\begin{tabular}{|l|l|}
\hline Resource & Selected \\
\hline Power stations & 3 \\
\hline Eco power & 2 \\
\hline Schools & 2 \\
\hline Universities & 2 \\
\hline Hospitals and health services & 2 \\
\hline Dentists & 3 \\
\hline
\end{tabular}




\begin{tabular}{|l|l|}
\hline Law and order & 3 \\
\hline Fire brigade & 3 \\
\hline Social care and welfare & 3 \\
\hline Public housing & 3 \\
\hline Libraries & 0 \\
\hline Community and leisure centres & 3 \\
\hline CCTV & 1 \\
\hline Armed Forces & 2 \\
\hline Border and passport control & 2 \\
\hline
\end{tabular}

The oldest participant added leisure activities to her blank canvas and gave examples of football pitches and basketball courts. Two of the participants in BYP were happy to share the reasoning behind their choices, the third chose not to. First was participant J:

Table 4.2.2 Participant J: Choices and reasons

\begin{tabular}{|l|l|}
\hline Choice of service & Reason \\
\hline CCTV & To stop robberies or if more zombies come. \\
\hline Power station & For electricity to keep the lights on \\
\hline Public housing & So people can live \\
\hline Dentists & For no bad breath \\
\hline University & To test for zombies \\
\hline Armed forces & In case the zombies come \\
\hline Borders and passport & To make sure no immigrants come into the country \\
\hline control & For free time and play \\
\hline leisure centres & \\
\hline Social care and welfare & For the kids who may be orphaned because of what's happened \\
and their parents might be dead because of zombies. \\
\hline Fire brigade & No reason given \\
\hline Law and order & So no-one goes out of control \\
\hline
\end{tabular}


Next was the older participant Kay:

Table 4.2.3 Participant K: Choices and reasons

\begin{tabular}{|c|c|}
\hline Choice of service & Reason \\
\hline $\begin{array}{l}\text { Communities and leisure } \\
\text { centre }\end{array}$ & So people can be productive in their spare time \\
\hline Armed forces & Things can go out of control and other countries can interfere \\
\hline Universities & It is part of life to want to go and learn \\
\hline $\begin{array}{l}\text { Hospitals and health } \\
\text { services }\end{array}$ & If you get ill \\
\hline Dentists & No reason given \\
\hline $\begin{array}{l}\text { Border and passport } \\
\text { control }\end{array}$ & Other people could be coming in who should not be coming in. \\
\hline Power station & We need electricity to do mostly everything \\
\hline Eco power & To reduce pollution \\
\hline Schools & $\begin{array}{l}\text { Parents want their kids to go to school so they can have free } \\
\text { time }\end{array}$ \\
\hline Law and order & $\begin{array}{l}\text { Otherwise the country would not run properly. In Libya there } \\
\text { are no rules so everyone runs wild. }\end{array}$ \\
\hline Fire brigade & No reason given \\
\hline Social care and welfare & Some people are less fortunate and need people to help them. \\
\hline Public housing & Not everyone can afford to buy \\
\hline Charities & $\begin{array}{l}\text { As a Muslim it is our duty to help others, plus the less fortunate } \\
\text { need our help. An orphan or anyone who is poor needs charity } \\
\text { help for clothing and stuff like that. }\end{array}$ \\
\hline $\begin{array}{l}\text { Football and basketball } \\
\text { teams leagues \& pitches }\end{array}$ & No reason \\
\hline
\end{tabular}

$\mathrm{K}$ was very forthcoming in expressing her views on the link between charity and faith and that charity was about faith, but she did not expect everyone to share this; 
"Charity doesn't have to be about faith, you feel good about doing it after, you feel like you have done something, even if it means a little to someone"

J's choices show that she is very much in the fictional scenario with a notable exception of borders and passports to prevent immigrants coming into the country. This is later challenged in the discussion around immigration and refugees. $\mathrm{K}$ however was very much in the real world as seen by the reference to Libya, which is an example from her own life. Her maternal Grandmother and mother were Welsh, her father Libyan. $\mathrm{K}$ was born in Wales and the family moved to Libya only to return to the UK when war broke out. The reasons she gave for the family returning is to seek safety, better education and a better life.

In BYP session we did not cover rights and responsibilities as K's backstory led to a discussion about refugees and then immigration. At this point two of the participants asked for clarity on whether we were discussing real world issues or the imaginary scenario. I told them we had moved from the fictional into the real. I did not see the value in backtracking to explore rights as I did not want to break the flow. $\mathrm{K}$ believed that countries like the UK "have a duty to help refugees". One of the other participants, $Q$, disagreed and the following exchange took place;

Q: It's not our problem, it's their country who should be helping them.

K: Let me explain about Syria, it's not just war between them, other countries are getting involved, especially USA, Russia and the UK, if the UK is getting involved in their country then they should still have the right to come here.

Q: I'd still only let certain types of refugees in, good people.

This led the debate into the area of how do you know who are 'good people'. Once again $\mathrm{K}$ shared how her experiences shaped her views;

"Because I have been through it, to some extent we should allow refugees in, but prioritise between children, women and men. So I think women and their kids should be allowed in first as some men are dodgy".

This was a view that the other two participants agreed with and expressed concern that the country would become too full and there would not be enough food to go around. This 
threat to the destination country was further explored as we next moved onto discussing orphans and immigration. $\mathrm{K}$ would not let in any immigrant who had a criminal record and $\mathrm{J}$ was very concerned about overcrowding and would only let immigrants in who had "jobs and good qualities". The concern of overcrowding was such that it would still be a major consideration for her even in the case of orphaned children. The third participant who had kept silent joined in at this point to say that she would:

"Would have no border and it should be left to law and order to deal with immigrants who step out of line".

Her view had shifted it seemed due to the stories and examples she heard from her peers. This did not strike me as conforming but a person changing their views upon hearing more about a subject.

\section{Grangetown Youth Project}

In Grangetown three of the young men from the previous work took part in this activity. Before I began the activities I spoke to them about how the previous week had gone. I positively emphasised the intelligence and value of their work. I then asked them if they could just concentrate a little bit more and joke around a little bit less in this session. The reason I did it this way was linked to my positionality as a stranger and their guest. The choice of words was important as well, I could have described their behaviour as childish, but that might have antagonised them. This did lead to improved engagement, whilst still keeping some of the joking around.

\section{Table 4.2.4 GYP overall selection totals}

\begin{tabular}{|l|l|}
\hline Resource & Selected \\
\hline Power stations & 0 \\
\hline Eco power & 1 \\
\hline Schools & 1 \\
\hline Universities & 1 \\
\hline Hospitals and health services & 1 \\
\hline
\end{tabular}




\begin{tabular}{|l|l|}
\hline Dentists & 2 \\
\hline Law and order & 1 \\
\hline Fire brigade & 1 \\
\hline Social care and welfare & 2 \\
\hline Public housing & 3 \\
\hline Libraries & 2 \\
\hline Community and leisure centres & 3 \\
\hline CCTV & 0 \\
\hline Armed Forces & 2 \\
\hline Border and passport control & 1 \\
\hline
\end{tabular}

One of the participants also wished to see the creation of football pitches. I asked them if they would explain their choices but they decided they did not want to and were keener to talk about law and order. This was led by one participant who had strong views and advocated punishments such as chopping off hands and the death penalty and a blanket ban on all pork products. I asked him about the pork ban and discovered that it was partly influenced by religious beliefs and partly because his family owned and ran a fried chicken shop, so it would be good for business.

This talk of law and order enabled a natural transition to discussing citizen rights and responsibilities with the Grangetown participants. They were in agreement that the first responsibility would be not to steal. The other responsibility they were united on was people taking responsibility for their own health and to this end they would ban harmful substances such as drugs, cigarettes and alcohol. The subject of health was discussed in relation to both rights and responsibilities. One of the participants was against taxation and believed citizens should work, that taxation was robbery and citizens should pay for their own services. His view of government was that its role was to protect the borders and enforce the ban on dangerous substances, pork and stealing. This is a very civic model, a very USA style version of citizenship, with small government and a high level of individual responsibility. The other two participants had a more welfare based social contract. They believed in benefits when necessary and cited maternity leave and illness as examples of 
how people sometimes cannot work. They wanted to have free health care and education for everyone, up to university level and recognised that this could only happen with taxation. They did not want benefits for the lazy, which links to media and social narratives of benefit cheats. They did not talk about tax avoiders or evaders. They understood the theory of the police but their own negative experiences made them reluctant to create a service. All three agreed that the voting age should be lowered to 16 , thinking it unfair that they did not get a vote on their future.

We briefly talked about immigrants and refugees and it began with having a policy which only allowed professional immigrants but soon changed to having a one country world, with a blanket ban on pork, cigarettes and alcohol. They did not believe this would be achievable in the real world. GYP thought we should help refugees then, but that did not necessarily mean letting them into the country. This aid could include sending them water or the creation of a new country for refugees. This was the last of the action in this session as one of the participants had previously ordered a pizza which he now took delivery of. He shared the pizza with his friends and with me and we all talked about football, an enjoyable and appropriate way to help build a positive relationship.

\section{Monkton Priory}

In Monkton I had three returning young people from the previous week, two boys and one girl. They all engaged in a really positive and enthusiastic manner, enjoying the activities and debates.

Table 4.2.5 Priory overall selection of services

\begin{tabular}{|l|l|}
\hline Resource & Selected \\
\hline Power stations & 2 \\
\hline Eco power & 3 \\
\hline Schools & 2 \\
\hline Universities & 1 \\
\hline Hospitals and health services & 3 \\
\hline Dentists & 3 \\
\hline Law and order & 1 \\
\hline
\end{tabular}




\begin{tabular}{|l|l|}
\hline Fire brigade & 3 \\
\hline Social care and welfare & 0 \\
\hline Public housing & 2 \\
\hline Libraries & 0 \\
\hline Community and leisure centres & 0 \\
\hline CCTV & 2 \\
\hline Armed Forces & 3 \\
\hline Border and passport control & 0 \\
\hline
\end{tabular}

In terms of adding their own ideas to the blank canvass one participant listed farms to produce food and counselling services. The latter was for people who might require the service after the apocalypse. Another participant designed his BNW to include football clubs and pitches, pubs and MacDonald's, because people like to eat and drink. He also wanted wildlife in his BNW to make people happy, to hear the birds sing and he rather beautifully illustrated it by drawing a bird in a tree.

The Priory participants' views on rights and responsibilities came out as bullet points and there was an unspoken consensus around them:

Table 4.2.6 Priory rights and responsibilities

\begin{tabular}{|l|l|}
\hline \multicolumn{1}{|c|}{ Rights } & \multicolumn{1}{c|}{ Responsibilities } \\
\hline All people equal & Pay taxes \\
\hline Right to speak & Look after each other \\
\hline Right to health & Behave normally and forget about the ZA \\
\hline Love whoever you want & Obey the law \\
\hline Right to socialise with whoever you want & To agree and listen to each other. \\
\hline Education & \\
\hline Food and drink & \\
\hline To not be discriminated against & \\
\hline To not be a victim of racism & \\
\hline Social care and welfare & \\
\hline
\end{tabular}


Housing

I liked the checks and balances of the right to speak and the responsibility to listen. When asked to explain how people would look after each other they spoke of recognising the value of all skills and abilities. They gave an example of how a woman with a small baby cannot build a house, so others could build it for her while she looked after the children. In regard to migrants and refugees they discussed reasons why they might be required:

Build houses, pay taxes, do any work, fight for us, bring knowledge, strengths and skills; wiring up CCTV, getting the Wi-Fi to work.

They did not however think immigration should be allowed. In the words of one of them; "they don't speak English, they're taking all our work off us, taking our money and houses, whereas there are British citizens who have lived here all their lives who don't have any of that"

I established that they were talking about both the real world and the fictional scenario. I asked them what they would do in the case of a skills gap, such as a shortage of Doctors. They conceded that they would allow them if needed. In line with their thinking that they did not want immigrants stealing their resources they had a slightly bizarre conversation about whether a Doctor with a range of disabilities, including missing limbs, would be allowed entry. The conclusion was that skilled professionals would be accepted regardless of disability on the proviso they could still do their job. Given a choice they choose refugees over immigrants, believing their need was greater. However they still emphasised the concern over job stealing and would not accord any immigrants or refugees equal rights. Giving an example one participant explained how this would manifest itself in the criminal justice system.

"Send me to prison, send them away. Goodbye. This is my country, I go to jail, they go back to their country". 


\section{Discussion and reflection}

It is worth looking at the combined selections of services for the BNW by participants across all three groups.

Table 4.2.7 Combined selection of services

\begin{tabular}{|l|l|l|l|l|}
\hline Resource & BYP & Grangetown & Priory & Total \\
\hline Power stations & 3 & 0 & 2 & 5 \\
\hline Eco power & 2 & 1 & 3 & 6 \\
\hline Schools & 2 & 1 & 2 & 5 \\
\hline Universities & 2 & 1 & 1 & 4 \\
\hline Hospitals and health services & 2 & 1 & 3 & 6 \\
\hline Dentists & 3 & 2 & 3 & 8 \\
\hline Law and order & 3 & 1 & 1 & 5 \\
\hline Fire brigade & 3 & 1 & 3 & 7 \\
\hline Social care and welfare & 3 & 2 & 0 & 5 \\
\hline Public housing & 3 & 3 & 2 & 8 \\
\hline Libraries & 0 & 2 & 0 & 2 \\
\hline Community and leisure centres & 3 & 3 & 0 & 6 \\
\hline CCTV & 1 & 0 & 2 & 3 \\
\hline Armed Forces & 2 & 2 & 3 & 7 \\
\hline Border and passport control & 2 & 1 & 0 & 3 \\
\hline
\end{tabular}

Overall the most common services were public housing and dentists. The reason given for public housing was universally to provide people with somewhere to live. The only explanation I got for dentistry was to prevent bad breath. The only explanation for the fire brigade was to put out fires. I got the distinct impression that they saw the reasons for these services as self-explanatory. One participant in each group included leisure facilities that showed that participants did not just want a world of services such as education, health and housing. Marston \& Mitchell (2004) discuss that citizenship is best seen through how it is formed and justified, and the participants in designing their worlds generally created a social contract with a civilised standard of living. Turner and Isin (2008) explain in more detail the 
terms of Marshall's idea of a social contract. A citizen works, nurtures family, pays taxes and in return receives a civilised life which ensures "members have a life protecting them from unpredictable vagaries of accident, sickness and unemployment", Turner and Isin (2008:7). In regard to their views on citizenship the participants did all support self-responsibility in citizenship including securing paid employment. This shows an element of neocommunitarian citizenship (Sinclair et al 2010). The majority of the young people had a balance between them and came across as by and large pro social citizens. They wanted the civilised lifestyle to include some form of health, education and welfare and gave the impression that these should be universally accessible. They seemed to relish the opportunity to build a new world and in many ways a more peaceful one where hatred and inequality was eradicated. What I took away from this was that they did not dwell on the past or show focus imaginarius (Bauman, 1991) for a bygone age, perhaps this is because they have no discernible past, lost youth and predominantly look to the future. If as Westheimer and Kahne (2004) suggest citizenship is a continuum where civic and political acts are both important then many of the participants illustrated how this would be balanced. The Priory's housebuilding/babysitting labour exchange, and two of the GYP participants talking about maternity leave was balanced by people having to work and contribute. There was however one participant in GYP who designed a civic society where people took responsibilities for themselves and the government's role was to protect the borders. Interestingly part of the act of individuals taking responsibility involved the government banning harmful substances and hence depriving people of choice.

This vision of their largely pro social BNW however did seem to only stretch to the incumbent citizens of their country, displaying a one nation view of citizenship. The armed forces were chosen for defence against either other countries or Zombies. This shows that at this stage of the activity some participants had already moved into the real and others were still in the fictional. One of the significant things about this game was that the majority of participants had some form of armed forces, but very few selected borders or passports. These latter notions can make the existence of a state or country become real and mark the world as 'our' space and 'their' space, (Said, 1978; Gregory 2006). Instead the participants marked out their territory by distinguishing between who was entitled and who was not, with those seen as a threat in the latter category. Any immigrant or refugee was seen 
through a lens of human capital and what Bagnall (2010) and Davies (2013) deem an economic imperative for a stranger to be a resource or asset and by implication not a burden. Their tangible fear of the potential dangers posed by strangers appeared influenced by wider world events, which shows affinity with Younis et al (2002) argument that local and national concepts and views can be shaped by global events. These global events influenced decision making regarding others in both the real and fictional world. There was also evidence of Mountz's (2015) politics of fear in which the risk of others is prioritised over the risk faced by the others. An example of this was in BYP where they had grave reservations over letting in male refugees and in the Priory about any refugees and immigrants. This shows how some aspects of the human stories are made invisible by fears of safety and that the securitisation of migrants sees politics and the media successfully blend refugees seeking asylum and terrorism as the same problem, namely one of danger (Pugh, 2004).

Another key thought on citizenship was the civic role of the individual. The BYP participant K's view that charity is part of civic life and an emphasis on civic life can be seen in a civic model of citizenship such as in the USA (Isin \& Turner, 2008) or as part of neocommunitarian model (Murphy, 2017). Kay's attitude toward charity is closer in nature to the civic model than to the neo communitarian one. This is because she does not do it for reward in terms of qualifications and improved life chances or as part of some educational programme. Instead her civic virtue is based in her religion. Painter and Jeffrey (2009) discuss how international belief systems can exert a political authority which can challenge a state. Kay's inclusion of charity is an example of a religious authority but not a challenging one to a political authority. Her religious beliefs motivate her to make a strong and direct civic contribution, which is seen as positive in most societies including the fictional one of BNW and our current world. An individual view from the fictional scenario based partially on a religious belief that could be seen as a threat if crossed over into the real world would be the ban on pork and the use of corporal and capital punishment as championed by one of the GYP young men. Dunn and Hopkins (2016) discuss how Islam is portrayed as a religion of violence, populated by terrorists, who are a risk to our society. This view might be seen as an example of this as it includes state violence. However I am confident that those who would like the return of capital punishment come from a wide cross section of society. The views on pork however would threaten traditions such as the full English breakfast but that 
is hardly a violent risk to our society. Dunn and Hopkins (2016) say the portrayal of Islam is in part down to a mainstream media who repeat and reinforce this stereotype by "pursuing business models that benefit from the scandalising of public interest" (p255)and it is easy to imagine a Sun headline about Islam banning bacon sandwiches. These views can be seen by reactions of the western world to major events such as $9 / 11$. In this an orientalism influenced imagined geography portrayed the West as the good guys and Islam as the enemy (Gregory, 2006). This has continued to be done by highlighting the differences rather than the similarities or positives such as charitable involvement (Goodhart, 2004). Islam is rarely portrayed as a religion of civic duty and the concentration on violence, threat and difference has resulted in a state of "a forever unfinished practice of othering" (Fisher, 2015:57).

Ultimately none of the groups were really committed to accepting immigrants and refugees, despite all showing a degree of cognitive empathy. This was because of a dual threat to both their security and employment. This may have origins in their own experiences. I have heard members of the Pembrokeshire Gyspy traveller community talk of how many of the seasonal jobs that they used to do such as fruit picking in the summer and plucking turkeys at Christmas are now jobs done by overseas workers. All these attitudes seem to point towards a one nation first attitude and a rejection of being involved in a more cosmopolitan world.

This game was a springboard to explore a variety of issues. What I took away was that this exploration meant each session had its own narrative arc. This session followed the activity script in Monkton Priory but not in the other two locations. I believe the difference was because of the formal as opposed to informal settings in which they were carried out. One way in which this manifested itself was in the length of the sessions. The participants in the Priory assumed it was an hour long, as that is how long a lesson lasts. In the other two projects the time was decided by the interest of the participants. As a result the Priory did all the activities in sequence, as I steered the session whereas in BYP and GYP some were skipped as the young people's engagement levels steered the sessions

The game is also only an introductory springboard. The participants seemed to see the reasons for a fire service as self-explanatory. Yet the changes made to it over the last 20 
years, from reaction to prevention, from full time firefighter to retained makes this subject more nuanced than the participants realised. Then there are the issues that participants raised through their views on services. For example in Grangetown the participants expressed great resentment and mistrust of the Police. BNW could also be used to explain and explore concepts such as taxation, legal systems and democracy. The majority of discussion in the BNW creation focused on the services of low politics. There is space in this activity to focus on high and low political services separately and then together. The focus on high politics might present an opportunity to explore the concepts involved with imaginary geographies and how they become performance, including looking at societies in various stages of development including peace time and non peace time.

The game responded well to my research questions as I gathered interesting views and believe the materials used would work in both a formal and informal curriculum. As said previously this game could be adapted to explore many issues. I was slightly apprehensive over the number of participants and would have liked higher numbers. In BYP the two females from the previous week were on the premises, but when they saw me, they avoided me and had I been their project worker I might have attempted to convince them to join in. This exemplified what I wrote about in the pen picture of BYP in chapter three about how this is a very precious time to these young people and that should be respected by strangers such as myself.

A key design of this activity was to avoid treating young people as pre-adults in citizenship training who should explore the world through its existing arrangements and overall I believe it did so. This shows that there is value in taking this approach in discussing citizenship and othering with young people. In both ZA and BNW the use of an imaginary scenario did work to make sense of the real world, with the early part of BNW providing the bridge, shown through the increased use of discussion in understanding views. The switch to discussing the real world was largely seamless and a natural part of the discussions.

There were two moments that I took away and would use to inform future delivery and practice. The first was K's unexpected commitment to faith and charity as at no point did I consider the 5 pillars of Islam when planning my activities; I was conscious of respecting Islam but it did not occur to me to incorporate it. The second was the punishments 
suggested by the participant in GYP such as chopping off hands. I question whether I should have delved deeper into his thinking. Cutting hands off though is something I associate with the middle ages and was quite shocked when he said it. I avoided discussing it at the time partly from not wanting to undermine the freedom of expression within the session and also I was not sure how to. There is also a possibility that he said it to challenge or provoke me and make me feel uncomfortable. This could have been in part due to my position as a white man. However I am no stranger to dealing with uncomfortable scenarios and these same scenarios can be viewed as the price of an approach that attempts to be nonjudgemental. Within this framework listening and avoiding censoring participant views is important but so too is exploring these views. I was reluctant to do the latter regarding corporal punishment. The thought of exploring it made me uncomfortable because of my own views and the potential controversy. As previously mentioned I did ask about the pork ban and found out that was partly influenced by religious beliefs and partly because his family owned a fried chicken shop, so it would be good for business. Perhaps the lesson here is not to be so hesitant. Overall, in these first two activities the participants demonstrated that they were willing to share and challenge views and opinions. This is very positive for future sessions and both ZA and BNW showed that they are effective, firstly in introducing the areas of research, secondly in garnering views and opinions on the subjects and thirdly and perhaps most importantly introducing me to the project and the young people and beginning to get to know and understand them. 
Chapter Five:

Part one: Citizenship Snakes and Ladders.

Part two: Political approval game. 


\section{Chapter 5, part one: Citizenship Snakes and Ladders}

\section{Introduction}

This session focuses on the British citizenship and English language tests explored through a board game called 'Citizenship Snakes and Ladders'. The British Citizenship Test has been a requirement for naturalisation since 2005 and for settlement since 2007. Its content is largely based upon Labour Government advisor Bernard Cricks' book titled 'Life in the United Kingdom: A Journey of Citizenship' written in 2004 (Bryne, 2017).

It would be reasonable to say that the introduction of a citizenship and language test is an example of how Brown (2015) believes that neo-liberal valuation is being used in a social and political arena which previously may have been considered non-economic. Fortier (2013) views the English language test as a foundation stone of integration by the potential naturalised citizen. She says it a state defined desirability that those who wish to become citizens should be able to speak the language. Learning English not only enables them to operate in UK society but, perhaps more importantly, demonstrates a commitment to integration and the UK. Through taking the effort to learn a language they are perceived as desiring to become British. Fortier (2013) believes that an inability to pass a language test is equated to an unwillingness to integrate. If we accept this as a probable aim of the test then it is yet another example of neo-liberal valuation in action.

In 2011 the then Prime Minister David Cameron shifted the focus of the test away from Cricks' approach of everyday life in the UK to questions on history and culture (Cameron, 2011). The idea of behind this was that knowledge of key moments in British history would "ensure that new citizens could better engage with modern British culture" (Brooks, 2012:562). Brook (2012) also argues that the test should be seen as a bridge to citizenship rather than a barrier, as it will promote integration. This view can be interpreted as showing that integration or the performance of integration is as important in the citizenship test as it is in the language test. Byrne (2017) discusses the content and utility of the Citizenship test and the ongoing debate on whether the test should focus on Crick's practical or Cameron's cultural and historical aspects of life in the United Kingdom. Her work highlights that a potential citizen may "display knowledge that most other citizens do not know" (Byrne, 2017:334). If this knowledge is valued by the willingness and desire to learn it as much as 
the meaning, then the imbalance in knowledge between the born and naturalised citizen is not such an issue. In this way the tests have "become emblematic of the new citizens" commitment that new citizens are making the imagined community of Britain their own" (Fortier, 2013:710). This suggests that the test focuses on citizenship identity above functional citizenship. People who show an effort to identify as British are perhaps seen as more desirable than a person who merely wishes to live and work in the UK, such as an EU citizen.

I wished to know participants' views on the citizenship test and whether it might lead to them expressing opinions and views about citizenship and othering. I was particularly interested in their views on the possible imbalance of knowledge as suggested by Bryne (2017) and their views on the content, echoing the debate between the Crick and Cameron approaches. I was also wished to explore their views on desirability, as suggested by Frontier (2013) and whether they thought the tests were a good thing.

\section{Planning and preparation}

From the early stages of my studies I was keen to use the test in my research, and it cried out to my inner practitioner to be turned into some form of quiz game. My experiences have taught me that young people enjoy games and quizzes and find them fun. Fun is not a common word in education, youth work or Children Geography. Mason (2015) explains how open access youth work provisions, which are based upon voluntary engagement and socialisation, have been reduced in favour of pre-scripted curricula that do not allow innovative working methods. This is a practical example of Brown's (2015) view of the impact of neo-liberalism in all areas of society as discussed in the literature review. In the neo-liberal world success is measured in tangible values and less on more traditional areas of youth work such as signposting, support and advice. This continued encroachment of a neo-liberal agenda based on valuation has become more prevalent in social and economic political agendas (Garner, 2012; Edmonstone, 2016).

I saw this test as a chance to have a fun, game based activity. After all "fun is good, play is the most powerful way a child explores the world and learns about himself" (Labi, 1998:86). Play can be unpredictable and unscripted and while competition may give it a result this is 
different from a school term's lesson plans focused on a result, which can be valued according to a national qualifications framework and the demands of funders.

My initial thoughts included a team quiz or actually making them sit a mock citizenship test. I discounted the first because I wanted the game to be inclusionary and interactive. I disregarded the idea of their sitting the test because I thought most would fail and it would not be any fun for them. This may show a lack of faith in their knowledge but I was basing it on my own experiences of taking the test. I took countless online practice tests and would pass approximately three quarters of the time. I have a reasonable level of general knowledge, acquired from a lifetime of living in the UK which has seen me absorb a lot of culturally specific knowledge. I knew when the Battle of Bannockburn was because having watched the 1995 film Braveheart I had a rough idea of the history period in which it was set and was able to guess correctly due to the multiple choice format of the test. There were also questions about events I had not heard of and about which I could not even make an educated guess. In my experience young people, being young, have not had the years to gain the same quantity of knowledge. Failing could be perceived as a negative experience by some young people. I was also acutely aware that there might be participants in BYP or GYP who might know people studying for the test or have to take it themselves one day. It might be quite upsetting for them to fail a citizenship test.

In the end I choose the form of board game and I looked to existing games for inspiration. Board games are normally played in teams and this allows for sharing knowledge and peer teaching (Speers, 1993). Gibson and Douglas (2013) explain how a monopoly inspired game called Criticality was used to support trainee nurses revise knowledge from an acute and critical care module. This game was designed to follow a narrative of a potentially complex situation, "...however this would be in a fun way, but with some seriousness attached" (Gibson \& Douglas, 2013:1614). I liked the idea of having a citizenship narrative running throughout the game and began designing a Monopoly style board, combined with a variety of challenges similar to Cranium ${ }^{5}$. Players moved around answering different categories of questions, competing to gain UK citizenship. The three categories of question were:

\footnotetext{
${ }^{5}$ Cranium is a board game where teams complete colour coded activities through spelling, drawing, acting, humming, modelling or guessing.
} 
- Language; using actual questions from the English language test;

- True or false: from the citizenship test;

- Test: also from the citizenship test, these could be multiple choices.

I also incorporated the idea of the Monopoly chance cards. Chance remained the same and consisted of scenarios that might help or hinder a person applying for citizenship. I drew these from a combination of historical events and stages of the citizenship application process.

\subsubsection{Table of negatives and positives.}

\begin{tabular}{|l|l|}
\hline \multicolumn{1}{|c|}{ Negatives } & \multicolumn{1}{c|}{ Positives } \\
\hline Fail English language test & Marry a British citizen \\
\hline Child commits a criminal offence & Marry a member of the royal family \\
\hline Brexit & Britain joins EEC \\
\hline Forget to sign application form & Arrive on the Empire Windrush \\
\hline Divorce from British spouse & British Empire ends \\
\hline Non-attendance at citizenship ceremony & Pass British citizenship test \\
\hline
\end{tabular}

I introduced a 'Perform' card which was to bring in an entertainment factor by requiring players to take part in a micro game of Charades, Articulate or Pictionary. They would have to act out, describe or draw a famous person, character or landmark associated with the UK e.g. The Queen, Harry Potter or Stone Henge.

I played this game with some members of my family who loyally allowed me to conscript them. They enjoyed the content of the game and the playing of it. Unfortunately the mechanics of the game did not support a citizenship narrative and one team could win on their first go. I was pleased with the addition of the Perform square as it nicely counter balanced the factual questions. After contemplation I realised that trying to be too clever or complicated in the design may distract from the content and I decided to use the game Snakes and Ladders. The snakes would be negative impact on citizenship and the ladders positive impacts on citizenship. I was still concerned of the slim possibility that the team 
who went first could win straight away. To reduce this further slim possibility even further I made the following rules:

- Up a ladder or down a snake and your turn ends;

- Get a question wrong and your turn ends;

- Perform square was an all player, meaning another team could take control of the board;

- To win the game the team had to win a perform square.

I also allowed myself the following three game control options in my role as the quiz master:

- Choose the questions rather than leave to random selection;

- Choose whether to give multiple choice answers.

These techniques would be used to keep the game close, if one team was looking likely to comprehensively beat the others. I did this so that the full extent of the range of questions and challenges involved in the test and gaining citizenship could be aired and participants did not give up. The number of team members was also something I considered. In playing Criticality, Gibson and Douglas (2013) found the ideal number of members of a team was three, as a pair or team of 4 or more meant it more likely that a student might "...not participate or for them not to be heard if they were not assertive enough" (Gibson \& Douglas, 2013;1615).

Now I had decided on my format and content I created my Citizenship Snakes and Ladders using a broad and flat piece of wood, 100 squares of different coloured post it notes, each category represented by one colour and paper snakes and ladders stuck on with glue.

\section{Delivery and engagement}

\section{Butetown Youth Pavilion}

When I arrived I informed the participants about the nature of the activity and that we would be playing a game, backed up by the production of my colourful game board. This saw my number of participants rise from two to five females. The game lasted for around forty minutes and the participants enjoyed themselves, particularly the competition and 
were interested in learning new knowledge. They thought it was a good way to learn and that

"We don't do anything like this in school"

\section{Grangetown Youth Pavilion}

In this session I had twelve participants, all males, playing in four teams of three. It was very loud and very lively and I ran out of questions, partly due to the numbers of participants and also because they were really good at it. This meant that for a short period of the game I had to fall back on my aforementioned general knowledge. This question shortage came about because I did not anticipate having that many participants taking part in the session or knowing so many of the answers. The game lasted just under two hours and the audio recording is like listening to a football crowd on the radio. Towards the end I was actually trying to accelerate the game to a finish as I was tired and hoarse. It was a pleasure to play the game with them however, as this extract from my research journal may show;

"They enjoyed playing the game immensely and part of this was having the chance to demonstrate their knowledge and in fact their co-players encouraged this at all times. I think this may have been down to the competition, although there was no prize. They also showed a thirst for learning new information; when they got a question wrong they were very interested in knowing the correct answer. Sometimes they would look it up on the internet, shushing each other to be quiet so they could hear the answer and in doing so making as much noise as those they were shushing".

\section{Monkton Priory School}

There were four participants, three males and one females and they played in pairs. We were joined ten minutes from an end by a fifth male- at this point the game had stopped and we were in the discussion phase. This was his first time attending school in weeks and it was important that he felt welcome as this school is a safe place for him. I explained what I was doing and gave him the choice of joining in or sitting quietly until we finished the session and he choose the latter. 


\section{Discussion and reflections}

One of the most significant findings about this game, which has relevance to views on citizenship is that across all three projects there was support for the functional elements of the test. Namely, the knowledge that people required to live their daily lives in the UK. The BYP participants did not think that historical questions were as important as questions on the rules and laws of the country and highlighted the question on the legal age to buy tobacco as a good example of important information. The GYP participants enjoyed answering the history questions but did not think they should be included in a citizenship test because of the history it covered. They thought there should be more recent history included such as the $21^{\text {st }}$ century wars in both Afghanistan and Iraq. In the Priory they also enjoyed learning about history and thought it was important for potential naturalised citizens to learn about the UK's past. This was to aid integration so that they would not cause offence to other citizens by behaving or saying something inappropriate. This could be termed recognition of a need for culturally sensitive integration.

The game once again gave participants the chance to learn off each other, which is positive in regard to developing curriculum materials. In BYP four of the participants admitted to having a limited amount of knowledge about the legal and court system and were given a rudimentary but accurate explanation by the fifth whose knowledge came from experiences of a close family member. The game also allowed discussions of rules such as in GYP. Here they viewed questions and answers on UK laws, processes and behaviour as 'common sense' which was 'gained from living in this country'. They thought it was important information and a lack of knowledge and experience in these areas would make it harder for people seeking naturalisation to integrate. The Priory thought that the inclusion of questions on the law and courts helped make the game an activity which was:

"Educational and fun and encouraged teamwork and got people working together, learning and having fun"

They also thought that the game was:

"A good way to learn about Britain" 
This could give the game wider education applicability in the future. The Priory participants saw all the questions as relevant, including the ones around culture and entertainment. This was not shared by the participants in GYP who thought that questions to do with entertainment and culture were not important and should not be included in the test. These views affected their views on what the pass mark should be. Based upon the current content they thought it could be as low as $50 \%$ as:

\section{"Some of the questions are not needed to be known"}

However if the test contained questions of what they saw as important, e.g. questions based on laws and the courts, they would increase the pass mark to $85 \%$. They thought that to pass the test a person should require 'a lot of knowledge about Britain' but did not view it as a tool towards integration. They saw integration as rooted in day to day activities and the systems which govern the country, again demonstrating a substantive view of citizenship; BYP participants were of a similar mind-set. The Priory however seemed to view the whole test as important, and was the only group who valued the commitment shown in taking and revising for it. The Priory thought that the test created an imbalance of knowledge in favour of naturalised citizens and would give them an advantage over incumbent citizens, including taking things such as jobs, which they thought was wrong. In GYP they also thought that the test may create an imbalance in knowledge but did not see this as a threat:

\section{"If new citizens need to know it, then we should also need to know it"}

The reason behind this rationale is if the information is deemed important it should be important for all citizens. The Priory took the view that being born in the country was all they required to be considered citizens of the country, which may have informed their views on the commitment to integration that they saw inherent in the test.

The Priory's views especially responded to current debates in citizenship by showing solidarity with David Cameron's view on what the test should do and contain. It is very much in line with Fortier's (2013) writings on desirability in that they looked for a desire through a show of commitment. Their view on naturalised citizens having an 'unfair' advantage is an example of differentiation in citizenship as discussed by Cynthia Weber (2016). In her Vimeo broadcast Weber (2016) proposes that people who consider themselves as full citizens turn 
meaningless differences into meaningful differentiations because of fear they have of those they consider less than full citizens. In the Priory there is the feeling that a naturalised citizen is still 'Other' because they were not born in the UK. One of the participants thought that part of the naturalised process should include asking the applicant what they would do if the UK went to war with their country of origin. Interestingly this could be seen as a variation of the Tebbit cricket test in a more serious context ${ }^{6}$. This was a very meaningful question for them and displayed a nationalistic form of citizenship. Their view of the knowledge imbalance was that the naturalised citizen would have too much, not that they had too little. Again I believe that this is in some way due to their view of the entitlement of their citizenship through birth. The participants in GYP and BYP were less concerned with desirability and commitments. Instead they largely viewed the test as a practical one and would seem to be on the same page as Crick's view of the purpose of a citizenship test.

These contrasting views show that Byrne (2017) is correct in her view that the debate around the test's content is very much ongoing. This may mean that gaining a consensus could be difficult. I think that is not unreasonable to suggest that the differences in these views are affected in part by the participant's backgrounds and experiences. Gillespie and O'Loughlin (2009) talk about how our citizenship practice is profoundly entwined with how we engage with the information and messages that stem from our history and social and cultural practices. The media and our experiences can have a huge impact on our knowledge and understanding of these things. I may have used Braveheart to place the Battle of Bannockburn in the Middle Ages but I would not call the film educational. The participants in GYP and BYP both live in communities which will include naturalised citizens and those seeking citizenship which may lead to a cosmopolitan and global view of citizenship. The Priory will have families who have lived in the same communities for generations and residing in a largely rural area this must affect their world view.

One significant experience I took away was how citizenship definitions are rapidly changing in the UK. This activity was originally planned before the Windrush scandal broke and exposed the nature of the Conservative Government's 'hostile environment'. This is

\footnotetext{
${ }^{6}$ Norman Tebbit was a Conservative politician and former member of Thatcher's cabinet who in 1990 suggested that immigrants from South East Asia or the Caribbean who still supported their native countries in cricket were not significantly integrated in the UK.
} 
explored in chapter six, part one, but is basically a bureaucratic approach to make it difficult for people with no right to remain to remain and to force them to voluntarily leave. The Windrush was a voyage to citizenship in that a person would live and work in the UK and many of their descendants would become British born citizens. What has emerged is that despite a lifetime and identity focused on being British it may not have provided the political citizenship and thus the legal security that many people thought it did. The hostile environment was aimed in theory at people with no right to remain, but the scandal of Windrush was how it was used on people who did in fact have that right. Brexit is of course controversial and I did consider not including it. After deliberation I chose to partly because it is a topical subject of great debate and also that young people voted overwhelmingly to remain. Brexit has the potential to strip EU nationals of their political rights. It also appears to promise uncertainty and confusion for everyone with any connection to the United Kingdom including current and future citizenship statuses, such as retaining or applying for it.

They all struggled with many of the questions and one of the participants said that it made him feel "that I'm dumb". This male is of a very low academic ability, not helped by a very poor attendance record, which is both a cause and effect of his educational struggles. His best involvement came through the perform category because I was able to tailor it to his knowledge. This vicious circle of a lack of knowledge, confidence and engagement is hard to work with. Long before this thesis I had to address my own prejudicial disbelief at how resistant some young people are to the absorption of knowledge. It is very important to stress the extent of this and when encountering and working with this a practitioner has to remain very non-judgemental and be prepared to strip a subject so far back that the basics seem advanced. It really becomes a juggling act when they are in the same class as highly capable students looking to be challenged. This is relevant to my questions around curriculum development as designing and delivering an inclusive game for all abilities is harder than doing it for participants of higher ability.

One of the most interesting comments was in GYP about the lack of inclusion of questions on recent history. This is a fascinating observation and from the countless mock online tests that I sat very legitimate. I wonder if this may be because the wars in Iraq and Afghanistan are not universally popular and may not be included in case they portray the UK as less than 
great, not to mention that applicants may be from areas of the world affected by these conflicts. History is a vast and subjective reservoir of information and if its use in a citizenship test is determined by the government of the day it would only be sensible to question said government's motives.

What I took away upon reflection was that the main success of this activity was more the playing of the game rather than the contribution to the research. Citizenship Snakes and Ladders is a winner, as a board game. The discussions after the game were short because of time constraints and a drop in engagement and energy levels of both myself and the participants. In short this session was about playing the game and as an educational tool it has many positives. I think that unlike 'Criticality' the game narrative, namely the road to citizenship was not clear and teams celebrated winning rather than 'becoming a citizen'. Their reaction to the snakes and ladders squares was based on how it affected their chances of winning and not the citizenship related reason. In this way it lacked some of the seriousness I had hoped for. It would have been interesting to have explored in greater detail their views on the content, the politics of desire and how the test might influence identity. Interestingly I have also played it with many groups of adults at dinner parties and they really enjoyed it and it has sparked debate. This perhaps shows that explorations of citizenship should be part of lifelong learning and not reserved almost exclusively to education.

In future I would seriously consider using this game as an introduction activity and have follow up activities around the issues attached to it. One of these could be to get the participants to research and write their own version of a test. The games structure makes it ideal for revision, as was used in 'Criticality' and as such could be adapted to many subject areas. One of the main aims of this game was to engage the participants through fun to ensure their continued participation and in that sense it worked well. It may be that I focused on that aspect more than the research to ensure the security of my position as an engaging practitioner. In terms of accessibility and ease of use the game has a lot of merit and this gives it impressive superficial qualities, but on its own it lacks substance due to its favouring competition over critical thinking and the break neck pace with which it is played. This is easily evidenced by the relative shortness of the findings, especially compared to 
following sessions. In the next session I play another game called 'Political Approval' which I believe has more value in bringing to the surface important discussions around citizenship. 


\section{Chapter five, part two: Political Approval Game}

\section{$\underline{\text { Introduction }}$}

This session develops materials designed to ask questions around political citizenship and political education. Starkey $(2017)^{7}$ explains differing approaches to the UK political education and the messages of citizenship they promote since 1997, first under New Labour and now under the Conservative Party. Tony Blair's Labour government believed in a cosmopolitan form of citizenship. This is defined by Painter and Jeffrey (2009) as citizenship that extends beyond the sole focus of the nation state. New Labour introduced Fundamental British Values (FBV) and intended them to promote tolerance and diversity by specifically mentioning concepts such as;

"concern for the common good, for human rights and the environment, belief in human dignity and equality, respect for the rule of law and determination to act justly" (Starkey 2017;151)

According to Starkey (2017) this was reflected in their citizenship education, which, whilst focused on active citizenship and voluntary service, had an international flavour and promoted multi-culturalism. The Conservative government elected in 2010 simplified FBV to mean respect for the rule of law, democracy and tolerance. Green (2013) marks out that they did this in a way that changed citizenship education from a cosmopolitan outlook to once again promoting ideas and commitment of citizens to the nation state. This appears to have been done in two ways. Firstly, as explained by Stanley \& Guru (2015), opposition of FBV can be seen through anti-terror legislation as extremist behaviour and promoting views against FBV can be seen as radicalisation. This firmly associates FBV and definitions of citizenship with issues of security of the nation state. The second way can be seen in what Bauman (1991) called the Focus Imaginarius, which is the yearning or fantasy for perfection or a nostalgic remembrance for how things once were. Moncrieffe \& Moncrieffe (2017) give an example of this, describing how some citizenship educational resources use imagery such as red phone boxes and afternoon tea, both quite uncommon in the modern day UK. This nostalgic regurgitation of symbols of the country's past, stereotypes of our national identity,

\footnotetext{
${ }^{7}$ This is Dr Hugh Starkey, Professor of Citizenship and Human Rights Education, UCL Institute of Education, London and not the controversial British historian David Starkey.
} 
are far more Swallows and Amazons than The Road to Wigan Pier ${ }^{8}$. Combined they promote a one nation form of citizenship that Starkey (2017) sums up as "security focused and narrowly nationalistic" (Starkey, 2017; 149). I was interested in whether the participants had a preference or view on national versus cosmopolitan citizenship, understanding that they may have neither or a combination of these two and many others.

One way to uncover young people's leaning concerning the cosmopolitan versus the national would be to explore their attitudes towards foreign aid. Fisher (2015) writing in The Times explains that many MPs across all parties and figures outside of parliament like Nigel Farage have voiced an opinion on this subject. She specifically mentions an incident involving Labour's Simon Danczuk MP who compared the severity of flooding in the UK with that of Bangladesh. He came in for heavy criticism from his party leadership for presenting it as a binary choice and that it is entirely possible to fund flood relief here and abroad. The concept of prioritising our services over humanitarian assistance is a good example of the national trumping the cosmopolitan.

One thing I was also keen on knowing was what the young people participating thought about the possibilities of privatising the NHS and specifically if young people would choose to privatise it and end state funded universal cover. In a pro social citizenship model or one that guarantees Marshall's (1950) view on a civilised standard of living, universal health care would seem a natural part of it. A national health system could be seen by promotors of a US style civic society as the interference of the state in its citizens' lives, undermining resilience and affecting market forces. It is an old debate. Maynard and Williams (1984) discuss it in their article exploring privatisation and the welfare state. They succinctly describe it as a philosophical battle between those who see health care as a reward and those who see it as a right. Citizens who work should be allowed to use their wealth to gain healthcare. The counter argument to this is that citizens should be allowed health care independent of income and wealth.

\footnotetext{
${ }^{8}$ Swallows and Amazons by Arthur Ransome is about the joyful outdoor adventures of two families of children in the Lake District in 1929. The Road to Wigan Pier is an early work of non fiction by George Orwell published in 1937, in it Orwell recounts his experiences of living with the working class of Lancashire and Yorkshire and experiencing first hand the bleak conditions and grinding poverty.
} 


\section{Planning and preparation}

In chapter three I mention how feedback from the pilot project focused on the lack of interactivity. During this I had delivered two lecture based sessions and the participants made it clear that they wanted to do something fun the following week. I thought a week was more than enough time and was confident I could design a suitable game in the timeframe. Three days and several failed attempts at game designing later I was beginning to consider that this confidence may have been misplaced. Then I watched episode 7 from season 4 of the US comedy show 'Parks and Recreation' titled 'The Treaty'. In this episode two of the principal characters act out a relationship argument through participation in their local High School's Model United Nations. I was inspired to use the concept behind a Model UN as the basis for a new board game.

Levy (2016) explains that Model UNs are civic education programmes that began in the 1940s where students are assigned countries to represent and debate issues and events based upon real life scenarios. Participants are political players rather than observers or commentators and learn about elements of governance including procedures such as tabling motions and voting as well as gaining an insight into the complexity of decision making. Model UNs have proven to be effective: "research indicates that when young people are involved in interactive political experiences, such as political simulations and discussions, they are more likely to become politically engaged." (Levy, 2016:14). I decided to borrow the idea of introducing complexity of decision making through political simulation, anticipating that this would lead to a discussion about politics and politicians. In BNW they got to design a country, now I would be asking them to run a country. By using simulation I would be able to uncover participants' views on a variety of issues including cosmopolitan versus national without being seen to sway their views.

I decided that instead of being different countries, participants would be rival political parties campaigning to win an election. The first stage of the game would consist of them being given a fixed sum of money and choosing how to spend it across 10 different government departments. The ten departments I choose were:

- Health, education, welfare, pensions, defence, police, prisons, foreign aid, infrastructure and emergency fund. 
The reasons for choosing health have already been explained as has foreign aid. Prisons, police and defence were chosen because of their association with security. Welfare, education and pensions represent considerable blocks of UK government expenditure and the emergency fund was a device for the game playing. Once the political parties had set their budgets I would ask them to briefly explain their reasons. The amounts would then be compared against a figure which was a scaled of the approximate comparison with actual Government expenditure as reported by Milligan (2014). Each political party would gain one approval point for every department that received a minimum level of funding benchmarked against UK averages. The twist here was that to fund every department fully would require $£ 1200$ whereas the parties only had $£ 1000$, which is an example of the dilemma political parties' face in allocating finite resources to a multitude of competing demands. I then drew up three categories to make up squares on a board that the political parties would move around by throwing a die. The categories, examples and the reasons were:

- Events: This included events in other countries such as earthquakes, as well as internal issues such as winter flu epidemics, teacher's strikes and prison riots. On an event square, if the party had sufficiently funded the corresponding department e.g. the NHS in the flu epidemic, then they would receive an approval point for being able to deal with the situation, conversely if they did not meet the funding requirement they would lose a point. They could use funds from their emergency funds to minimise the loss of political approval points;

- Press: opinions or judgements on a party's performance. Opinions work in a similar fashion to the Events, e.g. Press reports you are weak on crime, a police underspend will cost a point. An example judgement is you are soft on welfare cheats lose 2 points. There is nothing that a party could do to mitigate this;

- Policy: the party would be read a policy that they could introduce. All policies would have a financial and approval point consequence, e.g. legalise cannabis 
would raise $£ 250$ but you would lose 2 approval points. This square would also explore the issues around NHS privatisation.

The game would end on a general election decided upon a combination of who had the most approval points and funds.

\section{Delivery and engagement}

\section{Butetown Youth Pavilion}

This game was played by 6 females split into two teams. The centre's manager observed some of the game and was impressed by how the participants engaged and worked together. It turned out that most of the participants only knew each other by sight. The participants remarked that the game allowed them to express what they really thought.

\subsubsection{Graph showing BYP Team A budget allocation}

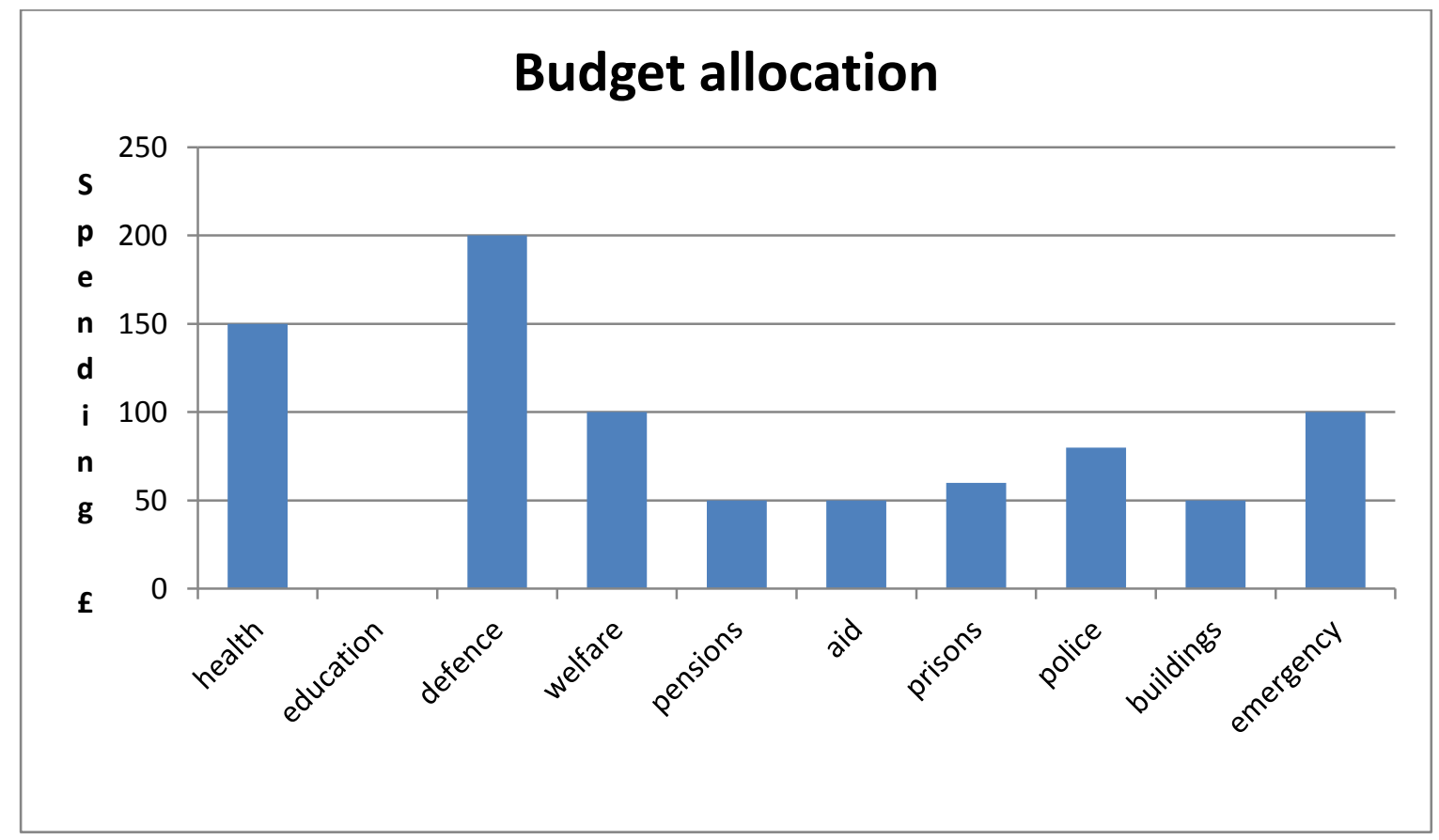

The glaringly obvious in this spending plan is that education receives no funding- naturally I was curious to find out:

Me: you haven't spent anything on education, why is that?

YP: Because no-one needs it. 
Me: Okay, but you've spent a lot of money on health, how do people become Doctors without education?

YP: they get education...I don't know

The unspoken words here were 'stop asking me questions and leave me alone', which is what I did.

\subsubsection{Graph showing BYP Team B Budget Allocation}

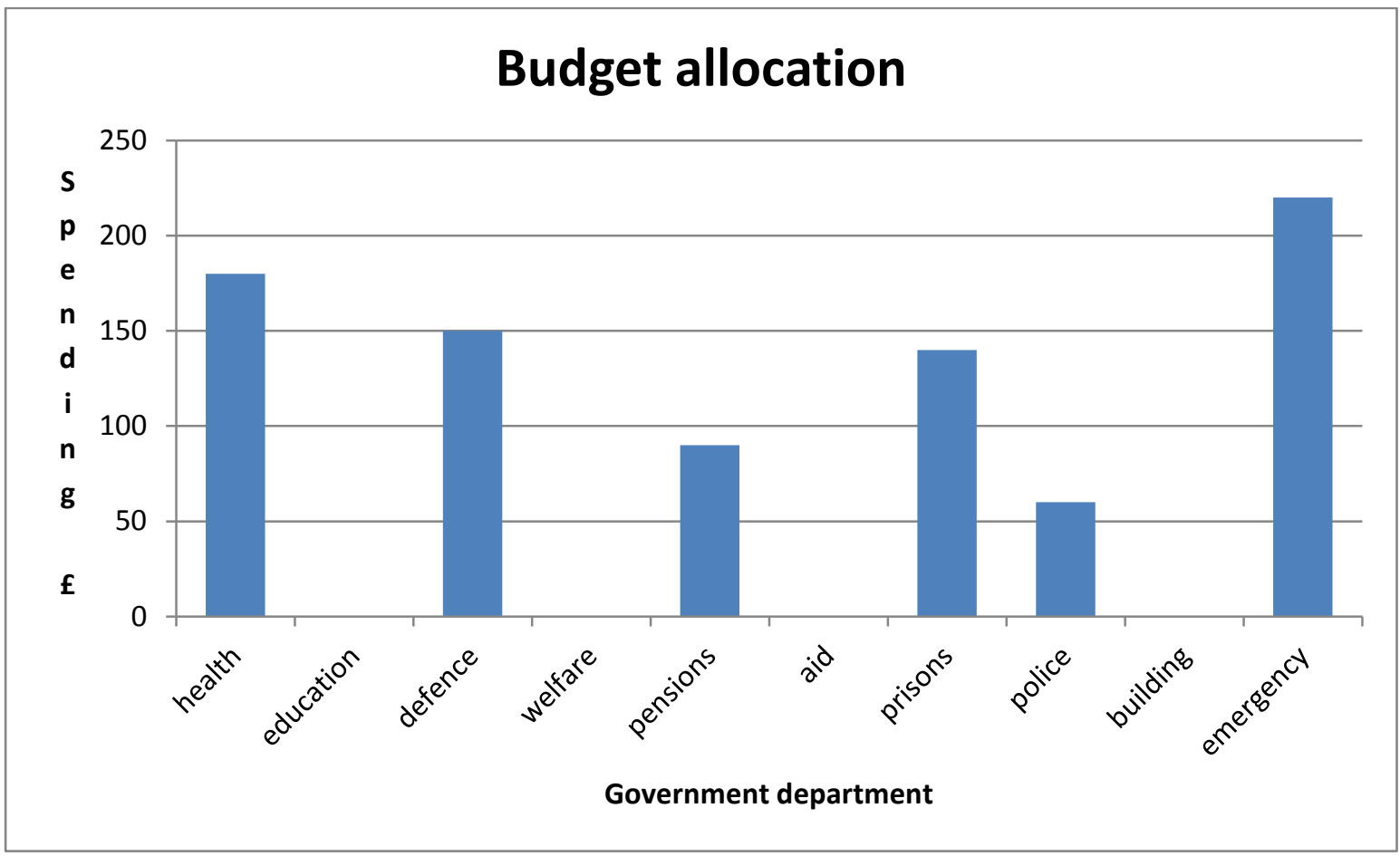

This team only funded six out of ten departments. Like team A they were not fussed over education for similar reasons. I asked them if their lack of welfare spending was a reflection of a belief that people should take responsibility for themselves. Their response was: "we didn't have enough money". They did not believe in sending money to other countries. I did suggest that they could spread the money out some more but they refused. I think this was partly due to their convictions and partly because they wanted the game to move on.

The game was played with passion and enthusiasm and at break neck speed. Spectators and players alike enjoyed the excitement of the events squares. It came down to a double tie breaker and the game was eventually won by Team A, although Team B contested the fairness and validity of the result. There was a distinct split in the approaches to decision 
making. Team A based their decisions on winning. They were against privatising the NHS but only because they would have lost nearly all their approval points. Had they had points to spare they would have done it without hesitation for the money. Team A strongly considered legalising cannabis, identifying how the money could be used to build hospitals, but decided against it to not lose approval points. Team B made their decisions based on 'the best thing to do' and 'what's right for the country'. They refused to consider privatising the NHS or raising University tuition fees, despite not believing in education, because they believed these services should be free.

We discussed the nature of politicians and their views about them. This began when Team A asked me if they could use money to pay people to vote for them, because they believed this went on. They also believed that politicians lie:

"they say they'll give you free gas and electric if you vote for them, then when they get in they don't do it", "(they) meet people in dark alley ways and give them 150 ", "they do secret things without people knowing", "you can't trust them"

I followed up by asking them what they think should happen to politicians who lie:

"Locked up", "killed", "taken to court and the judge can decide", "politicians should go to jail if they lie"

\section{Grangetown Pavilion}

This game was played by twelve males split into two teams. I would like to have done three but I did not have enough money or boards. 


\subsubsection{Graph showing GYP Team A budget allocation}

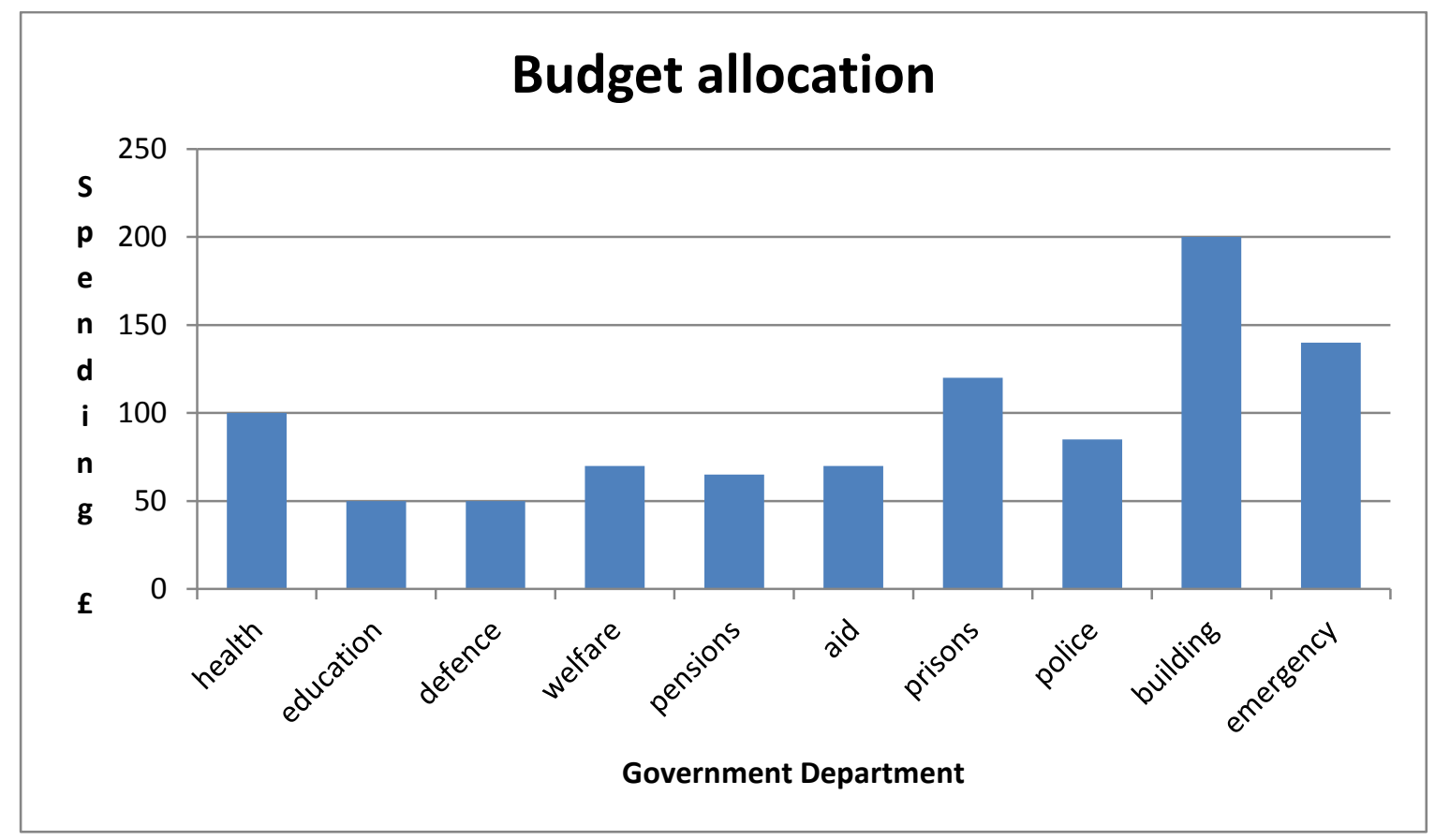

As can be seen this team prioritised infrastructure. This was because 'clearly you need a lot of building and roads'. They spent the least on defence and education. They did not think either was worth spending a lot of money in, particularly education. They made a conscious effort to spend money in all areas.

\subsubsection{Graph showing Team B budget allocation}

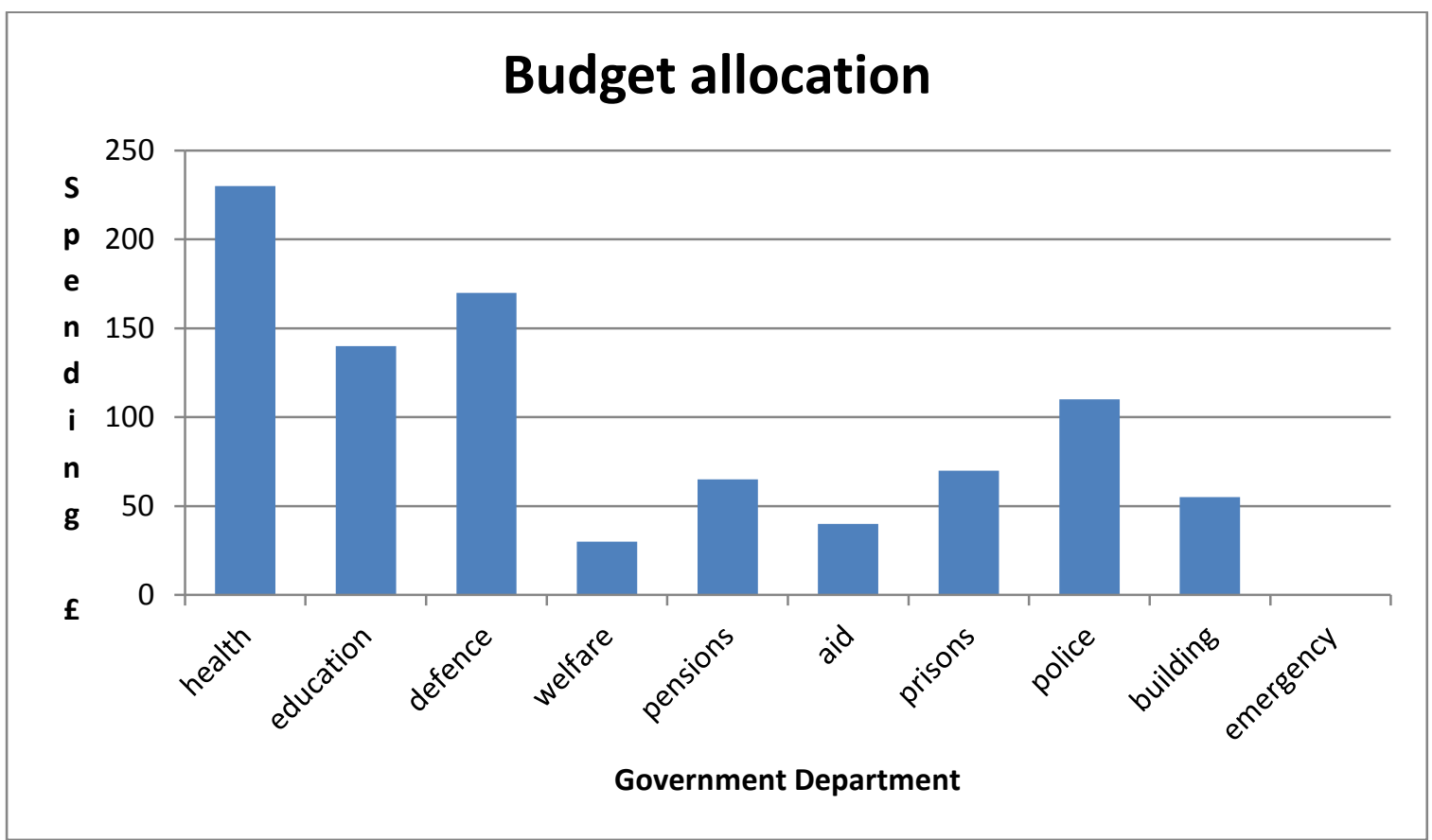


This team prioritised health care spending. This was behind their reasoning for putting the third highest amount of money into education. The logic being; "if you're going to have Doctors it all starts with education". I was impressed with this holistic, joined up thinking. The other rationale for team B's high spending on health was that "if there is no health there is no point of having all the rest".

The game was played with enormous energy and excitement. It made trying to audio record the game playing a fruitless task. They insisted on two laps of the board and would have gone for a third if I had not put a stop to it. This was because it was two hours later, and once again, I had run out of questions. The best testimony and compliment I can pay how this game engaged the young people comes from an entry in my research journal;

It was the hottest day of the year, the group of 12 plus boys were 10 metres away from a $3 G$ astro turf pitch and half way through the game a friend came running in to tell everyone 'that loads of hot college girls are here'. They told him to be quiet and remained to play the game, he joined in. Now, perhaps they were shy, but in my experience the opportunity to show off flicks and tricks on the football pitch to a group of girls pretending not to watch is not normally ignored to play an educational board game. It's been one of my favourite sessions of the whole project.

There were several younger children watching, who could not play due to the ethical age restrictions. I involved them in the game by making them honorary treasurers who distributed the approval points and funds from the World Bank. I did this so as not to be exclusionary in an inclusionary space and the help was much appreciated. Afterwards I asked them if they would have liked to play the game to which they said they would.

After the conclusion of the game which saw Team A narrowly win I asked them about some of their decisions. Team A had privatised the NHS but when I asked if they thought people should have to pay for healthcare they were against the idea. They explained that they had privatised the health system for the sake of the game; to gain more approval points and gain more money. Team B greeted this view with a degree of outrage;

"He's (me) talking about real life!" and "only rich people can afford to pay for health care" 
Team B had refused to privatise the NHS because;

"Even though we're playing the game, we have to relate it to real life situations" and "it's not about winning at the end of the day"

Team A did not share this view and their decisions were motivated by points and money. This led to accusations of only caring about the game and retorts such as;

"We made smart decisions" and "we're still on top"

Voices and temperatures were beginning to rise and so I shifted the topic of conversation to diffuse the situation. Firstly I asked them what they thought of the game; responses included;

"It was good", "it was educational", "it was interesting", "I got to see other people's points of view in a topic or situation", "it may help me see how politician's think in real life", "it was a good game and gave me more knowledge about what's going on".

We finished by discussing their views on politics and politicians on which they did not have anything good to say:

On Politics: "corruption" "it doesn't matter, it's all fixed", "it's a gamble", "it's like roulette"

On Politicians: "politicians are corrupt", "I don't know how Teresa May became President", "if you're in power you don't want to lose it", "politicians do what is best for themselves, before they think of anyone else they put themselves first"

Finally I asked them if they would have more faith in politics if there were more people from ethnic minority backgrounds. They had a mixed response to this and one participant had strong feelings on the issue

"No! I want to see some young people, doesn't matter what colour, if we saw them we'd know we were being listened to". 


\section{Monkton Priory}

The organisation of the two teams occurred in a very different way from at the other two venues. In both Butetown and Grangetown the young people organised themselves. At the Priory I was worried that if the young people split themselves through friendships the teams would be very unbalanced, in terms of ability and participation levels. I chose two of the senior students, whom I have known for several years, to be the captains and select their teams. How they selected the teams justified that faith as they chose in 'reverse' order, starting with the students who were seen or perceived by the class as the 'weakest'. This meant that everyone felt included and that really helped the participation. They also allocated themselves the names Team May and Team Trump, after the UK prime minister and USA President.

\subsubsection{Graph showing Team A (May) Budget allocation}

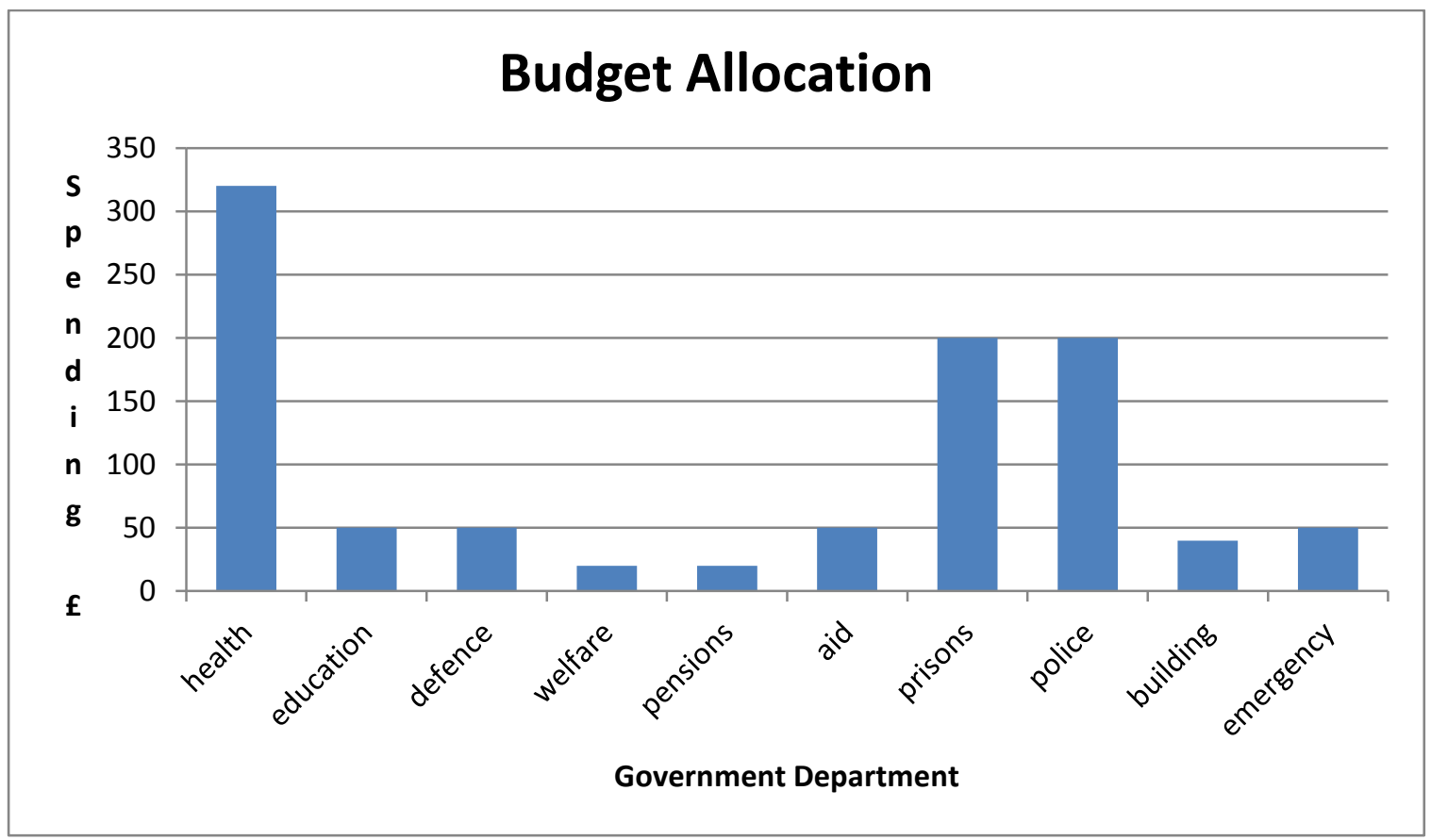

Team May considered it important that every department was allocated funding. Although they ranked education as a high priority they thought that "sometimes it does not teach you what you need to know". They saw the Police as being "important to catch the bad people" and that prison prevents people behaving like "maniacs" and "running around like retards". I did point out that this was an offensive term. They thought people should be working and not relying on welfare and that "old people do not need money" and could "go in a home or 
on the dole". I did point out that with such a small welfare budget they may struggle to home or pay benefits to the elderly, but they shrugged this off.

\subsubsection{Graph showing Team Trump (B) budget allocation}

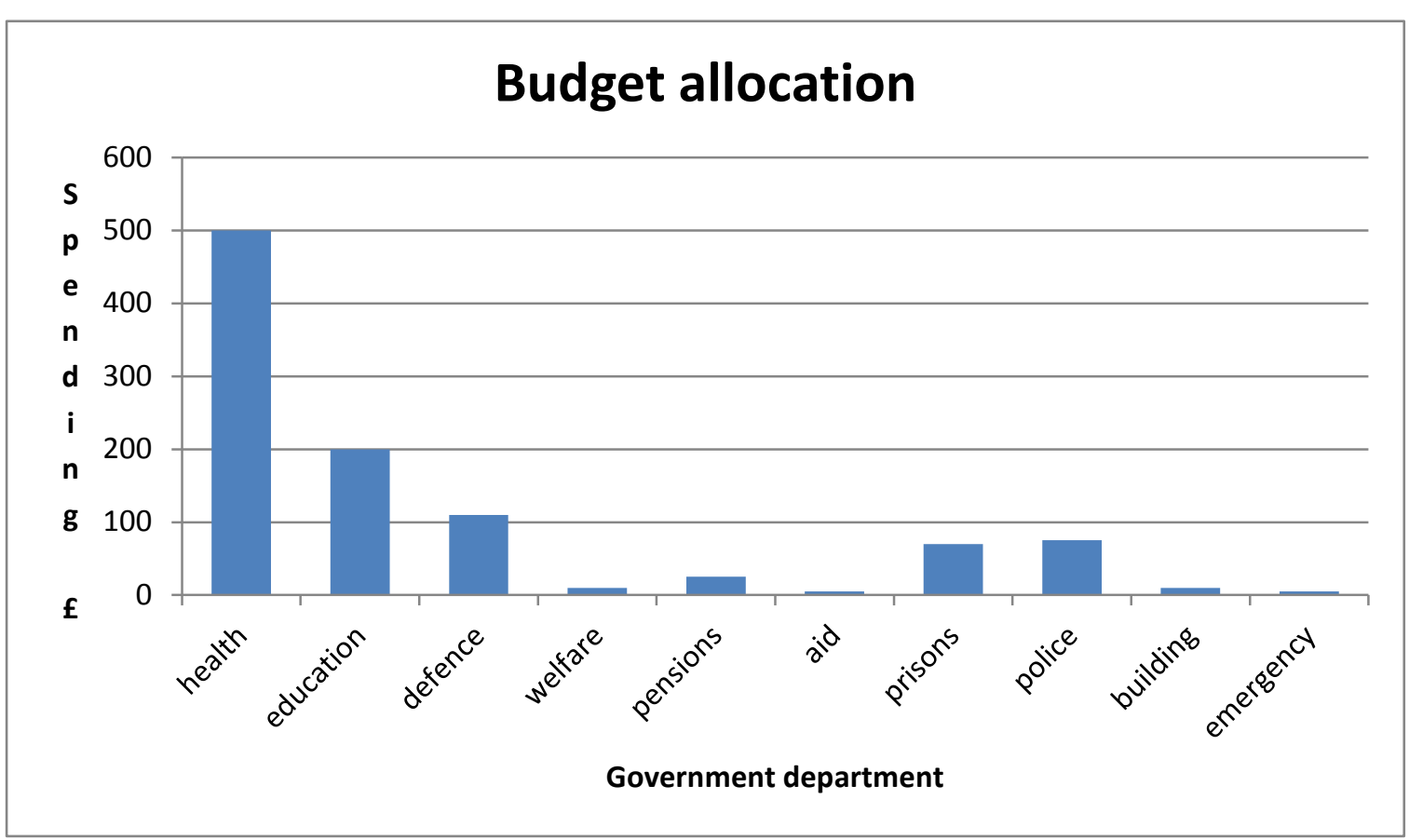

Health was again the priority because; "it's your life, it's the most important thing".

Education was important as it aided people in gaining employment and living their lives. This was directly linked to their views on welfare, which they linked to laziness and that people should "get off their bum and get a job". Accordingly pensions would be a waste of money as the elderly "should save up when they're young and put some (money) away, not rely on the government". They saw the Police as important and their main role to imprison criminals in jails, whose raison d'etre was explained by the slogan "Keeping the bad in and the good safe".

Reacting to how long the game had been played for in the first two venues I had arranged for extended time. The tactics and reasoning of the two teams once again split between Team May doing what they thought was best and Team Trump focused on winning. Team May had the opportunity to introduce charges for GP appointments but refused;

"If people stop going to the Drs, then we will stop getting any money, people will stay home when they're ill or they'll all be dead, some people ain't rich enough to pay for $i t^{\prime \prime}$ 
When Team Trump were given the option of privatising the NHS they did so without any hesitation:

"All day long, it's all about the points"

When Team May had the same chance they declined:

"We don't want to privatise the hospital because people might want it"

The decision of Team Trump was criticised by Team May on several fronts. First was the humane angle:

Team May: that's not nice

Team Trump: But we'll win

Second was the personal appeal:

Team May: then if you'll get ill, you'll have to pay.

Team Trump: that's all right, I'm a multi-millionaire.

Third and finally was the political sustainability:

Team May: you may win the next election, but no-one will have health care.

Team Trump: Don't care

Team May: But the next time you'll lose

Team Trump: Maybe, but I'll have another 4 years in office

Team May said that throughout the game they were trying to do what was best. Both teams thought that politicians made their decisions to win and not to do what was best for the people. Team Trump had consciously adopted this approach and Team May rejected it. Rather ironically team Trump actually lost the game and had they not privatised the NHS they would have won. This was different from previous games showing that the result was not dependent on any one decision. They did not take this well and said my behaviour was cringe worthy, accused me of being a poor man's Dermot O'Leary and banned me from the White House. Team May's gloating did not help matters and heated bickering and 
recriminations followed. In the end I had to raise my voice and take the unusual step of telling them off before sending them for an early lunch.

\section{Discussion and reflection}

To begin this section I will look at the comparative spending in each project.

\subsubsection{Graph showing BYP comparative spending}

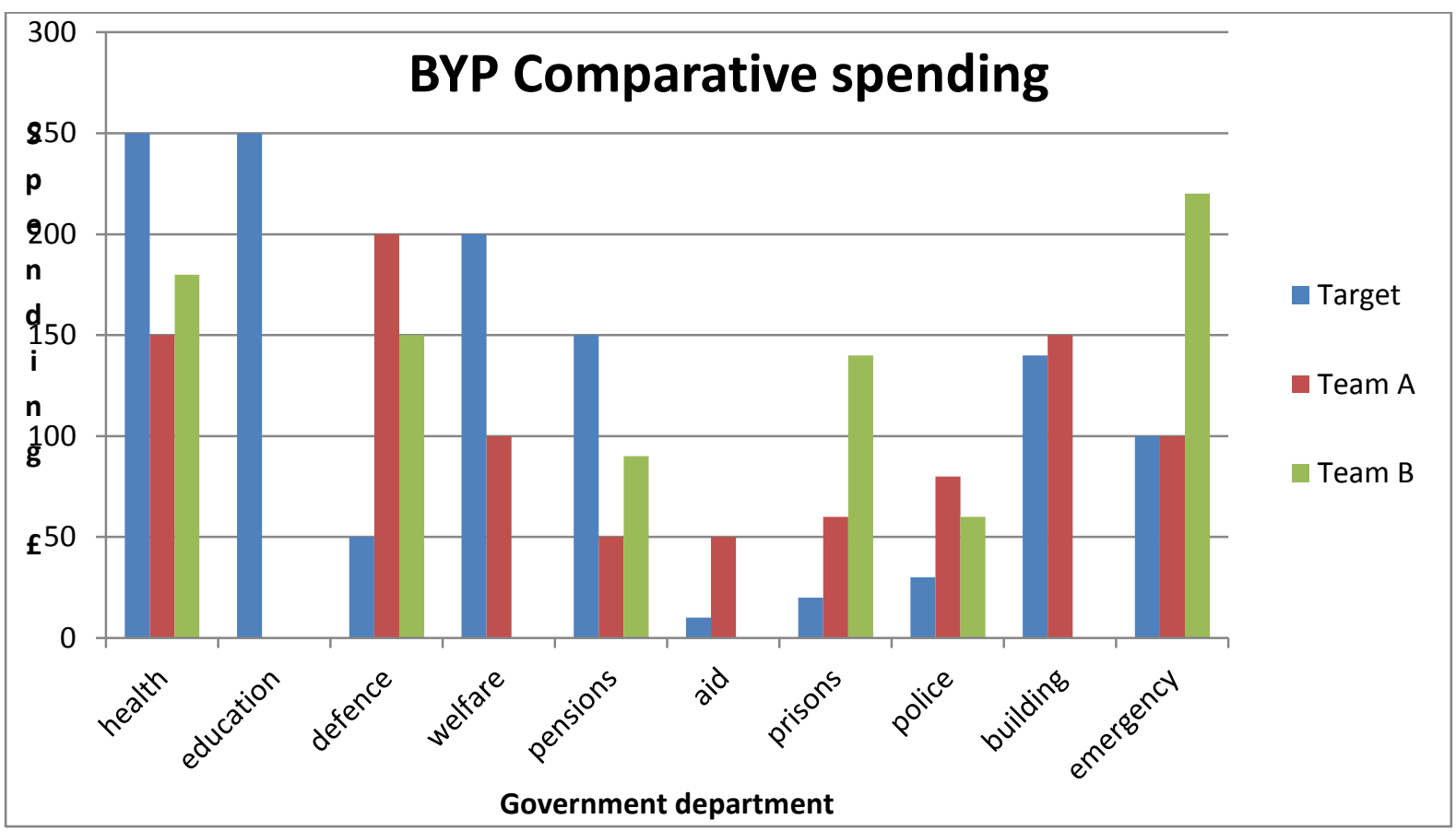

In BYP Team A prioritised defence, health, infrastructure, welfare and emergency. Team B prioritised health, defence, prisons and emergency. Heavy spending on defence could be seen as an indication of a nation first view, particularly as neither team was keen on foreign aid spending. Team A, who did have an aid budget were surprised by how much they had overspent. Both teams were surprised by how little of the government's budget was spent on foreign aid. The views on education immediately exposed the participants to the complexity and interconnectness of services, after all without education how do you get health professionals? 


\subsubsection{Graph showing GYP comparative spending.}

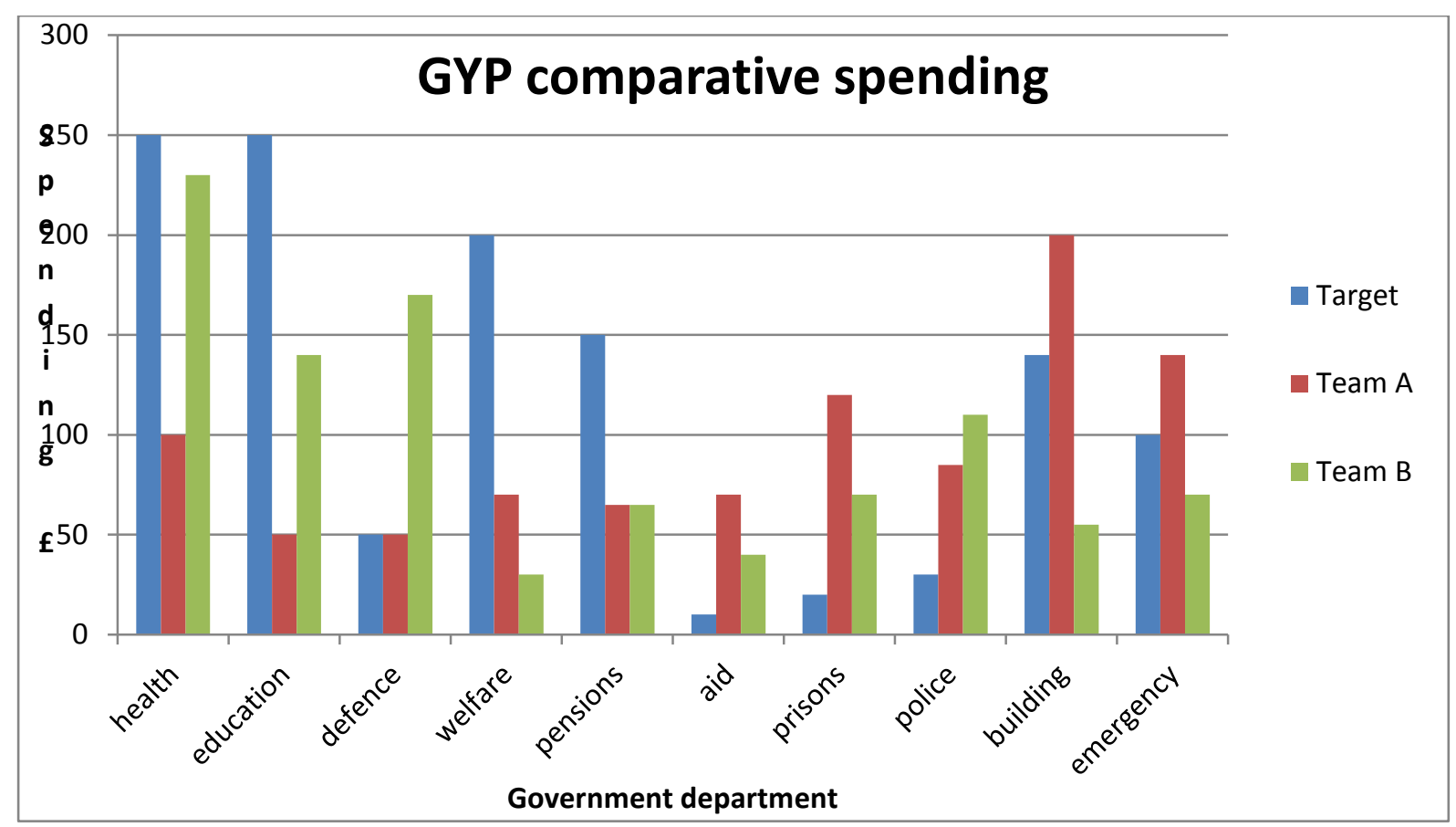

GYP Team A prioritised infrastructure, emergency, prisons and health and they deliberately chose defence and education as the least important. Team B prioritised health, defence, education and the Police. Both teams showed a degree of joined up thinking: Team A in understanding the importance of being able to connect places and Team B in recognising education is part of a good health service. Neither team considered defence as a priority, despite Team B's high spending on it. 


\subsubsection{Graph showing Priory comparative spending.}

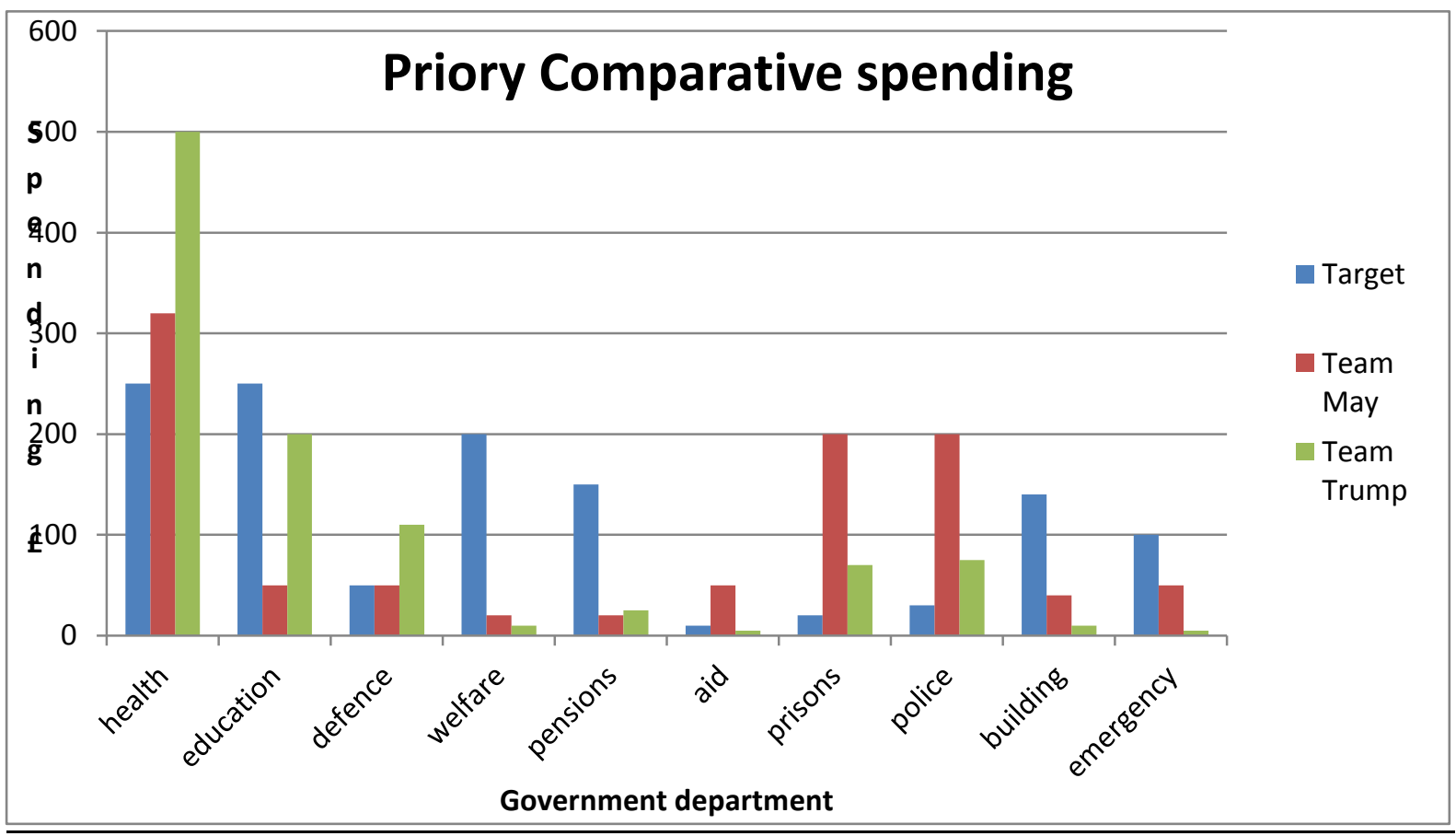

Team May prioritised health, prisons and the police. They gave the same amount of money to foreign aid as to defence and while they considered the latter important it was not a priority. Team Trump considered defence of great importance, along with education and health. They thought it was important that "we protect our country and Her Majesty the Queen". Neither team were big on infrastructure in general and roads in particular;

May: We don't need roads, have you ever heard of grass.

Me: What about transporting foods?

May: Use handbags or move closer to the shop, get a landrover or quad or a motorbike

Trump: We're all going to live in tree houses, so we don't need houses

Me: How are you going to get to work?

Trump: walk, quad with a trailer, zip wire, get a closer job, get a donkey

Both teams in the Priory were very anti foreign aid: 
May on aid "we shouldn't be helping other countries; they're not helping us are they!".

Trump on aid "they should stand on their own two feet".

What was significant about this game was that this view on foreign aid was shared by the participants in BYP but not GYP, who were in favour of foreign aid and thought the government should spend more on it. This showed views on citizenship in BYP and the Priory as leaning towards a national view, which reflects the debates of neo communitarian citizenship education. In several cases they cite the importance of looking after your own people before others. This very much reflects how Nussbaum (2012) defines the one nation approach to citizenship by promoting a view that your nation is of more importance than any other. Gates \& Gates (2016) challenge the myth of how much is spent on foreign aid and how it is spent by challenging the notion that it is expensive to the donor. They say that the World Bank recommends a country spend $0.7 \%$ of their GDP on foreign aid. Yet for a country such as the UK this small fraction still means billions of pounds, which is a lot of money. Some of the participant views, such as the Priory believing nearly half of the government's spending was on foreign aid, reflect the rhetoric used by certain politicians. It has also been weaponised by various politicians to promote a Britain first rhetoric. One of whom is Esther McVey, who on the $20^{\text {th }}$ May 2019 as part of her campaign to become Leader of the Conservative Party, is reported in the Independent Newspaper calling for foreign aid to be redirected into policing and schools. This can be seen as an attempt to win back members of the electorate who may have lost confidence in the current government's policies and would be met with approval by a number of participants. Dench, Gavron \& Young (2006) discuss how citizens may be inclined to show support for groups who indicate a one nation approach as opposed to mainstream political parties that may take a more cosmopolitan approach. This is done as a way of "registering their loss of faith in mainstream political currents" (Dench, Gavron \& Young: 2006:159). Some of the perceptions around foreign aid shows once again that many of the participants have both limited understanding of and faith in government. This game showed that it is possible to develop materials to challenge pre-conceptions and misinformation. 
In regard to young people and politics Pattie, Seyd \& Whiteley (2014) studied democratic values and participation in young people. The young people involved in their study shared their views on politicians:

"They all say they're going to do something then once they get voted in they do the opposite"

"I feel that they are just people spouting false promises"

"They promise so much but give so little. They use their power to manipulate the situation"

“... In politics, NO, there's no one I admire. I think they all lie and deceive, and never fulfil their promises. Take Nick Clegg ${ }^{9}$ for example. You're not safe to trust anybody in politics"

"They can say what they want to get into power. Once they have the office it's a totally different ball game unfortunately."

"... It feels like they'll say anything to get you to vote for them."

"They say they listen to the public but really they don't"

"They don't listen, they want votes and power and no responsibility"

The young people involved in my study in GYP and BYP had similar negative views, expectations and sentiments. Pattie, Seyd and Whitely (2014) and Henn \& Foard (2014) are both of the mind that there exists a democratic deficit in young people although they disagree as to why. Henn \& Foard (2014) believe it is due to a low level of political knowledge. Henn \& Foard (2014) give examples of how young people become involved in politics by other means and cite examples of the tuition fee protest, the Occupy movement and even the 2011 London riots. Pattie, Seyd and Whiteley (2014) refer to the lazy and common assumption that young people are apathetic about politics. Whilst these findings contribute to these debates I would argue they also advance them as the energy levels and

\footnotetext{
${ }^{9}$ Nick Clegg was the leader of the Liberal Democrat Party in 2010 when they formed a coalition government with the Conservatives and he became Deputy Prime Minister. He is remembered for reneging on his promise to not increase university tuition fees.
} 
passion which the participants showed in engagement demonstrates that they are interested. Certainly many of my participants showed a lack of understanding about the symbiotic relationship between government departments e.g. the Priory not seeing the importance of roads and BYP not funding education. Several of them also referred to Teresa May as the President not Prime Minister. I would wager that the majority of them do not understand the difference and its significance, or how a parliamentary democracy works. A lack of knowledge does not mean a lack of interest though. The extent of how much the participants enjoyed and participated in this game ran deep and can be added as further evidence that young people care about issues that affect their lives. What they appear to have across all the projects is a distrust of politicians and whilst this may be accompanied by a lack of understanding of the political process I doubt that filling this gap in knowledge would change their views on politicians. I would agree with the suggestion of Henn et Al (2005) that young people are only disillusioned with the agents of politics and democracy, rather than the existence of them. I would add that coupled with a lack of knowledge it creates a space for a democratic deficit to exist.

The cause of this lack of understanding of political systems and complexity could be linked to the views of Cramer (2016) who believes that within our education system there is an increasing fixation on qualifications. This is because the production of citizens is being driven by preparing people to work rather than to participate in democracy. The participants displayed low confidence in our education system, not prioritising it as a service. It would be easy to dismiss this as stroppy teenagers resenting having to go to school. Yet this ignores the fact that a majority of them saw the importance of education, just were not impressed with the existing system. The fixation on producing workers is further evidenced by Murphy's (2017) exploration of the National Citizenship Service. This flagship government programme was evaluated as giving very little credence to political and rights based citizenship and that the aims, measures and motivations were fixated on improving education or employment opportunities. Murphy (2017) called this a neocommunitarian approach that judges citizenship on not just measurable targets such as employment but also individual responsibility and self-responsibility. There are not over whelming signs that this is reflected and supported by the young people participating in my 
project. They may lean towards a UK first view but one more pro social than neocommunitarian or civic.

This activity further contributes to debates around young people having a preference for cosmopolitan citizenship. Kaldor (2003) suggests that young people are more naturally inclined towards a cosmopolitan style of citizenship. This is shared by Starkey (2017) who discusses how there exist many agendas aimed at a global audience of young people and centred on young people's rights. Two examples given by Starkey (2017) include UNICEF'S UK Rights Respecting School programme and the United Nation's Convention of the Rights of the Child (UNCRC). Yet I would say there is nothing in my findings that would lead me to conclude that these young people favour it over other forms of citizenship. If anything a heavy focus on defence, police, prisons and even health demonstrate a lean towards safety and self-preservation. Attitudes towards the health system also reflected this in the discussions of budgets. Whilst it was privatised during the game on three occasions it was done for strategy and not ideology. A lot of the participants did think that it should only be free for British citizens.

What contributes to this leaning towards a one nation citizenship of safety and selfpreservation could be down to several factors. There are two I would like to discuss here, one from the research and one from the supporting literature. A lack of understanding of political systems and realities will contribute to these attitudes of safety and selfpreservation. In all the projects teams thought actual UK spending on foreign aid was higher than it is. This degree of misunderstanding could lead to further acts of protest as listed by Henn \& Foard (2015). This could be classified as a form of insurgent citizenship, defined by Painter \& Jeffrey as citizenship that "functions in forcible opposition to lawful authority and seeks to disrupt the operation of the state" (Painter \& Jeffrey 200:84). Whilst these participants are not there yet, their lack of faith in politicians and the political system could be the first rung on a ladder especially against the backdrop of global issues such as the environment and Covid -19 .

A main take away from this session compliments Nussbaum's (1999) arguments that a government has a moral imperative to function as a system and provide services that meet the needs of its citizens. I would argue that my participants show great appetite and need 
for political citizenship education and I would question if they are receiving education of sufficient scope and depth to satisfy this. They also demonstrate the traits of a range of citizenship behaviour and therefore any attempt to categorise these participants as a certain type of citizen would be repeating the mistakes of past and current government. Particularly as this categorisation may in fact be attempts at indoctrination and motivated by political ideologies and agendas.

What I have learnt in past practice is that teaching politics in school may leave the practitioners open to accusations of bias or politically influencing their students. This can impact the validity of curriculum materials around political citizenships education. I had to make sure the game was about the young people, regardless of the choices they made or the consequences of their decisions. I did not pass any judgement or give an indication of my preference. An example of this was the privatisation of the NHS, which I am against. My preference for free universal health care makes any question I ask young people about healthcare open to reasonable accusations of bias or an attempt to sway young people to a particular political view. I believe that in all three venues I maintained my neutrality and am quick to point out that leading this activity did not leave much room for my own opinion. This neutrality gives the game strength as an educational tool and was effective in engaging young people. The game was not rigged for an outcome, there was no set formula to win an election meaning the activity allowed the participants to explore issues and express opinions independently.

What is clear to me from this activity is that political education should not be tipped into a box and then closed. Staeheli \& Hammett (2010) suggest that governments will use citizenship education to maintain a community that they can govern, one in which nation takes precedence over everything. If misinformation around foreign aid contributes to an atmosphere of fear which leads to more votes for a political party, why would you change this? Perhaps the answer lies with universities. Cramer (2016) postulated the Wisconsin Idea, in which a university extends its academic space to its state boundaries "... in order that the work we do should serve people well beyond our campus" (Cramer, 2016; 444).

The final thoughts of this game look at the value of the game as a curriculum material in the way it was played. There was always an argument at the end of the game and sore losers. 
This could be interpreted as more stroppy teenage behaviour and I initially regarded it as such myself. Upon reflection and review of the results I realised that is a very lazy assumption, partly because the behaviour of sore losing and stroppiness is by no means the sole property of young people. Also, the participants cared. What is interesting is where their views came from. If young people have been receiving inadequate political citizenship education, then learning from MacAllister's (2001) work about the social influence in his theory of the neighbourhood effect, where social interaction within residential communities and the class of these communities can affect voting behaviour and political attitude, it could mean they are learning from people who also haven't received political citizenship education.

Finally, I am absolutely fascinated that in all four of the venues, including the pilot, one team played to win and the other team did what they thought was best for the country. It is therefore probably not an accident that the team playing to win, was indeed successful three times out of four. I am not sure how this split occurred every time and did not notice it until afterwards. One speculative hypothesis is that a team saw their opponents doing the 'right thing' and saw it as an opportunity to win. Another might be that they copied how they believed politicians behave and perhaps those motivated by doing the right thing took a deliberately opposite stance. Or, maybe, they are just competitive. What stands out in my mind from this activity is the comment from the winners in the Pilot Project about how they started by wanting to do the right thing but in the end just wanted to win. I wonder if this is true of a great many politicians over the years.

In the next chapter I look at the fragility of citizenship and how it can be given and taken away in 'Should they stay or should they go'. Then I explore the participant's views on liberty and security in a framework of a securitised nation state. 
Chapter six:

Part one: Should they stay or should they go?

Part two: Liberty versus security. 


\section{Chapter six, part one: Should they stay or should they go?}

\section{Introduction}

Early on in my studies I read a fascinating article by Caroline Sawyer (2006), titled "Not every child matters; the UK's expulsion of British citizens". In this article Sawyer explores interpretations of the jus soli and jus sanguinis rules by examining real life legal cases which resulted in people remaining in the UK or being deported. She also explores how the denial of citizenship can affect family life. I decided to use the article as a template to explore young people's views on jus soli, jus sanguinis, the right to family life and how citizenship may be gained in general. As my work progressed, topical issues around the granting and rescinding of citizenship came to my attention, namely the treatment of the Windrush generation and the hostile environment. Reynolds (2018) explains that the hostile environment was designed to deter people from coming to the UK, especially refugees but this was extended to anyone assumed to be 'foreign', including people of African-Caribbean descent. This resulted in the following situation:

"People who had spent most of their life in the UK were declared illegal immigrants, threatened with deportation, denied access to NHS treatment, benefits and pensions and lost their jobs" Reynolds (2018; 72)

The case of Windrush is connected to the history of British citizenship as it concerns people who arrived in the UK as British subjects under the empire, only to have their citizenship questioned some seventy years later. Windrush reinforces Karanti and Gill's (2002) view that "To understand British citizenship today requires not just a knowledge of the law, but a sense of history and feel for the facts" (Karanti \& Gill, 2002:8). As mentioned above and in the literature review, key aspects connected with citizenship are the concepts of jus soli and jus sanguinis. Jus soli is the rule of soil, meaning if you are born in a country you automatically become a citizen. Jus sanguinis is the rule of blood, meaning if one or both parents is a citizen of a state then you inherit that citizenship upon birth. The application of these rules in recent British history demonstrates ways in which a government can change or rescind citizenship status. Bhambra (2016) presents an early example of this in the transition of status for individuals who pre 1948 were considered UK subjects, and post 1948 understood as UK citizens. Karanti \& Gill (2002) explain a second occasion when the 
terms and conditions were changed through the British Nationality Act 1981 . This act reformed the jus soli rule by the addition of jus sanguinis. This meant being born in the UK no longer entitled a person to citizenship. To inherit citizenship a parent has to be a British citizen or settled in the UK and not be subject to restrictions on the length of their stay. The Windrush generation represents an example of when the burden of proof of citizenship was shifted up, with the government defence being that the people never were citizens.

There are writings within Children's Geographies suggesting that the process of gaining and retaining citizenship are changing in Britain. Williams, Cassor, Siggers et al (2016) report that up to $70 \%$ of unaccompanied child refugees in the UK will have their right to remain rescinded when they become adults and face detention or pre-departure holding similar to incarceration. Macklin (2018) explores how banishment has once again become part of a government's armoury, especially in relation to citizenship and safety and focusing on counter terrorism. Denationalisation as it is now known is not uncommon in countries such as the UK, USA, Canada, Austria, Australia and the Netherlands, and involves the involuntary loss of citizenship. Macklin (2018) goes on to explain that in the UK the Home Secretary has the power to strip citizenship for the public good or if someone does not meet the standard of good character.

Much like the Fundamental British Values discussed in the previous chapter, these are opaque definitions at best. The consequence of this is that legal citizenship is no longer secure:

"The defining feature of contemporary legal citizenship is that it is secure. Making legal citizenship contingent on performance demotes citizenship to another category of permanent residence. Citizenship revocation thus weakens citizenship itself" (Macklin, 2018: 163)

There are famous examples of young people such as Malala Yousafzai who was given honorary citizenship in Canada and has lived in the UK since leaving Pakistan. I know from conversations with young people that many have learned about her in school as a heroic figure. I was interested in exploring with participants how her representation and ordeal might impact her legal right to remain and opportunities in the UK. 
Drawing from these events and literatures, I decided that I would give the participants the choice to grant someone citizenship or deportation; or, in other words, 'Should they stay or should they go'. The focus would be on the three following areas:
1) Jus soli and Jus sanguinis
2) The right to family life
3) The granting and rescinding of citizenship

I felt it would be interesting to see the views of young people in these areas and whether I could design an activity that would enable critical thinking on the subject of citizenship status.

\section{Planning and Preparation}

I wanted to ask the young people directly about Malala and whether they thought her remaining in the UK past 18 and being free to pursue a university education was fair when many other young people faced such uncertainty. I also thought that looking at Malala through a different lens would encourage critical thinking. This gave me the idea that I should use other real-life cases in order to make it real to the participants. This would firmly bring the research into the real world, where it would remain for the next four sessions. I decided upon the following seven case studies for discussion. Several of the actual stated legal cases are from Sawyer's (2006) article.

\section{$\underline{\text { Jus Soli and Jus Sanguinis }}$}

Robin, a 27 year old female, born in Australia, her father is Australian and her mother is British. It is designed as a straight test of the rule of jus sanguinis only.

Yelena, a 25 year old female who was born in the UK to Russian parents, who are now facing deportation and the question is should their daughter be deported with them. This is a simple question of the jus soli rule and how important the participants regard this.

\section{The right to family life}

Pablo, a 35 year old male, born in Columbia, who moved to the UK in 2010 to be with his Welsh girlfriend, who he married in 2012 and with whom has since had two children. He is 
in the process of applying for British citizenship but has been rejected because of a criminal conviction for drunk driving. As a consequence he is facing deportation and his wife does not want to live in Columbia. This was influenced by the case of Jaramilla v UK (1995) where a father protested deportation because it violated his human right to a family life. More recently the UK Government has stripped members of the Rochdale Grooming gang of their citizenship and will deport them to Pakistan. The men also challenged this ruling on the basis that it violated their human right to family life an argument rejected by the Court of Appeal (McGann, 2018). This was followed by the following statement from the UK Home Office: "Citizenship is a privilege, not a right, and it is right that the Home Secretary can deprive an individual of their citizenship where it is believed it is conducive to the public good to do so" (Daily Telegraph, 2018). Pablo's offence was deliberately pitched as less serious. This was because I did not feel discussing child abuse and grooming gangs would be appropriate and I have met people who fear deportation for low level offences despite having a British family. By beginning with a relatively lesser offence there would be room for gradual escalation of the debate to include more serious offences, after having established a rational discourse.

Anastasia, a 45 year old female who was born in Ukraine and moved to the UK after marrying her English husband, after which they had two children. Anastasia and her husband are now divorcing and the father wants nothing to do with her or his children. Anastasia and her children are now facing deportation back to Ukraine. This is built upon the case of Sorabjee v UK (1995). This concerns a Kenyan mother who was deported and when a young child went to live with her mother in a different country despite having a British father. The mother argued that she should be allowed to remain in the UK through her child's citizenship. In this case had the father not abandoned the child, both them and the mother would have been allowed to remain. The young person's future is based upon the behaviour of adults and although the child did not lose her citizenship they did have to live in a different country.

\section{Granting and rescinding citizenship}

Christophine is a 64 year old female who was born in Jamaica and who arrived in the UK as a 16 year old in 1970. Since then she worked full time up until 2017 when she was 
diagnosed with a brain tumour. Due to never having got a passport she was told that she would have to pay for her medical treatment and was declared an illegal citizen and faces deportation to Jamaica, where she has not been since 1970. This was an amalgamation of numerous cases from The Guardian Newspapers reporting of the Windrush generation..

The penultimate case was is that of Malala Yousafzai, the young woman from Pakistan who was shot in the head by the Taliban. As mentioned previously the idea to include her came from the participants of the pilot project who had learnt about her in school. She has also became a significant figure in British cultural politics, as confirmed in the writings of Kharshid and Pitts (2019) who explore her positionality within the western media and Qazi and Shah (2017) who explore the reaction to her media image in both the west and her home country.

Imran is a 17 year old boy who was born in Afghanistan and came to the UK as a refugee in 2005. He was placed with foster parents, with whom he still lives and given the right to remain. Sawyer (2006) explains that in the case of deporting a young person their ability to integrate with their new country is considered. The younger the child the more likely they are to be able to integrate into their new life and language. It was this reasoning that prevented Jaramilla from deportation by claiming it would affect family life. As well as exploring the plight of child refugees with the right to remain, this case may also explore the issue of when does re-integration become an issue and should this be considered. This was inspired by my own experience in meeting a boy with this story as part of the youth exchanges I ran as a practitioner.

In the pilot project, I used these case studies within another session titled 'The Laws of Gods and men' The participants were not especially enthused by this activity as it involved a lot of listening so I gave some thought as to how to make it more interactive. I decided that I would let the participants chair the debate by taking turns in reading out the individual case studies. I would encourage them to play devil's advocate and draw out the opinions of others as well as offer their own. 


\section{Delivery and engagement}

\section{Butetown Youth Pavilion}

This session saw three young females participate. They were reluctant to read out loud and did not go into great depth during the discussions, which were short and to the point. At times they showed signs of boredom and disinterest. We did not discuss Anastasia because a man walked past the window on his mobile phone and bumped into a tree causing much hilarity and wrapping things up for that particular day.

\subsubsection{Table of BYP decisions and discussion.}

\begin{tabular}{|c|c|c|c|}
\hline Case & Consensus & Reasons & Conditions/variables \\
\hline Robyn & Citizenship & $\begin{array}{l}\text { Had done nothing } \\
\text { wrong }\end{array}$ & $\begin{array}{l}\text { Maintain good } \\
\text { behaviour }\end{array}$ \\
\hline Yelena & Citizenship & Born in the UK & Parents deported \\
\hline Anastasia & No discussion & & \\
\hline Pablo & Citizenship & $\begin{array}{l}\text { Keep the family } \\
\text { together }\end{array}$ & $\begin{array}{l}\text { If it had been a more } \\
\text { serious crime would } \\
\text { have considered } \\
\text { deportation }\end{array}$ \\
\hline Christophine & Citizenship & $\begin{array}{l}\text { Length of time she } \\
\text { had worked and paid } \\
\text { taxes }\end{array}$ & $\begin{array}{l}\text { Uncertain had she } \\
\text { not been a working } \\
\text { tax payer }\end{array}$ \\
\hline Imran & Citizenship & $\begin{array}{l}\text { Length of time he's } \\
\text { lived here combined } \\
\text { with differences } \\
\text { between UK and } \\
\text { Afghanistan }\end{array}$ & \\
\hline Malala & Citizenship & $\begin{array}{l}\text { The ordeal she had } \\
\text { undergone }\end{array}$ & \\
\hline
\end{tabular}


The one case that they were passionate and became quite emotional about was that of Malala. They spoke at length about what she had gone through and stood for, and saw it as their responsibility to educate me. This was because they had studied her extensively in school and related to Malala through similarities such as age, gender and religion. Imran was initially greeted with a hard line of deportation as he was neither born in the UK nor had UK parents. This changed when they discussed the Imran/Malala debate and they came to a conclusion which showed some dialogical thinking:

"Everyone should be treated equally? well they're not, are they. Not everyone is treated the same, it is hard to know what is fair and what is not"

Their initial reaction to Christophine was that her age would make her a burden on the state and so she should be deported. Through discussion they changed their minds and decided she had earned her right to citizenship. One of them became quite indignant that having come to help the UK she was now facing this uncertainty:

"We brought her over here and now we're sending her back?! Dumb!"

\section{Grangetown Youth Pavilion}

This session saw five young men participate. They were all at least 16 years old and possessed great interest and individual knowledge on this topic. This led to far ranging and fluid discussions and they embraced the opportunity to facilitate the discussion themselves.

\subsubsection{Table of GYP decisions and discussions}

\begin{tabular}{|c|c|c|c|}
\hline Case & Consensus & Reasons & Conditions/variables \\
\hline Robyn & Citizenship & British parent & Ethnicity a factor? \\
\hline Yelena & Citizenship & Born in the UK & $\begin{array}{l}\text { Split on the fate of } \\
\text { her parents }\end{array}$ \\
\hline Anastasia & No discussion & & \\
\hline Pablo & Citizenship & $\begin{array}{l}\text { Keep the family } \\
\text { together }\end{array}$ & $\begin{array}{l}\text { Could he have } \\
\text { planned it this way? }\end{array}$ \\
\hline Christophine & Citizenship & $\begin{array}{l}\text { Length of time she } \\
\text { had lived in the UK. A }\end{array}$ & Behaviour matters \\
\hline
\end{tabular}




\begin{tabular}{|l|l|l|l|}
\hline & & $\begin{array}{l}\text { lifetime of working } \\
\text { and paying taxes }\end{array}$ & \\
\hline Imran & Uncertain & See below & See below \\
\hline Malala & Citizenship & $\begin{array}{l}\text { The potential of her } \\
\text { future contributions }\end{array}$ & $\begin{array}{l}\text { Her story provokes } \\
\text { sympathy }\end{array}$ \\
\hline
\end{tabular}

In the case of Robyn, one of the participants raised her ethnicity. It was his belief that if she was from Africa or Asia she would be more likely to be refused citizenship, even with one British parent. This was a view shared by his peers, one of whom remarked:

"The same person, they could be Australian, African or Pakistani, should all have the same rights"

As in BYP, Imran was initially considered for deportation due to having no connection to the UK through blood or soil. During the discussion their attitudes softened, firstly focusing on the cruelty of being told that in a year you may be returned to another country. The debate continued in favour of Imran as they could not understand the sense in sending him away when he was about to become an adult and would start benefitting the UK financially. One participant who had been especially vocal in his support for deportation became an advocate for his citizenship:

"He is refugee, so there may be people after him, he's been here a long time, made friendships, probably got a family of foster parents, he's started a new life, why accept refugees only to send them back again, he'd be returning to nothing except poverty and war"

The mention of potential future contributions was again raised in the discussion of Malala and they made the connection between the disparity between the treatment of Imran and Malala. They believed that Malala's story provoked sympathy. One young person asked:

"Imagine how many other people went through the same thing, why is it only her getting the recognition?"

To which their friend replied; 
"She is a someone, basically"

In the cases of Robyn, Yelena, Pablo and Christophine they focused on behaviour and how their view might differ if the person had committed certain types of crime. They believed that if a person had committed a serious crime such as murder then they should face deportation, unless they already had UK citizenship, in which case it was the country's responsibility to deal with them.

\section{Monkton Priory Project: Group one}

Due to attendance I ran this session on two different occasions. The first session was with three boys and three girls. This group had a mixed range of abilities and an interesting dynamic which meant they did not fully engage with the activity. This is supported by the following exert from my research journal:

I knew most of them, but there were a couple of new young people. They came from a very troubled background and although Gypsy Travellers they were not from the same traveller community as the rest of the project. This created tension between the young people and damaged enthusiasm and engagement levels, which did affect the flow of the session and made it more difficult.

\subsubsection{Table of Priory Group one decisions and discussions}

\begin{tabular}{|l|l|l|l|}
\hline Case & Consensus & Reasons & Conditions/variables \\
\hline Robyn & No discussion & Born in the UK & \\
\hline Yelena & Citizenship & Not a British citizen & $\begin{array}{l}\text { Children were UK } \\
\text { Citizens but should } \\
\text { remain with the } \\
\text { mother }\end{array}$ \\
\hline Anastasia & Deportation & Length of time that & \\
\hline Pablo & No discussion & he had lived here & \\
\hline Christophine & No decision & \multicolumn{2}{|l}{} \\
\hline Imran & Citizenship & & \\
& & & \\
\hline
\end{tabular}




\section{Malala}

\section{Uncertain}

They did not have the confidence to read aloud in front of their peers and struggled to understand many of the terms used and had no real surrounding knowledge of the scenarios. Only one of the participants had heard of Malala. Their geography was hazy: they asked if Australia was somewhere in Wales. They were easily distracted, would antagonise each other and constantly find ways to try and leave the classroom, such as asking to go to the toilet and saying they had dentist appointments. The following conversation following my reading out the case of Christophine goes a long way to recount the general tone of the session;

YP: is she black?

Me: Yes

YP: I knew it

Me: Did you

YP: I like black people

Me: Good

YP: I met one once...John

Me: Yes

$Y P: I ' m$ bored

Me: Yes, I can tell

Before I finished however we did discuss the case of Anastasia. As with Yelena they thought the children should be granted UK citizenship because they were both born here and had a British parent. This entitlement was not extended to the mother and one participant suggested that Anastasia should be deported and the children put in care. This could be seen as a callous statement, lacking in empathy, but I saw it as more of an abstract logical decision. I encouraged them to explore further by asking them if they were willing to 
separate the children from their mother. They considered leaving the decision up to the children but in the end concluded that they should stay with their mother and return to Romania.

\section{Monkton Priory Project Group two}

The second session was with two men and one woman who had returned to school for exam revision. After my session with the younger students I asked them if they would stay and take part and they agreed.

\subsubsection{Table of Priory Group two decisions and discussions.}

\begin{tabular}{|c|c|c|c|}
\hline Case & Consensus & Reasons & Conditions/variables \\
\hline Robyn & Citizenship & British parent & \\
\hline Yelena & Citizenship & Born in the UK & $\begin{array}{l}\text { Reasons why she was } \\
\text { born in the UK }\end{array}$ \\
\hline Anastasia & No discussion & & \\
\hline Pablo & Uncertain & $\begin{array}{l}\text { Should marriage and } \\
\text { parenthood be an } \\
\text { automatic right? }\end{array}$ & \\
\hline Christophine & Citizenship & $\begin{array}{l}\text { Lived, worked and } \\
\text { paid taxes in UK for a } \\
\text { long time }\end{array}$ & \\
\hline Imran & Citizenship & $\begin{array}{l}\text { The length of time } \\
\text { spent in the UK and } \\
\text { differences between } \\
\text { UK and Afghanistan }\end{array}$ & $\begin{array}{l}\text { It would depend on } \\
\text { which country a } \\
\text { young person } \\
\text { originates from }\end{array}$ \\
\hline Malala & Citizenship & $\begin{array}{l}\text { She had nearly died, } \\
\text { would be in great } \\
\text { danger if she went } \\
\text { back to Pakistan }\end{array}$ & $\begin{array}{l}\text { Is it fair that she can } \\
\text { stay but Imran may } \\
\text { leave? }\end{array}$ \\
\hline
\end{tabular}


They were much more engaged and had their own perspectives on a couple of the cases. They believed that being born in a country should automatically qualify a person for citizenship but there should be some investigation as to how they come to be born in the country. They discussed the idea of a minimum residency either before or after the birth of a child to qualify for citizenship. They delved deeper into this matter, considering scenarios where work may take a family away from the UK. This led them to agree that the residency rule could be waived if one or both parents were British. Although they thought Imran should be granted British citizenship, they did not believe it should be a blanket rule. Their reasoning for this was that there are some countries which would be safe to return to, for example, Australia.

\section{Discussion and reflection}

The game responded to my research questions in many ways. An important view of citizenship was that three quarters of the groups recognised Robyn's right to citizenship through jus sanguinis, the exception being BYP. In GYP they did raise the issue of what Hughes (2009) calls social fetishism. This is the theory that some immigrants are more welcomed than others, particularly those who share characteristics such as culture, skin colour and language. GYP specified a perception of different treatment of white people from people from African or Asian heritage. This demonstrates that they believe social fetishism occurs. It also evokes Bhambra's (2016) contention that the UK intended beneficial migration agreements between themselves, Canada, Australia and New Zealand in the passing of the BNA 1948.

What was significant was that there was no consensus over the inheritance, granting or rescinding of citizenship. BYP made their decision about Robyn based on her behaviour. This was a reoccurring theme in several of the cases. Pablo was also routinely considered for citizenship because of the low-level nature of his offence, and so as to keep his family together. Many of the participants across all three groups would not have been so sympathetic to his case had he committed a more serious crime. This demonstrates that many of the participants would support conditionality in gaining citizenship. This was not the case in GYP, where it was made clear was that once gained, it should not be taken away 
- a position at odds with the current government's view. This could be a further display of the democratic deficit within these participants.

Collins (2018) argues that the UK should consider abolishing the jus sanguinis citizenship or at least modernise it. One suggestion is that of jus filiationis which would acknowledge that people's citizenship could be derived from a social parent or primary caregiver who was not necessarily a blood relative. This could apply to adoption and surrogacy but it is less clear if this would be extended to fostering, where carers act on behalf of the state. It could mean that a person qualifies for citizenship before 18 and thus is no longer eligible for deportation. Collins (2018) believes this is unlikely to be adopted in the UK because government officials are often all too eager to find reasons to refuse claims to citizenship. The case of Anastasia is relevant to this. The Priory group followed the decision made by the British court in Jasmine Sorabjee v UK (1995) by focusing on the mother's lack of right to citizenship. This highlights one of Sawyer's (2006) concerns that children born in the UK to foreign parents have a valueless citizenship. Yelena, born to two foreign parents is seen by the participants as having legitimate citizenship through the jus soli rule. As an adult she is independent of her parents whereas Anastasia's children, despite having both jus sanguinis and jus soli on their side would face deportation because they are children.

Malala was seen by GYP in a positive light and the participants of BYP were protective of her. Both these views and their sympathy for her reflect Kharshid and Pitts' (2019) view that she is presented in the media as a person of vulnerability and a champion of rights. This is reflected in how eager they were to repeat what they had learned about her in school. Both BYP and GYP saw her future potential as a reason for her to remain, which was linked to her position as a civil rights campaigner. Qazi and Shah (2017) question the validity of this position, instead seeing her as glorified by the West in an almost anti-Islamic way. They question why she is being praised yet Pakistani and Muslim humanitarians and philanthropists such as Abdul Sattar Edhi remain largely anonymous. The reaction of the participants would indicate that Malala's position as a 'vulnerable' champion of women's rights is established through educational discourses as well as those in the media. This session did not seem to impact upon these views. 
In the debate about the equality of treatment for Malala and Imran it was pleasing to see many of the participants recognise the risk of generalised and individual violence or persecution. Reynolds (2018) explains that these distinctions and the accompanying right to humanitarian protection are written in the EU Qualification Directive Article 15 of the 1951 UN Convention for Refugees. Reynolds (2018) warns that Brexit may see the UK abdicate their responsibility for those who face generalised violence. This is seen in the hostile treatment of any undocumented refugees where investigators are encouraged to find lies or inconsistencies in testimonies. The participants were all aware that Afghanistan was not a stable country and recognised that Malala may face individual persecution but gave equal weight to the general violence that Imran might encounter. While many of the participants saw that Malala had received more beneficial treatment because of her profile and ordeal, they did not think she should lose this privilege, instead that it should be extended to others such as Imran.

Hing (2018) makes the case of the financial contribution of young people who arrive in the country as refugees. They often receive education and have the potential to make significant contribution to the economy and tax revenues through both working and spending. In his own words "Driving out young workers who will pay into the system for many decades is, simply put, a very bad idea" (Hing, 2018:302). This is a view very much shared by the participants in GYP who could not understand why Imran would be deported back to Afghanistan, because of his potential contribution and the differences between countries. Similar to Collins (2018), Baubock (2018) also suggests modernisation of citizenship definitions and suggests jus domicilii, that is, citizenship gained automatically when you live somewhere that can then be lost when or if you leave. This could be used for people such as Imran but would still be conditional and temporary. The discussions in this session around Imran saw the participants add their own form of citizenship modernisation. They specified facilities that he would be used to, such as Costa Coffee and bowling alleys, music and games console, suggesting their understanding of how difficult it would be to leave in a cultural context. This could be termed jus familiaritatis, the rule of familiarity. As suggested by participants in the Priory, returning to Australia would not be that different to living in the UK whereas returning to Afghanistan would be. Hing's also recognises this and could be seen to support a jus familiaritatis rule as he believes it is "...cruel to send these 
young people to places many of them have never lived and do not know. For them this is home".

Christophine and many of the Windrush generation meet a performance standard that includes working and paying taxes. Yet through a hostile environment they found themselves facing a revocation of a citizenship which they thought automatically was theirs, in no small part due to their ancestors being British subjects for many generations. Cooper (2018) refers to the hostile environment and by extension the Brexit mantra of 'taking back control' and how it distorts the meaning of citizenship. Cooper (2018) introduces the concept of superposed nationality, which means that for those granted citizenship rather than gaining it through jus soli or jus sanguinis it is merely on loan or a trial. Nearly all the participants mentioned at some point that anyone who committed a serious crime should be denationalised or denaturalised. Macklin (2018) quotes from Chief Justice Warren of the US Supreme Court who in the 1950's said 'citizenship is not a license that expires on misbehaviour'. Considering the decision of recent British Home Secretaries to strip citizenships in the case of the Rochdale Grooming group this is clearly not the case in the Britain and a viewpoint agreed with by many of my participants.

Another significant aspect of this session was that conditions of citizenship were linked to security, fear and not having to pay for someone else. Sawyer's article from 2006 by dint of the year indicates that denationalisation is nothing new. She also gives further thought to why it may happen and the consequences: "the expulsion of a section of a country's own citizens justified as part of 'immigration' policy, is a very big statement about what it is to be a citizen" (Sawyer, 2006:182). Macklin (2018) suggests that immigration is no longer the only justification and that security is also a big factor and that in the UK there is a 2 tier citizenship standard of inherited versus granted, with the latter always at risk of denationalisation;

"The latest target of denationalisation is the convicted terrorist, or the suspected terrorist, or the potential terrorist or maybe the associate of a terrorist. He is virtually always Muslim and male" Macklin (2018; 163)

This could be seen as the emergence of a securitised form of social fetishism, where those not deemed as a risk to safety or resources are allowed to retain citizenship. This is shown in 
the discussion had by GYP over Robyn where they express doubt over the fair application of the one parent rule. Macklin's two tier system is given further credence by this activity as all the individuals had somewhere to be sent back to through their pluralistic heritage. Had Pablo committed murder then many of the participants would have had him deported. If he was a UK citizen through jus soli and jus sanguinis then he would be imprisoned. This again shows an imbalance in treatment between the inherited citizen and the one who has citizenship granted to them. As Macklin (2018) points out prison allows for rehabilitation whereas banishment sees the person cast aside.

When discussing Imran and Malala the boys of GYP echoed the findings of Thomas and Sanderson (2011) who found that male British Muslim youths struggled to understand the perceived double standards in how their white counterparts were treated and behaved. The participants thought that a double standard was applied to people of white ethnicity;

"young lads, say of white ethnicity, drop out of education, they don't do nothing all day, how can they stay, when they are doing nothing"

I did not see this as a complaint or whine of self-pity but rather that it represented evidence of how young people from an ethnic minority, many of who are UK citizens, feel that there is a two tier system and that by the nature of their heritage and colour they are in the second class category.

The participants in this project seemed to focus more on the performance or potential of the citizen than the personal situation, similar to their view on the admission of the mother and daughter to the tribe during ZA. This is again centred on security. Macklin (2018) explains this through the actions of Teresa May, when, as Home Secretary, she denationalised hundreds of people when they weren't in the country. Regardless of the morality of legitimacy of this it is nonetheless a process and could be seen to imply conditionality. Whether this conditionality is explicit or implicit is hard to say but it is easy to understand that people could perceive it as a danger to their status. Afterall, what is given can also be taken away.

If a nation state is imagination given substance through performance, the citizenship contract could be seen as the script of that performance. In the UK there can be little doubt 
that this script is largely in favour of inherited citizens and that for those whose citizenship is granted there is no security. Then there is the Windrush generation, descendants of British subjects and British citizens and now victims of the hostile environment. As Cooper (2018) makes clear the hostile environment has seen people who thought, with every reason, that they were UK citizens, be denied what turns out to be a privilege. This has huge ramifications for civil liberties and broader legal rights, including increasing the risk of making people stateless and the situation is made even more precarious by the toxic ambiguity of government policy and action. As mentioned throughout this thesis, Isin and Turner (2008) tell us that if UK citizenship is based on anything it is protection against the rule of the one or the few. Is this now under threat?

Citizenship revocation only enhances the discretionary and arbitrary power of the executive at the expense of all citizens, and of citizenship itself" Macklin (2018; 172)

In the space of two months between the pilot and the research project my awareness of the Windrush generation changed from seeing it as a way to citizenship to its members facing deportation. It shows a flexibility in planning that allows these materials to accommodate the ever-changing events around citizenship and this is important in the engagement of people in citizenship and Othering debates. Added to the practitioner's requirements of being aware of their own views and having the confidence to tackle difficult issues must now be the ability to stay informed of relevant current affairs.

I thought that this activity encouraged critical thinking in BYP and Monkton Priory. I believe in GYP the ability for critical thinking and the knowledge was already there, this gave it an opportunity to be aired and be heard and through being heard, to be challenged by peers. This was particularly prevalent in the discussion they had around Imran. I took away from this experience a feeling that the success of individual sessions was heavily influenced by the pre-existing knowledge of the young people. In GYP they were well versed on the issues and engaged with great enthusiasm, seemingly pleased to have the opportunity. The second Priory group, whilst lacking the knowledge, had a thirst for discussion and exploring issues. That both these groups were young adults is I believe a factor in this and pertinent to developing curriculum materials. With these extra years can come maturity and a desire to be treated as an adult and as an equal. The two younger groups in the Priory and BYP were 
both, at times, bored by the activity. I do believe that this is partly down to their age but I also have to accept some responsibility for the activities' design and content. It may assume an unreasonable level of knowledge and desire to discuss the issues. That there was a spike in enthusiasm in BYP when the participants discussed Malala shows that the participants showed more appetite for discussion when they had an understanding of the issues, the credit for which must go to school education. The difference in engagement between the two groups in the Priory is also a matter of confidence. The older participants were willing to admit to lack of knowledge and understanding. A lack of self-confidence makes a group tough to work with as it frequently manifests itself in evasive and challenging behaviour. Yet, it is this challenging nature that makes work with these groups of marginalised young people even more important.

This session showed evidence of how decisions around whether a person should stay or go often involve discussions of the security of a nation and the safety of an individual. In the second part of this chapter I focus and explore with the participants the relationship between security and liberty. 


\section{Chapter Six, Part two: Liberty and Security}

\section{Introduction}

I suggested in the activity 'Stay or Go' that the citizenship contract is the script of how to behave as a citizen with regard to whether you will maintain the privilege of citizenship. In this chapter I will continue to explore the privilege of citizenship by examining how the concepts of liberty and protection interact with threat and security. One of the driving factors in the development of British citizenship is the importance of liberty and freedom. As explained in the literature review, Isin and Turner (2008) discuss the historical context of the themes that underpin British citizenship. These include historical events such as the signing of the Magna Carta, the forming of a constitutional monarchy and parliamentary democracy, the English civil war and the creation of the power of common law. The work of Karatani and Gill (2002) discusses the Brixton riots of 1981 and how they led to the Scarman report. This report was influential in the establishment of the Police and Criminal Evidence Act 1984 and the Crown Prosecution Service. From Runnymede ${ }^{10}$ onwards, one of the fundamental concepts underpinning British citizenship is protection from tyranny or the power of 'the one'. One of the tools entrusted to carry this out is the rule of law. Aliverti (2019) discusses how "both in official document and popular culture, the rule of law is asserted as one of the defining values of Britishness" (Aliverti. 2019:284). This section of my thesis aims to explore the views of young people towards the ever present meanings and balances of liberty and security, which are an essential part of citizenship. Through looking at real life examples participants will be encouraged to share their views, understand the complexity of the issue and explore what impact Othering may have on the two themes.

Aliverti (2019) explains how successive PMs have talked up the importance of the rule of law. Tony Blair did it through civic values, David Cameron through the idea of muscular liberalism, where freedom came from the robust application of the law, and Teresa May enlisted it as a fundamental British value. There have however been incidents when this protection from 'the one' has been questioned. In his review of the shooting of Jean Charles de Menezes Vaughan Williams (2007) remarks on how the police acted as "Temporary sovereigns, (who) decide that de Menezes life was not worth living, but a life that could, and

\footnotetext{
${ }^{10}$ This is where the Magna Carta was signed on $15^{\text {th }}$ June 1215.
} 
should, be dispensed with" (Vaughan Williams, 2007: 187). Not only did the police dispense with his life, in doing so they also dispensed with his right to the due process of the rule of law. This demonstrates a complexity in the temporary sovereign role as it contradicts historical meanings of British citizenship's development through suspension of due process, briefly allowing the tyranny of 'the one'. The reason for the emergence of the role of temporary sovereign is explained by Tsoukala (2009) who explains that pre $9 / 11$ public security threats were linked to social problems, however in the post 9/11 world they shifted to international terrorism. Tsoukala (2009) explains that these threats are defined by "the listing of endangered values...British threat definers thus include in it the way of life, freedom and democracy" (Tsoukala, 2009:77). Now that freedom or liberty has become established as under threat from international terrorism, it allows security to be used to defend it.

Tsoukala (2009) goes on to explain that the endangered freedom is not that of philosophical charters like the Human Rights but instead:

A very specific political value, closely related to a dominant political and economic ideology in Western liberal democracies" (Tsoukala; 2009:78).

In the UK, those current specifics are fundamental British values. This means that the endangered value definition of freedom can become a tool of othering, almost applying an Orientalist framework and reflected in some post 9/11 rhetoric. The othering comes in the form of designating those who would take away the specific and politically designed freedoms as a threat, and creating a fear-based definition of freedom. Exploring the delicate balance between liberty and security in a post 9/11 world, Allhoff (2018) makes several critical observations. He states that "liberty and security both matter and the aim is to strike an adequate balance between the two" (Allhoff, 2018:55). This balance will prevent either anarchy or a police state but, since $9 / 11$ people, have felt more unsafe because of international terrorism and that, along with counter terrorism, this forms "the interface at which the tension between liberty and security is most pronounced" (Allhoff, 2018: 59). Allhoff (2018) believes that people are inclined to think that security is more valuable than liberty. One of the reasons for this is that the international element of the threat allows for 
the identification of a minority as the community in which the threat sits. This is a view shared by Tsoukala (2009) who adds:

"Temporary restrictions on freedoms are presented as necessary to better protect national security and public safety. In an overt trade off of the liberties of the few against the security of the many it is further assumed that these restrictions should be even more easily acceptable as they only apply to a small group of persons" (Tsoukala, 2009: 80).

This highlights the utilitarian question that I see as important with regard to modern day citizenship and invoking the rule of law as both a FBV under threat and arbiter of the tension between liberty and security. I wanted the participants to explore questions about whether some people are protected under the law more than others and how we balance the tension between liberty and security.

\section{Planning and Preparation}

As mentioned above, the shooting of Jean Charles de Menezes raises issues including the role of a temporary sovereign. This made the inclusion of this incident a natural choice. Building on this I decided to use three other real life scenarios outlined below. Like 'Stay or Go' the research was now completely based in the real world:

1. Jean Charles de Menezes was a young Brazilian man shot and killed by armed police in London on suspicion of being a suicide bomber during the hunt for the perpetrators of the attempted terror attacks of $21 / 07 / 2005$ that took place after the London terrorist attacks of 07/07/2005.

2. Mark Duggan was a British citizen shot by police on suspicion of carrying a firearm. His death contributed to the London riots of 2011.

3. Darren Osbourne was a Welsh man who hired a van and drove to Finsbury Park Mosque and tried to run over Muslims on the $19^{\text {th }}$ June 2017.

4. Kharum Butt was one of the London Bridge terror attackers on the $3^{\text {rd }}$ June 2017.

Both Butt and Osbourne were known to hold extremist views and were British citizens. Kharum Butt was shot by armed Police and Darren Osbourne was jailed for a minimum of 43 
years. Butt and Osbourne were seen as a potential threat but no action was taken against them until they were committing the act (Butt) or had completed their act (Osbourne). Jean Charles de Menezes and Mark Duggan were seen as potential threats and both were killed by the police because of this.

I believed that these four cases would give a chance to discuss issues of liberty and security and the role of the rule of law. With the exception of Duggan all the incidents are connected with terrorism and extremism. This highlights how modern day questions of security versus freedoms are largely, but not exclusively, carried out against terrorism and counter terrorism narratives. As I was looking at terrorism, I thought it important that both Islamic and far right extremism were given equal exposure. This was in part due to who was represented among the participants, and I did not want to offend the young Muslim participants and open myself up to allegations of bias. I also wanted to take the opportunity to show all the participants, particularly the young Travellers, that extremist views and terrorism are not associated only with Muslims, but with all kinds of different people.

I wanted to make sure that the way I presented this session would initiate critical thinking. This would be different to previous activities as we would be directly discussing what had already happened and been decided. Browne and Freeman (2000) explain how a key element of critical thinking comes from the facilitator stimulating controversy to create doubt in the minds of the participants. All four of these incidents were partially chosen because they provoke an emotional reaction and the complexity of each incident would potentially lead to "curiosity, openness to new ideas and willingness to listen to other views" (Browne and Freeman, 2000:179). How I introduced the subject would be important. Mayer (1986) advises that key to critical thinking is the learning environment and that it should be one that creates "conditions for participation, rather than passivity and in providing opportunities for emotional engagement with the materials" (Mayer, 1986:253). It was my belief that arriving and beginning with the case of Jean Charles de Menezes would be too intense a start. I decided to use a warm up activity that focused on exploring the competing uses different sections of society have for park benches. This would be angled towards engaging the participants through the Adultist perception of how young people may misuse public spaces. I would then suggest that the only way to moderate this would be the introduction of CCTV, which would lead into a discussion of security versus freedom. 
I ended up using a completely different warm up activity due to circumstances at BYP. Upon arrival the centre manager informed me that Cardiff City Football Club had organised an event for the youth club members at their stadium. I could do something with the girls if I wished on the understanding that it would have to end when the bus arrived. Determined to make the best of it, I agreed to run an activity to maintain the participants' interest. I decided to use the runaway train or trolley conundrum. In it five people are on one platform and one on another, a runaway train is headed towards the five people but an individual has the power to pull a lever so the train will change tracks and only kill the one person. The second part of this is that a runaway train is headed towards a crowded platform but an individual can push a large man off a bridge to stop the train. The advantages of this exercise are that you can physically re-arrange a room, its contents and the people to discuss the scenario, and you can also change the conditions. Shortly after starting, the football trip was cancelled and I was free to run my planned session. The runaway train dilemma proved a great warm up activity for 'Security versus freedom' with this group of participants, as it stimulated discussion, and I decided to use it with the other groups.

\section{Delivery and engagement}

\section{Butetown Youth Pavilion}

I started off with six females and the numbers changed as people dipped in out of the session. The trolley dilemma worked in establishing an environment of doubt and thoughtfulness and so I began the main course of the activity.

\section{Jean Charles de Menezes}

We discussed the build up to his death and they were very sombre in their consideration, understanding that if he had been a bomber many lives were saved. Yet they did suggest alternatives:

'They could have tazered him, they chose to shoot him'

Another young person suggested the following, which the rest of the group agreed with:

'They probably killed him because he looks Muslim' 
Before discussing the next case I briefly talked about how UK law is primarily based upon innocent until proven guilty.

\section{Mark Duggan}

One of the participants was living in London in 2011 and explained to the rest of the group about the riots and how she had seen parts of them including a massive fire. She had not heard of Mark Duggan. This could be seen as reinforcing Rankin's view that Duggan's death was largely forgotten. On his appearance, one participant remarked:

'This man has also got colouring'

The tone was cynical and because of this I did not think they were being offensive, it indicated a belief that non- white people were treated differently by the agents of security. They admitted to finding this case difficult because although Duggan had a criminal record, he was not committing a criminal act when he was shot. They did not believe that suspecting a person is going to do something is a good enough reason to shoot them. I compared it to the large man on the bridge who they were prepared to sacrifice. I asked them why they thought pushing an innocent to his death to stop a train was acceptable but shooting a man you think may have a gun or bomb was not. There was silence in response to this until one of the young people spoke, summing up the group's feelings:

'It's difficult'

\section{Darren Osbourne}

They strongly believed that he should have been arrested for having strong anti-Muslim, far right extremist views.

'He could tell them to other people', 'his thoughts could turn into actions',' his thoughts could lead somewhere'

\section{Kharum Butt}

They began by having an interesting conversation about whether Islamic extremists were targeting non-Muslims, white people or both. The participants could not agree, but it was bad either way. They believed Butt should only have been arrested if there was proof he 
was going to commit a crime. They believed Osbourne should have been arrested for his extremist views but not Butt for his extremist views. This was because they did not feel threatened by Butt:

"He wouldn't go after me, as I'm a Muslim from Somalia, he'd go after white people" They saw the likes of Osbourne as a threat to themselves and as such were willing to take his freedoms away. This is the same, not an inverse or a mirror, as securitisation, it is one section of society being scared of the potential behaviour of another.

\section{Grangetown Youth Pavilion}

This session took place with four male participants. After the trolley dilemma I explained to them the content of the session and one of them immediately made the link to CCTV.

Me: Is CCTV a problem?

YP: No, it's good.

Me: Why?

YP: Security and protection

Me: Does it take away freedoms?

YP: It does, but if you never do anything, you've no need to worry, init.

$Y P$ : As long as the law is fine

Me; Does it matter if people watch what you are doing?

YP: It stops fake accusations

YP: it's a problem when it's there and when it's not there

They told me that many taxi drivers now had cameras in their cars to prevent false allegations of inappropriate or criminal sexual behaviour. This would make both the driver and passengers safer. Interestingly they reasoned amongst themselves that this would only be reliable if the camera feed was linked to something independent. 


\section{Jean Charles de Menezes}

The young people had heard of him and described him in the following ways;

"He was completely innocent", "he was shot for no reason"

They quickly grasped that he had been killed to keep others safe, despite the police not having any real proof of whether he was or was not a suicide bomber. They discussed how the police should have carried out more research but may not have had the time and so had to make a decision but the decision was hard, dealing so much with uncertainties.

\section{Mark Duggan}

They knew he was a black man shot by the Police because they thought he had a gun when he did not. They knew that his death had contributed to the outbreak of the 2011 London riots. They believed that both Jean Charles de Menezes and Mark Duggan lost their lives and their rights for someone else's security. They distinguished between the terrorist threat of De Menezes and the criminal threat of Duggan. As Duggan was not a suspected terrorist his threat level did not justify the suspension of his liberty:

"In this accusation he wasn't a terrorist, so they could have told him to drop his gun and not shot him straight away. He hasn't got a suicide vest on, and if he has a gun they've (Police) got protection as well, body armour and guns. In this case they didn't have to shoot him. In the Jean Charles de Menezes case he was innocent, but he could have been a terrorist"

The others agreed with this participant's view and that as Duggan was not a threat to the public security he should not have been shot even if he did have a gun. They remained open minded; one of them thought that regardless of whether Mark Duggan had a gun;

"It was still a life or death moment for the copper"

\section{Darren Osbourne}

Several of the participants had heard of him and described his actions and character through expletives. I asked them not to use that language and they suggested the term 
doughnut instead. They understood why he had not been arrested prior to the incident but believed the police could have done more:

YP: You couldn't arrest him beforehand because he ain't committed no crime.

YP: they could have said he's got to stay at least 30 feet away from a Mosque or something like that

They thought that if restraining orders could be given to stalkers, violent ex-partners and used to keep paedophiles away from schools and playgrounds then why not something similar for people with extremist views. They were keen to talk about the Finsbury Park Mosque and the bad reputation that some people had given it. They had strong views about Abu Hamza al-Masri, the Iman of Finsbury Park Mosque known for his radical views, who they thought was another doughnut and they strongly expressed their disapproval of his teachings and methods. These are strong views and the participants expressed great dismay that people such as al-Masri were deliberately misquoting and misrepresenting the Koran to try and radicalise people. They saw radicalising as brainwashing Muslims and also turning people against Muslims. They viewed a Mosque primarily as a place of worship:

"Even this Mosque (Finsbury Park) brings bad for Islam, you can still pray there, just not get any information from them."

\section{Kharum Butt}

This case made them sad and they thought that there should be much more preventative work:

"He's obviously been radicalised. The people that radicalised him are clearly well known to the Police. I reckon the Police should have taken action before they got to him."

"He weren't born like this, none of them are, it's all about who you go with"

I then asked them what they thought the difference was between having the freedom to say what you thought and radicalisation;

"You've got to let them think it and the difference is when it turns to action" 
"Can't punish people for what they think, it's their opinion, but they need to stop being vulnerable and open their eyes, realise what's going on"

The participants believed that the police should be doing more work in preventing radicalisation by targeting those people, such as al-Masri, who did the radicalising. They had no problem with stripping away the freedoms and legal rights from people who did this. Yet they also recognised the vulnerability of people to far right extremists and mentioned the English Defence League's Jayda Franson, and how she;

"Gets in people's heads by talking rubbish and the people who listen don't then bother to go and do their own research"

They firmly believed that it was the responsibility of the individual and the family to promote resilience and lower vulnerability. They did not think it was the role of education, even sessions such as mine, because:

"The family's most important because it's who the kids trust the most and they will automatically follow the example that is set. Parents need to bring their children up in a way where they don't act like a doughnut"

They also came up with some ways in which this could be done:

"Look at others opinions, look at both sides and don't believe in any until you are certain and sure"

"Don't let anyone tell you what really is the situation"

"You can have your own opinions, everyone has their own opinions, just don't be hard headed about it, be open"

\section{Monkton Priory Project}

The trolley dilemma made for an excellent start to the session and I asked them what the words freedom and security meant to them. This is what they said about the meaning of freedom;

'Do what you want to do', 'not having curfews', 'to live your life', 'Innocent until you kill someone', getting arrested when you haven't done anything', 'evidence'. 
This is what security meant to them;

'cameras', 'persons looking after you, like government', 'bodyguards', 'army', 'navy', 'rich people - you can't touch them because they're too rich', 'prison where people go after court'

\section{Jean Charles de Menzies}

The young people did not think that the police had done the right thing in shooting him.

"It's not fair on the person, he might not be a bomber"

"They should have got evidence"

They discussed whether it was fair that the police involved, whilst being investigated and tried, did not get into trouble over this wrongful shooting. They recognised that it was an almost impossibly hard decision but did question the police's right to make the judgement call;

"That's not fair though, because if I shot someone and said he was a suicide bomber then I would go to prison"

One of the participants thought that he should not have been shot as;

"They had no evidence and he doesn't even look like a terrorist because they all have big beards and look Russian"

I told him that actually terrorists can look just like everybody else as we would see in later case studies.

\section{Mark Duggan}

This session's success can be partially judged by one of the participants volunteering to read out the explanation. Some of the participants had heard of the London riots, but were not aware of this incident, indicating that the London riots is an event more present in the minds of young Muslim people in Cardiff rather than traveller young people in Pembrokeshire. They debated whether his previous criminal behaviour gave the police 
grounds to think that he was dangerous. One of them hypothesised that the police may have thought he would use his gun to stop them arresting him and that

"Loads of police and maybe innocent people could have been killed if they had a gun fight"

Some of them thought otherwise and that the police should have had evidence that he had a gun and that he was planning to use it for criminal reasons;

"He shouldn't have been shot as he might have been going hunting and they had no evidence, your thoughts and your actions aren't the same thing"

Whilst the mention of hunting seems bizarre in the context of inner city London, what it highlights is a lack of awareness of the differences between urban and rural life. They did not think people should be shot for potentially having bad thoughts and once again expressed anger towards the police;

Yp; the Police can do what they want because they are the Police

YP: Yeah, did they get locked up for killing these people? No. See! If we went outside and shot two people because we thought they had guns and we found out they didn't, we would be sent to jail.

\section{Darren Osbourne}

The fact that Osbourne was known to hold anti-Islamic views and the police did not act made them very angry:

"What did the Police do, nothing, Oh my God! These two people (JCDM and MD) didn't do nothing and got shot and this one didn't and he actually killed a person"

They thought that the police could have taken some preventative action against him such as a warning punishment which could be a two day stay in jail or a public shaming. They also thought that should be more restrictions or at least inquiries into van rental listing possible criminal uses;

1) Robbing stuff

2) They could be killing people in it 
3) They could be a suicide bus

\section{Kharum Butt}

They were all in agreement that this time the Police had acted correctly;

"Good, he was definitely guilty and I was glad he got shot"

What they were not impressed with again was the police's lack of action before the incident. One of the participants touched upon the question of escalation and that they should not start with trying to kill people. They believed that the police should be involved at a much earlier stage;

YP: if I'm a Police woman and I see you doing bad stuff and just keep on watching you and don't do nothing one day you're going to do a really, really bad crime because you can get away with everything"

YP: I don't know what this world has come to, I swear to God

YP: we definitely need more security, we don't need more freedom

YP: you don't really need loads of freedom, we have too much freedom and that means people can kill people

\section{Discussion and reflection}

In regard to views upon citizenship the final words of the participants in the Priory above clearly indicate that they value security over liberty. This was shared to some extent by participants in GYP, who in their discussion on CCTV thought there was nothing wrong with security as long as you obeyed the rules. This perhaps shows how they see the rule of law: as something which must be obeyed rather than the source of liberty. This was partially contradicted in their general dislike and distrust of those in power - a common theme in this activity just as it was in the Political Approval game. Whilst in that game it agreed with debates centred on a lack of faith in politicians this suggests a lack of faith in the police. Throughout the sessions all three groups of participants suggested alternative action in each case. In the Priory and GYP they focused on early intervention or less fatal action and in the 
Priory there was anger in knowing that the views of Butt and Osbourne were not acted upon. This also indicates a support of security. De Goede and Sullivan (2016) discuss the politics of security lists and how they can often be used as a way of by-passing legal rights through framing the argument in a direct contest of security versus freedoms. Security is considered to be the more important and as such the state and its agents such as the police can "...depart from established procedures and classifications of suspicion codified in criminal law...they are deemed to be preventative rather than punitive in nature" (De Goede and Sullivan, 2016:69). The participants here appear to be calling for preventative action to be taken against people on these security lists and by this showing their support for them. In BYP, the participants thought that having extremist thoughts should be enough of a crime to be arrested but not enough to be killed. Early action in the cases of Butt and Osbourne might have prevented them from committing their crimes and this approach was favoured over reactionary security which involves violence by either the perpetrator or the state. In the discussions around Jean Charles de Menezes, all three groups expressed feelings that the police should have had more evidence.

The participants in GYP also expressed a view that certain people should be treated with punitive action. In a study titled 'Who deserves basic rights', Newheiser and Demarco (2018) examine the attitudes of their participants towards the treatment of terrorist suspects. When the suspects were seen as a continued threat to security this equated to being deserving of punishment. As such participants accepted that terrorist suspects should have their normal legal and physical rights suspended with regard to apprehension, questioning or detention. The participants in my study, especially GYP, did not think that this infringement of liberty should be applied to suspected criminals such as Mark Duggan but did support the suspension of normal legal rights. Allhoff (2018) discusses how acts of terror make people feel unsafe, which leads to a situation where counter terrorist measures see security overriding liberty. The subsequent behavioural profiling and differential targeting, with ethnicity, nationality and appearance often making a person more suspicious, is justified by the rationale that it is for the good of the many and "terrorism is the cost of security's absence" (Allhoff, 2018;71). This security focused approach may manifest itself elsewhere in debates on security and liberty. De Goede and Sullivan (2016) say how a lack of accusatory material is brushed aside by a vague security focused narrative that uses; 
"The groups that the individual is thought to be associated with, their alleged but usually unspecified terrorist activity and their criminal convictions" (De Goede and Sullivan, 2016;80)

In discussion the participants in BYP did allude to skin colour as being an association in the application of security and the general consensus of suspending liberty to minimise the risk opens the door to this kind of behaviour. Duggan was arguably a victim of a narrative that focused on his unspecified and alleged threat supported by his previous criminal convictions. The fate of Duggan could be evidence of the warning given by Newheiser and DeMarco (2018) that the tendency to suspend rights "may have consequences for the curtailment of all citizens' civil liberties" (Newheiser \& DeMarco 2018:50). Historical events such as the Brixton riots in 1981 suggest that black men have been victims of police profiling for decades. Has the rise of international terrorism, the subsequent fear and encroachment of civil liberties that this has brought about, blurred the lines between the treatment of criminal and terrorist?

The fear of terrorism that fuels the emphasis on security was evident in all the groups during this activity. In BYP they felt threatened by the actions of Osbourne. BYP were the only group who directly raised the issue of race, suggesting that in both the case of De Menezes and Duggan their ethnicity may have had something to do with their deaths. This resonated with them as they are of minority ethnic background. In the Priory and GYP they showed concerns and fear when discussing Osbourne and Butt, both acts of terror motivated by extremism. In the Priory they gave an example of feeling more threatened in London than they would travelling there. Wolfendale (2007) explores how terrorism is more of a worry to citizens than diseases, natural disasters and daily threats such as motoring. The reason she gives for this is that terror attacks are more symbolic. An act of terrorism is perceived as an attack on a nation. As sad as it is, a road traffic accident is perceived to only affect those involved and their family and friends. This is the reason why I believe that the participants in BYP had conflicting standards with regard to Osbourne and Butt. In the case of Osbourne they felt members of the targeted group, but not of the group targeted by Butt. Wolfendale (2007) states that counter terrorism makes unacceptable demands of liberty, unjustified by the small odds of being caught up in a terrorist attack. The key word in this view is unjustified. The participants deemed the demands on liberty as justified and reasonable and 
this is particularly significant in further proving their preference for security. It might be easy to dismiss this by saying the participants do not really understand the risk, but greater security can make people feel safer regardless of how unlikely they are to be a victim of a terrorist act.

In the Priory they shared a view that rich people had privilege. The etymology of privilege stems from the Latin for private law. The abuse of privilege was one of the factors that led to the English Civil War, seen by Isin and Turner (2009) as a significant part of the establishment of British citizenship focusing on the protection from tyranny. Vaughan Williams's (2007) temporary sovereign can be seen as a temporary return to tyranny. However, as Vaughan Williams (2007) explains, in January 2005 the Metropolitan Police adopted a policy to shoot to kill to protect. It was code named 'Kratos' and was designed to show force and strength, to be decisive and to prevail against the terrorist threat. This means that the police are carrying out the law which therefore means they are not necessarily temporary sovereigns but still agents of the law. It seems the firearms officers were operating lawfully and the mistake was made by the intelligence service and the process behind the operational decision should have been held to account under investigation. It seems that the participants across all three projects recognised the need for temporary sovereigns and supported it on the understanding they made the correct decisions. What this session did was give an insight, understanding and empathy that making these decisions is far from straight forward.

In a conversation with a fellow artist Rankin (2014) describes Duggan as "a black man, a husband, a father and a suspected drug dealer" (Rankin, 2014:115-116). This description impacted me because of the order the facts are presented: black man, husband, father rather than leading with suspected drug dealer or criminal. While this may present him in a favourable light I had only ever previously thought of him as a criminal. It made me think of a man rather than the riots which followed. I did consider presenting him to the participants in this context to see how representation can impact opinion. In future applications it might be interesting to give two groups from the same project alternative representations and see if their views differ. I chose to represent him as a UK citizen, killed by temporary sovereigns and so much of the anger that followed both his death and that of Jean Charles de Menezes 
was centred on how these two men were "denied the time to explain or defend himself as would be expected in the normal judicial process" (Vaughan Williams, 2007:187).

Security it seems is supported by the participants as another conditionality governing who is entitled to citizenship and a considerable part of the social contract between the state and the individual. The spectre of terrorism now sees the role of security to be internal as well as external. That the participants demonstrate support for the infringement of liberties for the sake of security should come as no surprise, reflecting as it does much of the literature on the subject. What is interesting is how these young people have formed their views and the extent that they show of critical thinking around them. If the press and neoliberal politics promote a use of the law to enforce security then young people are recipients of an adultist form of citizenship training where the views and opinions are handed down rather than the issues presented and explored. Across all three venues participants in this project showed that they were open to reassessing these views. Halpern (1999) says that people who are critical thinkers have a pre-disposition to be able to think critically but I would argue that people in general are capable of critical thinking, if they are given the opportunity. The participants in GYP distinguished between the shooting of de Menezes and Duggan. Whilst they saw both as wrong they could see the justification for De Menezes death due to the potential threat to the public. The lack of this greater threat was why they thought Duggan's death was not justified. They also had empathy for the policemen involved, showing a high degree of open mindedness. This was also reflected by their suggestions for alternative action. The alternatives suggested by BYP and the Priory focus on the deprivation of liberties elsewhere, whereas GYP focus on the importance of education and moral values, a view less dependent on fear.

This activity presented the opportunity for critical thinking and it took patience, prompting and allowing the participants the chance to express their thoughts. This in turn required an approach that did not look to jump on inconsistencies or contradictions. As a result of this activity, I believe that both academics and practitioners have to be cautious of the extent of discussion and critical thinking they expect from the participants, some of whom may not have sat their GCSE's. They are not going to critically discuss liberty and security in the same way a Human Geography Ph.D. student might. Interestingly many of the participants did explore where the source of critical thinking should stem from. In GYP it was from their 
families. But what if the families do not provide this? These participants have displayed a degree of fear, very much a product of securitisation and a one nation citizenship model in action. Where is this fear going to be challenged? Is it going to be challenged in their homes as suggested by GYP? Or is it possible that this fear is the view of the home and perhaps education's role is to empower the young people to take a different perspective and take it back with them to their families. If so, then it relies on having an educational system that allows this, requiring practitioners who are open minded, questioning and educated themselves. Many people working with young people may share their fears and directly or indirectly feed them. The very first stage then would be to ensure that practitioners are equipped and prepared through reflection and critical thinking of their own knowledge, thoughts and feelings.

With regard to expansion or changes to this activity; in future I would consider adding in the case of soldier $\mathrm{F}$, the former paratrooper facing trial for attempted murder during the Bloody Sunday massacre in Northern Ireland. This has similarities with the case of de Menezes except that on this occasion, the agent of the state is accused of acting unlawfully as a temporary sovereign. This activity would work well with bigger groups, as they could be divided up and given one case each to discuss in more depth before feeding back to the main group.

Shriver (2017) discusses the impact of how technology and global issues such as trade and currency wars may influence liberty and security. If in the future technology becomes implanted inside us, it takes Davis' (2018) idea of the quantified self to another level. It could allow every single part of a person's life to be measured and a Big Brother style surveillance network. Shriver (2017) suggests that this will be done in the name of security and applied through the rule of law: "The law is the law. You obey it to the letter. Freedom is what's left over. If the law doesn't say you can't do it, then you can" (Shriver, 2017:436). This would see freedom be a remnant or a secondary consideration. How far would people be willing to accept tightening of security through fear of threats such as climate change, terrorism and pandemics? Shriver (2017) makes an interesting proposition that the true definition of a free society is one which is "a place where you can still get away with something" (Shriver, 2019:435). The use of a futuristic, fictional scenario, such as this could be an interesting way to engage young people in the subject of liberty and security. 
Situating the discussion in the real world highlights fears to participants and results in calls for more security as it did in this activity. This is a complex subject where opinions and viewpoints may change with time and experience. It is vitally important that this subject is discussed with both ambiguity and uncertainty to prevent the eradication of freedoms or imposition of unnecessary security. Whilst opinions and views may differ greatly it is surely better they are discussed than ignored. Fear may be a barrier to critical thinking; play and simulation may be the way to encourage it. 
Chapter seven:

Part one: The warmth of other suns.

Part two: Against a sharp white background. 


\section{Chapter seven, part one: The Warmth of Other Suns}

\section{Introduction}

In this activity, I wanted to directly examine participants' attitudes and perceptions towards 'others', especially those perceived as immigrants and refugees. My aim was to promote a form of cognitive empathy where I would inform them of the different reasons why people journey to the UK. This would counter the neurotic, narratives of fear promoted through securitisation and political and media discourses. It would explore the notions of belonging and relate to Doty's (2014) work on how terms such as legal and illegal can stop a person from being considered part of a collective identity. I wanted to show the young people how there is another narrative to the politics of fear and, through empathy, try to get them to see how the individual becomes invisible as migrants are othered. This links with Mountz's (2015) concept of the invisibilisation of causes of displacement and the hypervisible reminders of the threat to resources and security presented by these others. This activity would also ask young people to consider the questions raised by Butler (2009) around what counts as a valuable life. As in the other empirical chapters, I discuss this by beginning with resources that both inform and stimulate critical thinking into why other people might journey to this country. I then look at some of the treatment they receive upon arrival and discuss with the participant's perceptions of images before allowing the space for the participants to discuss their thoughts and views.

For the first time, I would be delivering with a clear agenda: that of explaining the causes and reasons for displacement. The session activities would be designed to have an emotional side. We would look at what I term macro othering, an extension of Orientalism, where whole swathes of people of certain ethnicities, nations or religions are collectively othered. In keeping with this emotional edge, this is influenced and inspired by nonacademic literature. The book is called The Warmth of Other Suns by Isabel Wilkerson (2010) which tells the story of the migration of black citizens from the southern to northern and western cities of the USA from 1915 - 1970. It tells the stories of and experiences of people who undertook these journeys. The books and activity sessions title comes from a poem by Richard Wright which can be read in the appendix. In her introduction, Wilkerson writes a haunting description of why people migrate: 
Their migration was a response to an economic and social structure not of their making. They did what humans have done for centuries when life became untenable... What binds these stories together was the back against the wall, reluctant yet hopeful; search for something better, any place but where they were. They did what human beings looking for freedom, throughout history, have often done. They left. (Wilkerson, 2011:15).

A key term is 'when life became untenable' and what I was most keen to explore in this sessions was others who left their home countries for reasons categorised as:

- Reluctant yet hopeful: would any of us like to leave our homes, not knowing if we will be able to return?

- Search for something better: is it understandable that people wish this for themselves or for their loved ones?

- Any place but where they were: the journey may be long, perilous and expensive, but the potential is worth it. The risk of the journey is worth the reward of arrival because remaining is not viable.

\section{Planning and preparation}

Katawala, Ballinger and Rhodes (2014) wrote a paper titled 'How to talk about immigration' which includes a section on how not to talk about immigration aimed at liberals who often believe in a 'myth busting' approach:

"If we can just give people the real facts then they will be better informed - and so they will stop worrying and realise that migration is a good thing, not a bad thing" (Katawala et al 2014:26)

The authors' view is that this approach is not always effective with regard to immigration because:

1. Immigration is an area where public trust is in short supply.

2. Myths are often simpler and easier to understand and remember than the detailed explanation of facts. 
3. In a political argument both sides use 'facts', which they believe will convince the undecided and are already accepted by their supporters. This can often leave the undecided unsure of who to trust as both sides can sound equally convincing within an adversarial environment.

The result is that facts can be received with suspicion, meaning that an approach that relies on myth busting facts is unlikely to prove convincing. This is compounded by the tendency of myth busters to take the approach of lecturing rather than conversing. This can:

- Ignore legitimate anxieties and concerns;

- Ignore personal, everyday experiences;

- Make people think you are accusing them of being stupid, racist or easily swayed.

Katawala et al (2014) believe that most of the UK public actually sit in a conflicted or anxious middle, sandwiched between a minority on either side with definitive and conviction based views. They believe that this has implications for people such as me:

"The job of some public voices - such as civil servants, academics and BBC journalists - is to explain, not to persuade. It is important that the best possible information is available" (Katawala et al., 2014: 33).

The activities designed for the session 'The Warmth of Other Suns' (from now on 'Other Suns') are primarily designed to try and introduce some facts, that will promote a broader understanding of the identities, history and causes of displacement. I also wanted to stimulate debate and reverse the inversing of risk to put a human face on migration. This was attempted through the following activities:

- Save the Children videos 'Most Shocking Second a Day', parts one and two.

- World maps to explain reasons for migration and movement.

- Examples and examinations of U.K.'s reactions to movement and arrivals including those of politicians and journalists.

The order of these activities is interchangeable which allows me as a facilitator to respond to the participant's moods, engagement levels and interests. The 'Second a Day' video is 
filmed from the perspective of a young girl in the UK who goes about her life of school, friendships and birthday parties. Around her in the background are snippets of conversations and media reports of an unspecified deteriorating political situation, which finally descends into a civil war. She becomes displaced, separated from her family, flees the country and becomes a refugee. In total it is just under four minutes long and finishes with the caption; “just because it isn't happening here doesn't mean it isn't happening”. It is hard hitting with its intention to humanise refugees through the use of the innocence of a white child living in a western country. I used it after being shown it by a participant in the pilot project.

The maps used to explain reasons for migration and movement are as follows:

\section{Figure 7.1.1 Map of most violent and peaceful places in the world. Source: Economic}

\section{Intelligence Unit}

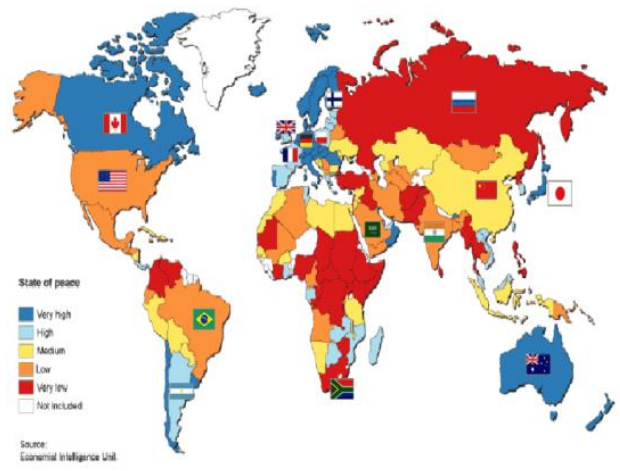


Figure 7.1.2 World risk index of vulnerability to natural disasters. Source World risk report.com

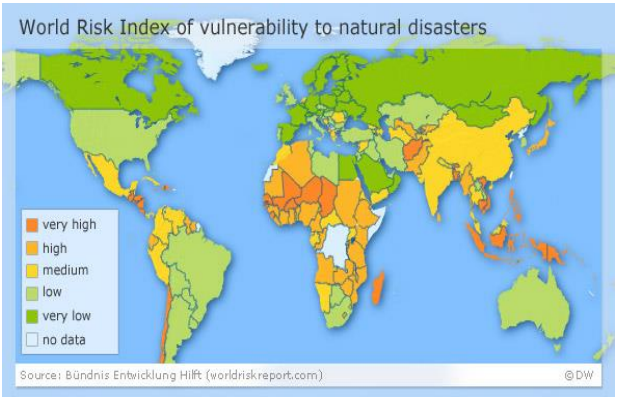

Figure 7.1.3 Wealthiest and poorest, purple richest, pale blue the poorest. Source World

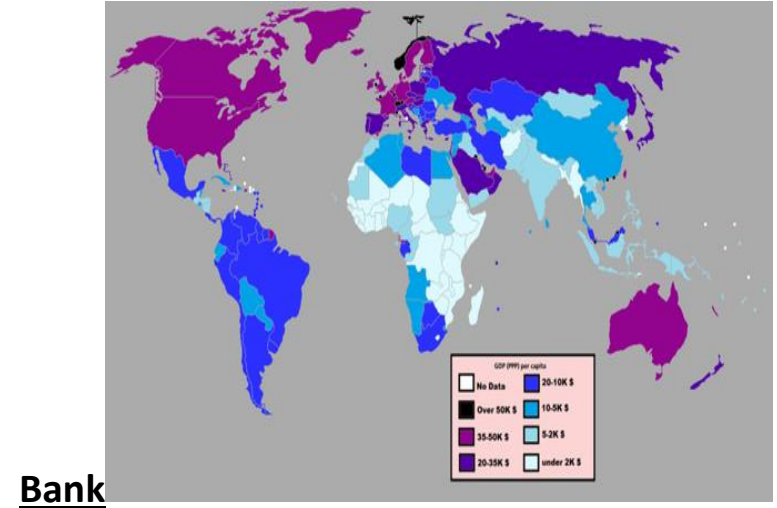

Figure 7.1.4 Refugees by origin. Source: ERCC Analytical team.

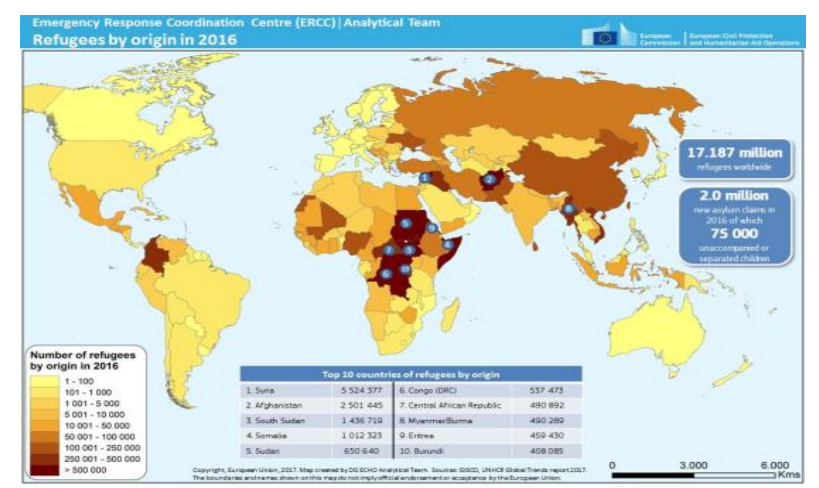




\section{Figure 7.1.5 Migration routes: Source National Geographic}

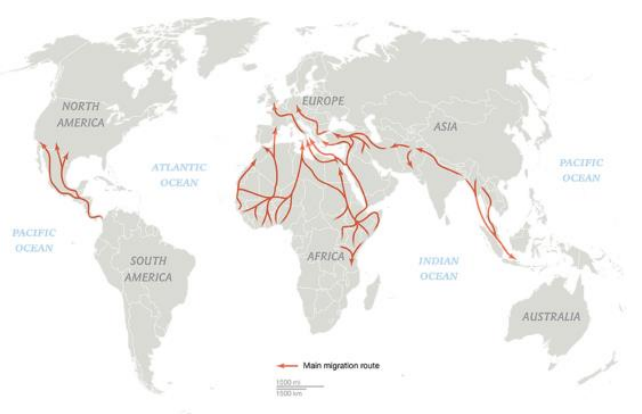

I showed the maps one at a time and each time asked the participants to call out the countries or areas that they understood to be the most peaceful, violent, and so on. I would then write these down on flip chart paper. I would do this knowing full well that the lists would only need to be written once. These maps give reasons for migration and in many aspects reflect Wilkerson's explanations of why people leave. The map of migration routes is important because although far from safe, journeying from Africa or the Middle East to Europe is achievable by land or sea. However despite being a relatively short distance a journey across the Mediterranean is dangerous as confirmed by this website that documents journeys: https://missingmigrants.iom.int/region/mediterranean.

I then give participants the following images:

\section{Image 7.1.6. Nigel Farage posing in front of Leave.EU campaign.}

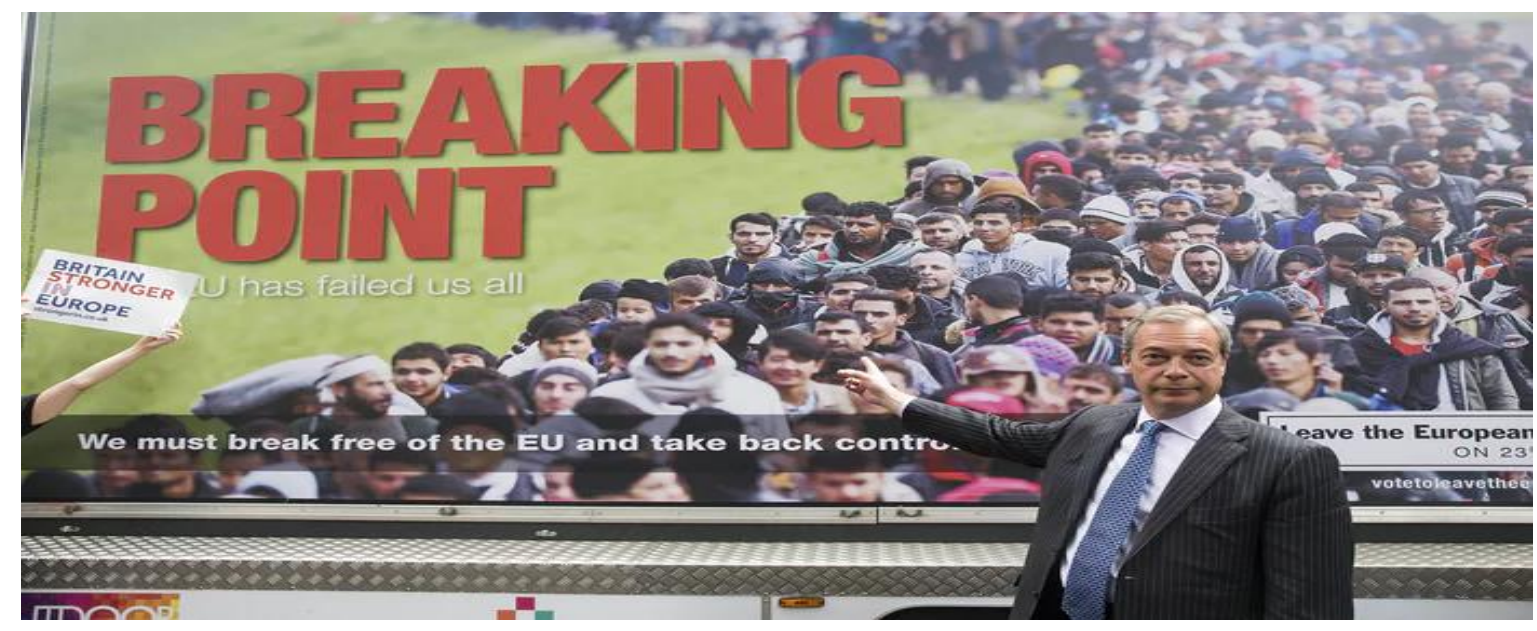




\section{Image 7.1.7 Photo of a boat of refugees.}

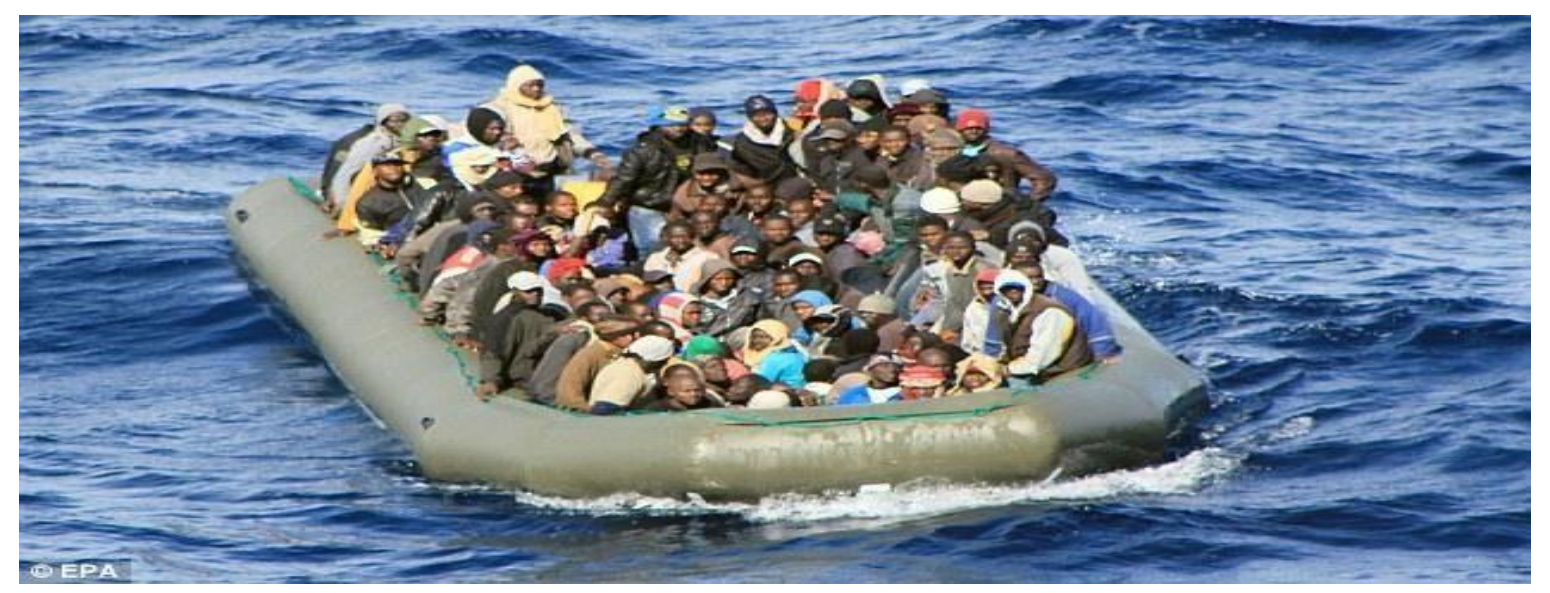

The participants look at these photographs and are asked to provide statements about them. They circle the statements that they agree with. The statements for the boat full of refugees were:

- I see people in danger;

- I see people fleeing war;

- I see people in need of help;

- I see people who are a danger to us;

- I see people who are looking to come to a rich country.

The statements for Farage were:

- We are being warned about a serious threat;

- I see people who are a danger to us;

- I see people who are trying to take our jobs;

- I see people being discriminated against;

- I see people having a hard time.

The participants can circle as many as they choose and add their own thoughts and feelings. I considered having no statements and leaving it entirely to the participants to write down their feelings. I felt however that many of them might not know what to write and this way would at least extract a view and potentially act as a prompt. It also managed the language used and avoided the use of any controversial or unacceptable phrases. 
Finally I would use the following two newspaper articles to explore the representation of immigrants and refugees in the press and ask the participants what they thought about them.

Image 7.1.8 Headline from front page of Daily Express Newspaper on 2/11/07.
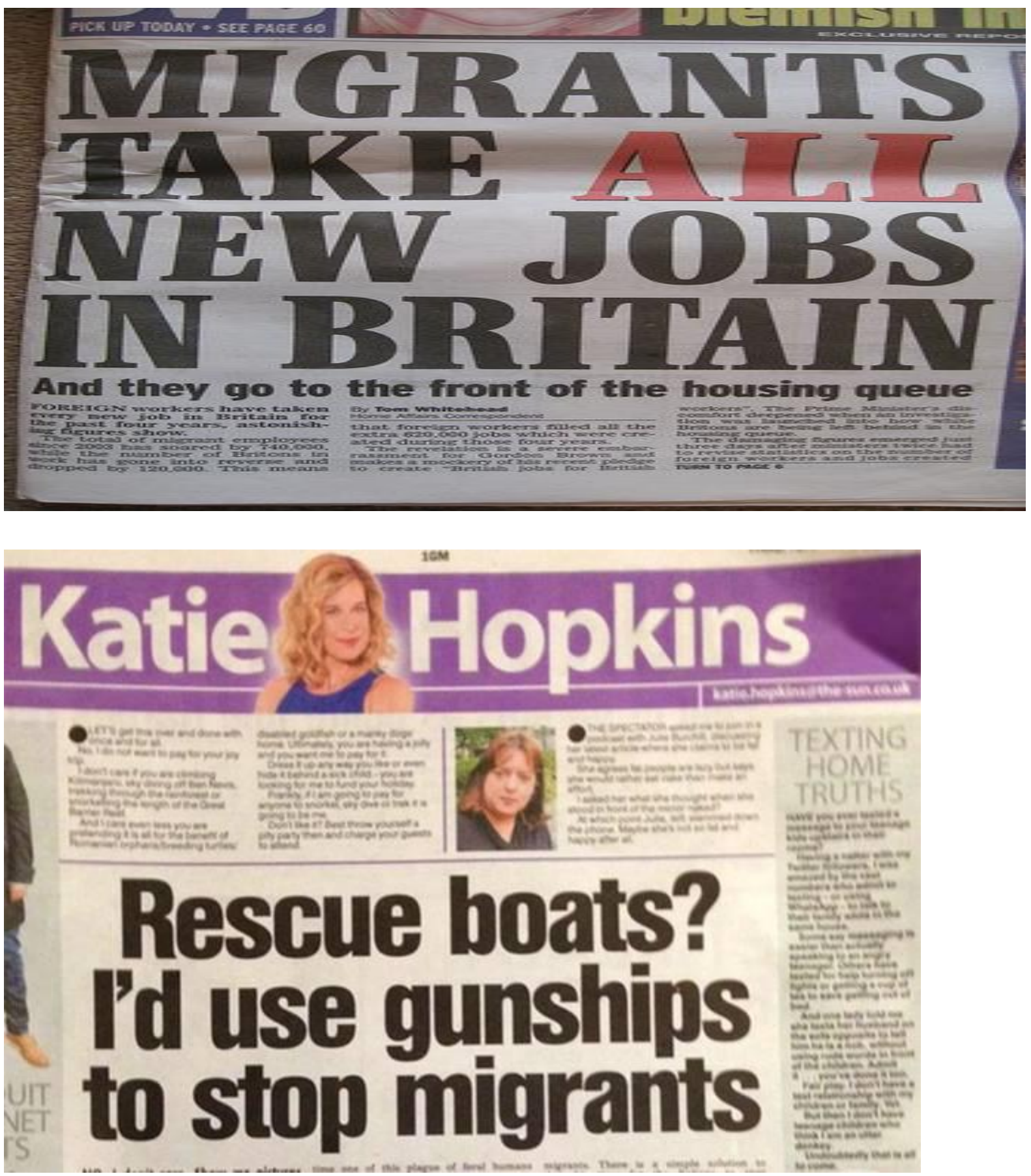

Image 7.1.9 Katie Hopkins Opinion piece. The Sun 17/05/2015 
Both these articles are good examples of the inversion of risk written about earlier, where the focus is on the potential threat faced by incumbent citizens rather than the actual danger experienced by others. Katie Hopkins is aggressive and makes no attempt to disguise how she sees immigrants as others who are dangerous and unwanted. The newspaper headline tells a blatant lie in order to portray migrants as a problem and threat to the members of our society. The lie is easily disproved by asking if anyone in the room knows someone who has got a new job in recent years. If by some highly improbable chance no one does then I can use myself as an example, having done several new paid roles over the course of the PhD. Yet the media representation can make people disbelieve or ignore the reality of their own existences. This activity is not necessarily an attempt at myth busting through a lecture or explanation but allowing people to explore the realities of their own thoughts and lives and develop some understanding and cognitive empathy to inform their own opinions.

\section{Delivery and engagement}

\section{Butetown Youth Pavilion}

I decided to start with the 'Most shocking...' video as the three females were a little restless and I thought it would grab their attention. Watching the video they quickly became sombre and you could hear the sadness in their voices as they discussed it. They brought up the fact that the girl had a mobile phone and explained to me that some people did not understand that refugees were not actually poor.

Next we looked at the world maps and when we came to the third map of vulnerability to natural disasters I asked them to give me some examples. I did this to make sure that they knew what a natural disaster was. After looking at the maps they were pleased that they lived in the UK, as it was very safe. They were happy to not be living in Africa. This use of Africa is orientalism in practice and I did explain that Africa is not a country:

\section{"Africa has got all the bad things"}

"we can buy food and turn on the tap to get water and only have a 1\% chance of earthquakes and in Africa they have to be careful of Ebola, have you heard the Ebola song?" 
I will come to the Ebola song shortly.

When we looked at the newspaper headlines, they thought Hopkins was suggesting that we shoot people and were angry at this. I did explain that this was not necessarily what she meant. I asked them about the jobs and housing and they told me:

"They (immigrants/refugees) have nowhere to live and if people have somewhere to live then by giving them bigger or smaller houses the new people could be living on the streets where it is very cold"

Next we looked at the picture of the people in the boat. All three of them discussed it with each other, and then agreed/copied each other and circled the following:

- I see people in danger;

- I see people fleeing war;

- I see people in need of help;

- I see people who are a danger to us.

The only one that they did not circle was this one:

- I see people who are looking to come to a rich country.

They saw the biggest and most immediate threat being to the people in the boats who could easily fall overboard and drown. They did not really look at the picture of Farage due to having lost interest in the session. I asked them to quickly summarise what we had covered:

"The reason people leave a country is to flee war, to get a better life and get greeted rubbishly"

"We don't welcome them to our country because they may take our jobs, blow us up or have Ebola"

"It's not good to judge someone by their colour" 


\section{The Ebola song deviation}

After I had answered no to their question about the Ebola song they pestered me so I allowed them to play it. I expected it to be a rude and irritating song, which I could turn off, give them a mild rebuke about and then carry on with the session. It turns out I was wrong as it is a song by the rap artist Rucka Rucka Ali and is in a parody of 'L.A. Love' by Fergie. The song humorously highlights the stereotyping of black people during an Ebola epidemic in 2014 through lyrics such as these:

"I'll tell you where it's from, Africa, West Side, it's packed in a suitcase, two days later it lands in the USA, I get it from my girlfriend, give it to my Dad, catch it in the subway, leave it in the cab, every city in Africa has Ebola and every city in America's getting it now"

After the song had finished, I talked to them about its meaning and the lyrics - not convinced that they got the message it conveyed. After they had moaned about how I had ruined something they found funny, they started to understand that people making assumptions about Africans carrying Ebola is as much stereotyping, labelling and othering as saying all Muslims are terrorists.

\section{Grangetown Youth Pavilion}

There were half a dozen males who were all keen to talk about many things and I started the session off with the 'Save the Children' Video. Here is an extract from my research journal of what happened:

"Listening to the audio of them watching a video, there is no sound from them and it's (the video) still horrific with just the words and no image. The young people found it powerful, you could tell by the weight of the silence with which they watched, not a pin drop of noise"

They saw the video as depicting something that was among us and that it "was reality" for many people. One of the participants described how his own mother had fled from Somalia, where she was a member of a wealthy family. He told me:

"Refugees aren't poor, some of them are rich, war don't choose" 
I could tell at this point that they were eager for group discussion so we looked at the maps, pictures and newspaper articles as a group. They understood why people came to Europe, because most had family members who had made that journey from Somali and Somaliland. With regard to the picture of the boat, they saw people:

- in danger;

- fleeing war;

- in need of help.

They did express the view that whilst they did not see these people as a danger or people determined to come to a rich country there would be people who did:

"Because they are judging a book by its cover and see people who want to come and bomb us"

Nigel Farage was politely referred to as a doughnut who was not warning us of a serious threat. Their reaction to the poster was:

- did not see people as a danger to us;

- did not see people trying to take our jobs;

- did see Farage discriminating against others;

- did see people having a hard time.

They expressed disbelief that people would believe Farage's message and embrace it;

"how could people do things like believe these posters as if they're intelligent it must bring them down and do damage mentally and some of them must realise it's wrong"

This sentiment was repeated when they discussed the Katie Hopkins's newspaper article; "I feel sorry for her, she's just a doughnut and people who agree with her are also doughnuts" 
By the tone of voice, I believe that this time they meant doughnut as in stupid or ignorant, rather than how they used it in reference to Farage, which was much more insulting. Their response to the jobs headline was one of anger. First at the insinuation that the immigrants were doing something wrong:

"They don't take the jobs they go and get them"

Secondly they were angry with the people who believed this kind of news:

"whoever says and complains about people taking their jobs and are on benefits, they just can't be arsed going on Indeed and just can't be arsed looking for a job online, think they should have free lives, smoke a lot and can't get their brains to think straight"

I brought up the subject of the risk inversion and they immediately understood and used the part of the newspaper article that related to immigrants going to the front of the housing queue:

"Because they have just fled war and are struggling and haven't got a house"

"Those people have got more risk than us, look where we are and look where they are $^{\prime \prime}$

"People who say they're taking all our jobs don't want these people to be on top of them, they want to look down on them"

"there is nothing stopping the people who say they're taking our jobs from getting a job"

This session was over two hours in length and the planned activities took less than $50 \%$ of this time. The rest of the time was spent talking about many things. Another focused on how Aaron Lambo, a bullish English bodybuilder and YouTube personality has compassion for refugees but contempt for the law and Police during which I challenged participants to not confuse the message with the messenger. President Trump came up and they thought he wanted to bring Islam down and the way to challenge him was to question what he said and not just dismiss him as stupid. There was some discussion about Stephen Yaxley 
Lennon, the former founder member of the English Defence League. He is more famously known as Tommy Robinson and at the time of this session he had just been jailed for contempt of court. They thought Robinson had planned his incarceration in order to gain more support. They hypothesized a scenario where Robinson was murdered in jail by Islamic fundamentalists, which resulted in civil unrest and a spiral downwards into the chaos of the 'Save the Children' video.

We discussed how Robinson presented himself as a journalist and defender of the victims of 'Islamic' paedophile gangs. The participants thought that the labelling of Islamic was unnecessary and that Muslims who carried out these acts were traitors to Islam. This led to a discussion of representations of Islam through the robe called a chemise. They saw this clothing as a sign of peace and religion but when traitors wear a chemise and perform horrible acts people draw connections between a chemise and the crime.

I would like to have explored this more but talking about Robinson would lead us to highly contentious and pernicious subjects. I felt that without any pre-prepared resources, it was better to steer the discussion back to the materials. This was dynamic reflexivity, meaning a decision made in the moment, as part of me did want to hear more about their views on Robinson.

\section{Monkton Priory.}

I started this session with the 'Save the Children' video, because again it was a good way of focusing their attention. They did not know what to make of it initially so I asked them about the Syrian war and the refugee crisis related to it. They did not know about Syria so I briefly explained this before asking them what they thought about the girl in the video having a mobile phone. They could understand why the girl had a mobile phone as they would never leave their house without one. When showing the maps I took some time explaining the difference between countries and continents and where different countries actually were. Eventually they began to understand why refugees come to the West:

"People from Africa come to Europe because it is safer, there is more money, jobs."

"Bring their kids up where there is no war" 
"To get away from their own country because it is bombed"

"They do not come here to piss us off"

The last comment provoked the following reaction from one of the participants:

"They do though, piss everyone off"

I asked how they did this and received multiple answers from several participants:

"They take all our jobs", "take food from Tesco", "Build up traffic", "They bring their children and there are loads and loads of children and it's too busy"

Some of these thoughts were repeated when we looked at the two newspaper headlines. According to them immigrants are worse than tourists for causing traffic so the gun boats might be useful. One of them did have this to say about Katie Hopkins however:

"Would be a completely different story if it was her though, then it would be all about 'oh, they're trying to shoot me and we want to come here because our country is at war'".

Two of the participants thought that the job headline was true. I then pointed out that they had both recently started new part time jobs this made them stop and think. On the subject of housing they thought that the homelessness problem in Swansea was terrible and that the homeless should be given priority. This was not a view shared by everyone with some of the participants believing that the homeless were all secretly rich.

It would seem that by and large these participants were concerned refugees would come to this country take our jobs, houses and food. I related it back to the video and they all agreed that the little girl was risking her life to get somewhere safe and when it came to refugees:

"Their life should be more important than chocolate"

I then showed them the picture of the boat. The immediate reaction of one of the participants was: 
"I don't want them in our country in case they bring a bomb, this picture makes me crazy because I'm scared of these people because you don't know what they are going to do"

Many of the other participants agreed with this view of potential behaviour. What they all did agree with was that the people in the boat:

- Were all people in danger;

- Were all people who need help.

The Farage picture had a similar impact on them with some torn between seeing people who looked like they needed help and because of the map activity the participants had more of a grasp of why they might be in transit. At the same time, they could not escape their fear of being bombed and saw Farage as warning us of a serious threat.

One of the participants was very vocal in her fear over what refugees and immigrants might do if they came to our country. It was she who was concerned about the traffic, had recently started a cleaning job and was most concerned about bombs. She is not the best learner due to an almost crippling low self-esteem manifesting itself in constant concern over her classmates' opinions and seeking their approval through either clowning around or attempts at outrageous behaviour. She is very quick to take umbrage when challenged, however this topic represented a genuine cause of anxiety for her and as such should be taken seriously. We had the following conversation about refugees:

YP: I don't like them.

Me: (softly) why are you scared of them?

YP: I don't know.

Me: You do know, just be honest, no-one is going to have a go at you for what you say.

YP: In case they bomb us. 
Me: And a lot of people feel the same and unless we discuss these issues, we'll never sort them out.

YP: they're going to bomb my home, they really, really scare me. I know what they've been through but they still scare me. I can't trust them, all the Chinese, Asians, Africans. They all look the same. Oh my God there is a spider!

YP exits loudly and locks herself in the toilet.

However over the lunch break she approached me and told me that she would quite like to meet some refugees because she thinks it might help her overcome her fear. It struck me that she did not like having these fears and wanted to change them but needed help and support to do so, which she had just asked for.

\section{Discussion and comparison}

This session responded to much of the research literature in terms of using empathy and the bystander approach. The video had a big impact in all three groups and established a form of empathy that was effective in how it engendered sympathy and compassion in line with Pedwell's (2012) views on promoting empathy through perspective taking. This avoided one of the potential pitfalls of affective empathy as it did not require them to have sympathy or acknowledge complicitness in the suffering of someone less privileged than themselves (Pedwell 2010). As explained by Mountz (2015) the suggestion of complicitness can play a role in the inversing of risk as it creates resentment in people who are tired of being blamed for things beyond their control. Therefore, this video establishes a counter narrative to the inversion of risk as it generated a strong element of what Yeomans (2016) would call self empathy in that its story, characters and setting allowed young people to directly relate to it. The use of video also fits with Katz, Heisterkamp and Fleming (2011)'s bystander model, as it creates a connection between refugees and the participants, by showing people who are like them or like someone they know. The scenario of this film was set within a privileged person's world and the unfolding drama seen through the eyes of a privileged child. Another aim of the bystander approach which was fulfilled by this video was that it created the environment for critical dialogue. This became more evident in the discussions around the photographs and newspaper articles. 
The use of the posters of the refugees and Farage and the two newspaper articles was influenced by Stuart Hall's (1997) work on the representation of the spectacle of the other. As Hall tells us: 'Representation is a complex business and, especially when dealing with 'difference', it engages feelings, attitudes and emotions and it mobilizes fears and anxieties in the viewer' (Hall, 1997: 226). The idea of complexity of feelings was certainly evident in the responses of the participants. In Monkton they had the conflicting emotions of sympathy and fear and there was almost an anguish to admitting that despite seeing people in danger and needing help they still had a fear for their safety. In BYP they had a similar reaction seeing the refugees in the boat as a danger. It was interesting that all the boat people were seen by these participants as a danger including some who saw them as potentially being terrorists. They were seen as 'a potential terrorist threat'. Hall's (1997) work deals with how pictures and their meanings are highly ambiguous and have multiple floating meanings that cannot be fixed. How they are represented may influence the feelings that they initiate in the observer. Certainly Nigel Farage is using the picture to represent others as a threat, in this case to our resources and space. In GYP they did not see any threat in the two photographs. If anything they passionately refused to consider the refugees in either photograph as a threat. This I believe was partly because of their experiences and partly because of the way I represented the photographs. Earlier in the session one of the participants had spoken about his mother's experience as a refugee and this representation could engage a different response from participants who would not wish to express a view associating a peer's mother with terrorism. GYP has a large Somaliland community and as such stories such as this are probably quite common. However had a participant in the Priory discussed a family members experience as a refugee I would have been very interested in how it would have affected the responses.

These findings respond to research questions on the participant's thoughts, views and opinions on othering and one of the significant factors of this activity could be that representation is key. This representation of threat comes from both the press and politicians. Dunn and Hopkins (2016) believe that the presentational geography of Muslims in particular, whether they be immigrants, refugees or living in western societies are stereotyped in the media as violent or potentially violent terrorists as part of "business models that benefit from the scandalising of public interest" (Dunn \& Hopkins: 2016:255). 
Dempster and Hargrave (2017) in an overarching analysis of literature and data regarding public attitudes towards refugees found that;

"The British press are more likely to frame refugees as potential threats to culture, welfare, security and the health system than any other country in Europe" Dempster \& Hargrave (2017:17).

Esses et al (2017) discuss how many politicians also use disparaging language to describe immigrants and refugees. This includes the use of terms such as "swarms and marauders" (Esses et al 2017;87) who are on their way to strip the UK's welfare system to the bone because they are "'a plague of feral humans' and 'cockroaches' and 'parasites'" (Esses et al, 2017:87). They found it was very rare for the focus to be on women and children or any detailed explanations given as to why these people travelled to the UK. They attribute this to a dehumanisation of these others and how they are represented as threats and lacking the necessary values considered important by the accepting group. Both posters and the newspaper articles are clear examples of these two types of representation. In this case however the pictures were presented in conjunction with the maps and other resources which created a broader and more complex narrative and this may have led the participants to have a more positive feeling towards the people in the pictures. By situating these photographs within a context where they could be discussed I gave the participants an opportunity to change the typical conversation about others. An example of this typical conversation comes from Squire (2015) who discusses how images of others at risk can quickly flip into images of the risky other. This trait is also present in the UK's Prevent programme with young Muslim men in particular being seen as at risk but also a threat. In the GYP and BYP it may be that the positivity came from recognising the real threat faced by the refugees and not just the potential threat they are often shown to represent. However in Monkton there still existed a high degree of irrational fear.

In some of the comments by participants in the Priory there were views which denied the reality of experiences. Tesco in Pembroke Dock has yet to run out of food, tourism is what causes traffic issues and two of the participants had recently started new jobs. Not only does this reflect the impact of a negative representation of refugees by elements of the media and politics but also the irrationality involved in forming these views. Mountz (2015) 
attributes this to the hypervisibility which draws attention to what is being done to keep us safe e.g. fences, border checks and stops, military patrols and the presence of armed police. Hypervisibility draws our attention to what is wrong, what is dangerous and ultimately to what threatens us. The hyper nature means that participants in the Priory ignore the real risk to life that refugees face on a daily basis but people can also reject the truths of their own lives. This gives further evidence to a neurotic form of citizenship and the importance of constructively challenging the media and their politically fuelled narratives. This was achieved to some degree in this session and is an important part of developing curriculum materials in this area. It is not simply a case of accusing the media or politicians of lying but allowing information to be shared and discussed.

To do this may involve exposure as a practitioner to different points of view and being prepared to tackle them. In 'The Warmth of Other Suns', Wilkerson explains the reasons and motivations behind migration, in other words her intention is to inform. Others such as Jean Raspail's 1973 novel The Camp of the Saints promotes fear of immigrants and refugees, but the author may well argue that he is not. Writing about another white supremacist novel, The Turner Diaries (1975), Lyle Stuart (1996) describes it as a best selling book despite not being available in bookshops. It was banned and consequently became a favourite of white supremacists. Yet Stuart believes it should be published, so that we can understand the values and beliefs of others and by knowing them we can do something about them;

\section{"People from all sides of the political debate seem to want to interfere with others} having access to ideas with which they disagree. In the spirit of free expression I'd suggest a far more appropriate course of action would be to expose and debate those ideas in a concerted effort to make certain that the truth emerges" (Stuart, 1996:5)

This is a standpoint I agree with and another learning factor in this session is the importance of exploring controversial subjects, particularly if they are brought up by the participants such as the case of Tommy Robinson. In a free flowing discussion it is impossible to predict what will come up but if I was to do this again I would try and develop contingencies for a situation like this. This is because Katawala et al's (2014) idea of the anxious middle could well be represented here by many of the participants. The question of who this anxious middle is exposed to and how the information is presented will ultimately influence their 
perceptions of refugees and migrants. At present the answer appears to be coming from newspaper headlines and politicians who dictate a climate around immigration to one defined through security and indeed the fear that this produces can be seen in several of these research sessions including this one.

This activity really seemed to highlight the difference in views between young people living in an urban city, and drawn from communities that had migrated to the UK over several generations, and a rural, largely monocultural area. Although the participants in BYP did highlight a potential terrorist threat they were much more matter of fact about this risk than the almost hysterical reaction of participants in the Priory. It very much reminded me of the C.U.R.E. project I refer to in my introduction, especially as one of the Priory participants requested a meeting with a refugee or immigrant. As I have seen this can challenge perceptions of minorities and refugees. It presents a real experience as opposed to a constructed one via the media or politicians. It does however require the practitioner to walk a couple of fine lines. The first is between recognising a person may have a gap in his or her knowledge or experience and suggesting or accusing them of being racist or stupid. Accusations can be perceived as covert as well as overt. The second is showing that immigrants are human and representing them in a positive light. But a positive stereotype can focus on an attributed inherent talent e.g. black people are good at sports, which still prevents a person from being fully seen. They still only see an individual insofar as they see them as part of a different group. Stuart Hall (1997) describes this process when he discusses how views of the other can vacillate between positive and negative.

This activity certainly informed participants of the many reasons why people come to the UK, especially refugees. The validity of these reasons predominantly comes from my positionality as a trusted practitioner through a combination of previous interaction and the approval of gatekeepers. The young people did not challenge my 'expertise'. No doubt my academic credentials and the rigour that accompanies them prevents me from simply making things up but did the participants view me as an expert and/or trusted source? Yet this presumed expertise could equally be attributed to politicians and the press through their status. In BYP and GYP in particular they appeared to embrace the fact that I did not present a fear and security based narrative. In the Priory many of the participants lack a general knowledge in subjects like Geography and aside from sessions such as these do not 
have many opportunities to discuss the subject material I present them with. This makes me wonder whether they believe who tells them more than what they are told. This demonstrates the enormous responsibility on individual practitioners not to use their position to further their own views. This can be prevented by good reflexivity, having good critical thinking and supervision, but will come down to the individual and the watchman of their conscience.

Another related consideration is what the participants should do with the information and adjusted views they leave with. Does it merely remain floating in their consciousness waiting to be regurgitated next time they happen across a related conversation? Might it embolden them to challenge views of othering and prejudice against refugees and immigrants, possibly in several years' time when they are adults? This session could be accompanied by positive action such as raising funds or collecting clothes for places such as the Calais refugee camp. Actions such as these may be laudable but would surely be open to accusations of adultism as it inculcates a clear point of view i.e. refugees deserve our help and compassion. I planned this session with the idea in mind that they would gain cognitive understanding and be able to make an informed decision as to how they felt about immigration and refugees. Ultimately, I feel that any acknowledgment or appreciation of the complexity of the situation presented is better than an almost blind acceptance of a monological view that others represent multiple threats. What the participants decide to do with this information is entirely up to them. 


\section{Chapter 7, part two: Against a Sharp White Background}

\section{Introduction}

In the activity 'The Warmth of Other Suns', I directly explored the world of macro-othering with the participants. This session was marked by trying to get the participants to look outwardly at the world. In this session I am attempting to explore micro-othering, the type that occurs daily and which most people have experience of. The aim is to promote empathy, this time through encouraging the participants to look inward at their lives and experiences. This would use elements of the bystander approach but instead of asking them how they would feel if it happened to someone else, getting them to concentrate on their experiences of othering in everyday life. This session is inspired and based around Claudia Rankin's (2014) book Citizen: An American Lyric, a book that left a lasting impact on my view of the world. Citizen: An American Lyric is described by Pinkosi (2017) as a book about how "racism violently affects citizenship within daily lived experience for a particular group of people" (Pinkosi, 2017:74). Hersi (2016) explains how the book deals with micro aggressions which are "brief, daily, commonplace verbal and behaviour" (Hersi, 2016:2) and these can lead to macro aggressions, which are; "blatant acts such as hate crimes" (Hersi, 2016:2). These definitions of micro and macro aggression are transferable to the concepts of micro and macro Othering. Reading it, I was forced to challenge my own assumptions and the ugly side of unspoken thoughts as exemplified by this extract from the book:

"At the end of a brief phone conversation, you tell the manager you are speaking with that you will come by his office to sign the form. When you arrive and announce yourself, he blurts out, I didn't know you were black!

I didn't mean to say that, he then says.

Aloud, you say.

What? He asks

You didn't mean to say that aloud.

Your transaction goes swiftly after that." 
Pinkosi (2017) believes that Rankine's writing as much as her ideas reframe how the reader looks at citizenship and racism and that the book "disrupts not only how citizenship is conceptualised, but also how it is written about" (Pinkosi, 2017:74). I would go further than this and say that the book demonstrates a creative and challenging approach to exploring citizenship and in the design and delivery of this activity I am attempting to answer Rankin's creative approach to citizenship with a creative response.

\section{Planning and preparation}

Throughout her book Rankin uses a variety of sources and material one that became central to this session was from Zora Neale Hurston:

"I feel most colored when I am thrown against a sharp white background........Beside the waters of the Hudson" I feel my race. Among the thousand white persons, I am a dark rock surged upon, and overswept, but through it all, I remain myself. When covered by the waters, I am; and the ebb but reveals me again."

'How It Feels to Be Colored Me.' The World Tomorrow. May, 1928,215-16

Rankin focuses on the first line; "I feel most coloured when I am thrown against a sharp white background" because of a piece of art done by Glenn Ligon in 1990.

\subsubsection{Against a sharp white background by Glenn Ligon}

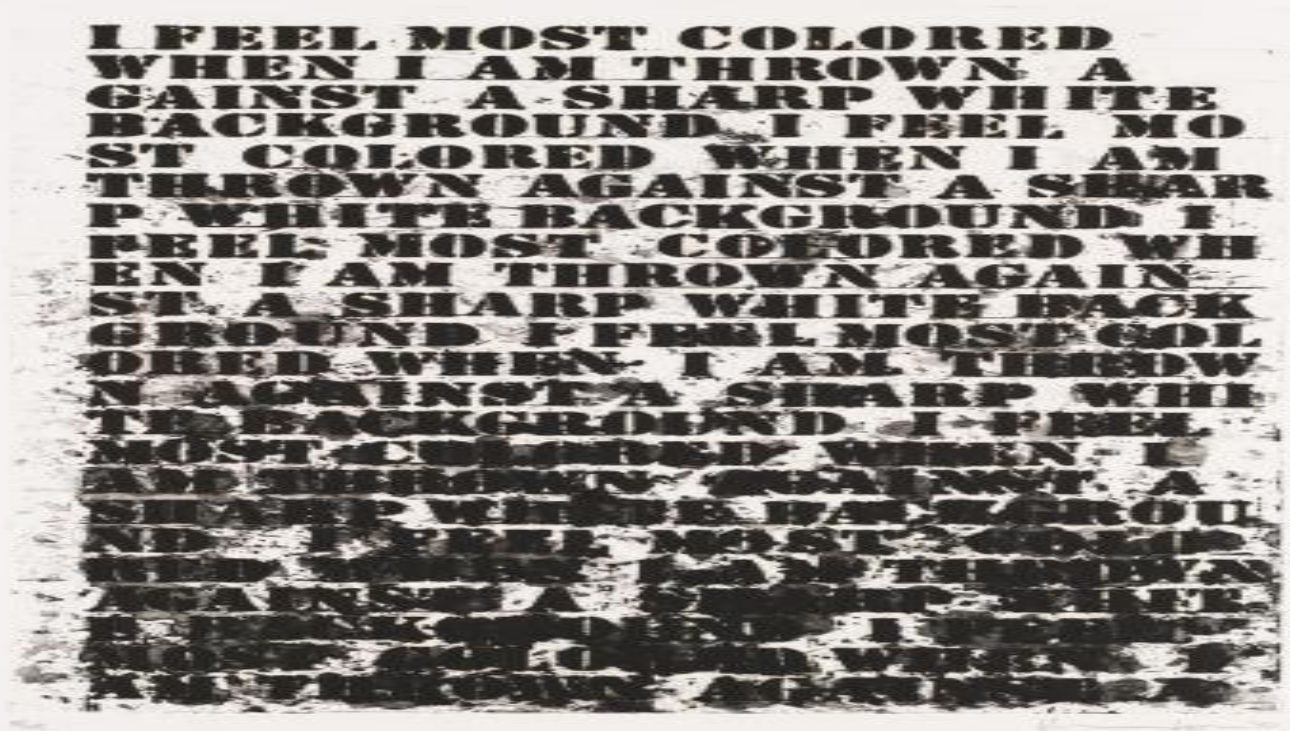


This line resonates throughout the book and is used as a theme for people struggling against microaggressions all their lives, which have led to outbursts of aggression and violence. The two examples from Rankine's many that I used are those of Serena Williams and Zinedine Zidane.

Serena Williams is a black tennis player and one of the most successful players in the history of the game. Rankin tells us that tennis is a game mostly played by white middle class people and Serena is not seen as welcome in their world:

"Her black body, didn't belong on their court, in their world" (Rankine, 2015:26)

One example she gives of this is when Serena was criticised for being immature and classless due to a three second celebratory dance at Wimbledon that was labelled Cripwalking. Instead of recognising that she was celebrating winning a Grand Slam title and a large cheque the connection to black gang culture was almost seamlessly made. The most powerful example Rankin uses to discuss Serena experience of microaggressions was a 2004 match against Jennifer Capriati in the quarter finals of the US Open. This incident forms the basis of one of these session's main activities. In the match there are four line calls that go against Serena and she loses the match. These line calls are all wrong and at one point Serena approaches the chair umpire and demands answers about what is going on. Rankin explains that Serena is clearly suspicious of racist motivations, but does not overtly express them. Serena was heavily criticised for her reaction and that she should not have behaved that way on the tennis court. Rankin points out that Serena's reactions were not just about that moment, but a reaction to the everyday microaggressions she has faced in her life. Rankine describes this as the unseen and the invisible provocation, but her reaction is the visible seen that judgements are made on.

The use of Zinedine Zidane focuses on the former French footballer's behaviour in the 2006 men's football World Cup Final between France and Italy, held in Germany. Zidane, a son of Algerian immigrants, was playing in his second world cup final. He was the French captain, talisman and playing his final game before retirement. He was voted the player of the tournament and had scored a penalty to put France ahead in the game. The Italians equalised through their defender Marco Materazzi and it was these two players who were involved in an incident almost more famous than the match itself. In extra time Zidane 
jogged past Materazzi when he suddenly stopped, paused and then headbutted Materazzi in the chest and was sent off. France went on to lose the game in a penalty shoot out. Materazzi scored his penalty. Rankin writes of the accounts of lip readers who believe Materazzi said the following things to Zidane:

- Big Algerian $\mathrm{s}^{* *} \mathrm{t}$;

- Dirty terrorist;

- $\mathrm{N}^{* * * * *}$.

Rankine also shares with us Zidane's own words to explain why he did what he did:

"Do you think two minutes from the end of a World cup final, two minutes from the end of my career, I wanted to do that? What he said "touched the deepest part of me" (Zidane as quoted by Rankine, 2015:128)

Rankin sees this is another example of a person who has experienced a lifetime of othering because of his heritage decided enough was enough and that he would no longer let it pass. In this case it resulted in an explosion of violence. However as with the Serena incident it was the reaction and not the provocation that was focused on. In the eyes of many people his reaction was to be expected:

"For all that he is, people will say he remains for us an Arab. 'You can't get away from nature'” (Frantz Fanon as quoted by Rankine, 2015:124).

I prepared powerpoints of these incidents with pictures, video links and the relevant quotes but as in previous sessions I did not set a strict order in which to present them to groups. What I did want though was an introduction to the subject in order to establish a suitable environment and chose the film version of To Kill a Mockingbird. A key rationale behind this was that as it is taught in schools it has respectability, meaning the unfairness and othering it portrays is widely accepted as wrong. In keeping with the theme of the sharp white background I decided to show the participants the trial of Tom Robinson and get them to be the jury and decide whether Tom Robinson was guilty beyond reasonable doubt. To emphasise the sharp white background I used this still from the film, with the caption Tom Robinson standing out against a sharp white background: 


\subsubsection{Still from the film version of To Kill a Mockingbird - Atticus Finch and Tom Robinson.}

\section{Source:Pinterest.com.}

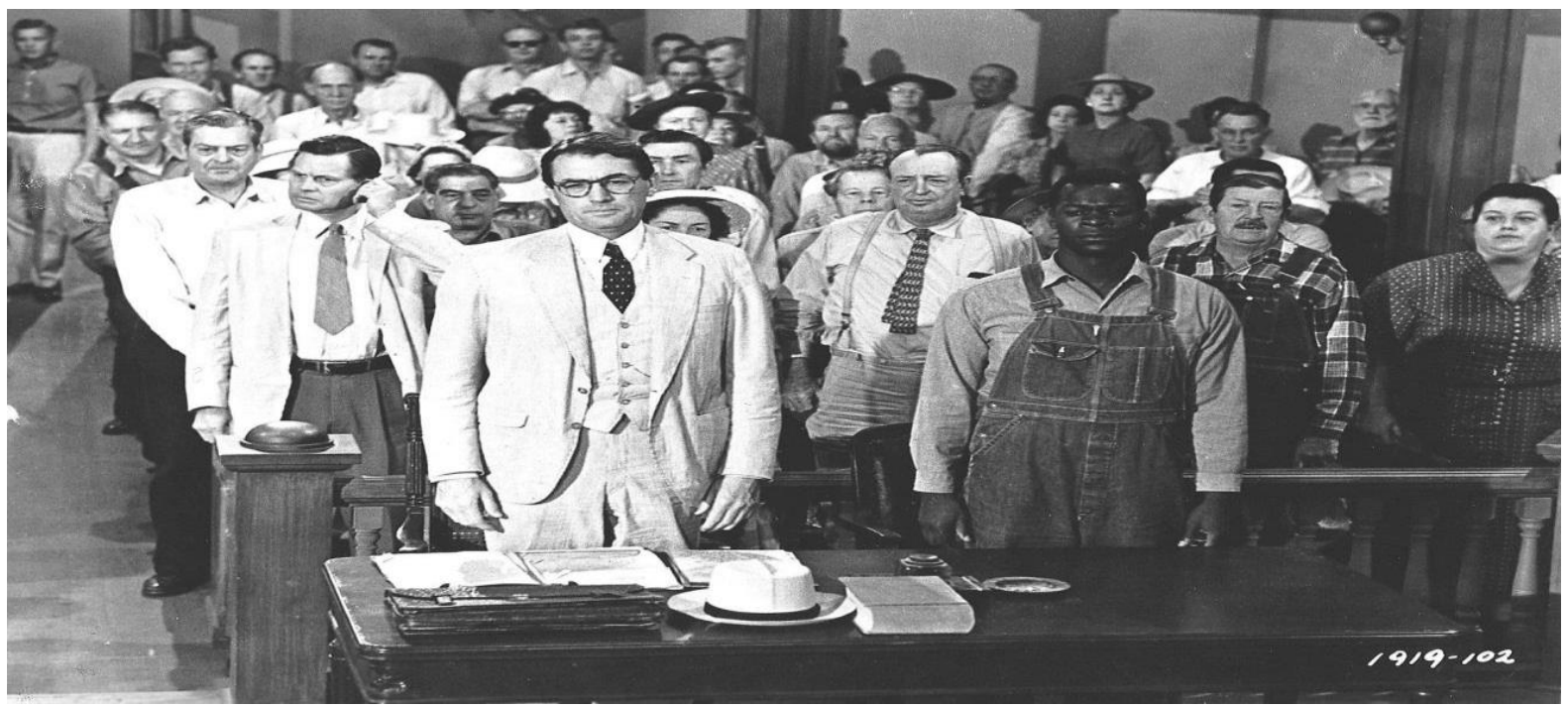

While preparing this it occurred to me to look for similar examples of Serena standing out against a sharp white background. After some searching I found the following photograph:

\subsubsection{Women's tennis association at forty. Source: WTA tennis.com}

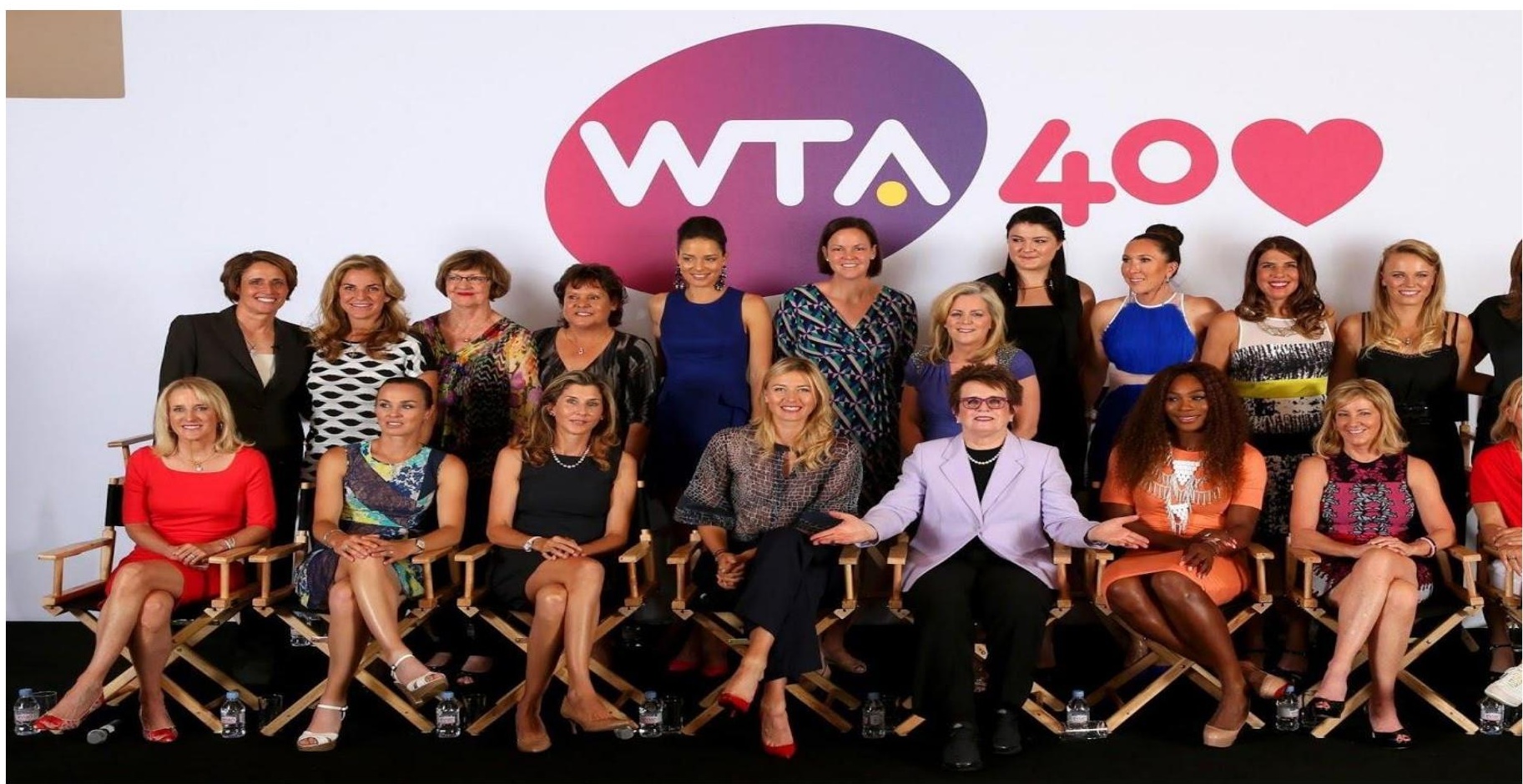

This is a picture taken at an event to celebrate the $40^{\text {th }}$ anniversary of the Women's Tennis Association. Serena is the only black woman in this photo. There are a lot of athletes in this 
picture who Rankine would see as having the right kind of bodies to be on the tennis court, what Rankin calls the "image of smiling blond goodness" (Rankin, 2015:36). I used this picture after showing them the clips of the bad line calls and related it to the still of Tom Robinson and asked the participants if they understand how some people feel most coloured when thrown up against a sharp white background.

The final part of this session is an activity designed to make them think about when they have been thrown up against a sharp white background, and when they may have done it to others. In other words I ask them to share with me when they have othered and been othered in their lives and explain why they think it happened and how it made them or the other feel. In this activity othering can be anything, from height to speech to hair colour to race and religion and they were asked to do it on a sharp white background to write on:

\subsubsection{A Sharp White Background.}

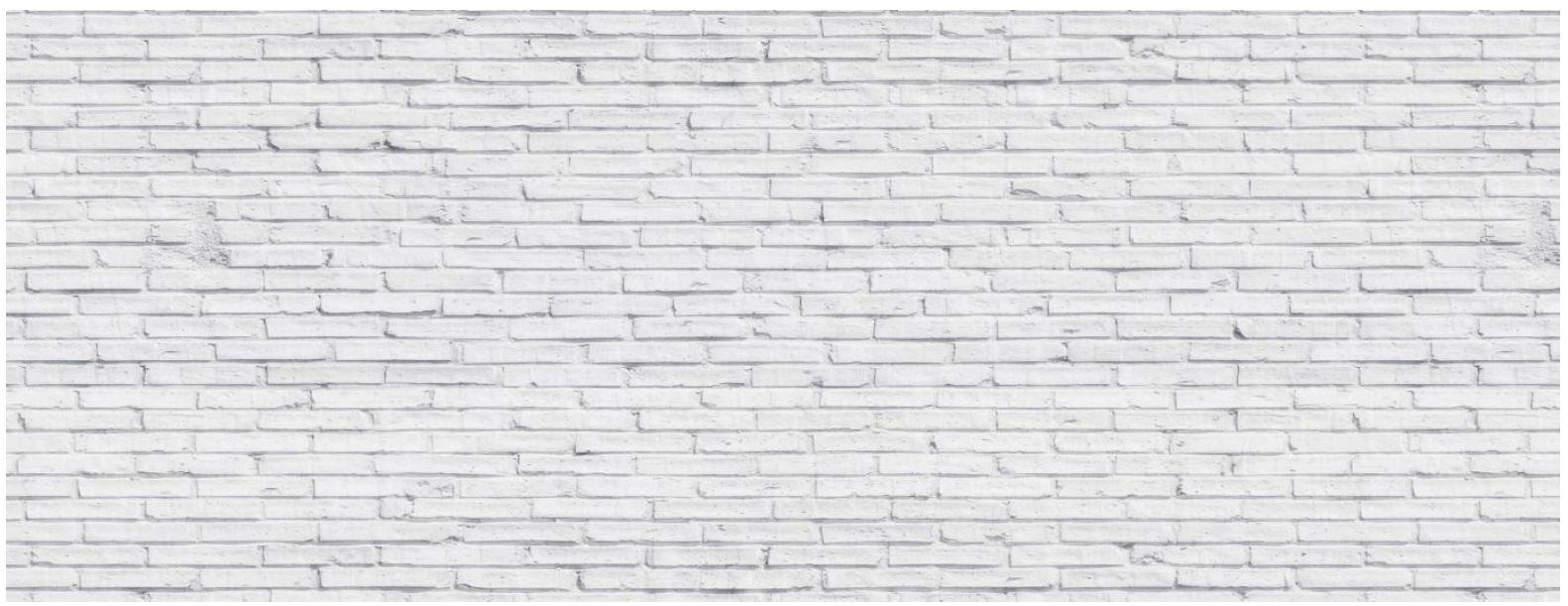

\section{Delivery and engagement}

\section{Butetown Youth Pavilion}

This ended up taking place over three weeks and so was very disjointed. In the first week they went on a very short notice re-arranged trip to Cardiff City football Club. The second week was the lead up to Eid Al-Fitr and the participants were preparing themselves and on the third week they wanted to make a Chicken Biryani. The first week I began with 'To Kill a Mockingbird', which did not go down very well with the three participating females. They were studying the book in school and thought: 
"To Kill a Mockingbird is some boring $s^{* *} t$ ", "It's rubbish, I fell asleep in the second chapter", "I fell asleep after the first word"

I temporarily changed the subject and asked them what they remembered from the previous week and after a little thinking came up with:

"Immigrants tend to come from where things are bad to where things are good". I next asked them to come up with a sweeping statement or stereotype:

"All Muslims are terrorists, they're not though"

The participant who said this addressed this last part directly to the dictaphone, she wanted to make that very clear. Having given them time to express themselves they agreed to watch the movie excerpt. As they watched it they changed their minds about the film and were genuinely keen to watch all of it. I asked them what they thought of the trial and one of them said the following:

"There's lots of reasons to think that Tom Robinson did not commit the crime but that he would have been found guilty because he was black,"

After the shaky start, they were getting into the session as the controversy had got them indignant and involved. They began to get angry at the injustice when they watched the Serena Williams clip. Unfortunately at this point in time a coach from Cardiff City Football club turned up to take them to a soccer skills evening. Two weeks later only two participants returned but I was joined by the Centre manager and a young youth worker who were interested in the subject matter. I started where I had finished with the Serena Williams tennis match. They thought it was highly likely that Serena was being discriminated about and that she would have been ignored if she had complained about racism. When I showed them the picture of the ATP fortieth anniversary the first thing they noticed was that Serena was the only black woman.

When we looked at the incident involving Zidane they were shocked and appalled by what Materazzi was alleged to have said to him and had a positive reaction to Zidane's explanation of his actions. They expressed views that demonstrated that they were viewing the incident beyond and past the singular action of Zidane: 
"It's easier said than done to say hold it together if you've been taking this crap for so long. It could be the last drop that overflows."

"Maybe he always wanted to do that"

"He'd had enough and put up with it his whole life"

I then brought in the white wall and asked them about their experiences of othering. The centre manager shared an example from her professional life. In a previous role as a supervisor of a team of Learning Mentors in a predominantly white school she experienced problems with a lack of support and cooperation from the school's senior staff. She knew that she was doing her job properly and queried the school as to if there may have been an issue with her race, a suggestion that was immediately and abruptly dismissed. I was hoping that this would spark the participants into sharing their experiences but at this stage they had begun pestering the youth worker to supervise them making a chicken biryani and so the participants merrily skipped away to make curry, which I had some of.

\section{Grangetown Youth Project}

This final session saw five young males participate. I give them a brief introduction to the subject matter of the session and learning from what I did at BYP asked them for an example of a sweeping statement about a group of people:

\section{"All Muslims are terrorists"}

Again, they want to make it very clear that this is not true. I reassured them I know it is not true and asked them if they could give me some other examples;

"Young people steal", "young people do drugs"

Before showing them the film clip from 'To Kill a Mockingbird' I asked them what they knew of the treatment of black people and they shared with me some knowledge about slavery and the Kul Klux Klan. After watching the film clip they all agreed that Tom Robinson was not guilty. They cannot understand why he would be found guilty and I reflected this back to them:

Me: Why do you think? 
YP: Because he is black?

To introduce the sharp white background I showed them the still of Tom Robinson in court and asked them to consider how he must have felt surrounded by all those white people and on trial for his life.

When they watched the video of Serena in the US Open they were appalled by the line calls. They struggled to express their thoughts and feelings as they could not understand how the calls were made. I asked them if they thought the umpire was racist:

"Maybe"

We had a brief discussion about other possible motivations for the bad line calls and they offered gambling, match fixing and bribery, all of which have featured in sports. When we started watching the clip of Zidane one of them remarked that Zidane looked like an Iraqi. They were touched by Zidane's explanation of why he did it and simultaneously recognised that in that moment it was very calculated. One of them said:

"Zidane should have head butted him harder and knocked him out"

They believed that words were really hurtful and one of them summed up how much damage they can cause by saying:

\section{"All fights and wars start with talk"}

After this we went about exploring othering and I gave them a minor example from my own life to show them that I trusted them in the hope that they would trust me. One participant told how he had arrived in Wales four years previously and spoke no English and was othered because of it. Not being able to understand and speak the language made him angry. Other students would think him stupid and take his stuff but he could still understand actions and tones of voice. This othering made him angry and when he retaliated to this bullying with fighting back he got into trouble. In his words it made him feel:

"Pissed off in the head as I couldn't speak out loud, I couldn't talk to the teachers or anything" 
He then went on to say that when he learnt English one of the first things he had done was join in abusing another pupil for having ginger hair. He said he did not always understand what he was saying but understood what he was doing and felt sorry about it later, but by then the boy had left the school. Another participant explained that he was a refugee from Sudan and felt that he stood out against white people because he had different coloured skin. Another thought that having the name Mohammed would go against him when he applied for jobs and see him treated differently if he was queuing to get on a plane. They spoke collectively about how they felt Othered outside of Grangetown and told me that they had all been in fights at school between youths from different areas of Cardiff. Through this discussion they were able to realise that if someone from another community came to Grangetown they might feel Othered. We concluded the session with the following conversation:

YP: People feel the same thing as I feel when they treat me different

Me: How should we treat everyone?

YP: we should treat everyone the same?

Me: Is that easy to do?

YP: No!

Me: Why do we treat people differently?

YP: Because of how they look, how they dress, how they act. What's fair and what's not.

Me: Do you think we're the same?

YP: Yes

YP: No

YP: Yes we are, but we're not, we have differences and are different in different ways Me: Does this make people dangerous?

YP: No 
YP: Treat them like how you would like to be treated.

YP: Because they'll think the same about you, it goes both ways

I thanked them very much for their time and their contributions. One of them told me that this session had made him think and next time heard someone saying something about race, colour or religion he would stand up to them. Even if that thought was only a fleeting one, it was a good ending.

\section{Monkton Priory}

There were five young people in this session, three females and two males. I started by asking them to come up with some examples of sweeping statements. They responded with the following:

\section{"All Muslims are terrorists"}

"Gypsies cause havoc everywhere"

"Stinking gypsies"

"Blondes are all stupid"

They clarified this last one by telling me that:

"A dumb blonde is not dumb because she is a blonde"

We then watched the film clip and one participant asked the astute question of how Tom Robinson had not been killed prior to the trial. I showed them the previous scene when the townsfolk do attempt to kidnap Tom Robinson and Atticus faces down the lynch mob, with the help of his daughter Scout. When I asked them for their verdict four of them said innocent and one said guilty, but immediately changed her mind to agree with the majority. She could not or would not explain her original answer. The four participants who said innocent thought it hardly surprising that he was found guilty given the time, place and allwhite jury.

I then showed them the video of Serena, and one of the participants remarked: 
"There is no evidence of racism, but I can understand why she might think that there is".

When I showed them the picture of the ATP fortieth anniversary one of the participants pointed out:

"They're all white, apart from her"

When they saw the Zidane video all the participants thought it was right that he was sent off. However when they learned about his heritage and what was allegedly said to him they changed their mind:

"If someone punches you, you can get over it, but if someone says something to you, it gets stuck in your brain"

They understood that Serena and Zidane may have been treated differently and in a negative fashion within their sports because of their background. They were torn in whether responding to provocation was the right thing to do. They pointed out that Materazzi won a World Cup and if he was a racist then being head-butted would not have changed that:

"But if you don't respond you're just letting them get away with it" The exploration of the participant's experience of othering was an interesting and occasionally surreal experience. The first thing they did was reference it to the 2017 film Wonder which is about a young boy born with a rare facial deformity and the issues he had in school:

\subsubsection{Still from the film Wonder}

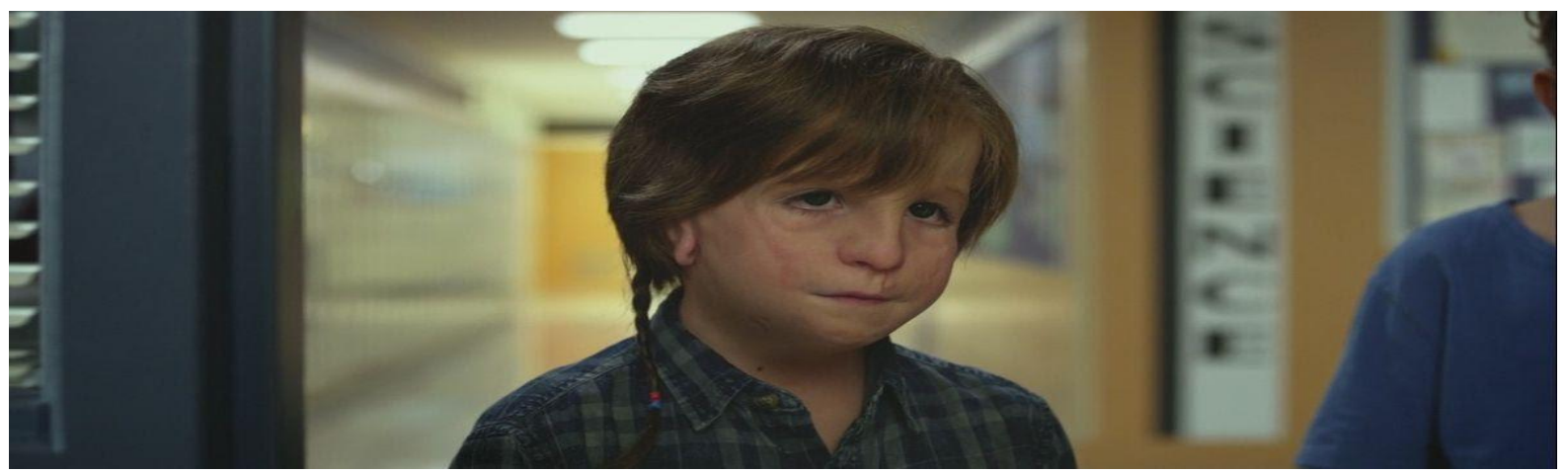


I asked them to think of ways in which they may have been treated differently and to write them down on the white walls I had given them. There then broke out a massive argument over how to spell certain words, which got so heated that I had to intervene and move one to a separate desk. Inadvertently leading to the first example of being othered:

YP: I'm being treated differently now for being moved!

Me: How does that make you feel?

YP: Really angry

One participant shared a story of how he had heard boys on his college work experience course use the word 'gypo' to describe a bad workman. Another boy told me of a time in a vocational training centre a group of Comprehensive school students called him and his small group racist names. This would have led to a fight if staff had not intervened. One of the females spoke about how in her old school she was constantly getting into trouble because she was getting into fights and one of the reasons was because of the racial abuse she was receiving. It was this that led her to leave mainstream education and come to the Priory. The participant who had been moved seats then said:

"I've never made anyone feel bad and I've not othered anyone"

The participant who she had the spelling argument with replied:

"You call me names all the time, like guts and cheesy hair"

Another young person then told me of how one time he was picked on in a local playground as a child because he was a gypsy and some children would not play with him. He explained it by badly attempting to adapt the lyrics to Will Smith's song from The Fresh Prince of Bel Air. I realised then that the session had run its course, the allotted time was almost up and so on this moment of merry harmony I finished my research with them.

\section{Discussions and comparisons}

What was significant in this session was when asked to come up with a stereotype of people mentioned ones that directly related to their ethnic group. In BYP and GYP this was about Muslims being terrorists and in the Priory about gypsies being seen negatively, causing 
havoc or stinking. I believe from context that stinking refers to the stereotype that gypsies leave rubbish wherever they go. The very existence of these stereotypes means that those mentioned are being othered. One of the strengths of Rankine's (2014) work is that it tells the stories of everyday racism and othering as experienced by a particular group of people. When the participants were asked to share their experiences of everyday othering all groups came up with experiences related to the initially stated stereotypes. In both the Priory and GYP this had led to near or actual outbursts of violence. Sue et al (2007) offer a very good distinction of microaggressions, calling them:

"Brief and commonplace daily, verbal, behavioural or emotional indignities, whether intentional or unintentional, that communicate hostile derogatory or negative... slights and insults... Perpetrators of microaggressions are often unaware that they engage in such communication when they interact with racial/ethnic minorities" Sue et al (2007:271)

The examples given in BYP and the Priory of the member of school staff and the young person on a college course reflect the potential unintentional or unaware micro aggressions. However in the Priory and GYP the young people gave examples of intentional verbal racial insults and these led to physical explosions of violence, just as in the case of Zinedine Zidane. In GYP they openly supported Zidane's act of violence against the Italian, believing he should have gone further. In Monkton they did not go quite this far but certainly understood how he must have felt. Rankin (2015) quotes Frederick Douglass to explain;

"But at this moment - from whence came the spirit I don't know - I resolved to fight; and, suiting my action to the resolution" (Douglas as quoted by Rankine 2014:128).

Perhaps this is how the males in GYP and the Priory felt when being verbally attacked for their ethnicity. What is sad about this is these incidents took place in educational institutions where they should have felt safe. The male in GYP told how he perceived the school punished him and ignored the othering he experienced, just the same as the female in the Priory. There was the fear in GYP that their name might see them discriminated against in the future. 
All the incidents spoken about by young people could be said to be microaggressions and examples of everyday racism or othering. This supports othering debates such as that of Essed and Goldberg (2002) who discuss how every day racist micro aggressions are in fact "common societal behaviour" (Essed, 2002:447). This takes the form of racist practice which will be familiar, recurrent and repetitive to the recipient of the practice. Essed and Goldberg (2002) see three strands to this everyday societal behaviour. All three of them can be applied to the experiences of this session's participants. The three strands are as follows:

- Marginalisation;

- Problematisation;

- Repression.

Marginalisation is when there is social exclusion or special treatment for those who are different. This could be treatment at an airport or the fear that one participant had that his Muslim name may effect his job opportunities. The same can be said for some of the Priory participants who may believe that they will also struggle to find work because of stereotypes of gypsy workmanship and tidiness. Problematisation is when the differences of other ethnicity and identities are othered they can ignore the commonalities of birth, shared cultures and language. All the participants live in Wales yet have experienced different treatment. The third, repression, is very interesting and relevant to this session. The everyday microaggressions are met with resistance but this is met with counter claims of oversensitivity or humiliation. Rankine (2014) demonstrates this in how Serena is criticised for her on court outburst and Zidane sent from the field, their provocation, perceived or real, rooted in daily suffering and historical persecution, ignored. The centre manager in BYP, the pupils who fought in both GYP and the Priory all shared the same experience of having their concerns over possible racist motivations dismissed, and in the latter cases punished for their reaction to the provocation. Knowing this, it is no surprise that they quickly understood how Serena and Zidane felt.

Rankine (2014) talks about the line calls in Serena's game dividing the world into the seen and the unseen. The seen was the outburst and reaction and the unseen is the micro aggressive racist incidents she has experienced her whole life. Rankine believes that these repetitive occurrences build up and that "the daily diminishment is a low flame, a constant 
drip" (Rankine, 2014:32). None of Serena, Zidane or the project's participants resorted immediately to violence in the face of persistent micro-othering. Hersi (2016) believes that the repression of micro aggressions means that the root of the anger is not recognised as valid and because of this there is a fear of standing up to it. Instead it becomes an issue which "you can deal with personally. No-one will ever know except you" (Hersi, 2016:75). Rankine (2014) believes that this suppression of this daily drip, which can dramatically affect how a person feels, can manifest itself in acts of verbal or physical violence. The feelings that precede these outbursts could perhaps be best reflected in the words of the participant from GYP who found not being able to speak the language, being othered and ignored made him "feel pissed off in the head".

In other activities I have talked about many aspects of citizenship including rights and responsibilities, security, freedom and rights to remain to name a few. These activities have included a lot of discussion around race and racism. However this is the only session that firmly fixes its attention on the othering element of my research questions. It attempts to create an understanding of this but judging from their own experiences most of the participants already understand about their existence and live with micro and macro racism, discrimination and othering. Like Serena and Zidane they are all members of ethnic minorities that have suffered macro aggressions such as securitisation of Islam post 9/11 and the restrictions on Traveller rights. Rankine (2014) believes that a nation can be selective in what it decides to remember and when. In the case of Serena her critics forget about slavery and segregation when she questions if there is racist motivations involved: "Forget all that the world says. The worlds had a lot of practice."(Rankin, 2014:6).

This treatment of history as a buffet of convenience may be linked to white privilege. It is worth noting that on both occasions the sporting officials were white and that many of the participant's stories featured white people as either antagonists or those who responded with repression or focus on the singular act of aggression. In the introduction I have already spoken of Pinkoski (2016) belief that Rankin's work makes the reader re-examine how they view citizenship. Pinkoski (2016) makes it reader, including me, see the unseen provocation behind these outburst and this means: 
"The reader is compelled to re-order their perceptions of citizenship to account for these newly evident spaces, as well as to account for their own racially-assumed narratives" Pinkoski (2016:76).

I believe that Rankin's exploration of Zidane's behaviour not just explores the triggers of when the drip turns to an outburst, but also how events are singled out, represented and viewed through the context of when they happen, therefore stripping them of all history and nuance. The context which the Zidane incident is looked at through is that of a football match, where of course head butts should not be allowed. For the young female in the Priory it was through unacceptable behaviour in a school, where fighting is not allowed. Rankin (2014) believes that during and after the outburst a person's race, colour, ethnicity and religion are "rendered hypervisible" (Rankin, 2014:49). This may be down to white privilege, of which a model belonging to McIntosh (1998) is presented by Hersi in relation to Rankin's work. McIntosh (1998) believes that white privilege assumes the existence of racial equality, much like the repression of everyday micro aggressive occurrences it encourages the reduction and eradication of history and replaces it with the belief that opportunities are now universally available and that the past is the past. This ties in with Essed and Goldberg's (2002)third strand of everyday racial microaggressions of repression, as a white person who believes in equality may see the victim of racism as being over sensitive.

Much of this has resonance with Pedwell's (2012) contention that the complicit element of affective empathy is now being eroded. Acknowledgement of everyday microaggressions would require contrition and re-evaluation of our daily practices and thoughts and that does not sit well in a populist, one nation country. We conveniently forget our role in history and instead as suggested by Mountz (2015) inverse the risk. Inversion could then become the fourth strand of the denial of everyday racial microaggressions. If the explosions of physical or verbal violence by the minority or victim are seen as direct aggression against the majority or perpetrator it could be deemed a threat, other and worthy of policing. This additional strand would also account for the neurotic citizen and incidents such as the securitisation of Muslims, the deportation of the Windrush generation and concerns over the amount of money spent on foreign aid. 
This session speaks to different ways of developing citizenship curriculum materials. Patel (2017) discusses how citizenship as a subject is often introduced to young people in schools through subjects such as history and social studies. Within these subjects citizenship is not always overtly taught and instead may be an ancillary support. An example could be exploring what life was like for people living in Britain in a certain period of history e.g. World War I. This might focus on the work, food and clothing of the time not subjecthood, restrictions on voting and the global rise of socialism. The reaction of the participants in BYP to 'To Kill a Mocking Bird' was perhaps an example of this. They were studying it in English and having taught this text myself no doubt they were exploring themes of prejudice, loyalty and family many of which skirt around ideas of citizenship but they were not enjoying the story. In this session they did enjoy it and this may possibly be due to showing its wider application and relevance to their experiences. This may be self aggrandisement on my behalf but it does seem to suggest that there is room for cross subject learning. In history a student may learn about the macro-aggressions of the Jim Crow laws and in English the micro-aggressions endured by Tom Robinson, but never both and the same time.

It is interesting that most of them began to understand the power of words and the harm that can be done with them, sometimes without realising. It is also interesting that it is easy to shock and appal people with the Serena line calls and the Materazzi words. Creating indignation and anger is a powerful tool and therefore has to have accountability. Now the academic, public servant or journalist will have supervisors, managers and editors but surely it has to begin with the individual in the position of power, to know the power that they potentially have and to be measured in how they exercise it. Afterall;

"Perhaps the most insidious and least understood form of segregation is that of the word" (Ralph Ellison as quoted by Rankine, 2015:122)

Looking back at this session I realised that I was influenced by the success of this activity in the pilot project. In the pilot all my participants were white, British young people and they embraced the term othering through discussing Serena and Zidane and their own experiences. Their experiences were not racially motivated and instead concentrated on appearance, family reputations, fashion sense and communication styles. In this session the energy and change was dramatic and evident and I remember not being able to sleep for 
many hours because of the adrenalin the session gave me. I learned later that they had begun using the term othered and were discussing their unintentional othering actions with each other. Two of the participants befriended the Syrian refugee in their school and brought her to their youth project. This filled me with pride and a sense of a job well done and I looked to repeat this in the research project. What I learned from this session was I had not realised I was working with participants whose experiences could have been used by Rankin in her book. They have been called a 'stinking gypo' or 'Muslim terrorist' and the success I had in the pilot where I bestowed my new found enlightenment like a white intellectual saviour upon attentive white participants who responded appropriately was not relevant. In these three sessions the participants were actually continuing my education and teaching me about othering. I cannot help but think it was hubris that prevented me from seeing how this would be the case, as in hindsight it seems obvious. Still, the environment was a safe one and my approach was flexible and the issues were explored and discussed and I learned from them. This rings true to one of the principles of participatory action research in that it is a partnership between the researcher and their participants. This was perhaps never more the case throughout this project as in these sessions.

Of course that then asks the question of where to go with this activity in the future? I believe that this session does allow for the invisibility of context and nuance to be made visible, and that this creates empathy and critical thought. In the Priory this session could have been an opportunity to encourage the participants to use their experience of racist othering to challenge their previously stated views on immigrants and refugees. Anonymised these accounts could add to the activity and be used as examples of real life incidents in Wales. I would also be interested in developing role plays of some of the microaggressive examples that Rankin uses, to potentially freeze the scene and ask the participants to volunteer their thoughts on the reasoning. If people are given the opportunity to explore experiences on all sides of othering it should make them think empathetically about their words and action. The experience of the manager in BYP also indicates that there is scope for this work to be done with adults, something I will explore more in the conclusion chapter. Perhaps with greater understanding people may be more likely to moderate or change their behaviour. What I will most take away from this session 
however is the stories of the participants. These can be used in future applications of this work as further examples of the existence of everyday racial microaggressions. 
Chapter eight:

Conclusion. 


\section{Chapter eight: Conclusions}

\section{Overview}

In preparing this thesis I have developed a variety of activities and sessions and a method of engagement that have enabled me to explore and compare the thoughts and views of young people. The participants have come from four different youth settings, one during the pilot and three in the research itself. This involved challenges including balancing newfound academic knowledge with practitioner experience, making sure that the planned activities both engaged the participants and also allowed them to express views on the subjects and themes of citizenship and othering. My main contribution has been to address how citizenship is gained, whether it has permanence, what rights and responsibility should a citizen have and what may constitute acts of citizenship. I have also explored elements of how Citizenship Education could be taught to children and young people by developing an approach that uses empathy, discussion and controversy to explore contemporary citizenship topics and also involve participants as a partner in the work, where they contribute to knowledge instead of being a receptacle for it.

Throughout this project I have striven to create a bridge between theory and practice using my position as a PhD student and my experience as a practitioner. At its best the praxis enabled ideas to travel freely in both directions. There were also times when the similarities between theory and practice were very evident. All the activities development was heavily influenced by Kemmis and McTaggart's (2005) explanation of PAR being with and not on participants, further supported by Tyrrell's (2012) contention that PAR plays a key role in Children's Geographies. This is very similar to practices that encourage expression and participation by young people in social and civic organisations and the creation of a Welsh Youth Parliament. Zombie apocalypse was initially an ice breaking activity however it became an activity about othering, the citizen contract and how the precariousness of resources can influence behaviour. Brave New World was another pre-existing activity that was developed by the theories and themes that it sought to explore. I did not attempt to take an activity from my practice and force it to fit the themes but it was a great advantage in the development of them to be able to call on ideas and activities from practice. 
The field work in this research project took place in the school year of $2017 / 18$. The thesis was submitted in September 2020, examined in December 2021 and the minor corrections were completed by March 2021. This meant that there was a substantial period of time between field work and completion. Two and a half years is a generation in terms of young people and their relationships with the hosting organisations. All the Priory Project participants had left the school by June 2019. Many of the participants from GYP and BYP would have also moved on from the organisations, some because of age and others because of new and adult interests. This meant that it was very difficult to consider tracking participants down to reconnect with them and review the final research findings. The participants were also keen to remain unknown in the presentation of the research which is why the findings were anonymised at source. I would have liked to have evaluated the medium and long term effectiveness of this work and perhaps this is something I can do in the future. In the meantime I hope to honour their participation and contribution by using this research in future activities in my practice.

The research questions in this thesis were:

1. What are the thoughts, views and opinions of young people in Cardiff and Pembrokeshire towards Citizenship and Othering and how do they compare?

2. How can curriculum materials and games be used to engage young people in questions of Citizenship and Othering?

3. How effective and valuable are those curriculum materials and games when used with young people in Cardiff and in Pembrokeshire, including any potential future application?

4. How do these materials and the findings contribute to and advance existing debates in Children's Geography, Empathy and Citizenship?

In the next part of this conclusion I will first address the second and third of these questions and before finishing with question one and then question four. It is important to consider that there are overlapping areas, which is to be expected in a qualitative narrative based on people's stories and opinions. 


\section{How can curriculum materials and games be used to engage young people in citizenship}

and Othering?

\section{$\underline{\&}$}

How effective and valuable are these curriculum materials and games when used with young people in Cardiff and Pembrokeshire, including future application.

I believe that the participants enjoyed participating in the materials and games that I designed for my research sessions. This can be shown by their contribution, feedback and behaviour. In both GYP and BYP they often made comments about it was more interesting than what they learnt in school. This supports Sharpe's (2018) contention that young people find political education uninspiring in school. The avoidance of self-aggrandisement does make me treat comments like that with caution. There are many differences between my work and a formal lesson in a mainstream school. Perhaps the biggest one is the numbers of young people involved. I may have had twelve young people engaged in some sessions but an average class size in school may be at least double this.

As discussed, I was determined to avoid what I deemed adult intellectualism - the name I gave to Gordon and Tafts (2011) view that adultism can render children and young people powerless in adult led projects. I did not force participants to share views or work and instead attempted to nurture contributions always conscious of their right under voluntary participation to withdraw. They appeared to enjoy the PAR approach where they were not expected to be passive participants. This is evident in how they gave back during the research. They often shared examples of the sources of information that influenced their ideas.

One of the ways that I think the young people enjoyed their participation was in being able to have fun whilst expressing themselves. Tew, Michel and Noe (2016) write that whilst fun is a strategy to encourage and promote learning, the fun must not lose sight of its intended impact. Whilst there was fun and enjoyment, we did not stray outside the aims of the research project during the activity sessions. Fun therefore has to be used correctly and in this case a tool for engagement and learning on the subjects of citizenship and othering. Tew, Michel and Noe (2016) say that fun can help with bonding and togetherness and can 
promote positive emotions and attitudes. In my case it was between the participants and me, using fun allowed for friendly interactions between me and my participants. The use of fun activities in the sessions also aided participants in finding new ways of thinking and acquiring new knowledge.

Bagelman \& Bagelman (2016) shares her use of zines in a university module to counter the neo-liberal influence that is becoming more prevalent in universities. This creates a frenetic approach to university education where:

"Frazzled teachers, increased fees and receding employment prospects are a recipe for producing burn-out and a consumer-student-subjectivity wherein knowledge is viewed as a product to be delivered" (Bagelman \& Bagelman, 2016:369).

Among the many results of using zines was the return of both spark and passion to the experience of teaching and learning. I like to think that my activities created some spark and passion in my participants because I know they did in me. Bagelman \& Bagelman (2016) view of the neo-liberal university reflects the views of Mason (2015) and Murphy (2017) who both saw both neo-liberalism and neo-communitarian behind the decline of open access youth work and influencing citizenship education schemes. Bagelman \& Bagelman (2016) still had the responsibility of awarding marks for the zines and this is one way my work differs. There was no neo-liberal based valuation to my work and no grades which meant the participants had the freedom to learn and explore issues and their own thoughts about them.

This means the effectiveness and value of these materials relies on them remaining independent of neo-liberal valuation. Since I delivered them these activities have been used in work with other groups of young people. Whilst I was carrying out my research in BYP I was approached by a resilience worker from the Ethnic Youth Support Team (EYST), based in Swansea. He was looking for sessional workers to deliver their anti far-right resilience workshops and was impressed by my content and delivery and offered me a job. This was very satisfying, especially as I have a history with EYST that he was not aware of. As a youth project manager, I worked in partnership and collaboration with EYST for many years and had an excellent relationship with their C.E.O. I also knew that they are one of the leading agencies in Wales in dealing with anti-extremism and radicalisation. I have deliberately 
avoided any temptation throughout the Ph.D. to take advantage of my prior standing and relationship because I wished to earn the right through my work. I believe that being offered this opportunity validated that choice. The anti far-right extremism project had its own script and activities but I was able to incorporate some of my own work into it. On one occasion, due to a mix up, the participants had done the same workshops three months earlier so I used all my activities over a two day workshop minus the political approval game which I did not have with me.

The use of these activities in this work enabled me to see more potential of how they could be used. During ZA a colleague highlighted to the participants that they immediately became very protective and defensive about what their tribe had and suspicious of others because we had told them resources were limited. He challenged them by asking if this is how they reacted in a game, how might they react in a real-life scenario. This differed from how I had used the activity as he had made an instant connection between the simulated and real world whereas I had not done this until the middle of Brave New World. In the following sessions we used ZA as an introduction to looking at attitudes towards immigration and refugees, including activities from the Warmth of Other Suns, by pointing out how the participants always became protective of resources. This showed that the materials have flexible application in how they can be used. This creates room for different practitioners to adapt and combine separate activities as they see fit and not have to follow a rigid structure.

Throughout this thesis I have spoken on how the knowledge and confidence of the practitioner is important. I explore this more fully later in this chapter when I look at the contributions this work has made to existing debates. However, before the qualities of the practitioner can be examined, I have to reflect on a potential flaw in my materials. Bagelman (2017) writes about how the refugee crisis can be seen as new and as a singular crisis impacting a distinct group. Effectively responding to and solving these crises requires an intersectional form of politics which is inclusive and does not focus on one crisis. Some of my materials does present issues as a singular crisis and could be seen as basic or even crude as it does not present the full extent of complexity. In the 'Political Approval Game' I use foreign aid as an uncontextualised form of government spending to explore cosmopolitan versus national views on citizenship. In 'Should they stay or Go' I simplify legal 
cases to discuss the granting or rescinding of citizenship. This worked in that it introduced themes and the existence of complexity and laid a foundation of critical thinking. However I believe to be more effective in future use elements of the subject material would need to be expanded.

This would be best accomplished in a formal educational setting. In GYP and BYP the delivery of material was fluid and often missed out activities within individual sessions, which is only right and proper when it is the young people's time being taken up. The other drawback of voluntary engagement is that the session can be disjointed with a high turnover of participants. This can dilute the message and make it difficult to make connecting points between themes such as micro othering leading to macro othering. That these materials can work in both settings is a strength, but for long term impact they would require becoming part of a curriculum delivered in educational establishments. This is highly unlikely and even if they did, they would have to remain independent of quantitative valuation. I will revisit reasons for this in my answers to research question four.

\section{What are the thoughts views and opinions of young people in Cardiff and Pembrokeshire}

\section{towards citizenship and Othering and how do they compare?}

Painter and Jeffrey (2009) listed three citizenship rights: civil rights, political rights and social rights. There appeared to be a consensus across all three venues that social rights, being defined as a certain standard of economic and social wellbeing, were considered extremely important. However, whether it be in allowing others to join their tribe in ' $Z A^{\prime}$ ', making decisions in 'Political Approval' or discussing the cases in 'Stay or Go', these rights always had to be earned. For those perceived as others these were often conditional rights. Across all the activities there was concern or fear expressed by the participants around safety and protection of resources. One of the consequences of this is how the participants may see civil rights, defined by Painter and Jeffrey (2009) as there being no restriction on liberty and this is protected. Fear and concern appear to put security ahead of liberty. This was particularly evident in the Priory and to a lesser extent in BYP. In GYP it was different, probably because the participants there were all young Islamic men, who Heath- Kelly (2013) tells us are most likely to be defined as at risk of radicalisation and of carrying out extremist behaviour. All three groups challenged some of the stereotypes attached to their black and ethnic minority backgrounds but in GYP there seemed to be more understanding 
of othering and these men came across as savvy, informed and aware of how they were seen by some sections of society. Even in BYP there was suspicion of the other, when in ZA a young woman highlighted her own views around the dangers of the figure of the Islamic man, no doubt influenced by having to flee her homeland because of war, which is all too often fought by young adult men.

This fear of the other, be it refugee, immigrant or a different citizen, which was most prevalent in the Priory, would appear to stem from Orientalism as suggested by Pugh (2004). Mountz (2015) describes this as the invisiblisation of the human story of suffering and displacement, how history is obscured and the risk inversed to be only considered by how it may affect the people to whom the other looks to for sanctuary or a better life. In Snakes and Ladders, the young men of GYP had much greater knowledge of the information contained in the test than either of the other two projects. Many of them had their own stories and experiences of displacement. It could be that this knowledge and experience contributed to them being less susceptible to believing the stereotype of the dangerous other. In the WOOS I attempted to expose this active obscuring of reasons for displacement through perspective taking. This is seen by Chabot and Davies (2004) as including an element of recognising complicity in those who are suffering. I did perspective taking by seeking to make the invisible, visible, with no blame attached. This is what Clark (1997) describes as cognitive empathy. Both the WOOS and SWB did have some effect in challenging the pre-conception of the idea of 'the dangerous other' in both BYP and the Priory. I believe a large part of this was down to the avoidance of implying blame, complicity, or a moral responsibility to take action. The participants responded through listening, discussion and sharing opinions and views. In this way the work was successful in providing "critical information and refute common myths, but do so in a way that would invite, not indict, and engage them in critical dialogue" (Katz, Heisterkamp \& Fleming, $2011 ; 686)$. The difference between inviting and indicting is comparable to the difference between informing and persuading in that one invites critical dialogue and the other pushes a point of view.

On the subject of the bystander approach it is worth noting that there was a brief discussion about Tommy Robinson in one of the sessions with GYP. He also uses elements of the bystander approach and cognitive and emotional empathy to generate support. It 
demonstrated that pedagogical approaches are merely a tool: it is how they are used which is important. They also require other accompaniments and safeguards to ensure that they focus on informing rather than persuading and I believe my approach focuses on the creation of critical dialogue and discussion. The distinction comes from the presentation of a subject. Browne and Freeman (2000) discuss how the stimulation of controversy can provoke debate. I tried to do this in a passive way through showing sources and stepping back and letting the young people discuss them. I was facilitating information and from the beginning I had assured the young people that they were in a safe space to express views. If information is presented from a personal angle this can automatically mean it is aiming to persuade. This has undertones of the monological approach of President Bush post 9/11 described by Gregory (2006) where he pre-emptively accused those who did not support the USA as against the USA. This can have the consequence of pressurising people to conform to the monological narrative for fear of blame and the accusation of being overtly complicit in whatever is seen as the problem. This means that even inaction can be seen as actively being against us (Sasikumar, 2009). Bush's words are an example of a sovereign narrative that seeks to divide populations into simple categories of us and them, with us and against us. Bush and Robinson use the argument of 'look what has been done to us'. However, the bystander approach is designed to be used as a preventative tool, originally used to stop violence towards women, and which can be transferred to othering. What this research showed is that all participants had a view of some sort on the issues and did not need a narrative to tell them conclusively what to think.

In this project young people did embrace the ambiguity and complexity of these issues. By doing so they demonstrated a desire for what Painter and Jeffrey (2009) would term political rights: they showed an interest in governance and government. Yet the rights that they seemed most concerned with were social rights. Similarly they concerned themselves with the de facto citizen, the citizen who contributes to society (Painter and Jeffrey, 2009); the cultural citizenship, namely how does the citizen apply themselves to their duties (Jackson, 2010) and the substantive citizen relating to the carrying out of obligations in everyday life (Karanti and Gill, 2002). Citizens should not be a burden on their country in terms of using the NHS and taking benefits, they argued. Staeheli (2013) looks at the relationship between citizen obligations and responsibilities, with the latter not being 
compulsory and therefore a sign of a liberal democracy. In the views of young people, working and looking after yourself would appear to be more of an obligation and that failing to do this and breaking the rules lends conditionality to citizenship. In 'Stay or Go' most participants thought Christophine should stay because she had worked and paid taxes, not because of her own historic claim to Britishness. The political right to family life was often sacrificed by participants if a person had not fulfilled their obligations. People who were not considered useful were not allowed entry. This may reveal how embedded neoliberal ideas of hard-working citizens and deserving citizens are.

Whilst a lot of the participants expected the state to provide for them, they believed, as Barber (2009), that there is an expectation on citizens to carry out duties previously regarded as the state's responsibility. To understand why there is this focus, the work of Starkey (2017) is well worth considering. Starkey (2017) explains that under New Labour Tony Blair promoted a citizenship that focused on international and cosmopolitan angles. Yet as Fisher (2015) points out his reaction to terrorism was to place it within an international framework. Starkey (2017) believes that these competing and contradictory agendas caused confusion and the cosmopolitan citizen was rejected in favour of the national citizen. The Conservatives have openly pushed a neo- communitarian form of citizenship (Murphy, 2017) which may have turned responsibilities into obligations. Whilst the participants may be unaware of these factors, they have grown up in the times created by them and been educated in a system influenced by them. Therefore, it should not be a surprise that young people have a focus on security and self-preservation. The fear of the other makes it difficult for a cosmopolitan form of citizenship to gain any traction.

Yet within the focus on security and a neo liberal one nation there emerged signs of a democratic deficit. The participants did not have a good word to say about politicians deeming them to be corrupt or self-serving. Some participants shared negative perceptions of the Police and they frequently demonstrated dis-satisfaction with the education system. This could be because a neo-communitarian approach to citizenship education and the valuation laden education system has neglected their political education in favour of readying them for work. Isin (2013) writes an overview of how the state creates situations through politics and foreign policy that can trap citizens "involuntarily in a web of rights and responsibilities" (Isin, 2013:16). In this case it may be the obligation of work and the fear of 
the other. Through participating in this activity, they have seen an alternative or been allowed to express their thoughts about an alternative. Isin (2013) says that it takes imagination to break what he calls the citizen habitas - a result of social and cultural history in this instance, neo-liberalism, neo-communitarianism and the framing of immigration as a security issue. The research activities had an element of creativity about them and so do the participation and views of the young people. If not addressed, this may lead to further examples of insurgent citizenship to escape this trap.

I did not encounter any particular patriotic views about Britishness or Welshness. The process of othering was based upon security, contribution and fear rather than ideas about the superiority of their nation. None of the participants knew about the prescribed fundamental British values of either New Labour or the Conservatives. This exposes what Starkey (2017) sees as a major flaw in successive governments' promotion of citizenship in that they have lacked a framework, rationale and perhaps most importantly consent. What young people do seem to have been influenced by is the politics of fear and securitisation which may make nationalism a natural choice, even if it does not reflect the individual's views and morals. Throughout the project it was always the usefulness and behaviour of the other which was given the greatest consideration not their race or ethnicity. In ZA the religious preacher was rejected regardless of their religion. In the Priory where they were most 'one nation' focused I did not encounter any out and out racism, just concern over resources and fear over safety.

What was significant by its absence throughout this research was the initial lack of compassion from the participants for people at risk. In discussions of the other it was always very fact and performance based and often resorted to the inevitable theory of Mountz's (2015) inversion of risk where the participants focused on themselves. It would be easy to label the participants who did this as neurotic citizens but if challenged they would adapt or reverse this position. It may be another indication of how indoctrinated we are to neoliberal values and it is interesting to note that in the dozen or more times I have played ZA no one has ever suggested letting all the others in on humanitarian grounds. 
How do these materials and findings contribute and advance existing debates in Children's Geographies, Empathy and Citizenship?

In this final section of my thesis, I will look at the contribution this research has made both in its content and its delivery. Brassett and Vaughan-Williams (2013) believe that there should be more collaboration between academics and practitioners in research and that both groups should look to "draw people from their professional silos and make them think differently about what they do" (Brassett \& Vaughan Williams, 2014:229). I agree with this but would take it further and suggest that this collaboration should not only take place in research but in education. In my experience of researching and writing this thesis I have found that my practitioner skills and experience supported my academic research. The academic knowledge from the likes of Isin, Painter and Jeffrey and Mountz and skills such as the Bystander approach has improved my practitioner skills and throughout this project, both academia and practice have happily complemented each other. Practitioner experience enabled me to be more resilient and confident in carrying out the work with young people, drawing on my 'practitioner personality'. Moser (2008) argues that personality is a part of positionality and reflexivity and that the "Iong believed thought that the ideal scholar need to strive for absolute neutrality so as not to 'taint' the research with his or her individuality" (Moser, 2008:384) is no longer as relevant. I agree with this and Guelke's (1974) empty vessel approach would be hard to do in PAR and play based activities. In Children's Geography I would argue that personality is vital to engagement. Personality in practice or research has to be a construct containing professional boundaries and considerations of role and purpose; it does not mean unleashing your private or personal personality but there should be elements of it included. This may come in sharing examples from your own life or displaying an appropriate sense of humour. In line with PAR approaches, a researcher should explore a subject they are passionate about and are interested in but hold back from being overbearing and opinionated about it. I have actually found that during this time my personality has changed and absorbed the neutral, dialogical approaches of my academic practitioner personality. This highlights something of great importance, namely you should believe in what you do.

My 'academic personality' allowed me to find a new way of talking to young people that would not have been possible had I delivered these activities through a solely educational 
framework. I found this very liberating and enjoyed the freedom of not having to worry about interpretation of the motivations or appropriateness of my questions and activities. This is almost certainly linked to not having to achieve some quantifiable and accredited outcome. The resilience of practice meant I did not get upset by unexpected events or uncomfortable experiences including the frosty welcome I received in BYP. Rose (1997) carried out research with community arts workers in Glasgow. She was a white, female, middle class English researcher and on one occasion her interviewee made a joke about how he was being interviewed for Radio 4 and this made Rose question her positionality to such an extent that she felt unable to continue her research. It struck me when reading this that she expected her research subjects to act to the same high standard of neutrality and adhere to the same theories of positionality as herself in her role as the researcher. During reflexivity Rose may have over thought in line with Moser's (2008) warning about the difficulties of aspiring to achieve complete neutrality. I think that practitioner skills should also be valued and given serious consideration because they can give the researcher different perspectives and resilience.

Research within Children's Geographies will almost certainly entail working with children and young people and probably in a school, youth project or other youth dominated setting. Schools and youth settings can be loud, busy and intimidating and traditional conditionalities apply but perhaps the biggest factor is that you are a stranger in the tradition of Georg Simmel's Stranger. Indeed, a researcher intrudes into positions in a society that are already occupied. In this case, the society is the venue and the adult role is occupied by incumbent practitioners. The adult researcher is associated with members of the system but not strongly attached to it, and as with Simmel's stranger they are identified as a potential problem or threat because they lack a common identity (Rogers 1950). This identification as a problem or threat can come from both practitioners and young people. Familiarity of being an adult within a youth environment can dilute this, previous exposure can be reassuring, previous experience can help with confidence and practitioner skills can help with meeting the challenges and unpredictability that lie ahead. There was also the connecting factor of race and ethnicity within these projects. In Cardiff there were times when my being a white man may have influenced the behaviour of the participants. I also found limits to my experience in dealing with new young people. Mills and Withers (1992) 
suggest that "fieldwork requires imagination and creativity and as such, is not for everyone" (Mills \& Withers, 1992:163). Indeed, reflexivity may mean a person recognises their limitations in regard to experience and confidence, but why should they not incorporate this as part of the research? O'Hare (2016) uses research experience to examine practice matters to contribute to research on evidence-based practice in the area of social work. I believe that this can be built on by using practitioner skills and experience to inform research practices to improve research with young people.

To explain how I think this could be done requires considering the role of the academic practitioner. Citizenship is a key component of the Welsh Government's new curriculum, due to come into full effect in 2021. This will quite naturally take place predominantly in schools and be primarily delivered by teachers. With regard to citizenship education, I agree with Sharpe (2018)'s findings that school based political education is often found uninspiring. I am concerned that there will be the same issues around citizenship education as there were around the Prevent programme. Thomas (2012) tells us that Prevent failed at informing and educating because of the practitioners involved. Many of these including teachers did not feel confident, informed or resourced enough to deliver. This is not a slur against teachers or other practitioners; it is only through having researched and written this thesis that I feel confident, informed and resourced to deliver citizenship education. Stanley and Guru (2015) saw social work become the default agency for Prevent and perhaps teachers are seen as the default agencies for delivering citizenship education. As mentioned, there is a tendency towards a tipping box approach in education (Hess, 2009), and as Mason (2015) reports a reliance on quantitative results which can be used to secure or retain funding that blocks innovation and progress. It is not apparent how the new curriculum will in practice overcome this. Brown (2015) explains that economic valuation now exists in public services and ignores other forms of thinking including human conditions and experiences, creativity, traditions and aspiration. This indicates that citizenship education in Wales will remain focused on a neo-communitarian approach, with a neo liberal valuation. Even if it were to deviate from this line it is questionable whether the practitioners will have the necessary knowledge and skills to deliver the work.

Englebert (2015) asks whether subjects such as political education and othering should be provided through education or come from social and economic influences. In a neoliberal 
world it is more likely to be the latter and whilst there may be possible bias in education there is probable bias in this method. This can be simply explained by MacAllister's (2001) neighbourhood effect, where social interaction within residential communities and the class of these communities can affect voting behaviour and political attitudes. This in turn can be affected by the role of the press and political reporting that promote what Painter and Jeffrey call the "mythical homogeneity of a given state" (Painter and Jeffrey, 2009:84) or the politics of fear and strategy used by a government seeking to retain power by promoting fear and scandalising the public interest (Dunn and Hopkins, 2016). None of this will allow the direct and complex conversations that are important to support young people to understand the issues connected and part of both citizenship and othering. This research shows that there is a roadmap through which young people can understand other cultures and motivations through their own experiences. Othering and the discrimination and stereotyping it brings about can be avoided by open discussions that avoid blame, complicity and listening to all sides. I cannot think of better placed institutions to do this than universities.

I have mentioned Sharpe's (2018) findings about the lack of inspiration in political education within schools several times. He has more to say on this subject and it revolves around university. Sharpe (2018) found that the inspiration for young people to discover and develop their political literacy was more likely to occur at university, where new, informed adults such as lecturers would expose students to new ideas and ways of thinking through discussion and debate. Hess (2009) believes that universities should go beyond their borders and boundaries to share their knowledge and expertise. I am not a young person, but my knowledge of political literacy has grown enormously during my studies, especially about new ways of participating in discussions and debates. I have also taken this beyond the university and into a field work and practitioner environment with some success. Davies (2018) believes that whilst subject to the assault of neo-liberal valuation universities are still able to protect and nurture ideas about how things could be different. This refers to both the subject matter and the methods by which it is delivered and taught and is exemplified in the previously mentioned use of zines by Bagelman \& Bagelman (2016). Thus then comes the call for the academic practitioner who focuses on delivery both within and without the borders of the university. The academic practitioner should combine both practitioner skills 
and experience with academic ones. I have outlined how practitioner experience can help while academic knowledge offers knowledge and the opportunity to learn and debate and constantly review what you think you know. This is a role I could see myself doing, working with students and also in schools and other youth settings on the ever-evolving subjects of citizenship and Othering. The support and access from the institution, the processes and shared knowledge of students and staff mean that the work could remain accountable, relevant and informed. Any education carried out beyond the university borders could be assisted by post graduate students in the early stages of their courses. This would give them valuable training and experience of being a practitioner in a sometimes intimidating and unpredictable environment. This could lead to improved resilience and confidence when they undertake research field work in similar environments.

\section{Contribution to wider citizenship debates: The Essential Citizen.}

Isin (2013) explains that substantive citizenship is now closely linked with nominal citizenship. This has been seen repeatedly through this research. Young people in my projects tended to judge a person's membership of a political unit based upon whether they fulfilled the obligations of work, good behaviour and usefulness. As said earlier, neo-liberal values appear embedded in the views of the participants and this made me consider how citizenship may continue to develop in the UK. Isin (2013) believes that:

"Within Anglo-American states, the post war consensus on the welfare state and social citizenship has ended in a morass of vague disavowal, while neo-liberalisation of the provision of social services has created new injustices and inequalities" (Isin, 2013:16).

This slow erosion of the social citizen cannot have been helped by what Starkey (2017) sees as the lack of consultation and consent by successive governments in the twenty first century in their promotion of a citizenship model. The strength and expression of these injustices are accompanied by inconsistencies and contradictions. In this research, a young person claimed that 'foreigners' took all the new jobs, despite having started a new job herself only a week before. Rankin (2004) believes that 9/11 and the subsequent actions of the USA and its allies "stole from us our willingness to be complex" (Rankin, 2004:91) and that people now often choose one emotion at a time and avoid the contradictions that can 
be highlighted when a person's own thoughts do not measure and fit when held up to each other. This can be a very deliberate rejection of rational debate or evidence in favour of irrational response and further evidence of Isin's (2004) neurotic citizen.

Isin's (2004) neurotic citizen is the butterfly to the caterpillar which is the bionic citizen. The bionic citizen is self-governing and self-reliant and does not look to the state to provide them with a civilised standard of living. Gradually the bionic citizen metamorphoses into the individual citizen who resents those whom they do not think are self-reliant and selfgoverning. Thus emerges from the cocoon the neurotic citizen, concerned with their rights to have rights and convinced that their rights are being ignored whilst others are being catered for. The neurotic citizen may have gained enough inertia that the historical notion of British citizenship being rooted in protection from tyranny (Turner and Isin, 2008), has been rejected in favour of a neurotic citizenship. This historical concept relied on rights being protected but the neurotic citizen does not believe that they are. The Political approval game showed that great emphasis was placed upon defence, prisons and the Police. This can be understood through Isin's concept of the neurotic citizen but the focus on state level security and threats goes beyond personal issues into a shared neurotic citizenship and towards matters which affect the state. There are multiple causes for neurotic citizenship including hypervisibility, inversion of risk and invisiblisation that have led to securitisation and othering, and neo-liberal austerity creates a breeding ground for these causes. This leads to the demise of complexity and a tendency to choose one emotion or one thought at a time. This fear based neurosis of a country and its citizen is heightened by the neo-liberal fixation on the measurable and the quantifiable. Another contribution towards neurotic citizenship is the previously mentioned democratic deficit evident in the participants' outlook on politicians. Painter and Jeffrey (2009) see the democratic deficit as what occurs when citizens see decisions which affect their lives seemingly taken beyond the control of the nation-state governments that they have voted for. Painter and Jeffrey (2009) see two possible ways of bridging this democratic deficit which are a global civil society or cosmopolitan democracy. There is another way which is to re-embrace nationalism and turn instead to right wing parties as a way of registering a loss of faith in cosmopolitan or international politics (Dench, Gavron \& Young, 2006). Greenspan (2017) sees this as leading to the rise of dominant one nation, neo-liberal ideologies including Brexit and the election 
of President Trump. Greenspan (2017) sees actions such as these as "a cry of pain by the populace for some leaders to arise to take charge and lessen their pain". I would argue that one nation citizenship is the homeopathy of politics and citizenship. It offers a magic pill remedy with no structured philosophy or scientific evidence and while it may have a mild placebo effect it is hard to imagine it solving problems such as climate change and Covid 19.

It is through the reaction and response to Covid - 19 that I saw how the 'neurotic citizen' has possibly evolved again within the structures of neurotic citizenship into the essential citizen. Essential has become a key word in Covid - 19 times: essential journeys, essential workers, and essential services. I observed first-hand that when schools closed, there emerged a clamour verging on panic by educational bodies, including my own, that they would not be seen as idle during the lockdown but instead as essential. Whilst it is too early to understand the impact of the Covid - 19 lockdown, the essential citizen was a concept that continued to grow in my mind. The essential citizen emerges from the neurotic and the bionic. These have established the importance of the individual and created paranoia over the actions, inactions and intentions of others. Now however, the neuroticism has crossed over into not just concern over what others are doing but how individuals must also clearly demonstrate that they are meeting society's expectations, that what they do is essential and they cannot be accused of being a threat to resources. The essential citizen is not complex, partly because they do not have the time or luxury as they are busy being and being seen to be 'with us' rather than 'against us'. Essential citizens cannot allow themselves to think that they are part of the problem. This is caused by the self-importance and self-aggrandisement that harks back to the bionic citizen and this self-focused thinking creates the paradoxical scenario where anything the essential citizen does automatically and by default becomes essential, because they are doing it. Is it possible that within the hostile environment, where people have been stripped of political membership and legal rights it has highlighted that citizenship is temporary, conditional and a privilege? If it can be taken away from some, it can be taken away from all, a statement which could be seen as neurotic in itself, but perhaps that makes it appropriate for these times. The slow decay of state-run services and the transfer of them from non-economic to economic concerns have taken away the safety belt of a civilised standard of living. The economy has never been far away 
from the government's thoughts in responding to this global pandemic, meaning that while temporarily people have not been able to work, the necessity of work remains. Again, what choice does the essential worker have: the privilege of staying home or being able to work from home is not an option for everyone.

I believe neurotic citizenship and the essential citizen can and should be challenged through education that encourages dialogical, complex thinking, as this dissertation has argued. Whatever success I have had in doing this has begun with listening to people without condemnation, so that their voice and any cry of pain is heard. This can create a nonjudgemental environment where exclamation marks can be replaced by question marks. Rankin's (2014) writing tells us that othering is embedded in citizenship practice, but we should not accept that as final - especially if we accept that othering is a complex relationship between micro and macro othering that people have experiences from both sides (both othering and being othered). By the appropriate use of informing and not persuading and using approaches such as the Bystander it may be possible to generate a cognitive and sympathetic empathy. Rankin, who along with Isin has had the most profound impact on me during this time, writes with a resigned melancholy, using beautiful lyrical prose and turns of phrases reminiscent of Kurt Vonnegut. In his seminal novel Slaughterhouse 5 Vonnegut (1969) describes many unfortunate events and finishes them with the epitaph 'So it goes', as if there is nothing that can be done about it. Rankin writes of unfortunate events and her epitaph could read 'so it is' with the reader forced to ask themselves the follow up question, 'and what is to be done about it?'. Having the ambition to change hearts and minds through a patient and partnership approach with young people could be part of the answer. They are interested and concerned about their futures and this creates a space to explore citizenship and Othering with a fresh vision and a clean slate.

\section{The End.}




\section{References}

Ahmed, S., (2014). Cultural politics of emotion. Edinburgh University Press, Edinburgh.

Aitken S., (2007) Desarollo integral y fronteras [Integral development and borderspaces], Children's Geographies, 5:113-29

Aldred, R (2008) Ethical and Political Issues in Contemporary Research Relationship, Sociology, 42 (5): 887-904

Aliverti, A. (2019), Law, nation and race: Exploring laws cultural power in delimiting belonging in English courtrooms, Social and Legal Studies, 28(3) 281 -302, https://doi.org/10.1177/0964663918776486.

Allhoff, F. (2018), Liberty and security: a balanced approach, University of Pennsy/vania Journal of law and Public Affairs, 3(1): 53-83

Ameida. P, Pedrosa. J \& Watts. M, (2008), Developing a mini project: student questions and learning styles, The Psychology of education Review, 32 (1): 6-17

Bagelman, J. (2019), Sanctuary and Unsettling "the" Refugee Crisis. In The Oxford Handbook of Migration Crisis.

Bagelman, C.C. and Bagelman, J., (2016). Zines: Crafting change and repurposing the neoliberal university. Acme, 15(2), pp.365-392.

Archibugi, D. (2003), Cosmopolitan Democracy and its Critics: A Review, European Journal of International Relations, 10(3): 437-473

Bagnall, R., (2010), Citizenship and belonging as a moral imperative for lifelong learning, International Journal of Lifelong Education, 29(4): 449-460.

Balibar, E. (2015) Citizenship, Polity Press, Cambridge.

Banaji, S., (2008), The trouble with civic: a snapshot of young people's civic and political engagements in twenty-first-century democracies, Journal of youth studies, 11(5): 543-560.

Barber T (2009) Participation, citizenship, and well-being: Engaging with young people, making a difference, Young, 17(1): 25-40 
Baubock, R (2018), Jus Filiationis: A defence of citizenship by descent, in Baubock R (ed), Debating transformations of national citizenship. IMISCOE Online Research Series, Springer Open, https//doi.org/10.1007/978-3-31992719-0

Bauman, Z. (1991), Modernity and ambivalence, Cambridge, Polity Press

Bauman, Z. (2004), Wasted Lives: Modernity and its outcasts, Cambridge, Polity Press, Bauman, Z. \& Tester, K. (2001) Conversations with Zygmund Bauman, Cambridge, Polity Press

Berger \& Calabrese (1975), Some explorations of initial interactions and beyond: Toward a developmental theory of Interpersonal communication, Human Communication Research, 1: 99-112.

Berkowitz, A. (2009), Response ability: Transforming values into action, Chicago, Beck.

Berry, J.W., Phinney, J.S., Sam, D.L. and Vedder, P., (2006). Immigrant youth: Acculturation, identity, and adaptation. Applied psychology, 55(3):303-332.

Bhambra, G.K., (2016) Brexit, the commonwealth and exclusionary citizenship, The Open Democracy Website, https://www.opendemocracy.net/en/brexit-commonwealth-andexclusionary-citizenship/

Bizzell, P. (2014), Academic Discourse and Critical Consciousness, Pittsburgh, University of Pittsburgh Press. ProQuest Ebook Central, https://ebookcentral.proquest.com/lib/swanseaebooks/detail.action?doclD=2038090.

Blanchard, K. (1995), The anthropology of sport: An introduction (second edition), Westport, Bergin \& Garvey.

Brassett, J. \& Vaughan - Williams, N. (2013) The politics of resilience from a practitioners perspective: An interview with Helen Braithwaite OBE, Politics, 33(4): 229 -239.

Brooks, T (2012), The British citizenship test: The case for reform, The Political Quarterly, 83(3): 550-566. 
Browne, M \& Freeman, K (2000), Distinguish features of critical thinking classrooms, Teaching in higher education, 5(3):301-309

Brown, W. (2015), Undoing the demos: Neoliberalism's stealth revolution, New York, Zone Books.

Burke, R.H. (2016), Young people crime and justice, $2^{\text {nd }}$ edition, Abingdon, Routledge Bulmer, M. (1982) Ethical Problems in Social Research: the case of covert participant observation in Bulmer, M. (Ed) Social Research Ethics (3-12), London: MacMillan

Burgess, M. (2006), Comparative Federalism: Theory and Practice, London, Routledge.

Butler, J. (2009), Frames of war, New York, Versa. 2009, Versa.

Buzan, B, Waever O and De-Wilde J (1998), Security: A new Framework of Analysis, Boulder Co, Lynme Riener in Michael Pugh, Drowning not Waving: Boat People and Humanitarianism at sea, 2004, Journal of Refugee Studies, 17(1): 50-69.

Byrne, B. (2017), Testing times: The place of the citizenship test in the UK immigration regime and new citizens response to it, Sociology. 51(2): 323-338.

Cameron, D (2011) Government Immigration Policy, Speech presented at the institute for government, London, UK

Cantle, T (2005), Community Cohesion: A new framework for Race Relations, Palgrave, Basingstoke.

Caretta, M.A., \& Riano, Y., (2016), Feminist participatory methodologies in geography: creating spaces of inclusion, Qualitative Research, 16 (3):258-2266

Carter, S., Kirby, P. and Woodyer, T.L., (2015). Ludic-or playful-geopolitics. In Children, young people and critical geopolitics (pp. 61-73). Ashgate Publishing Limited.

Caulfield, L. \& Hill, J. (2014) Criminological Research for Beginners, Abingdon, Routledge Clark, D.B. \& Doel, M.A. (2011), Zygmunt Bauman, in Hubbard, P. \& Kitchir, R. (eds) Key thinkers on space and place, $2^{\text {nd }}$ edition, London, Sage. 
Clark, C. (1997) Misery and company: Sympathy in Everyday life, University of Chicago Press, Chicago, Illonis

Collins, K. (2018), Abolishing Jus Sanguinis Citizenship: A proposal too restrained and too radical, in Baubock $\mathrm{R}$ (ed), Debating transformations of national citizenship. IMISCOE Online Research Series, Springer Open, https//doi.org/10.1007/978-3-31992719-0

Cooper, F. (2018), Citizenship, inequality and difference: Historical perspectives, Princeton, Princeton University Press.

Coplan, A (2011) Will the real empathy please stand up? A case for a narrow conceptualization. The Southern Journal of Philosophy, 49: 40-65

Colombo, M. (2003). Reflexivity and narratives in action research: A discursive approach. Forum : Qualitative Social Research, 4(2) Retrieved from ttps://search.proquest.com/docview/868195327?accountid=14680 Cramer, K.J. (2016), The turn away from government and the need to revive the civic purpose of Higher Education, Perspectives on Politics Cambridge, 14(2): $442-450$

Crick, B. (2004), Life in the United Kingdom - a journey to citizenship, London, Home Office.

Csikszentmihalyi, M. (1979), The concept of flow, in Button-Smith, B. (ed), Play and learning, New York, Gardner Press.

Davis K Chabot, 2004, Oprah's Book Club and the politics of cross-racial empathy, International Journal of Cultural Studies, 7: 399-419

Davies, W. (2018), Review essay: The democratic critique of neo-liberalism, Renewal: $a$ journey of social democracy, retrieved from: http://www.renewal.org.uk/articles/thedemocratic-critique-of-neo-liberalism

DeGoede, M \& Sullivan, G. (2016), The politics of security lists, Environment and planning, Society and Space, 34(1): 67-88

Dench, G., Gavron, K. \& Young, M. (2006). The New East End: kinship, race and conflict, London, Profile Books. 
DeWied, M., Maas, C., Van Goozen, S., Vermande, M., Engels, R., Meeus, W., Matthys, W. \& Goudena, P. (2007), Bryant's Empathy index: A closer examination of its internal structure, European Journal of Psychological Assessment, 23(2):99 -104

Diener, E., \& Crandall, R. (1978) Ethics in Social and Behavioural Research, Chicago: The University of Chicago Press.

Doty, R.L. (2014) Why is peoples movement restricted? In Edkins, J. \& Zehfuss, M. (eds) Global Politics: A new Introduction, Abingdon, Routledge.

Dunn, K.M., Atie, R., Mapedzahama, V., Ozalp, M., \& Aydogan, A.F. (2015) "The Resilience and Ordinariness of Australian Muslims: Attidudes and Experiences of Muslims Report", Sydney, Western Sydney University and Islamic Sciences and Research Academy.

Economic and Social Research Council, $(2005,2015)$, Research Ethics Framework, Swindon: ESRC

Edmonstone, J. (2016) Action learning, performativity and negative capability, Action Learning: Research and Practice, 13(2): 139-147, DOI: 10.1080/14767333.2016.1168735

Edsel, R.M. and Witter, B., (2010). Monuments men: Allied heroes, Nazi thieves, and the greatest treasure hunt in history. New York, Random House.

Englebert, E.A. (2015) Education' - a thing apart: Educators and political scientists in conflict over relationships of schools to local government systems, National Civic Review, 104(1): 5861

England, K.V.L., (1994), Getting personal: reflexivity, positionality and feminist research, Professional Geographer, 46 (1): 80-89.

Essed, P. (2002) Everyday racism: A new approach to the study of racism, in Goldberg, D. (ed) Race Critical Theories $1^{\text {st }}$ edition, Malden, Blackwell Publications.

Esses, V.M., Hamilton, L.K. \& Gaucher, D. (2017). The global refugee crisis: Empirical evidence and policy implications for improving public attitudes and facilitating refugee resettlement. Social Issues and Policy Review, 11(1): 78-123. 
Fisher, K.M. (2015) Spatial and temporal Imaginaries in the securitisation of terrorism, in Jarvis, L. \& Lister, M. (eds), Critical Perspectives on Counter Terrorism. Abingdon, Routledge.

Fisher, L. (2015) "Foreign Aid should be spent at homes, Tory MPs demand" The Times, edition 2, $29^{\text {th }}$ December, retrieved from:

https://search.proquest.com/docview/1752160234?accountid=14680

Fortier, A.M., (2008). Multicultural horizons: Diversity and the limits of the civil nation. Routledge.

Fortier, A.M. (2013) What's the big deal? Naturalisation and the politics of desire. Citizenship Studies, 17 (6-7): 697 - 711

Garner, A., (2012), Boneland, London, Fourth Estate.

Gates, B. \& Gates, M. (2016). 'Three Myths on the World's Poor.' Wall Street Journal, January 17, 2014. Retrieved from http://online.wsj.com/news/articles/SB10001424052702304149404579324530112590864.

G Genat, B. (2009) Building Emergent situated knowledges in participatory action research, Action Research, 17 (1): 101-115

Gibson, V. \& Douglas, M. (2013) Criticality: The experience of developing an interactive educational tool based on board games, Nurse Education Today, 33:1612-1616

Gillespie, G.W.,(2006) Generating Grounded Theory with Community Partners, J Community Nutrition, Vol 8(1): 16 - 23,

Gillespie, M \& O'Loughlin, B (2009) Precarious citizenship: media and insecurity in multicultural Britain, in Noxolo, P. \& Huysmans, J. (eds) Introduction, Community citizenship and the war on terror: Security and Insecurity, New York, MacMillan.

Gillespie, G.W., \& Sinclair, P.R., (2000), Qualitative sociology in rural studies, Rural Sociology, 65(2):180-193.

Goldberg, D.T. (2002), The racial state, Malden, Blackwell Publishing.

Goldberg, D.T. (2009), The threat of race, Malden, Blackwell Publishing 
Goodhart, D. (2004), Too diverse?. Prospect magazine, 95(30): 7.

Gordon H, Taft J (2011) Rethinking youth political socialization: Teenage activists talk back. Youth \& Society, 43(4): 1499-1527

Green, A. (2013).Education and State Formation: Europe, East Asia and the USA (2nd edition) Basingstoke: Palgrave Macmillan.

Greenspan, A. (2017) 'Trump populism a cry of pain', BBC News, retrieved from: https://www.bbc.co.uk/news/av/business-39135274

Gregory, D (2006), The Colonial Present, Oxford, Blackwell Publishing Ltd.

Grossberg, L. (2016) 'Caught in the crossfire: Kids, politics and Americas future' Abingdon, Routledge.

Guelke, L. (1974), An idealist alternative in human geography, Annals of the Association of American Geographers, 64: 193- 202

Hall, S. (1996) Who needs identity? in Hall, S. \& DuGuy (eds) 'Cultural Identity', London, Sage Hall, S. (1997), The Spectacle of the Other in S. Hall (ed) Representation. Cultural Representations and Signifying Practices, London, Thousand Oaks, New Delhi: The Open University.

Halpern, D.F. (1999). Teaching for critical thinking: Helping college students develop the skills and dispositions of a critical thinker. New directions for teaching and learning, 80: 6974.

Hand, M. (2008), What shall we teach as controversial? A defence of the epistemic criterion, Education Theory, 58: 213-228

Hart S (2009) The 'problem' with youth: Young people, citizenship and the community. Citizenship Studies, 13(6): 641-657

Haste. H \& Hogan, A (2006), Beyond conventional civic participation, beyond the moral political divide: young people and contemporary debates about citizenship, Journal of Moral Education, Vol. 35 (4): 473-493 
Hay, I. (2016) Glossary in Hay, I (ed), Qualitative Research Methods in Human Geography, Ontario, Oxford University Press.

Hayden, M., \& Thompson, J.,(2007) Policy making in practice: Issues arising from evaluation of the Welsh Baccalaureate, The Welsh Journal of Education, 14(1): 85 -99.

Heath Kelly, C. (2013),Counter Terrorism and the Counterfactual: Producing the 'Radicalisation' Discourse and the Up Prevent Strategy, British Journal of Politics and International Relations, 15: 394-415

Henn, M., Weinstein, M. \& Forrest, S., (2005). Uninterested youth? Young people's attitudes towards party politics in Britain. Political studies, 53(3): 556-578.

Hersi, A. (2016) 'Rethinking Racism in Claudia Rankine's 'Citizen: an American lyric', Masters Thesis (Literacy Studies), University of Stavanger

Hess, D.E. (2009), Controversy in the Classroom: The democratic power of discussion, New York, Routledge.

Henn, M. \& Foard, N. (2014), Social differentiation in young peoples political participation: The impact of social and educational factors on youth political engagement in Britain, Journal of Youth Studies, 17(3): 360-380

Hing, B.O. (2018), Beyond DACA - defying employer sanctions through civil disobedience, UCDL Review, 52:299 - 339.

Hoggart, L. (2017), Collaboration or Collusion: Involving research users in applied social research, Womans Studies International Forum, 61: 100-107.

Homan, R. (1991) The Ethics of Social Research. New York: Longman Inc Hopkins, P., \& Dunn, K., (2016) The Geographies of Everyday Muslims in the West, Australian Geographer, 47(3): 255 -260

Hörschelmann, K. and van Blerk, L. (2012) Children, Youth and the City. London: Routledge 
Horton, J. and Kraftl, P., (2017). Three playgrounds: Researching the multiple geographies of children's outdoor play. Environment and Planning A:

Economy and Space, 50(1): 214-235

Horvath, C.P. \& Forte, J.M., (2011) Critical Thinking and Systems Thinking, in Reynolds, M., (ed) Critical Thinking, New York, Nova Science Publishers.

Hughes, G (2009), Governing the Social and the Problem of the 'Stranger', in Noxolo, P. \& Huysmans, J. (eds) Community citizenship and the war on terror: Security and Insecurity, New York, Macmillan.

Hurston, Z.N. (1928) How It Feels to Be Colored Me, The World Tomorrow, May, 1928,21516

Isin. E.F. (2004), The Neurotic Citizen, Citizenship Studies, Vol 8 (3):217-235.

Isin, E.F. (2013) Theorising acts of citizenship, in Isin, E.F. \& Nielsen, G.M. (eds) Acts of citizenship, London, Zed Books Ltd

Isin, E.F. \& Turner, B. (2008), Investigating citizenship: An agenda for citizenship studies in Isin, F., Nyer, P., Turner, B., Routledge (eds), Citizenship between Past and Future, Abingdon, Routledge.

Jackson. P (2010) Citizenship and the geographies of everyday life, Geography, 95 (3):139141

Jennings, L.B. (2010) Challenges and possibilities of Holocaust education and critical citizenship: An ethnographic study of a fifth grade bilingual class revisited, Prospects, 40:3556.

Jones, H., Gunarathnam, Y., Bhattacharyya, G., Davies, W., Sukhwant, D., Forkert, K., Jackson, E. \& Saltus, R. (2013), Go Home: the politics of immigration controversies, Manchester, Manchester University Press.

Joseph, J. (2013) 'Resilience in the UK and French security strategy: An Anglo saxon bias?' Politics, 33(4): 253-264 
Kaldor, M. (2003) "Global Civil Society", London, Polity Press

Karanti, R. \& Gill, G.S.G., (2002) Defining British Citizenship: Empire, Commonwealth and Modern Britain, Abingdon, Taylor and Francis.

Katwala, S., Ballinger, S. \& Rhodes, M. (2014), How to talk about immigration, London, British Future, http://www.britishfuture.org/wp-content/uploads/2014/11/How-To-TalkAbout-Immigration-FINAL.pdf.

Katz, J. (2013), Sports and hypermasculinity: An interview with Daryl Fort, Voice Male Magazine, p. 15.

Katz, J., Heisterkamp, A.H. \& Flemming, M.W., (2011) The social justice roots of the mentors in violence prevention models and its application in a high school setting, Violence Against Women, 17(6):684 - 702.

Kemmis, S. \& McTaggart, M. (2005) Participatory Action Research: Communicative Action and the Public Sphere in Denzin, N.K. \& Lincoln, Y.S. (eds) The Sage Handbook of Qualitative Research, Third Edition, Thousand Oaks, Sage Publications

Kharshid, A. \& Pitts, B. (2019) Malala: the story of a Muslim girl and a Muslim nation, Discourse: Studies in cultural politics of education, 40(3): 424-435

King M (2007) The sociology of childhood as scientific communication, Childhood, 14:193213

Kiste, R.C., (1980), Review: Ethics in Social and Behavioural Research, American Anthropologist, 82 (1): 141-142.

Klocker, T. (2012), Doing PAR and doing a Ph.D.: words of encouragement for prospective students, Journal of Geography in Higher Education, 36(1):149 - 163.

Kostakopoulou, D (2009), How to do things with security post 9/11, in Noxolo, P. \& Huysmans, J. (eds), Introduction, Community citizenship and the war on terror: Security and Insecurity", New York, Macmillan. 
Kraftl, P., (2013). Beyond 'voice', beyond 'agency', beyond 'politics'? Hybrid childhoods and some critical reflections on children's emotional geographies. Emotion, Space and Society, 9:13-23.

Labi, N. (1998) Fun is good, Time Magazine, 152(210: 86

LaCapra D, 2001 Writing History, Writing Trauma, Baltimore, Johns Hopkins University Press. Lakin, R \& Mahoney, A (2006), Empowering youth to change their world: Identifying key components of a community service program to promote positive development, Journal of School Psychology, 44(6): 513-531

Lamb, J.B. (2012), Preventing Violent Extremism: A Policing Case Study of the West Midlands, Policing, 7(1): 88-95.

Lee, H., (1960/2006) To Kill a Mockingbird. New York :Harper Perennial Modern Classics, Levy, B.L.M. (2016) Advising a Model United Nations club: A scaffolded youth-adult partnership to foster active participation and political engagement, Teaching and Higher Education, 159:13-27.

Leyshon, M. (2002) On being 'in the field': practice, progress and problems in research with young people in rural areas, Journal of Rural Studies, 18: 179-191

Lister, R. (2010) The age of responsibility: Social policy and citizenship in the early $21^{\text {st }}$ century in Holden, C. \& Kilkey, M. \& Ramia, G. (eds) Analysis and debate in social policy, Bristol, Policy press

Macallister, I., Johnston, R.J., Pattie, C.J., Tunstall, H., Dorling, D.F.L. \& Rossiter, D.O. (2001) Class dealignment and the neighbourhood effect: Miller revisited, British Journal of Political Science, 31:41- 59

Macklin, A. (2018) The return of banishment: Do the new denationalism policies weaken citizenship, in Baubock R (ed) "Debating transformations of national citizenship". IMISCOE Online Research Series, Springer Open, https//doi.org/10.1007/978-3-31992719-0 
Mandaville, P (2018) How do Religious Beliefs affect politics, in Baubock R (ed) "Debating transformations of national citizenship". IMISCOE Online Research Series, Springer Open, https//doi.org/10.1007/978-3-31992719-0.

Marshall, T. H. (1950) Citizenship and Social Change, Cambridge, Cambridge University Press.

Marston, S.A. \& Mitchell, K. (2004), Citizens and the state: Citizenship formations in space and time, in Barnett, C. \& Lowe, M. (eds) Spaces of Democracy: Geographical perspectives on citizenship, participation and representation, London, Sage.

Mason, W., (2015) Austerity youth policy: Exploring the distinctions between youth work in principle and youth work in practice. Youth \& Policy, 114: 55-74.

Mason \& Urquhart, 2001, Developing a model for participation by children in research on decision making, Children Australia, 26:16-21.

Matthews, H., \& Limb, M. (1999). Defining an agenda for the geography of children: review and prospect. Progress in Human Geography, 23(1), 61-

90. https://doi.org/10.1191/030913299670961492

Mayer, J. (1986) Teaching critical awareness in an introductory course, Teaching Sociology, 14: $249-256$

Maynard, A. \& Williams, A. (1984) Privatisation and the NHS in LeGrand, J. \& Robinson, R. (eds) Privatisation and the Welfare State, London, Routledge

MacDonald, A., 1978. The Turner Diaries. William Luther Pierce.

McGann, K. (2018), Rochdale grooming gang members face deportation after losing appeal, Daily Telegraph 8/08/2018, retrieved from https://www.telegraph.co.uk/news/2018/08/08/rochdale-grooming-gang-members-facedeportation-losing-appeal/

Milligan, B. (2014) The Truth About Welfare Funding: Facts or propaganda, BBC News website, retrieved from https://www.bbc.co.uk/news/business-29898083. 
Mills, C.A. \& Wither, W.J. (1993), Teaching qualitative geography as interpretative discourse, Journal of Geography in Higher Education, 16:159-165

Moncrieffe, M. and Moncrieffe, A., (2017), Examining the representation of fundamental British values: What are the most prominent images used for display boards in the primary school?' BERA, London: British Educational Research Association

Morgan, M.F., Cuskelly, M., Moni, K.B., (2014) Unanticipated ethical issues in a participatory research project with individuals with intellectual disabilities, Disability \& Society, 229 (8):1305-1318.

Morrin, K (2011), 'Edward Said' in Hubbard, P. \& Kitchir, R. (eds), Key Thinkers on Space and Place, $2^{\text {nd }}$ edition, London, Sage.

Moser, S. (2008) Personality: A new positionality?, AREA, 40(3): 383 - 392

Mountz, A (2015) Invisibility and the Securitisation of Migration, shaping Publics through Border Engagement on Islands, Journal of Cultural Politics, 11(2):184 - 200.

Murphy, S. (2017), The rise of a neo-communitarian project: A critical youth work study into the pedagogy of the National Citizen Service in England, Citizenship, Social and Economics Education, 16(2):85-89.

Negri, A., (1999).Insurgencies: Constituent power and the modern state, Minnesota, $U$ of Minnesota Press.

Newheiser, A.K. \& DeMarco, T.C. (2018), Who deserves basic rights? People condone violations of procedural and physical rights in the treatment of terrorist subjects, Law and Human Behaviour, 42(1) 50-56.

Norcup, J (2010), Critical enquiries into the historical and cultural geographies of ID cards in Britain, Geography, Vol 95 (3):134-136

Norris, P. (2011) Democratic Deficit: Critical Citizens revisited, New York, Cambridge University Press. 
Noxolo, P and Huysman, J. (2009) Introduction, in Noxolo, P. \& Huysmans, J. (eds) Community citizenship and the war on terror: Security and Insecurity, New York, MacMillan.

Nussbaum, M.C. (1999) Sex and social justice, Oxford, Oxford University Press)

Nussbaum, M.C. (2012), The new religious intolerance: overcoming the politics of fear in an anxious world, Massachusetts, Harvard University Press.

O’Loughlin, B. \& Gillespie, M. (2012), Dissenting citizens? Young people and political participation in the media society nexus, Parliamentary Affairs, 65(1): 115-137, doi:10.1093/pa/gsr055

Ong A, (2006) Neoliberalism as Exception: Mutations in Citizenship and Sovereignty, Durham, Duke University Press.

Ozanne, J., \& Saalcioglu, B., (2008) Participatory Action Research, Journal of Consumer Research, 35 (3):423-439.

Pain, R., (2004), Social geography: Participatory research, Progress in Human Geography, 28:652-663

Painter, J \& Jeffrey, A (2009) Political Geography $2^{\text {nd }}$ edition, London, Sage Publications Ltd. Pattie, C., Seyd, P. \& Whiteley, P. (2004) Citizenship in Britain: Values, participation and democracy, Cambridge, Cambridge University Press

Park, R.E. (1928), Human Migration and the marginal man, American Journal of Sociology, 33: $881-893$

Patel, I. (2017), The Ink of citizenship, Curriculum Inquiry, 47(1): 62-68

Pedler, M., (2008) Action Learning, in Thorpe, R., \& Hall, R., (eds) The Sage Dictionary of Qualitative Management Research, Thousand oaks, Sage Publications.

Pickerill, J. (2009), Finding common ground? Spaces of dialogue and the negotiation of indigenous interests in environmental campaigns in Australia, Geoforum, 40: 66-79.

Pinkoski, M. (2017) Citizen: an American Lyric Review, Journal of Contemporary Issues in Education, 12(1):74-77. 
Prokopy, L.S. (2009), Determinants and Benefits of Household Level Participation in Rural Drinking Water Projects in India, Journal of Development Studies, 45(4): 471-95.

Pugh, M. (2004) Drowning not Waving: Boat People and Humanitarianism at sea, Journal of Refugee Studies, 17(1): 50-69.

Pyles, L. (2015), Participation and other ethical considerations in participatory action research in post-earthquake rural Haiti, International Social Work, 58 (5):628-645.

Pedwell C, (2010) Feminism, Culture and Embodied Practice: Rhetoric's of Comparison, London, Routledge.

Pedwell, C. (2012) Economies of empathy: Obama, neoliberalism and social justice, Environment \& Planning D: Society and Space, Vol 30: 280-297.

Penner, L. \& Finkelstein, M. (1998) Dispositional and structural determinants of volunteerism, Journal of Personality and Social Psychology, 74(2):525-537.

Philo, C. (2010) Michael Foucault in Hubbard, P \& Kitchen, R (eds) Key Thinkers on Space and Place, London, Sage Publications Ltd.

Pratchett, T. (1994) Interesting Times, London, Random House

Pullman, P. (2019) 'The Secret Commonwealth', London, Penguin Books

Pykett. J, (2010) Designing identity:exploring citizenship through geography, Geography, 95 (3):132-133

Qazi, H. \& Saeeda, S. (2017), Identity constructions through media discourse, Journalism Studies, 19(11): $1597-1612$.

Rankin, C. (2004) Don't let me be lonely: an American Lyric, First published in Great Britain in 2017, London, Penguin Books.

Rankine, C. (2014) Citizen: an American lyric, Minnesota, Graywolf Press Raspail, J., 1975. The camp of the saints. New York: Scribner. 
Reynolds, S. (2018) Open arms or a clenched fist: What kind of welcome will Brexit Britain offer to refugees, IPPR Progressive Review, 25(1): 69-75

Rieber, L.P., Smith, L. \& Noah, D. (1998), The value of serious play, Educational Technology, 38(6): 29-37.

Robin, R.T.(2001), The Making of the Code War Enemy: Culture and Politics in the MilitaryIntellectual Complex, Princeton, Princeton University Press.

Rogers, E.M. (2006) Georg Simmel's concept of the Stranger and intercultural communication research, Communication Theory, 9(1) Wiley online https://doi.org/10.1111/j.1468-2885.1999.tb00162.x

Rose, G. (1997) 'Situating knowledges: positionality, reflexivities and other tactics' Progress in Human Geography, 21: 305 - 320.

Ruddick, S., (2004), Activist Geographies: Building Positive Worlds in Cloke, P., Crang, P., \& Goodwin, M., (eds) Envisioning Human Geographies, London, Arnold,

Said. E.W. (1985), Orientalism, Penguin, Harmondsworth

Sasikumar. K. (2009) Mobility and Identity: India, the US and Cross Border Flows in a Time of Terrorism, in Noxolo, P. \& Huysmans, J. (eds), Community, Citizenship and the War on Terror, Security and Insecurity", New York, Macmillan.

Sawyer, C. (2006), Not every child matters: the UK's Expulsion of British Citizens, The International Journal of Childrens Rights, 14: 157-185

Schmidt, U. (2006), Justice at Nuremberg: Leo Alexander and the Nazi Doctors' Trial, Basingstoke: Palgrave MacMillan

Schrage, M. (2000), Serious play: How the worlds best companies simulate to innovate, Boston, Harvard University Press.

Sharpe, D., (2018). The Making of Democratic Actors: Counting the Costs of Public Cuts in England on Young People's Steps towards Citizenship. Societies, 8(4), p.111. 
Shavit U, (2009) The new imagined Community: Global media and the Construction of National and Muslim Identities of Migrants, Eastbourne, Sussex Academic Press.

Shriver, L. (2017), The Mandibles (A family 2029 - 2047) London, Harper Collins

Sinclair S, McKendrick JH, Scott G (2010) Failing young people? Education and aspirations in a deprived community. Education, Citizenship and Social Justice, 5(1): 5-20

Smith, J.M. (2001) When the Hands are Many: Community Organization and Social Change in Rural Haiti., Ithaca, Cornell University Press.

Speers, A. (1993), 'Games in nursing staff development' Journal of Nursing staff Development, 9:274-277

Spivack, G.L., (1988), Can the Subaltern Speak? In Nelson, C., \& Grossberg, L. (eds) Marxism and the Interpretation of Culture, Chicago, University of Illinois Press.

Spolin, V. (1986), Theatre games for the classroom: a teachers handbook, Chicago, Northwestern University Press.

Squire, V., (2015). Post/Humanitarian Border Politics. In Post/Humanitarian Border Politics between Mexico and the US: People, Places, Things (pp. 95-100). London, Palgrave Pivot.

Staeheli, L.A., (2013), Whose responsibility is it? Obligation, Citizenship and social welfare, Antipode, 45(3): $521-540$.

Staeheli, L.A. and Hammett, D., (2010). Educating the new national citizen: Education, political subjectivity and divided societies. Citizenship Studies, 14(6): 667-680.

Stanley, T \& Guru, S (2015), Childhood Radicalisation Risk: An emerging Practice Issue, Social Work in Action, 27(5):353-366.

Starkey, H. (2017) Globalization and Education for Cosmopolitan Citizenship, in Banks, J.A.,(Ed.) (2017). Citizenship Education and Global Migration: Implications for Theory, Research, and Teaching, Washington DC, American Educational Research Association, Washington $D C$. 
Starkey, H., (2018). Fundamental British Values and citizenship education: tensions between national and global perspectives. Geografiska Annaler: series B, human geography, 100(2): 149-162.

Stuart, L.(1996) Introduction, in MacDonald, A. The Turner Diaries. William Luther Pierce', New York, Barricade Books

Stringer, E., (2007), Action Research: a handbook for practioners, Thousand Oaks, Sage Publications

Sue, D.W., Capodilupo, C., Torino, M.C., Bucceri, G.C., Holder, J.M., nadal, A.M.B., Kevin, L. \& Esquilin, M. (2007), Racial microaggressions in everyday life: Implications for clinical practice. American Psychologist, 62(4): 271-286.

Tew, M.J., Michel, J.W. \& Noe, R.A. (2016), Does fun promote learning? The relationship between fun in the workplace and informal learning, Journal of Vocational Behaviour, doi: 10.1016/j.jvb.2016.09.006.

Thomas, P (2012) Responding to the threat of Violent extremism - Failing to Prevent, London, Bloomsbury Academic

Thomas, P \& Sanderson, P (2011) Unwilling Citizens? Muslim Young People and National Identity, Sociology, 45 (6): $1028-1044$

Tsoukala, A. (2009) Defining the terrorist threat in the post-September 11 era. in Bigo, D. and Tsoukala, A. (eds) Terror, insecurity and liberty: illiberal practices of liberal regimes after 9/11. Routledge.

Tyrrell, N., (2012) Why children's geographies?, Geography, 97: 124-128

Valentine, G., (2004), Public space and the culture of childhood, Ashgate, London. Van Blerk, L. and Kesby, M. (2008) Doing Children's Geographies: Methodological issues in research with young people. London: Routledge

Vanderbeck, R.M., (2007) Reaching critical mass, AREA, 40(3): $393-400$ 
Vaughan-Williams, N. (2007) The shooting of Jean Charles DeMenezes: New border politics?, Alternatives, 32:177-195

Vladimirou, I.E. (2015) The civic emotions and participatory drama: Childrens compassion, empathy and justice, Ph.D. Thesis, University of Warwick.

Vonnegut, K. (1969/2005). Slaughterhouse-five, New York: Dial Press

Wang, C.C., \& Redwood-Jones, Y.A., (2001), Photovoice ethics: perspectives from Flint Photovoice, Health, Education and Behaviour, 28(5):560-572.

Weber, C (2016) Ten years of terror, Vimeo broadcast, https://vimeo.com/42535232

Westheimer J, Kahne J 2004) What kind of citizen? The politics of educating for democracy. American Educational Research Journal 41(2): 237-269

Wilkinson, I (2010) The warmth of Other suns: The epic story of America's great migration. New York, Random House.

Williams, B., Cassor, C., Siggers, G. \& Taylor, S. (2016), Mental and social issues of child refugees in Europe, Archives of diseases in childhood, 101(9): 839-842.

Wolfendale, J. (2007) Terrorism, security and the threat of counter terrorism, 30 Studies in conflict and terrorism, 75: 75-92

Woodyer, T.L., Martin, D. and Carter, S., 2016. Ludic geographies. In Play, recreation, health and wellbeing. Springer.

Yarwood, R., and Gardner, G., (2000) Fear of Crime, Culture and the Countryside, AREA, 32: 403-411

Yarwood, R., \& Tyrrell, N. (2012). Why children's geographies? Geography, 97, 123-128

Yeoman, L (2016) Imagining the lives of others: Empathy in public relations, Public Relations Inquiry, $5(1): 71-92$

Youniss J, Bales S, Christmas-Best V,(2002) Youth civic engagement in the twenty-first century. Journal of Research on Adolescence, 12(1): 121-148 
Yu-Chu Yeh (2011) A 4 component instructional model for teacher training in critical-thinking instruction: its effectiveness and influential factors, in Horvath, CP, \& Forte, JM (eds) 2011, Critical Thinking, Nova Science Publishers. 


\section{Appendixes}

A - Some feedback from the pilot project.

B - Zombie Apocalypse trading cards.

C - Blank canvass of the Brave New World

D - Completed canvass of the Brave New World

E - Early attempts at game design

F - Finished Snakes and Ladders Board

G - Political Approval game board and budgeting board

$\mathrm{H}-\mathrm{A}$ completed white wall from Against a sharp white background 
Appendix A: Some feedback from pilot project

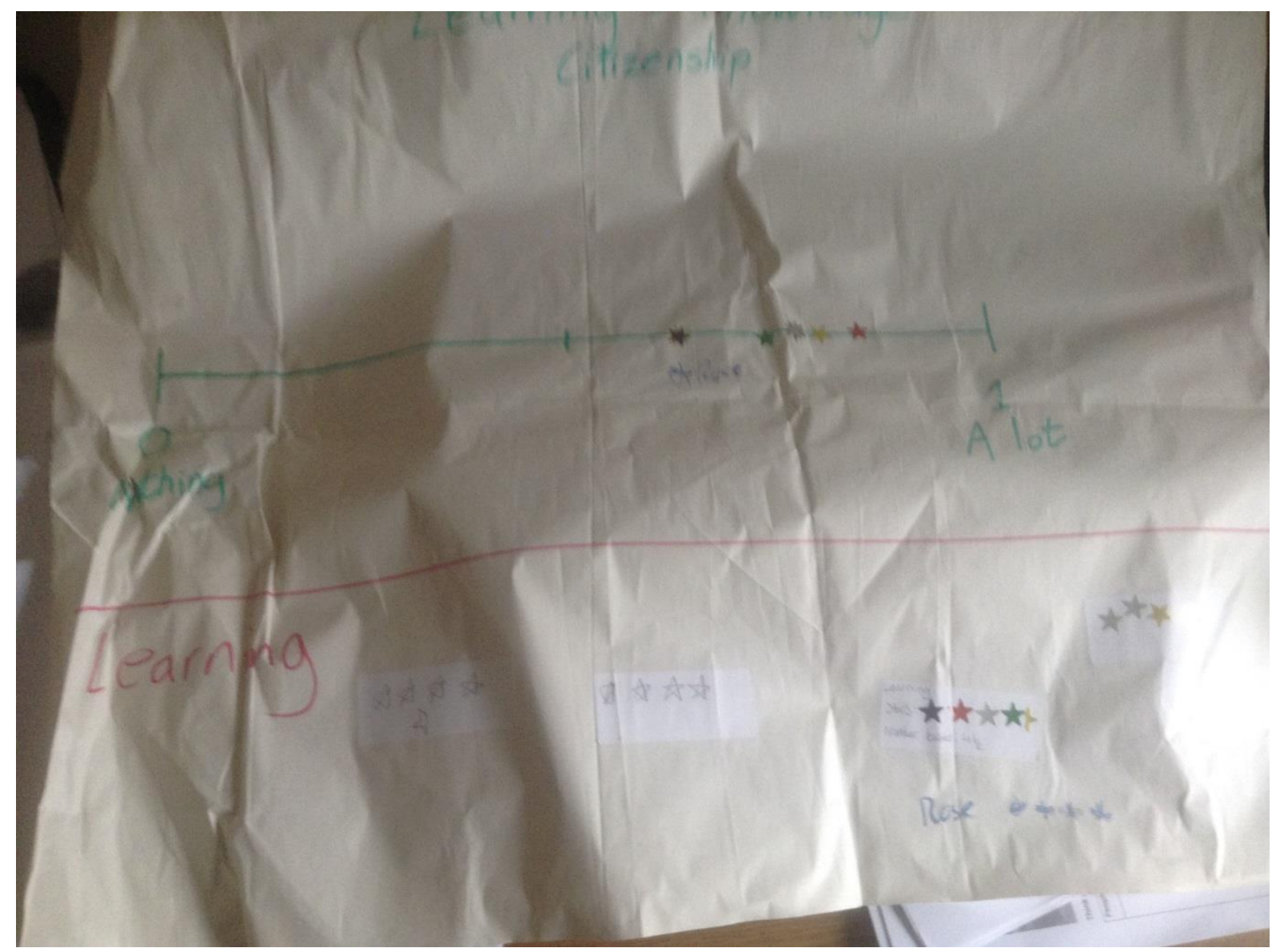




\section{Appendix B: Zombie Apocalypse trading cards}

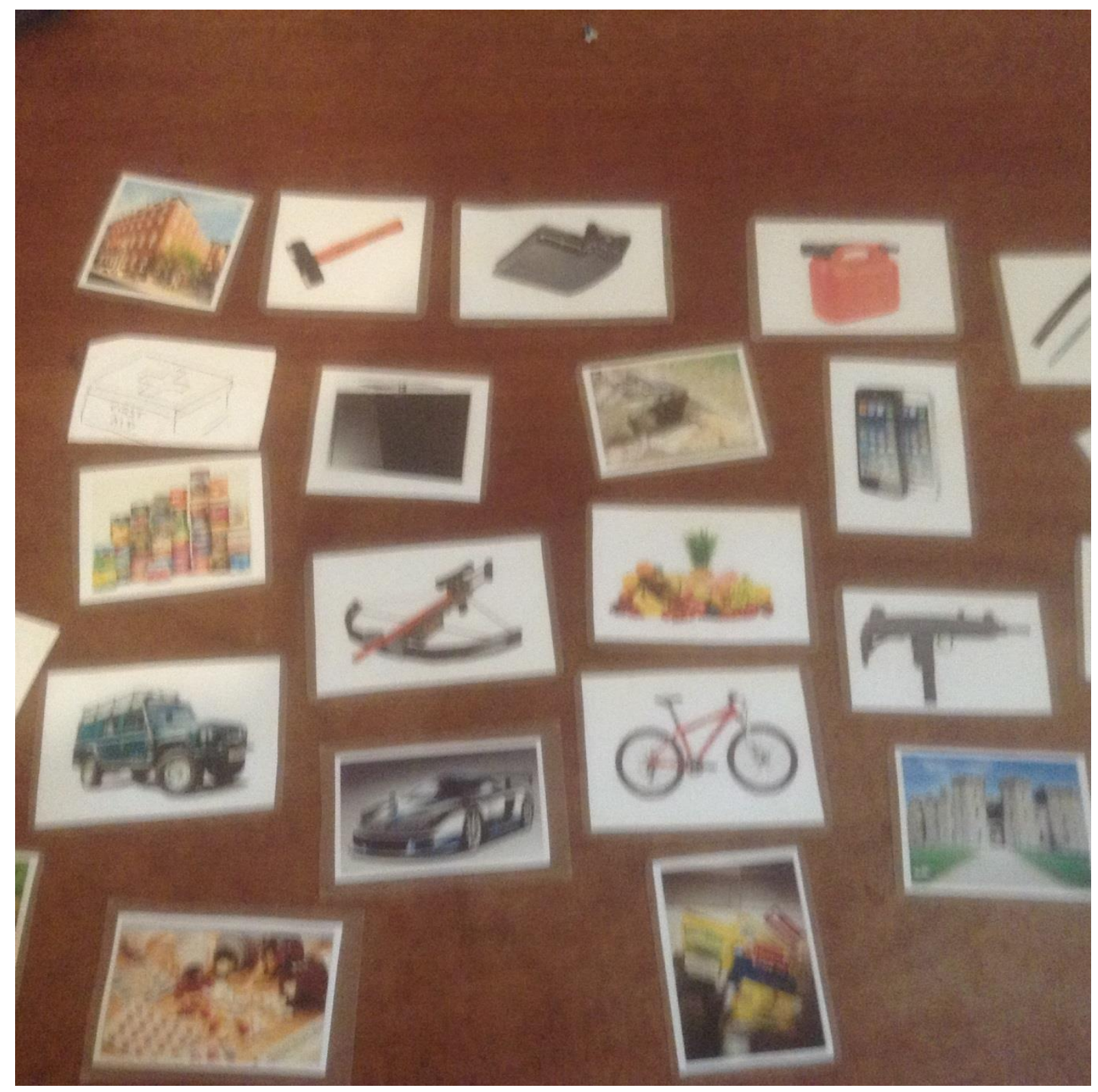


Appendix C: A blank canvass Brave New World

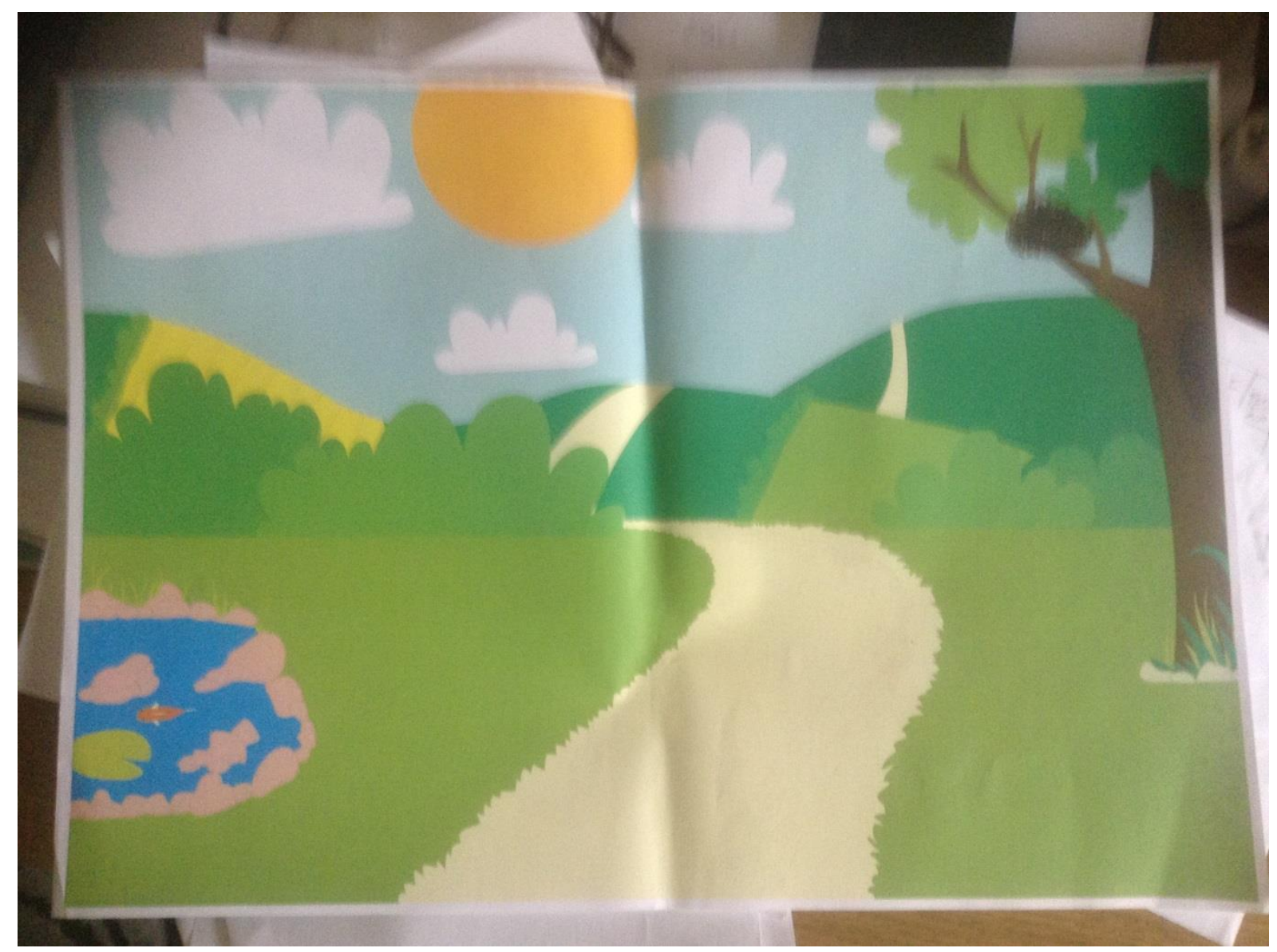


Appendix D: A completed Brave New World.

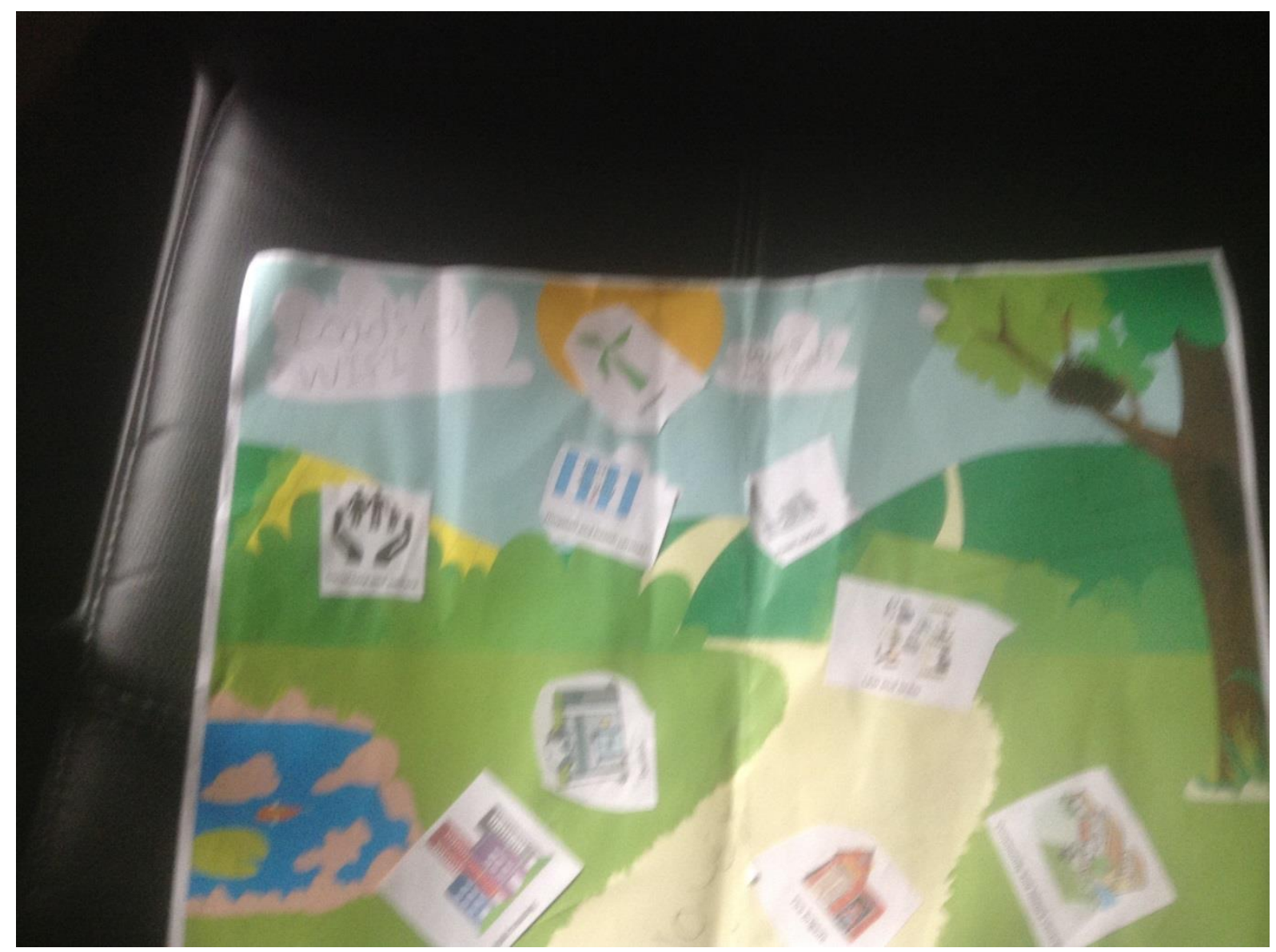


Appendix E: Some early attempts at game design for citizenship test activity.

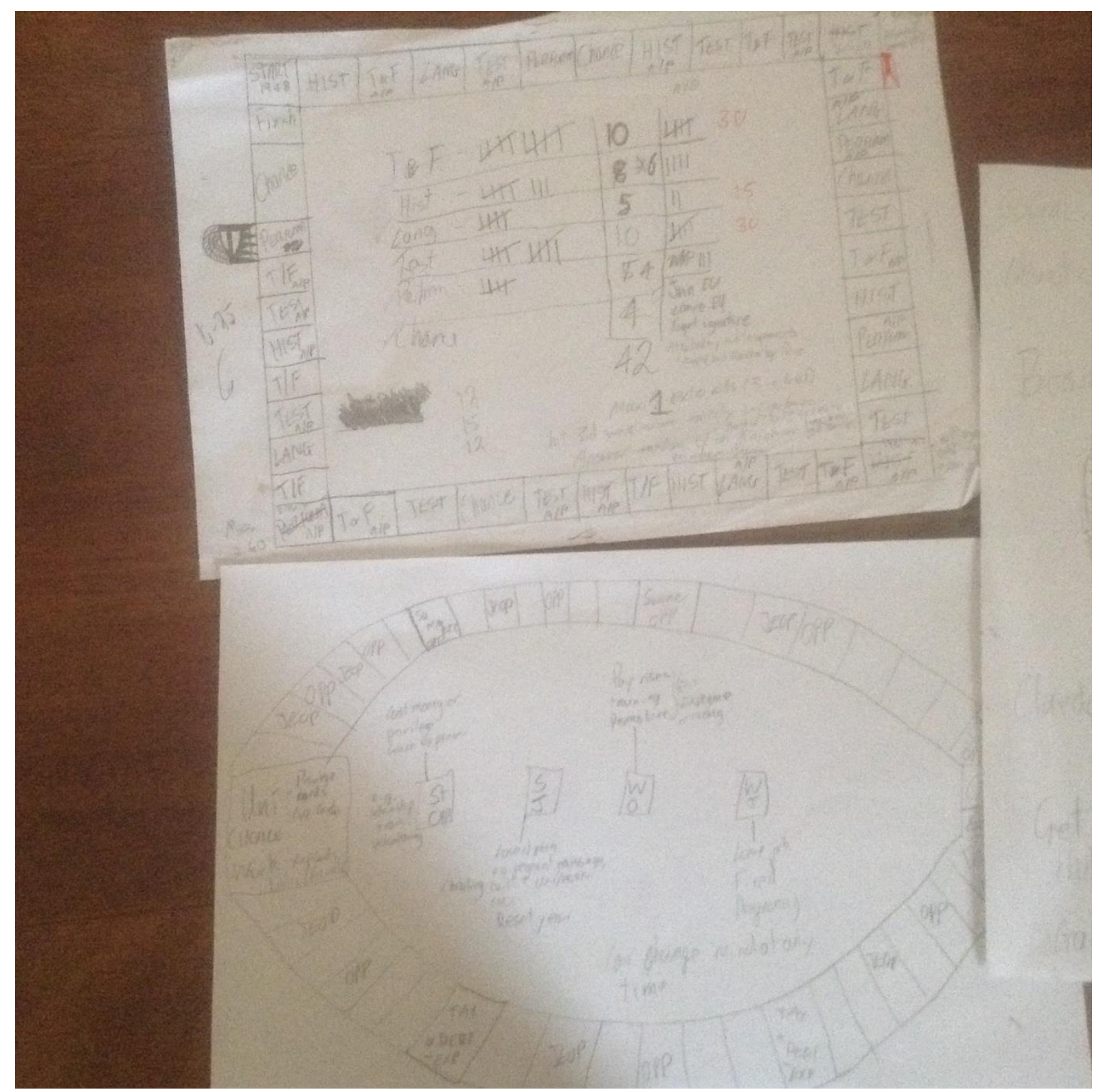


Appendix F: The final version of the Snakes and Ladders board.

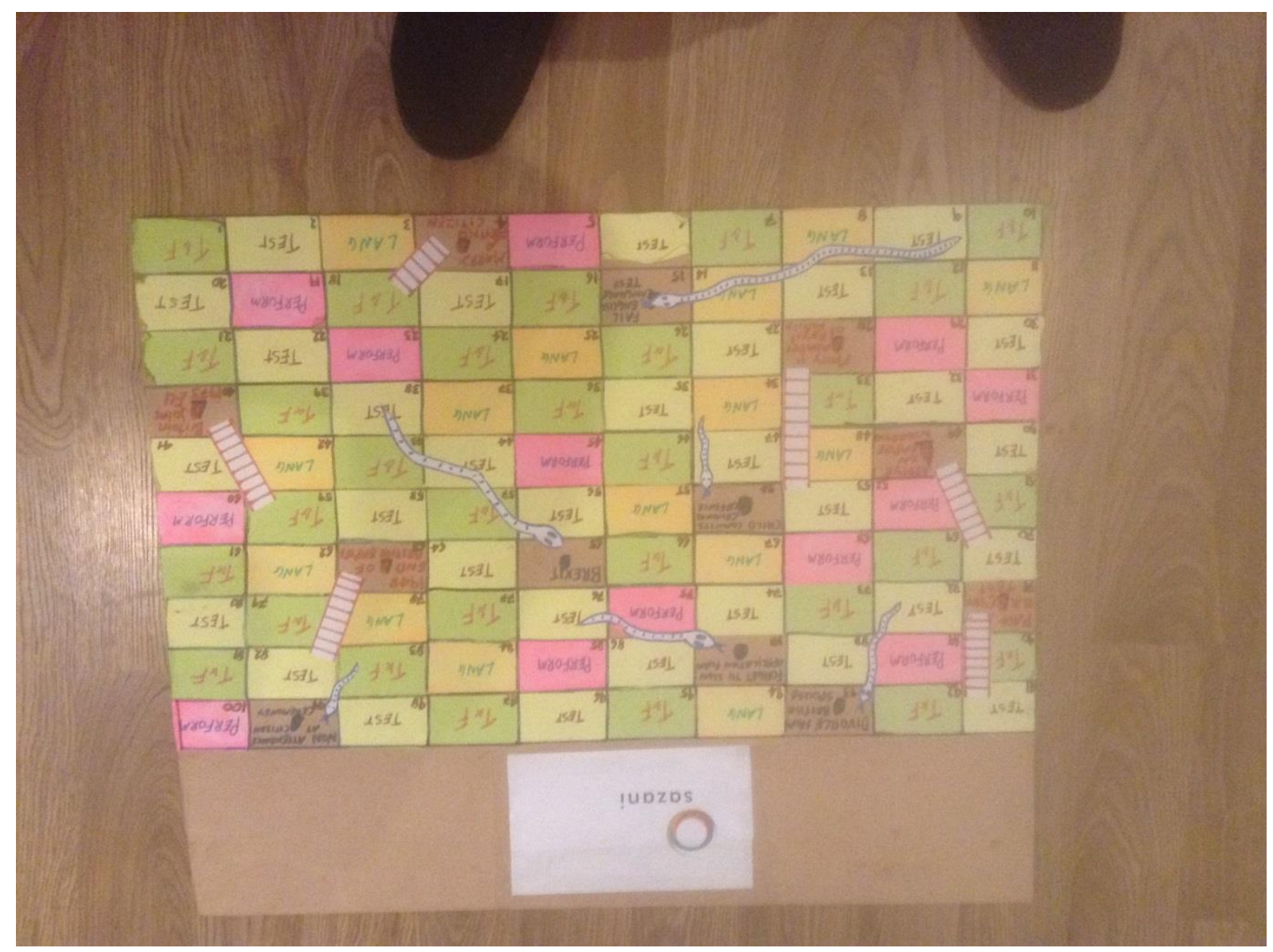


Appendix G: Political approval game board and budgeting boards.

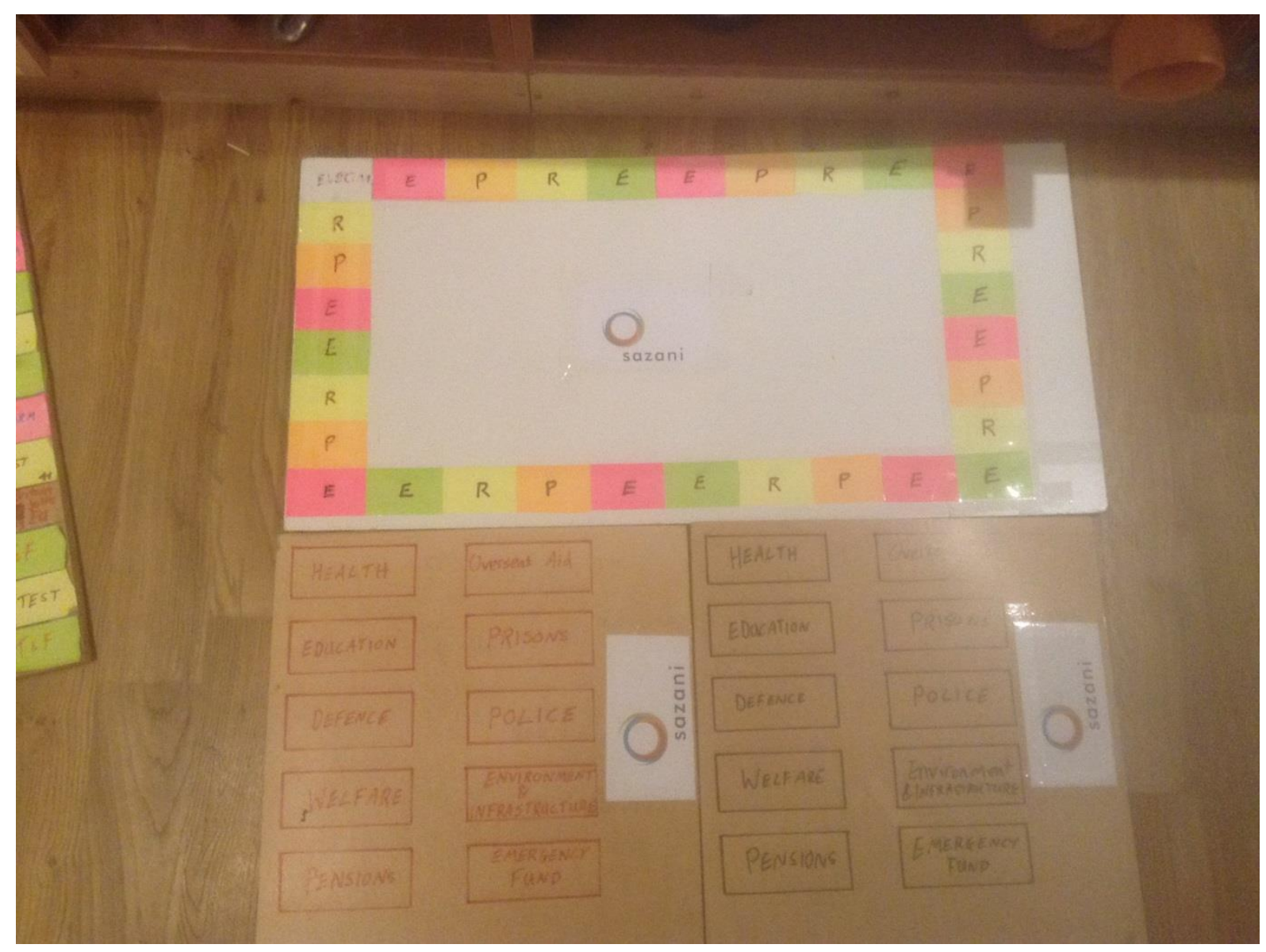


Appendix $\mathrm{H}$

The Warmth of Other Suns by Richard Wright

I was leaving the South

To fling myself in the unknown....

I was taking a part of the South

To transplant in alien soil,

To see if it could grow differently,

If it could drink of new and cool rains,

Bend in strange winds,

Respond to the warmth of other suns

And, perhaps, to bloom. 
Appendix I: A completed white wall from Against a sharp white background. 